\title{
STOCHASTIC OPTIMIZATION OF SUSTAINABLE INDUSTRIAL SYMBIOSIS BASED HYBRID GENERATION BIOETHANOL SUPPLY CHAINS
}

\author{
A Dissertation \\ Submitted to the Graduate Faculty \\ of the \\ North Dakota State University \\ of Agriculture and Applied Science
}

\begin{abstract}
By
Vinay Gonela

In Partial Fulfillment of the Requirements

for the Degree of

DOCTOR OF PHILOSOPHY
\end{abstract}

Major Department:

Industrial and Manufacturing Engineering

November 2013

Fargo, North Dakota 


\section{North Dakota State University}

Graduate School

\section{Title \\ STOCHASTIC OPTIMIZATION OF SUSTAINABLE SYMBIOSIS BASED HYBRID GENERATION BIOETHANOL SUPPLY CHAINS}

\section{By}

Vinay Gonela

The Supervisory Committee certifies that this disquisition complies with North Dakota State

University's regulations and meets the accepted standards for the degree of

\section{DOCTOR OF PHILOSOPHY}

SUPERVISORY COMMITTEE:

Dr. Jun Zhang

Chair

Dr. Kambiz Farahmand

Co-Chairs

Dr. Jing Shi

Dr. Joseph Szmerekovsky

Approved:

$11 / 12 / 2013$

Dr. Canan Bilen-Green

Date

Department Chair 


\begin{abstract}
Bioethanol is becoming increasingly attractive for the reasons of energy security, diversity, and sustainability. As a result, the use of bioethanol for transportation purposes has been encouraged extensively. However, designing an effective bioethanol supply chain that is both sustainable and robust is still questionable. Therefore, this research focuses on designing a bioethanol supply chain that is: 1) sustainable in improving economic, environmental, social, and energy efficiency aspects; and 2) robust to uncertainties such as bioethanol price, bioethanol demand and biomass yield.
\end{abstract}

In this research, we first propose a decision framework to design an optimal bioenergybased industrial symbiosis (BBIS) under certain constraints. In BBIS, traditionally separate plants collocate in order to efficiently utilize resources, reduce wastes and increase profits for the entire BBIS and each player in the BBIS. The decision framework combines linear programming models and large scale mixed integer linear programming model to determine: 1) best possible combination of plants to form the BBIS, and 2) the optimal multi-product network of various materials in the BBIS, such that the bioethanol production cost is reduced.

Secondly, a sustainable hybrid generation bioethanol supply chain (HGBSC), which consists of $1^{\text {st }}$ generation and $2^{\text {nd }}$ generation bioethanol production, is designed to improve economic benefits under environmental and social restrictions. In this study, an optimal HGBSC is designed where the new $2^{\text {nd }}$ generation bioethanol supply chain is integrated with the existing $1^{\text {st }}$ generation bioethanol supply chain under uncertainties such as bioethanol price, bioethanol demand and biomass yield. A stochastic mixed integer linear programming (SMILP) model is developed to design the optimal configuration of HGBSC under different sustainability standards. 
Finally, a sustainable industrial symbiosis based hybrid generation bioethanol supply chain (ISHGBSC) is designed that incorporates various industrial symbiosis (IS) configurations into HGBSC to improve economic, environmental, social, and energy efficiency aspects of sustainability under bioethanol price, bioethanol demand and biomass yield uncertainties. A SMILP model is proposed to design the optimal ISHGBSC and Sampling Average Approximation algorithm is used as the solution technology.

Case studies of North Dakota are used as an application. The results provide managerial insights about the benefits of BBIS configurations within HGBSC. 


\section{ACKNOWLEDGEMENT}

Today, as I reach the fulfillment of my lifetime goal, I remember and acknowledge all the people who have directly or indirectly contributed to my success. At any given time in my life, I can whole heartedly say "They all have made great difference to my life."

Firstly, I express my sincere gratitude to my advisor Dr. Jun Zhang without whom I would not have come so far in my life. I thank her for everything she has done for me during my research. I thank her for consistently motivating me, being patient with me and challenging me to go beyond boundaries to generate new ideas. "Dr. Zhang has made me a better researcher."

I state my gratitude for Dr. Kambiz Farahmand for guiding me both professionally and personally. The guidance provided by Dr. Farahmand helped me make better decisions during tougher times in my life. In addition, working under him in VERC projects has provided me with great experience to perform research. I acknowledge Dr. Jing Shi whom I always admired. Interactions with Dr. Shi in VERC projects has helped me to develop characters such as working consistently hard irrespective of the situation, be critical of myself and most importantly question myself, “whether I am better today than yesterday ?” I would like to thank Dr. Joseph Szmerekovsky for being in my committee and giving me great insights during my research. I thank the faculty of Industrial Engineering and Susan Peterson for helping me during my grad studies.

I express my sincere obeisance to my mother, Bapamani Mala Gonela, for her deep love for me. The pain taken by her to see me at great heights is immeasurable. "I thank her for all her sacrifices." I thank my father, Sanyasi Rao Gonela, whose cynicism about me has always made me grow stronger and determined and strive for something great. I would like to remind him that great things do not happen instantaneously. It needs lot of effort, commitment and most 
importantly patience. I would also like to thank my sister, Kavita Behara, my brother-in-law, Ramesh Behara, for their consistent help and motivation. I would like to remember my beautiful nephew Sriyansh and niece Sriya who have always made me happy.

In life, there are moments when I have to choose between the "right" and the "emotional." During the past two years, I have made right decisions that have been tough on me and my wife. But today, I take this moment to propose to my wife. "Asha, I love you and will love you forever." I appreciate Iddrisu Awudu and Atif Osmani for being with me, motivating me and helping me with all my research. I take this opportunity to thank my friends, Raghavan Srinivasan, Budhadev Layek, Nimish Dharmadhikari, Srujan Chekuri, Akhilesh Ambati, Suresh Paturu, Haribabu Bhavanari, Manoj Madamanchi, Nithin Jadhav, Sudhi Upadhyaya, Ganesh Tambidorai, Kiran Kumar Vallabh, Mariama Yakubu, Lemon Shah and many more. These guys have all helped me a lot.

I feel there is no better place to learn, share and gain experience than TRiO. I feel it is a temple of knowledge which has been instrumental in developing me into an individual who has highest regard for society. It is the program that is doing magnificent job in developing great American citizens. I express my sincere gratitude to Aida Martinez-Freeman, Jeri Vaudrin, Tiffany Gear, Charles Cherry, Ray smith, Sydney Knutson, Steven Bateman and Gretchen Junglas for believing in me, understanding me and showing great deal of concern for me. I would not have achieved this success without your consistent motivation. I am also thankful to all the tutors, tutees and all the staff whose lives have inspired me.

When life gets tougher and when there is not even a ray of hope, there is always a person who can bring joy amidst all the difficulties. One such person in my life is Lillian Mousel. I am 
very humbled and honored to have a friend like Lillian Mousel who brought a new dimension to my life. I congratulate her on her wedding with Jake Weess and hope they have a great life.

I would like to acknowledge the NDSU writers for patiently correcting my English and Gloria Jeans coffee shop (1020 19th N Ave, Fargo) staff for allowing me to work considerable number of hours in their facility without causing any trouble.

I take this opportunity to thank my role model, Dr. Jonathan Cole Smith, who inspired me a lot during my PhD. Dr. Smith is the one whom I look to and replicate at all instances of my life. I acknowledge all my teachers, friends and relatives who has played significant role in my success. In addition, I acknowledge Tim Tebow whose life has inspired me to live a moral life. I thank the world for giving me an opportunity to fulfill my dream and making me a better human being.

Finally, I would like to acknowledge my favorite book "Bhagavad-Gita" and Jagadguru "Lord Krishna" whose teachings to "Arjun" have inspired me to live a moral and humane life. The teachings of Bhagavad-Gita to remain unattached to success and failure, happiness and distress have made me live a stable and peaceful life amidst all the difficulties.

As I move on to the next phase of my life, I promise to be a person who will strive for a better society, develop great citizens and put the needs of society ahead of my needs. 


\section{DEDICATION}

\section{Dedicated to "GOD" and "M.C.L"}

"What profit have you made if you win the entire world, but lost your own soul?" 


\section{TABLE OF CONTENTS}

ABSTRACT iii

ACKNOWLEDGEMENT V

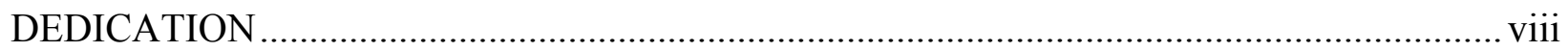

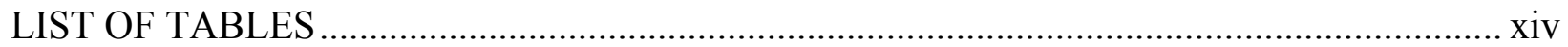

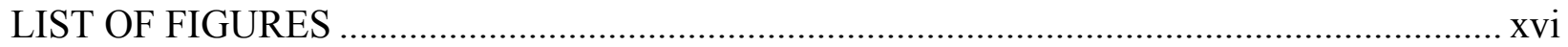

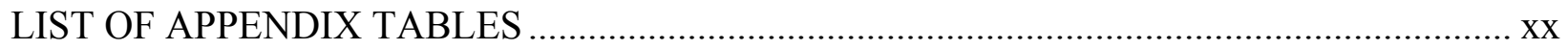

CHAPTER 1. BIOETHANOL SUPPLY CHAIN SUSTAINABILITY, UNCERTAINTIES AND INDUSTRIAL SYMBIOSIS STRATEGIES …................................... 1

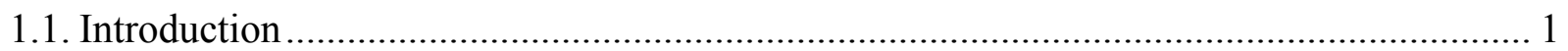

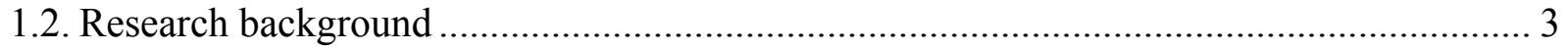

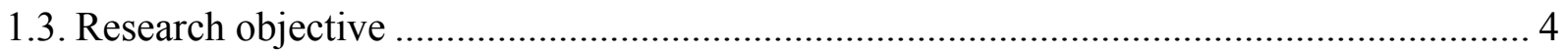

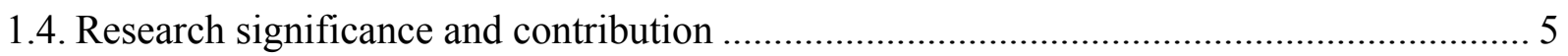

CHAPTER 2. LITERATURE REVIEW: BIOETHANOL SUPPLY CHAIN SUSTAINABILITY, UNCERTAINTIES AND INDUSTRIAL SYMBIOSIS STRATEGIES .... 7

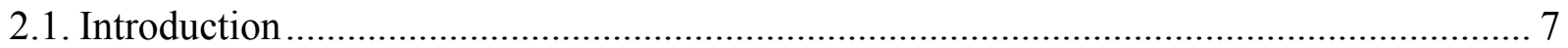

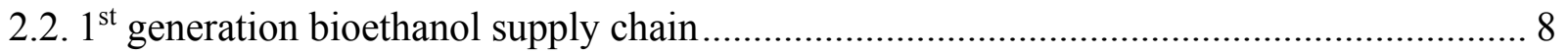

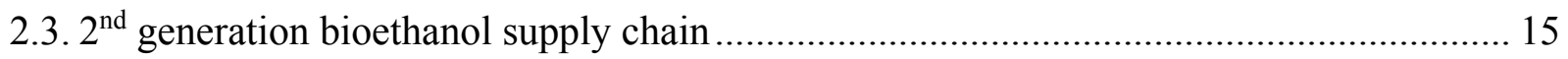

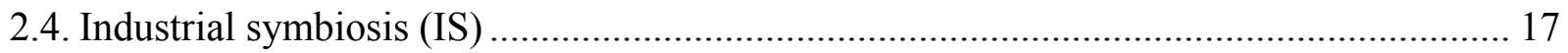

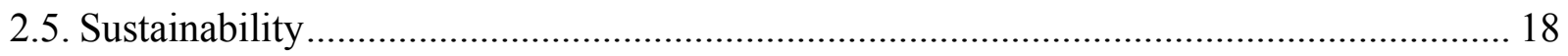

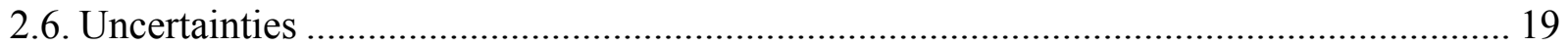




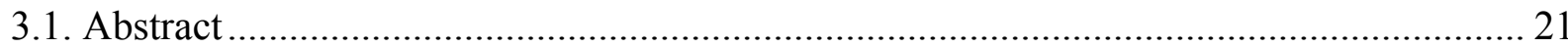

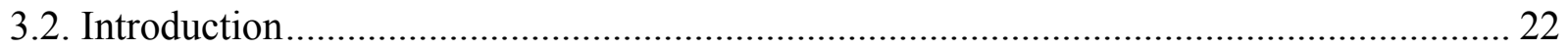

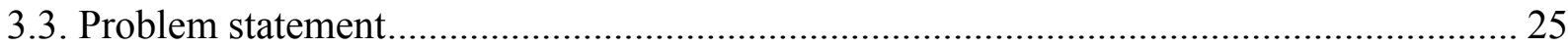

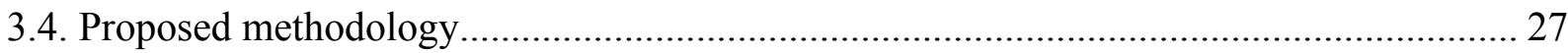

3.4.1. LP model formulation for standalone plants ..................................................... 31

3.4.2. MILP model formulation for BBIS system .................................................... 37

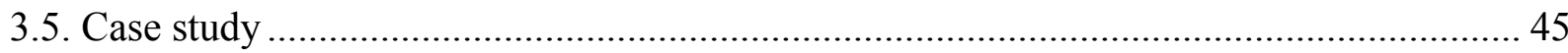

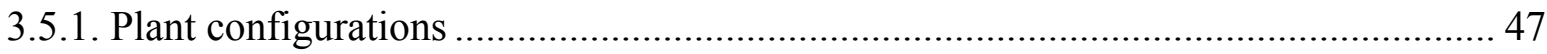

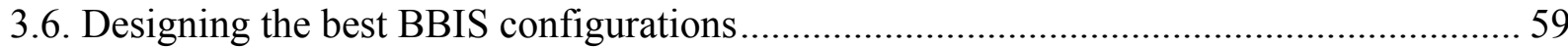

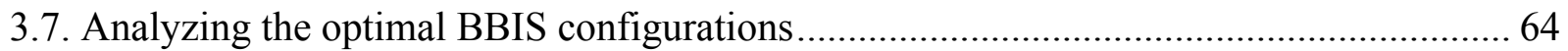

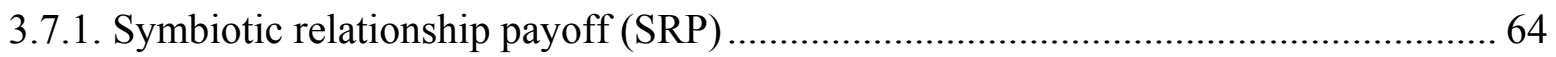

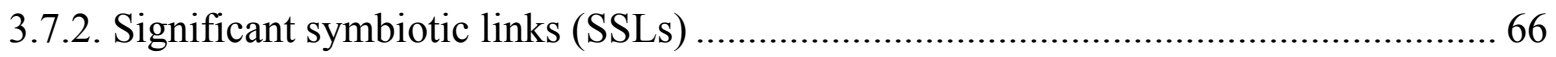

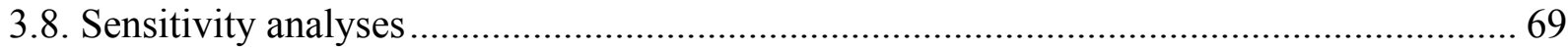

3.8.1. The impact of the CHP plant's capacity on the biorefinery plant's production ........ 69

3.8.2. The impact of the process steam price on the biorefinery plant's profit .................. 70

3.8.3. The impact of the capacity of the AD plant's livestock on the biorefinery

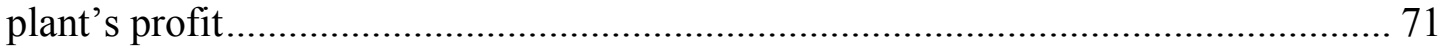

3.8.4. The impact of biomass types on BBIS configurations........................................ 72

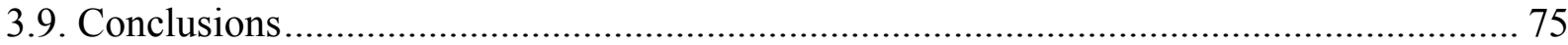




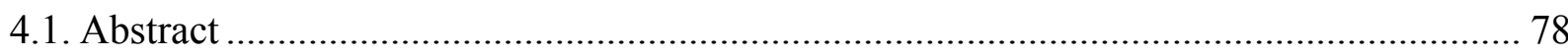

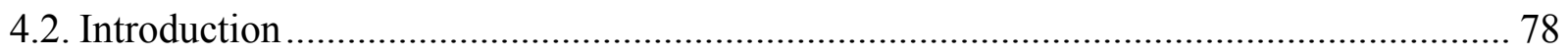

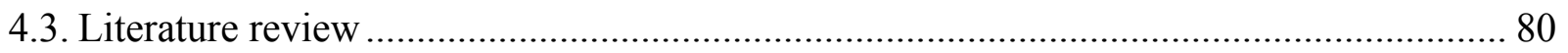

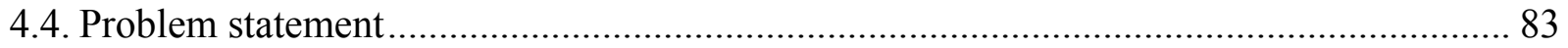

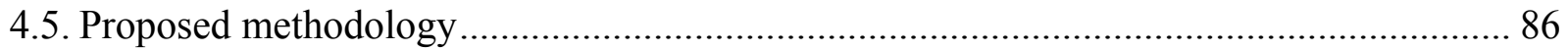

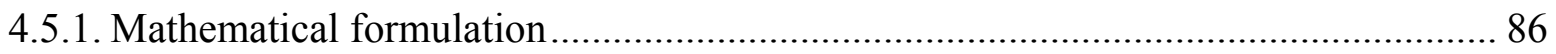

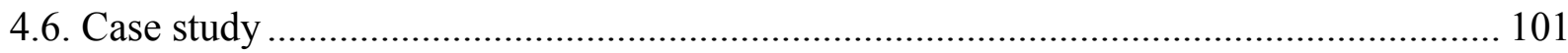

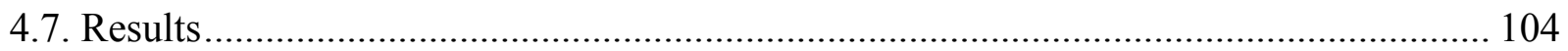

4.7.1. Economic analysis under different standards .................................................. 108

4.7.2. Environmental analysis under different standards ....................................... 111

4.7.3. Performances under different percentage of gasoline substitution ........................ 112

4.7.4. Tax credit decisions for policy makers ...................................................... 115

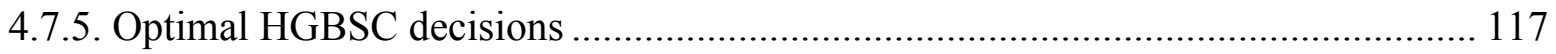

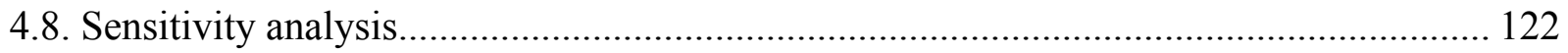

4.8.1. The impact of the bioethanol selling price.................................................... 122

4.8.2. The impact of the bioethanol conversion rate from switch grass .......................... 124

4.8.3. The impact of the $2^{\text {nd }}$ generation bioethanol production cost ............................. 125

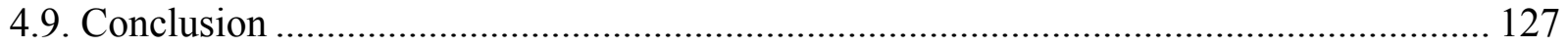


5.1. Abstract

5.2. Introduction

5.3. Literature review

5.4. Problem statement

5.5. Proposed stochastic model and solution procedure

5.5.1. Proposed stochastic model

5.5.2. Solution procedure 162

5.6. Case study configuration. 163

5.7. Results of the case study 166

5.7.1. Bioethanol production from various bioethanol plant configurations under various standards...

5.7.2. Economic analysis of ISHGBSC 172

5.7.3. Environmental analysis of ISHGBSC 175

5.7.4. Social analysis of ISHGBSC 176

5.7.5. Energy efficiency analysis of ISHGBSC 178

5.7.6. Comparison of ISHGBSC under RFS and CS 179

5.8. Sensitivity analysis 184

5.8.1. The impact of corn price on ISHGBSC with different standards 184

5.8.2. The impact of $2 \mathrm{G}-\mathrm{NBBIS} / \mathrm{CHP}$ unit capacity on sustainability 188 
5.9. Conclusion

CHAPTER 6. CONCLUSIONS AND FUTURE RESEARCH

194

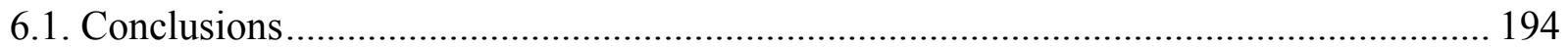

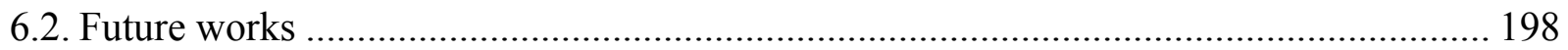

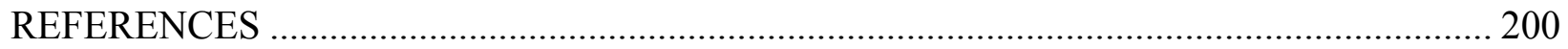

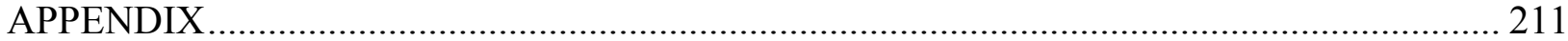




\section{LIST OF TABLES}

$\underline{\text { Table }}$

Page No

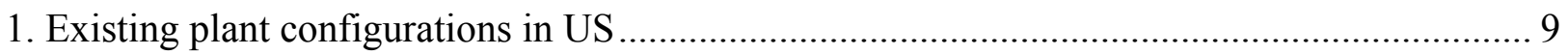

2. Existing $2^{\text {nd }}$ generation bioethanol plant configurations in US ...................................... 16

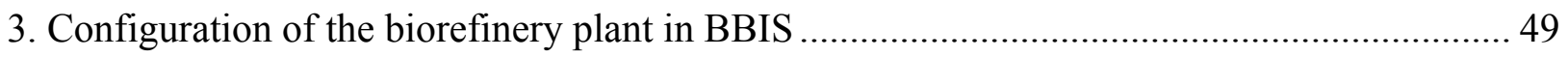

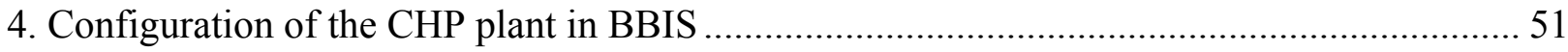

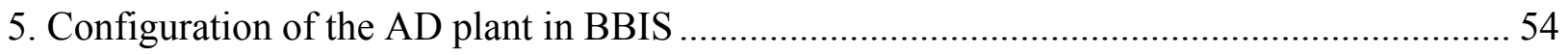

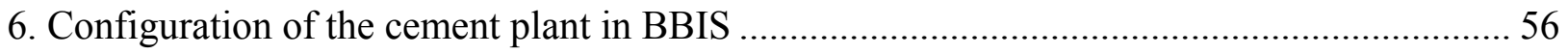

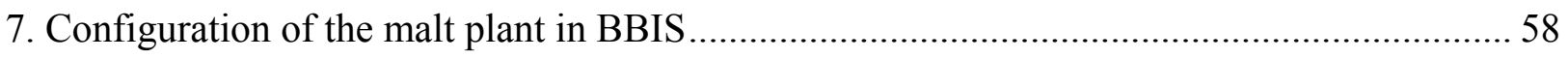

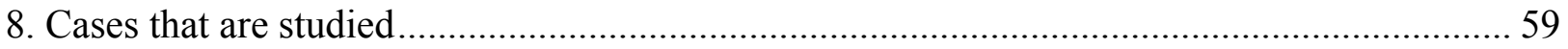

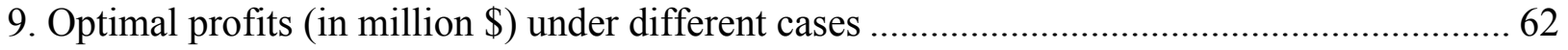

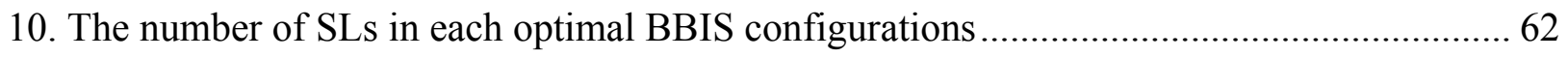

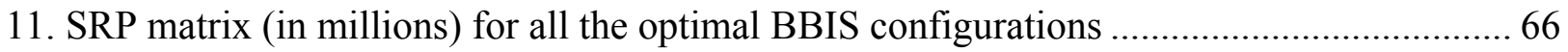

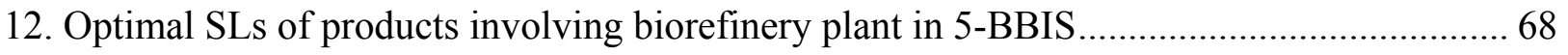

13. Initial and expansion capacities for existing 1 st generation bioethanol plants .................. 104

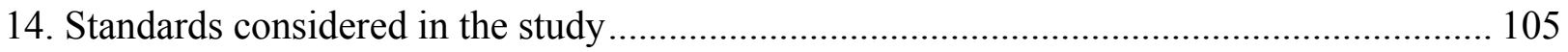

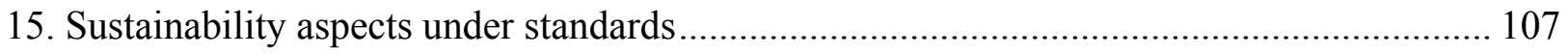

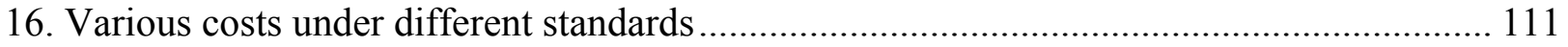

17. GHG emissions under different standards .......................................................... 112

18. Comparison of plant configurations between state 'A' and state 'B' ............................. 121

19. Optimal assignment of collection centers and demand zones to the bioethanol plants under state 'A'..... 
20. Optimal assignment of collection centers and demand zones to the bioethanol plants under state 'B'

21. Optimal transportation modes for states 'A' and 'B' ....................................................... 122

22. Configurations of bioethanol plants ............................................................................. 136

23. Initial and maximum expansion capacities for existing $1^{\text {st }}$ generation bioethanol plants.... 165

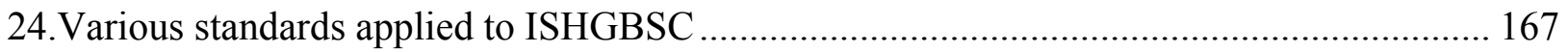

25. Sustainability measures under current conditions and estimated permit limits ................... 167

26. Performances of various standards under different sustainable metrics.............................. 169

27. Bioethanol produced from each bioethanol plant configurations (Million gallons)............ 171

28. Revenue (in billions) of ISHGBSC from different end products under different standards

29. Costs (in billions) from different logistic activities in ISHGBSC under different standards

30. Optimal plant locations, configurations and capacities for ISHGBSC under RFS and CS

31. Optimal assignment of collection centers, demand zones to the bioethanol plant in ISHGBSC under RFS and CS 


\section{LIST OF FIGURES}

Figure

Page No

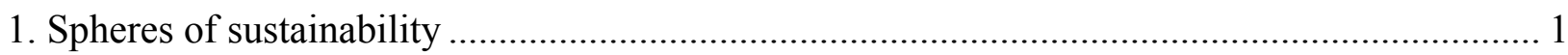

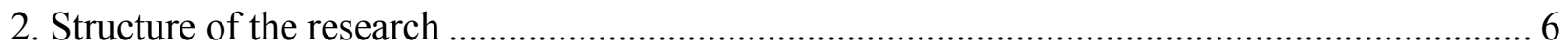

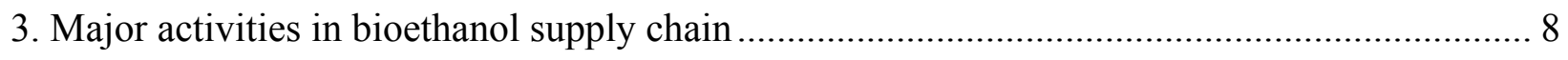

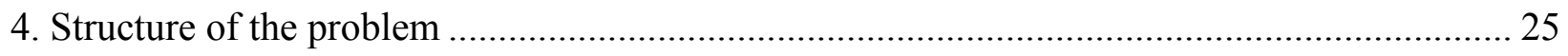

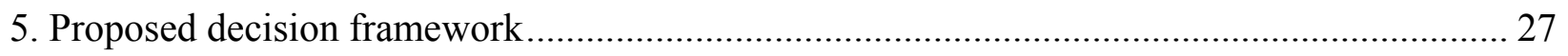

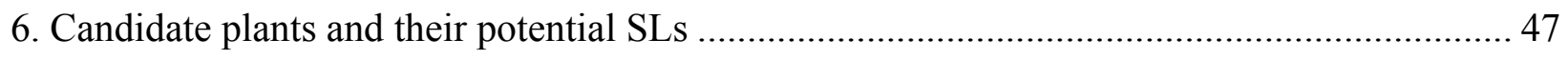

7. Input and output products of the biorefinery plant ……........................................................ 48

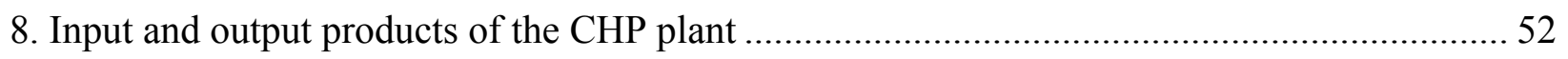

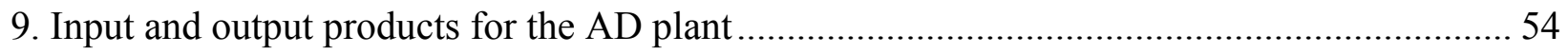

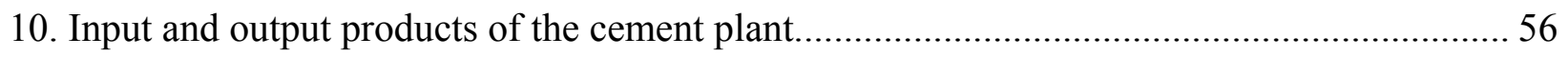

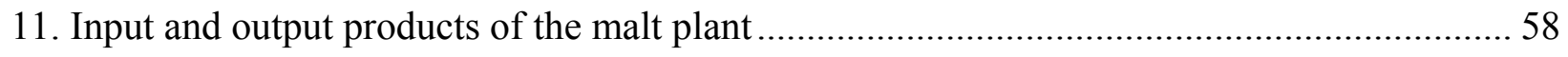

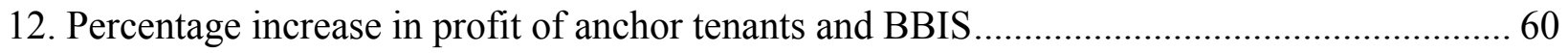

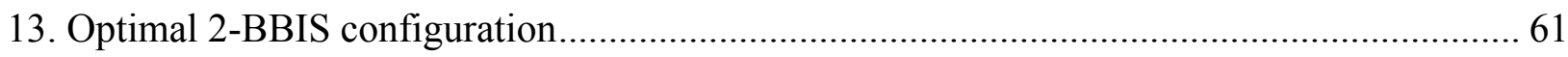

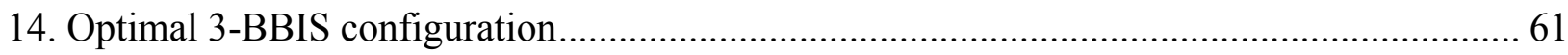

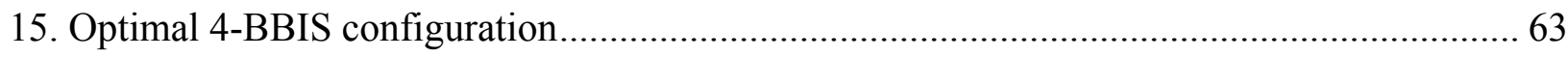

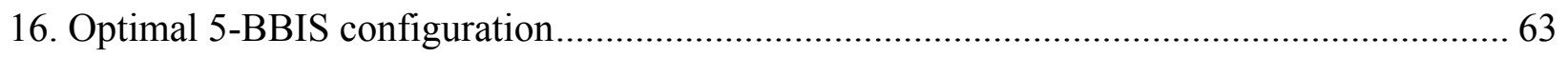

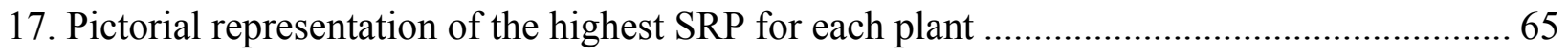

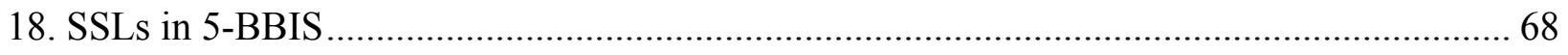

19. Impact of the CHP plant capacity on the biorefinery plant ………....................................... 70

20. Process steam price impact on the biorefinery plant …………………........................... 71

21. The impact of the livestock capacity on biorefinery plant.................................................... 72 
22. The biorefinery plant profit under different biomass input 73

23. The CHP plant profit under different biomass input ......................................................... 74

24. Bioethanol cost (\$/gallon) under various BBIS configurations .............................................. 74

25. Profit (\$/Gallon) under various BBIS configurations ........................................................... 75

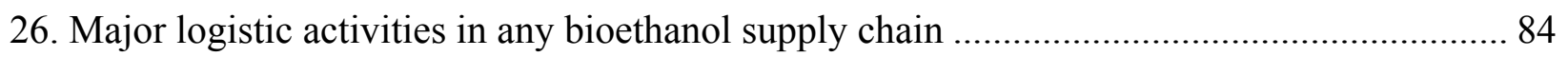

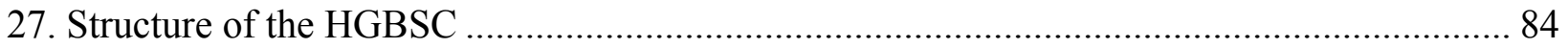

28. Current configuration of the bioethanol supply chain in ND State ..................................... 104

29. Economic aspect of HGBSC under different standards.................................................... 107

30. Environmental aspect of HGBSC under different standards ............................................. 107

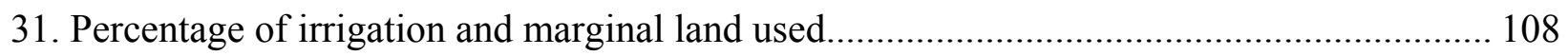

32. Profit from bioethanol and co-products ............................................................................. 109

33. Total bioethanol supply chain cost under different standards ........................................... 110

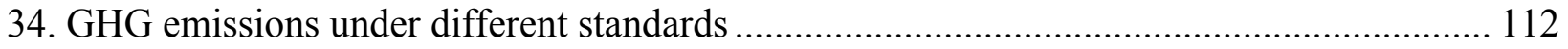

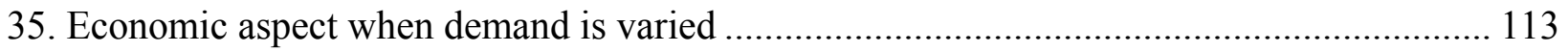

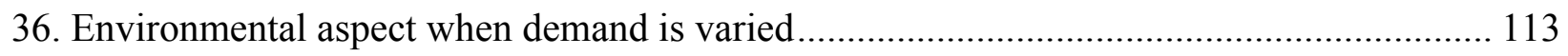

37. Demand met from $1^{\text {st }}$ generation biomass (social) when demand is varied ........................ 114

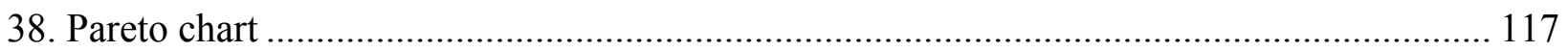

39. Network topology of biomass supply sites to bioethanol plants in HGBSC at state 'A' '.... 118

40. Network topology of biomass supply sites to bioethanol plants in HGBSC at state 'B'...... 119

41. Network topology of bioethanol plants to demand zones in HGBSC at state 'A' ............... 119

42. Network topology of bioethanol plants to demand zones in HGBSC at state 'B' ................ 120

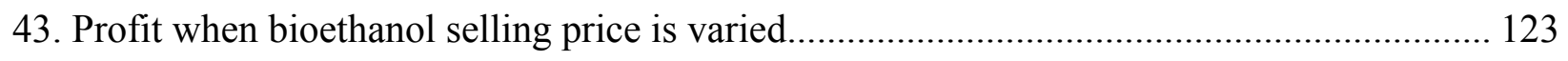

44. GHG emissions when bioethanol selling price is varied .................................................. 123 
45. Bioethanol demand met when bioethanol selling price is varied

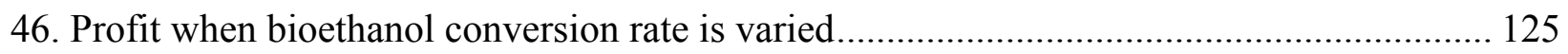

47. GHG emissions when bioethanol conversion rate is varied ............................................. 125

48. Profit when switchgrass based production cost is varied................................................... 126

49. GHG emissions when switchgrass based bioethanol production cost is varied ................... 127

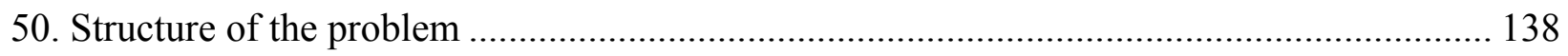

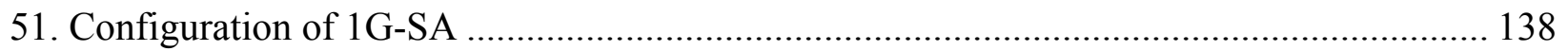

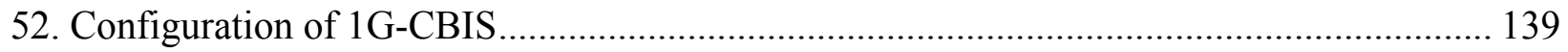

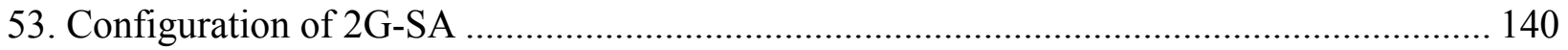

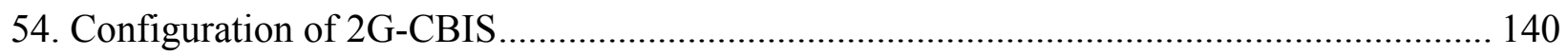

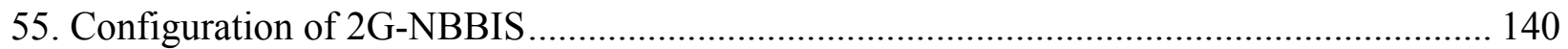

56. Current configuration of bioethanol supply chain in ND ................................................... 166

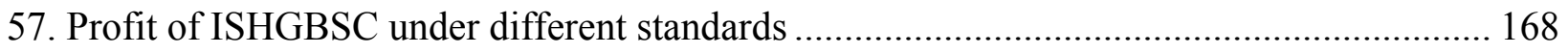

58. GHG emissions of ISHGBSC under different standards .................................................. 169

59. Irrigation land used by ISHGBSC under different standards ........................................... 170

60. Water used by SHGBSC under different standards ......................................................... 170

61. Energy efficiency by ISHGBSC under different standards .............................................. 170

62. Bioethanol produced by ISHGBSC under different standards ......................................... 172

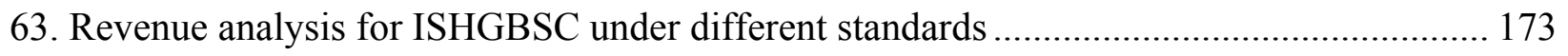

64. Cost analysis for ISHGBSC under different standards ................................................ 175

65. GHG emissions by ISHGBSC under different standards .................................................. 176

66. Land used by ISHGBSC under different standards ......................................................... 177

67. Water used by ISHGBSC under different standards......................................................... 177 
68. Energy produced by ISHGBSC under different standards 178

69. Energy used by ISHGBSC under different standards

70. Network topology of biomass supply to bioethanol plant in ISHGBSC under RFS . 181

71. Network topology of biomass supply to bioethanol plant in ISHGBSC under CS 182

72. Network topology of bioethanol plant to demand zone in ISHGBSC under RFS. 182

73. Network topology of bioethanol plant to demand zone in ISHGBSC under CS 183

74. Profit of ISHGBSC under different standards when corn price is increased..... 185

75. GHG emissions of ISHGBSC under different standards when corn price is increased 186

76. Irrigation land used by ISHGBSC under different standards when corn price is increased 187

77. Water used by ISHGBSC under different standards when corn price is increased 187

78. Energy efficiency of ISHGBSC under different standards when corn price is increased .... 188

79. Profit of ISHGBSC when CHP unit capacity of 2G-NBBIS is increased..... 189

80. GHG emissions of ISHGBSC when the CHP unit capacity of 2G-NBBIS is increased 190

81. Irrigation land used by ISHGBSC when CHP unit capacity of 2G-NBBIS is increased ..... 190

82. Water used by ISHGBSC when CHP unit capacity of 2G-NBBIS is increased 191

83. Energy efficiency of ISHGBSC when CHP unit capacity of $2 \mathrm{G}-\mathrm{NBBIS}$ is increased. 191 


\section{LIST OF APPENDIX TABLES}

$\underline{\text { Table }}$

$\underline{\text { Page No }}$

A. 1. Contribution of SRs in improving the CHP plant's profit in 5-BBIS ............................. 211

A. 2. Contribution of SRs in improving AD plant's profit in 5-BBIS .................................. 211

A. 3. Contribution of SRs in improving the malt plant's profit in 5-BBIS ............................ 212

A. 4. Contribution of SRs in improving the cement plant's profit in 5-BBIS .......................... 212

A. 5. Average values for uncertain parameters.................................................................. 212

A. 6. Maximum allowable land for each of the biomass considered .................................... 213

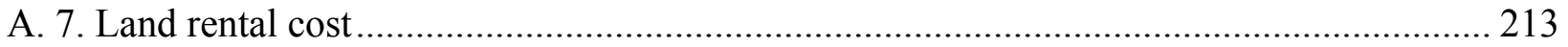

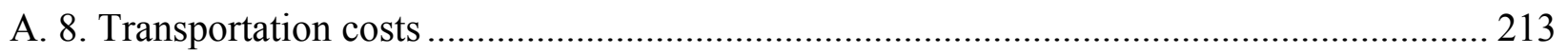

A. 9. Capacity, cost, yield, and GHG emission parameters ............................................. 214

A. 10. Average values for uncertain parameters .............................................................. 216

A. 11. Maximum allowable land for each of the biomass considered ................................. 216

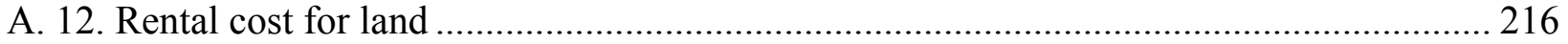

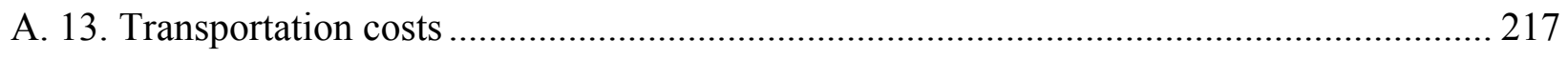

A. 14. Capacity, cost, yield, GHG emissions, water and energy efficiency parameters ........... 217 


\section{CHAPTER 1. BIOETHANOL SUPPLY CHAIN SUSTAINABILITY, UNCERTAINTIES AND INDUSTRIAL SYMBIOSIS STRATEGIES}

\subsection{Introduction}

The ever increasing concerns such as energy security and climate change calls for alternative renewable and sustainable ways of performing business. As a result, bioethanol has gained a great deal of attraction to replace gasoline because it is considered as both renewable and sustainable source of energy. However, designing a sustainable bioethanol supply chain is still questionable. Figure 1 presents the three spheres of sustainability. It indicates that any business is sustainable if it improves economic, environmental and social aspects. Therefore, designing an effective bioethanol supply chain should consider economic, environmental and social aspects of sustainability.

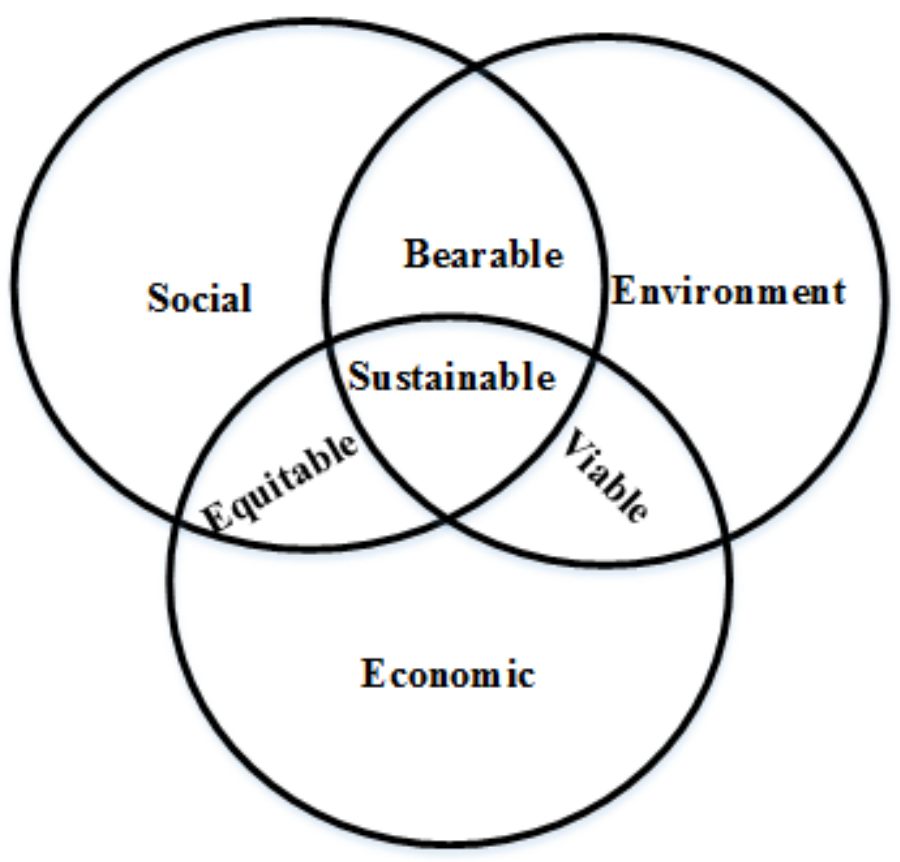

Figure 1. Spheres of sustainability

Source: You, Tao, Graziano, \& Snyder (2012) 
A number of standards or policies have been developed to promote bioethanol. As a result, $1^{\text {st }}$ generation bioethanol has been produced widely across various nations. However, the wide use of $1^{\text {st }}$ generation bioethanol has given rise to new social issues such as the food vs. fuel debate and the extensive use of irrigation land for energy purposes. This results in increased cost of food products and reduced available land (resource) footprint for cultivation of food products. In addition, $1^{\text {st }}$ generation bioethanol produces higher Green House Gas (GHG) emissions compared to $2^{\text {nd }}$ generation. Therefore, $2^{\text {nd }}$ generation bioethanol has gained great attraction as it is both environmentally and socially sustainable. In fact, the Renewable Fuel Standard (RFS) enforces that at least $55 \%$ of the bioethanol demand should be met from $2^{\text {nd }}$ generation by the year 2022 . Since $1^{\text {st }}$ generation bioethanol supply chains already exists, and the process of introducing $2^{\text {nd }}$ generation bioethanol should be gradual, there is a need to design hybrid generation bioethanol supply chain (HGBSC) to sustainably meet the bioethanol demand.

In addition, the United States Environmental Protection Agency (USEPA) Executive Order 13423 enforces $30 \%$ reduction in energy intensity by the year 2015 for all systems consuming energy. Therefore, it is necessary to develop strategies that can reduce the energy intensity of HGBSC. Industrial symbiosis (IS) is one of the sustainable strategies that can help to reduce the energy intensity of the bioethanol plant. In IS, traditionally separate plants collocate in order to improve resource utilization and reduce wastes resulting in improved economic, environmental, social and energy intensity aspects of sustainability. There are numerous ways to form IS and different IS developments or configurations provides different sustainability benefits. Therefore, it is necessary to explore different IS strategies while designing HGBSC. Consequently, an industrial symbiosis based bioethanol supply chain (ISHGBSC) should be designed. In addition, ISHGBSC is exposed to number of uncertainties such as bioethanol demand, bioethanol price and 
biomass price. Consequently, a robust ISHGBSC should be designed in order to be less vulnerable to risks. Therefore, this study provides a decision framework to design a robust and sustainable ISHGBSC. A case study of North Dakota (ND) is conducted to determine the efficiency and effectiveness of the proposed decision framework. In addition, the feasibility of numerous existing sustainability and IS developments are studied. Sustainability comparison analysis between $1^{\text {st }}$ generation and $2^{\text {nd }}$ generation bioethanol supply chain is also conducted. The findings provide deep insights to both bioethanol policy makers and investors.

\subsection{Research background}

Bioethanol is becoming increasingly attractive for the reasons of energy security, diversity, and sustainability. In fact, many countries view biofuel as possible substitute or alternative for petroleum products due to the growing environmental concerns and limited availability of petroleum products. As a result, significant amount of research is conducted to promote economically and environmentally sustainable $1^{\text {st }}$ generation bioethanol supply chain. However, the wide use of $1^{\text {st }}$ generation bioethanol has created new social issues such as food versus fuel debate. The quest for new biomass that can simultaneously improve economic, environmental and social aspects of sustainability has led to the emergence of $2^{\text {nd }}$ generation bioethanol. Consequently, in recent years, a considerable amount of research has been conducted to design economically and environmentally sustainable $2^{\text {nd }}$ generation bioethanol supply chain. The study of literature suggested that none of the up-to-date literature has focused on designing bioethanol supply chain in order to transition from existing $1^{\text {st }}$ generation bioethanol supply chain to new $2^{\text {nd }}$ generation bioethanol supply chain. In addition, only few previous literatures have considered all the three economic, environment and social aspects of sustainability while designing bioethanol supply chain. Therefore, it is necessary to design a bioethanol supply chain that can transition 
smoothly (without disruption) from the existing $1^{\text {st }}$ generation bioethanol supply chain to new $2^{\text {nd }}$ generation bioethanol supply chain.

In recent years, numerous federal agencies have promoted standards or policies to reduce fossil dependency for all energy consuming systems. Therefore, in order to reduce energy intensity, numerous other strategies have to be explored. IS is considered as one the sustainable strategies that can reduce fossil dependency. Only little research has been conducted to design optimal IS configurations. However, these studies have not considered designing IS within supply chains. Such studies where IS is not considered in IS can provide inaccurate insights to the decisions makers. Therefore, it is necessary to explore the role of IS in bioethanol supply chain in order to improve the sustainability.

In addition, bioethanol supply chain is exposed to number of uncertainties such as bioethanol price, bioethanol demand and biomass supply. In past, most of research is focused on developing deterministic models to design optimal bioethanol supply chain. However, the design of bioethanol supply chain based on deterministic models can significantly affect the performance under stochastic conditions. Therefore, it is necessary to design a robust bioethanol supply chain.

\subsection{Research objective}

The objectives of the research are as follows:

1) Identify gaps in literature by conducting comprehensive literature on bioethanol supply chain, Industrial symbiosis systems, sustainability and uncertainty concepts.

2) Develop mathematical model to explore various symbiotic opportunities for bioethanol plant to reduce the bioethanol production cost. 
3) Develop stochastic model to see the transition from existing $1^{\text {st }}$ generation bioethanol supply chain to new $2^{\text {nd }}$ generation bioethanol supply chain under uncertainties.

4) Develop stochastic model to explore the sustainability impact of various IS configurations on bioethanol supply chain under uncertainties.

5) Use Algorithm to solve the large scale model.

\subsection{Research significance and contribution}

This section presents the research significance and contribution. Figure 2 shows the problem solved. The significance and contribution of the research are as follows:

1) Conduct comprehensive literature on Industrial Symbiosis (IS), bioethanol supply chain strategies and sustainability concepts in order to identify gaps that include: 1) identifying the plants that can form symbiosis with the bioethanol plant, 2) identifying the factors that impact the bioethanol supply chain decisions and 3) identifying the factors that drive various sustainability aspects.

3) Develop mathematical models to design optimal bioenergy based industrial symbiosis (BBIS) system to improve bioethanol production.

4) Develop mathematical model to design hybrid generation bioethanol supply chain (HGBSC) that accounts for economic, environmental and social aspects under uncertainties in order to determine optimal decisions and standards.

5) Develop mathematical model to design sustainable industrial symbiosis based hybrid generation bioethanol supply chain (ISHGBSC) that accounts for economic, environmental, social, and energy intensity aspects of sustainability under various uncertainties to determine optimal decisions and standards. 


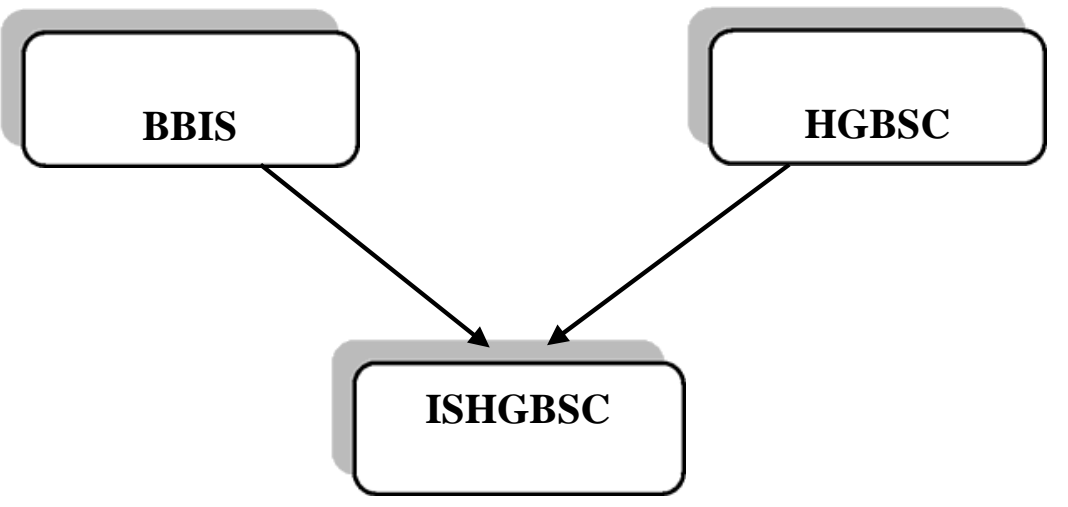

Figure 2. Structure of the research 


\section{CHAPTER 2. LITERATURE REVIEW: BIOETHANOL SUPPLY CHAIN}

SUSTAINABILITY, UNCERTAINTIES AND INDUSTRIAL SYMBIOSIS STRATEGIES

\subsection{Introduction}

A sustainable energy future calls for a wide range of alternative sources of energy that can reduce fossil fuel dependency (Chen and Fan, 2012). Biofuels are considered as one of the potential solutions to replace petroleum products because they are both renewable and sustainable sources of energy. Biofuels are liquid or gaseous fuels that are produced from biomass (Demirbas, 2007). Biofuels are considered to offer many benefits that include, but not limited to: 1) reduce Green House Gas emissions, 2) helps in regional development, 3) improve the social structure of the rural agriculture, and 5) provide energy security (Demirbas, 2007). There are two types of biofuels: 1) bioethanol and 2) biodiesel. This research mainly focuses on bioethanol.

While bioethanol offers numerous advantages, the design of sustainable bioethanol supply chain is still questionable. A bioethanol supply chain consists of number of logistic activities. Figure 3 presents the major logistic activities in bioethanol supply chain (Awudu and Zhang, 2012 a). Firstly, biomass is cultivated at the biomass cultivation sites. Secondly, biomass is harvested and transported to the bioethanol conversion plant where biomass is converted to bioethanol. Finally, the converted bioethanol is transported to the bioethanol consumption zones. Given the logistic activities, there are number of decisions that need to be made in a bioethanol supply chain. These decisions include, but not limited to: biomass type to be cultivated, biomass cultivation site locations, biomass harvesting technologies, biomass collection center locations, bioethanol plant locations and transportation modes (Awudu and Zhang, 2012). In order to design an efficient bioethanol supply chain, these decisions needs to be made such that it improves the 
sustainability of the bioethanol supply chain and is less vulnerable to the uncertainties. Biothanol can be produced from two types of biomass: 1) $1^{\text {st }}$ generation, and 2) $2^{\text {nd }}$ generation.

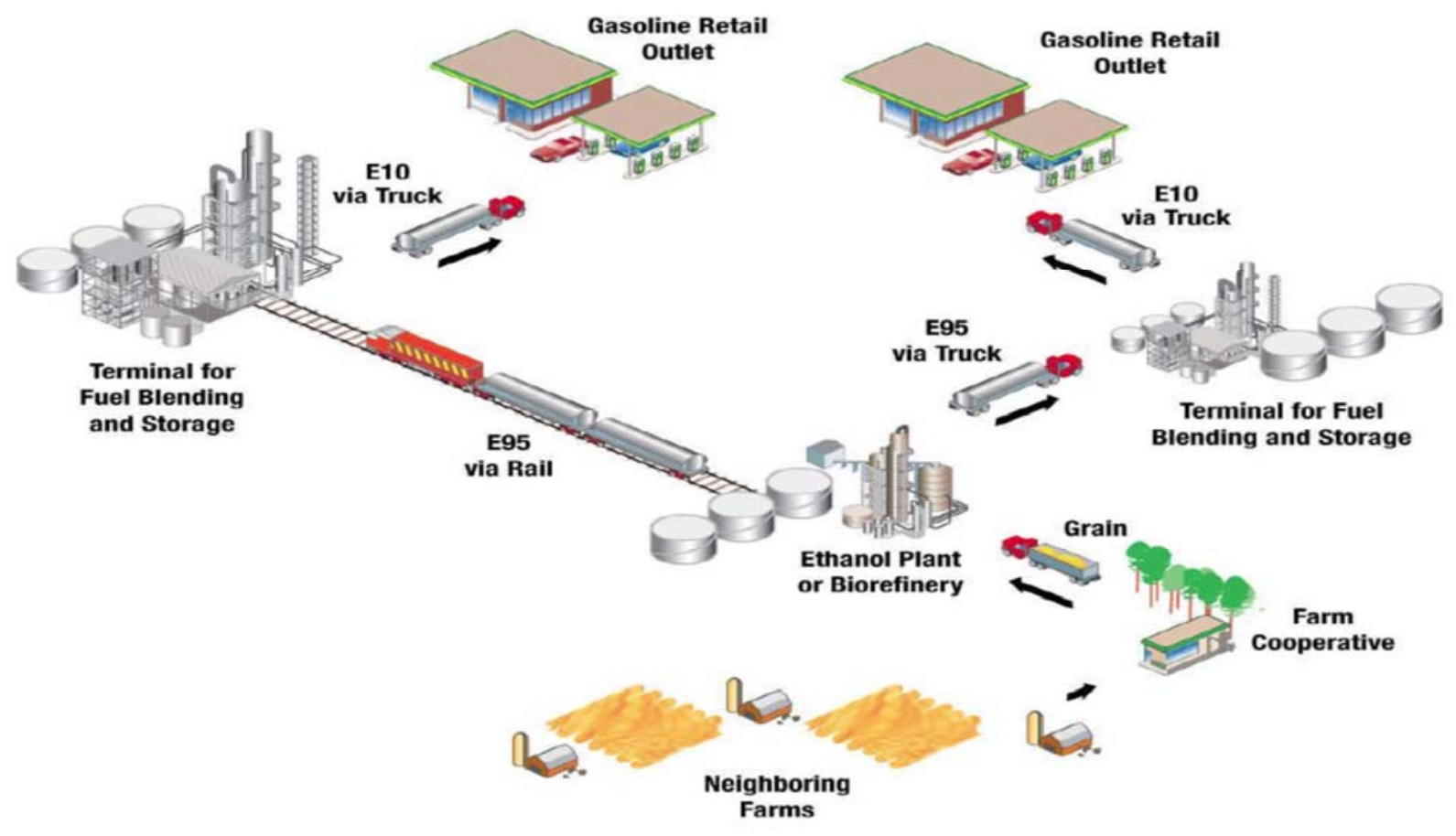

Figure 3. Major activities in bioethanol supply chain

Source: Awudu and Zhang, 2012

\section{2. $1^{\text {st }}$ generation bioethanol supply chain}

$1^{\text {st }}$ generation biomass is produced from edible or food products such as corn, sugarcane and soybean. A considerable amount of research is conducted to design a $1^{\text {st }}$ generation bioethanol supply chain. Zamboni, Shah, \& Bezzo (2009ª) and Zamboni, Shah, \& Bezzo (2009 $)$ develop a Multi-objective mixed integer linear programming (Mo-MILP) model to design a corn-based bioethanol ( $1^{\text {st }}$ generation) supply chain. The objective is to simultaneously minimize the cost and GHG emissions and the results suggest that supply chain decisions change when GHG emissions are considered. Corsano,Vecchietti, \& Montagna (2011) develop a mixed integer nonlinear programming (MINLP) model to design a sustainable sugar/ethanol ( $1^{\text {st }}$ generation $)$ supply chain. The results indicate that including sustainability into the bioethanol supply chain would 
significantly reduce the profit and change the supply chain design. Dal-Mas, Giarola, Zamboni, \& Bezzo (2011) develop a stochastic model to design a cost effective $1^{\text {st }}$ generation (corn) based bioethanol supply chain. Mele, Kostin, Guillén-Gosálbez, \& Jiménez (2011) develop a Multiobjective Mixed Integer Linear Programming (Mo-MILP) model to design economically and environmentally sustainable combined sugar and bioethanol supply chain. Awudu and Zhang $\left(2012^{\mathrm{b}}\right)$ develop stochastic production planning model for $1^{\text {st }}$ generation based bioethanol supply chain under demand and supply uncertainties. The objective is to improve the economic benefits. Table 1 presents existing $1^{\text {st }}$ generation bioethanol plant configurations in US (Ethanol Facilities capacity by state and plant, 2012). There are 202 existing $1^{\text {st }}$ generation bioethanol plants in US. The total capacity add to 13910 MMGY. All the existing $1^{\text {st }}$ generation plant uses sugar/starch platform.

Table 1. Existing plant configurations in US

Source: Facilities capacity by state and plant, 2012

\begin{tabular}{lllr}
\hline Plant & State & Feedstock & $\begin{array}{r}\text { Capacity } \\
\text { (MMGY) }\end{array}$ \\
\hline Pinal Energy LLC & Arizona & Corn & 50 \\
Aemetis Advanced Fuels Keyes Inc. & California & Corn, Sorghum & 60 \\
Calgren Renewable Fuels LLC & California & Corn, Sorghum & 58 \\
Pacific Ethanol Madera LLC & California & Corn & 40 \\
Pacific Ethanol Stockton LLC & California & Corn & 60 \\
Front Range Energy LLC & Colorado & Corn & 48 \\
Northeast Kansas Bioenergy & Colorado & Corn, Sorghum & 3 \\
Sterling Ethanol LLC & Colorado & Corn & 52 \\
Yuma Ethanol LLC & Colorado & Corn & 50 \\
Southwest Georgia Ethanol LLC & Georgia & Corn & 100 \\
Pacific Ethanol Magic Valley LLC & Idaho & Corn & 60 \\
Abengoa Bioenergy of Illinois & Illinois & Corn & 88 \\
Adkins Energy LLC & Illinois & Corn & 49 \\
\hline & & & Continued
\end{tabular}


Table 1. Existing plant configurations in US (Continued)

\begin{tabular}{lllr}
\hline Plant & State & Feedstock & $\begin{array}{r}\text { Capacity } \\
\text { (MMGY) }\end{array}$ \\
\hline Archer Daniels Midland Co.-Peoria & Illinois & Corn & NA \\
Aventine Renewable Energy-Pekin & Illinois & Corn & 160 \\
Big River Resources Galva, LLC & Illinois & Corn & 120 \\
Center Ethanol Co. LLC & Illinois & Corn & 54 \\
Illinois Corn Processing LLC & Illinois & Corn & 90 \\
Illinois River Energy LLC & Illinois & Corn & 110 \\
Lincolnland Agri-Energy LLC & Illinois & Corn & 50 \\
Marquis Energy LLC & Illinois & Corn & 140 \\
One Earth Energy LLC & Illinois & Corn & 125 \\
Patriot Renewable Fuels, LLC & Illinois & Corn & 110 \\
Abengoa Bioenergy of Indiana & Indiana & Corn & 88 \\
Archer Daniels Midland Co.-Decatur & Indiana & Corn & NA \\
Aventine Renewable Energy-Mt. Vernon LLC & Indiana & Corn & 110 \\
Cardinal Ethanol, LLC & Indiana & Corn & 100 \\
Cargill Inc.-Eddyville & Indiana & Corn & 35 \\
Central Indiana Ethanol LLC & Indiana & Corn & 50 \\
Grain Processing Corp.-Washington wet mill & Indiana & Corn & 36 \\
Green Plains Renewable Energy-Bluffton & Indiana & Corn & 120 \\
Green Plains Renewable Energy-Lakota & Indiana & Corn & 100 \\
Iroquois Bio-Energy Company LLC & Indiana & Corn & 40 \\
MGPI of Indiana & Indiana & Corn & 35 \\
New Energy Corp. & Indiana & Corn & 102 \\
Poet Biorefining-Alexandria & Indiana & Corn & 75 \\
Poet Biorefining-Cloverdale & Indiana & Corn & 99 \\
Poet Biorefining-North Manchester & Indiana & Corn & 73 \\
Poet Biorefining-Portland & Indiana & Corn & 73 \\
The Andersons Clymers Ethanol LLC & Indiana & Corn & 110 \\
Valero Renewable Fuels LLC-Linden & Indiana & Corn & 120 \\
Absolute Energy LLC & Iowa & Corn & 115 \\
Archer Daniels Midland Co.-Cedar Rapids dry & & & \\
mill & Iowa & Corn & 150 \\
Archer Daniels Midland Co.-Cedar Rapids wet & & & \\
mill & Iowa & Corn & 150 \\
Archer Daniels Midland Co.-Clinton & Iowa & Corn & NA \\
Big River Resources West Burlington LLC & Iowa & Corn & 110 \\
\hline & & & Continued
\end{tabular}


Table 1. Existing plant configurations in US (Continued)

\begin{tabular}{|c|c|c|c|}
\hline Plant & State & Feedstock & $\begin{array}{l}\text { Capacity } \\
\text { (MMGY) }\end{array}$ \\
\hline Big River United Energy LLC & Iowa & Corn & 120 \\
\hline Corn LP & Iowa & Corn & 62 \\
\hline Flint Hills Resources Arthur LLC & Iowa & Corn & 110 \\
\hline Flint Hills Resources Fairbank LLC & Iowa & Corn & 105 \\
\hline Flint Hills Resources Iowa Falls LLC & Iowa & Corn & 90 \\
\hline Flint Hills Resources Menlo LLC & Iowa & Corn & 115 \\
\hline Flint Hills Resources Shell Rock LLC & Iowa & Corn & 115 \\
\hline Golden Grain Energy, LLC & Iowa & Corn & 120 \\
\hline Grain Processing Corp.-Muscatine wet mill & Iowa & Corn & 87 \\
\hline Green Plains Renewable Energy-Shenandoah & Iowa & Corn & 65 \\
\hline Green Plains Renewable Energy-Superior & Iowa & Corn & 60 \\
\hline Homeland Energy Solutions, LLC & Iowa & Corn & 140 \\
\hline Lincolnway Energy LLC & Iowa & Corn & 62 \\
\hline Little Sioux Corn Processors LP & Iowa & Corn & 92 \\
\hline Louis Dreyfus Commodities - Grand Junction & Iowa & Corn & 100 \\
\hline Penford Products Corp. & Iowa & Corn & 45 \\
\hline Permeate Refining Inc. & Iowa & $\begin{array}{l}\text { Corn, Sorghum, } \\
\text { grains, sugar }\end{array}$ & \\
\hline Pine Lake Corn Processors LP & Iowa & Corn & 30 \\
\hline Plymouth Energy, LLC & Iowa & Corn & 50 \\
\hline Poet Biorefining-Ashton & Iowa & Corn & 57 \\
\hline oet Biorefining-Coon Rapids & Iowa & Corn & 53 \\
\hline Poet Biorefining-Corning & Iowa & Corn & 73 \\
\hline Poet Biorefining-Emmetsburg & Iowa & Corn & 57 \\
\hline Poet Biorefining-Gowrie & Iowa & Corn & 73 \\
\hline Poet Biorefining-Hanlontown & Iowa & Corn & 57 \\
\hline Poet Biorefining-Jewell & Iowa & Corn & 73 \\
\hline Quad County Corn Processors & Iowa & Corn & 30 \\
\hline Siouxland Energy \& Livestock Co-op & Iowa & Corn & 60 \\
\hline Southwest Iowa Renewable Energy LLC & Iowa & Corn & 125 \\
\hline The Andersons Denison Ethanol LLC & Iowa & Corn & 55 \\
\hline Valero Renewable Fuels LLC-Albert City & Iowa & Corn & 120 \\
\hline Valero Renewable Fuels LLC-Charles City & Iowa & Corn & 120 \\
\hline Valero Renewable Fuels LLC-Fort Dodge & Iowa & Corn & 120 \\
\hline Valero Renewable Fuels LLC-Hartley & Iowa & Corn & 120 \\
\hline
\end{tabular}


Table 1. Existing plant configurations in US (Continued)

\begin{tabular}{|c|c|c|c|}
\hline Plant & State & Feedstock & $\begin{array}{l}\text { Capacity } \\
\text { (MMGY) }\end{array}$ \\
\hline Abengoa Bioenergy Corp. - Colwich & Kansas & Corn, Sorghum & 25 \\
\hline Arkalon Energy LLC & Kansas & Corn, Sorghum & 110 \\
\hline Bonanza BioEnergy LLC & Kansas & Corn, Sorghum & 55 \\
\hline East Kansas Agri-Energy LLC & Kansas & Corn & 43 \\
\hline ESE Alcohol Inc. & Kansas & Seed corn & 1.5 \\
\hline Kansas Ethanol LLC & Kansas & Corn, Sorghum & 55 \\
\hline MGP Ingredients, Inc. & Kansas & Corn & 6 \\
\hline Nesika Energy LLC & Kansas & Corn & 10 \\
\hline Prairie Horizon Agri-Energy LLC & Kansas & Corn, Sorghum & 40 \\
\hline Reeve Agri Energy & Kansas & Corn, Sorghum & 12 \\
\hline Western Plains Energy LLC & Kansas & $\begin{array}{l}\text { Corn, Sorghum } \\
\text { Sorghum, }\end{array}$ & 50 \\
\hline White Energy Russell LLC & Kansas & Wheat & 55 \\
\hline Commonwealth Agri-Energy LLC & Kentucky & Corn & 35 \\
\hline Carbon Green BioEnergy LLC & Michigan & Corn & 50 \\
\hline Green Plains Renewable Energy-Riga & Michigan & Corn & 60 \\
\hline Marysville Ethanol LLC & Michigan & Corn & 50 \\
\hline Poet Biorefining-Caro & Michigan & Corn & 53 \\
\hline The Andersons Albion Ethanol LLC & Michigan & Corn & 55 \\
\hline Al-Corn Clean Fuel & Minnesota & Corn & 50 \\
\hline $\begin{array}{l}\text { Archer Daniels Midland Co.-Marshall } \\
\text { Biofuel Energy Corp./Buffalo Lake Energy }\end{array}$ & Minnesota & Corn & NA \\
\hline Corp. & Minnesota & Corn & 115 \\
\hline Bushmills Ethanol Inc. & Minnesota & Corn & 65 \\
\hline Central MN Ethanol Co-Op & Minnesota & Corn & 54 \\
\hline Chippewa Valley Ethanol Co. LLLP & Minnesota & Corn & 49 \\
\hline Corn Plus & Minnesota & Corn & 49 \\
\hline DENCO II LLC & Minnesota & Corn & 24 \\
\hline Gevo Agri-Energy & Minnesota & Corn & 18 \\
\hline $\begin{array}{l}\text { Granite Falls Energy LLC } \\
\text { Green Plains Renewable Energy-Fergus }\end{array}$ & Minnesota & Corn & 62 \\
\hline Falls & Minnesota & Corn & 60 \\
\hline Guardian Energy, LLC & Minnesota & Corn & 100 \\
\hline Heartland Corn Products & Minnesota & Corn & 104 \\
\hline Heron Lake BioEnergy LLC & Minnesota & Corn & 60 \\
\hline Highwater Ethanol, LLC & Minnesota & Corn & 59.5 \\
\hline
\end{tabular}


Table 1. Existing plant configurations in US (Continued)

\begin{tabular}{|c|c|c|c|}
\hline Plant & State & Feedstock & $\begin{array}{l}\text { Capacity } \\
\text { (MMGY) }\end{array}$ \\
\hline Poet Biorefining-Bingham Lake & Minnesota & Corn & 35 \\
\hline Poet Biorefining-Glenville East & Minnesota & Corn & 44 \\
\hline Poet Biorefining-Lake Crystal & Minnesota & Corn & 57 \\
\hline Poet Biorefining-Preston & Minnesota & Corn & 46 \\
\hline Purified Renewable Energy LLC & Minnesota & Corn & 20 \\
\hline Valero Renewable Fuels LLC-Welcome & Minnesota & Corn & 120 \\
\hline Bunge-Ergon Vicksburg LLC & Mississippi & Corn & 54 \\
\hline Golden Triangle Energy LLC & Missouri & Corn & 20 \\
\hline LifeLine Foods, LLC & Missouri & Corn & 50 \\
\hline Mid-Missouri Energy LLC & Missouri & Corn & 40 \\
\hline Poet Biorefining-Laddonia & Missouri & Corn & 56 \\
\hline Poet Biorefining-Macon & Missouri & Corn & 45 \\
\hline Show Me Ethanol, LLC & Missouri & Corn, Sorghum & 55 \\
\hline Abengoa Bioenergy Corp. - York & Nebraska & Corn & 55 \\
\hline Abengoa Bioenergy of Nebraska & Nebraska & Corn & 88 \\
\hline AltEn LLC & Nebraska & Corn, Sorghum & 25 \\
\hline $\begin{array}{l}\text { Archer Daniels Midland Co.-Columbus dry } \\
\text { mill }\end{array}$ & Nebraska & Corn & 150 \\
\hline $\begin{array}{l}\text { Archer Daniels Midland Co.-Columbus wet } \\
\text { mill }\end{array}$ & Nebraska & Corn & 150 \\
\hline Aventine-Nebraska Energy LLC & Nebraska & Corn & 45 \\
\hline Biofuel Energy Corp./Pioneer Trail Energy & Nebraska & Corn & 115 \\
\hline Bridgeport Ethanol LLC & Nebraska & Corn & 50 \\
\hline Cargill Inc.-Blair & Nebraska & Corn & 195 \\
\hline Chief Ethanol Fuels Inc. & Nebraska & Corn & 70 \\
\hline Cornhusker Energy Lexington LLC & Nebraska & Corn & 40 \\
\hline E Energy Adams LLC & Nebraska & Corn & 60 \\
\hline Elkhorn Valley Ethanol LLC & Nebraska & Corn & 50 \\
\hline Flint Hills Resources Fairmont LLC & Nebraska & Corn & 110 \\
\hline Green Plains Renewable Energy-Atkinson & Nebraska & Corn & 50 \\
\hline Green Plains Renewable Energy-Central City & Nebraska & Corn & 100 \\
\hline Green Plains Renewable Energy-Ord & Nebraska & Corn & 55 \\
\hline Husker Ag LLC & Nebraska & Corn & 75 \\
\hline KAAPA Ethanol, LLC & Nebraska & Corn & 60 \\
\hline Mid-America AgriProducts/Wheatland LLC & Nebraska & Corn & 40 \\
\hline Midwest Renewable Energy LLC & Nebraska & Corn & 26 \\
\hline
\end{tabular}


Table 1. Existing plant configurations in US (Continued)

\begin{tabular}{|c|c|c|c|}
\hline Plant & State & Feedstock & $\begin{array}{l}\text { Capacity } \\
\text { (MMGY) }\end{array}$ \\
\hline Nebraska Corn Processing, LLC & Nebraska & Corn & 44 \\
\hline Siouxland Ethanol LLC & Nebraska & Corn & 50 \\
\hline Trenton Agri Products LLC & Nebraska & Corn, Sorghum & 40 \\
\hline Valero Renewable Fuels LLC-Albion & Nebraska & Corn & 120 \\
\hline Abengoa Bioenergy Corp. - Portales & New Mexico & Corn, Sorghum & 30 \\
\hline Sunoco Fulton Ethanol Plant & New York & Corn & 85 \\
\hline Western New York Energy LLC & New York & Corn & 50 \\
\hline Archer Daniels Midland Co.-Walhalla & North Dakota & Corn & 10 \\
\hline Blue Flint Ethanol LLC & North Dakota & Corn & 65 \\
\hline Hankinson Renewable Energy LLC & North Dakota & Corn & 50 \\
\hline Red Trail Energy, LLC & North Dakota & Corn & 50 \\
\hline Tharaldson Ethanol LLC & North Dakota & Corn & 150 \\
\hline Guardian Lima LLC & Ohio & Corn & 54 \\
\hline Poet Biorefining-Fostoria & Ohio & Corn & 73 \\
\hline Poet Biorefining-Marion & Ohio & Corn & 73 \\
\hline The Andersons Marathon Ethanol LLC & Ohio & Corn & 110 \\
\hline $\begin{array}{l}\text { Three Rivers Energy LLC } \\
\text { Valero Renewable Fuels LLC- }\end{array}$ & Ohio & Corn & 50 \\
\hline Bloomingburg & Ohio & Corn & 120 \\
\hline Poet Biorefining-Leipsic & Ohio & Corn & 73 \\
\hline Pacific Ethanol Columbia LLC & Oregon & Corn & 40 \\
\hline $\begin{array}{l}\text { Pennsylvania Grain Processing LLC } \\
\text { Advanced BioEnergy South Dakota- }\end{array}$ & Pennsylvania & Corn & 110 \\
\hline $\begin{array}{l}\text { Aberdeen I } \\
\text { Advanced BioEnergy South Dakota- }\end{array}$ & South Dakota & Corn & 9.3 \\
\hline Aberdeen II & South Dakota & Corn & 46 \\
\hline Advanced BioEnergy South Dakota-Huron & South Dakota & Corn & 30 \\
\hline Dakota Ethanol LLC & South Dakota & Corn & 50 \\
\hline Glacial Lakes Energy LLC - Mina & South Dakota & Corn & 100 \\
\hline Glacial Lakes Energy LLC - Watertown & South Dakota & Corn & 101 \\
\hline NuGen Energy LLC & South Dakota & Corn, Sorghum & 100 \\
\hline Poet Biorefining-Big Stone & South Dakota & Corn & 81 \\
\hline Poet Biorefining-Chancellor & South Dakota & Corn & 102 \\
\hline Poet Biorefining-Groton & South Dakota & Corn & 53 \\
\hline Poet Biorefining-Hudson & South Dakota & Corn & 57 \\
\hline Poet Biorefining-Mitchell & South Dakota & Corn & 73 \\
\hline Poet Research Center & South Dakota & Corn & 11 \\
\hline
\end{tabular}


Table 1. Existing plant configurations in US (Continued)

\begin{tabular}{lllr}
\hline Plant & State & Feedstock & $\begin{array}{r}\text { Capacity } \\
\text { (MMGY) }\end{array}$ \\
\hline Red River Energy, LLC & South Dakota & Corn & 25 \\
Redfield Energy, LLC & South Dakota & Corn & 50 \\
Valero Renewable Fuels LLC-Aurora & South Dakota & Corn & 120 \\
Green Plains Renewable Energy-Obion & Tennessee & Corn & 120 \\
Tate \& Lyle & Tennessee & Corn & 110 \\
Agrigold Renewable Coop. & Texas & Corn & 2 \\
Diamond Ethanol LLC & Texas & Corn, Sorghum & 40 \\
White Energy Hereford LLC & Texas & Corn, Sorghum & 120 \\
White Energy Plainview LLC & Texas & Corn, Sorghum & 121 \\
Hereford Renewable Energy LLC & Texas & Corn & 110 \\
Ace Ethanol LLC & Wisconsin & Corn & 48 \\
Badger State Ethanol LLC & Wisconsin & Corn & 55 \\
Big River Resources Boyceville, LLC & Wisconsin & Corn & 60 \\
Didion Ethanol LLC & Wisconsin & Corn & 50 \\
Fox River Valley Ethanol & Wisconsin & Corn & 55 \\
Marquis Energy Wisconsin LLC & Wisconsin & Corn & 75 \\
United Ethanol LLC & Wisconsin & Corn & 48 \\
United Wisconsin Grain Producers LLC & Wisconsin & Corn & 58 \\
Valero Renewable Fuels LLC-Jefferson & Wisconsin & Corn & 120 \\
Western Wisconsin Energy LLC & Wisconsin & Corn & 45 \\
Renova Energy Wyoming Ethanol & Wyoming & Corn & 10 \\
\hline
\end{tabular}

\section{3. $2^{\text {nd }}$ generation bioethanol supply chain}

$2^{\text {nd }}$ generation bioethanol is the bioethanol produced from switchgrass, woody wastes and crop residues. In past, a large number of researchers have conducted research to design a $2^{\text {nd }}$ generation bioethanol supply chain. Zhang, Osmani, Awudu, \& Gonela (2012) develop a mixed integer linear programming (MILP) model to design the optimal switchgrass based supply chain $\left(2^{\text {nd }}\right.$ generation) to minimize the total cost. Huang, Chen, \&Fan (2010) develop an MILP model to design lignocellulosic bioethanol supply chain and conclude that the $2^{\text {nd }}$ generation bioethanol can be compatible at a cost of $\$ 1.10$ per gallon. An, Wilhelm, \& Searcy (2011) develop a deterministic model to design a lignocellulosic bioethanol supply chain $\left(2^{\text {nd }}\right.$ generation $)$ in order to maximize 
the profit of bioethanol supply chain. Chen and Fan (2011) designed a biowaste based bioethanol supply chain $\left(2^{\text {nd }}\right.$ generation $)$ and conclude that bio-waste based bioethanol can be feasible solution for future energy requirements. You et al. (2012) develop a Mo-MILP model to design a cellulosic bioethanol supply chain $\left(2^{\text {nd }}\right.$ generation $)$ to simultaneously improve cost, emissions and the number of jobs created. Marvin, Schmidt, Benjaafar, Tiffany, \& Daoutidis (2012) design an economically viable lignocellulosic bioethanol supply chain $\left(2^{\text {nd }}\right.$ generation$)$. Bernardi, Giarola, \& Bezzo (2013) develop a Mo-MILP model to design HGBSC that simultaneously improves economic, carbon and water footprint performance. The results suggest that HGBSC design changes when carbon and water utilization aspects are considered. Lambert and Middleton (2010) suggest that cellulosic bioethanol production is marginally feasible under current bioethanol prices and anticipated technologies, but emphasize that it would be viable if the bioethanol prices increased and the conversion cost reduced.

Table 2. Existing $2^{\text {nd }}$ generation bioethanol plant configurations in US Source: Facilities capacity by state and plant, 2012

\begin{tabular}{|c|c|c|c|}
\hline Plant & State & Feedstock & $\begin{array}{l}\text { Capacity } \\
\text { (MMGY) }\end{array}$ \\
\hline American Process Inc./Alpena & & & \\
\hline Biorefinery & Michigan & Wood & 0.8 \\
\hline BP Biofuels Demonstration Plant, & & & \\
\hline Jennings Facility & Louisiana & Energy Grasses & 1.4 \\
\hline $\begin{array}{l}\text { Dupont Cellulosic Ethanol LLC- } \\
\text { Vonore }\end{array}$ & Tennessee & Switchgrass, Corn Stover & 0.25 \\
\hline Fiberight Demonstration Plant & Virginia & Muncipal solid wastes & 0.5 \\
\hline Fiberight of Blairstown LLC & Iowa & Muncipal solid wastes & 6 \\
\hline ICM Inc. Pilot Integrated Cellulosic & & Corn Fiber, Sorghum, & \\
\hline Biorefinery & Missouri & Switchgrass & 0.32 \\
\hline Indian River Bioenergy Center & $\begin{array}{l}\text { Florida } \\
\text { New }\end{array}$ & $\begin{array}{l}\text { Agriculture Wastes, } \\
\text { Muncipal solid wastes }\end{array}$ & 8 \\
\hline Mascoma Corp. Demo Plant & York & Mixed Hardwood & 0.2 \\
\hline Western Biomass Energy, LLC & Wyoming & Cellulosic & 0.5 \\
\hline ZeaChem Inc.-demo & Oregon & Poplar, Straw, Stover & 0.25 \\
\hline
\end{tabular}


A considerable amount of research has been conducted to develop different strategies to reduce the bioethanol production cost. Kaylen, Van Dyne, Choi, \& Blasé (2000) anticipate that with current lignocellulosic bioethanol production technologies, bioethanol can compete with gasoline only if high value co-products are produced in addition to bioethanol. Table 2 presents the $2^{\text {nd }}$ generation bioethanol plant configurations in US. It consists of $102^{\text {nd }}$ generation bioethanol plants adding to production capacity of 18.22 MMGY. All the plants operate with cellulosic platform.

\subsection{Industrial symbiosis (IS)}

IS is a subset of industrial ecology where traditionally standalone companies collaborate or collocate for sharing service, utility, and resources in order to reduce waste and costs, add profits, and reduce the environmental impact (Laybourn and Morrissey, 2009; Veiga and Magrini, 2009). The concept of IS is analogous to that of closed loop supply chain. In closed loop supply chain, one plant's output will be the input for other plants, which improves environmental and economic benefits through efficient reuse of resources (Quariguasi Frota Neto, Walther, Bloemhof, Van Nunen, Spengler, 2010; Easwaran and Üster, 2010; Abdallah, Diabat, \& SimchiLevi, 2012; Kenné, Dejax, \& Gharbi, 2012).

Collaboration and the synergistic possibilities offered by geographic proximity are the major keys to the success of IS (Boons, Spekkink, Mouzakitis, 2011). Martin and Eklund (2011) suggest that IS creates a "win-win situation" for all companies in the coalition from both environmental and economic perspectives. They discuss the environmental benefits of an Handelo bioenergy symbiosis park where by-products and utilities are integrated among a biorefinery plant, a combined heat and power (CHP) plant and a biogas plant. Jacob (2006) conducts quantitative assessment of kalundborg IS and finds improvements in both economic and environmental 
aspects. Beers, Corder, Bossilkov, Berkel, (2007) and Park, Rene, Choi, Chiu, (2008) study various IS developments. Their studies suggest that industrial synergy is one of the sustainable strategies and the governments of various nations are gradually considering IS as a future strategy to improve resource utilization and reduce wastes.

Many researchers have conducted research to design optimal network flow of products within IS in order to improve economic and environmental benefits. It includes the works of Martin and Eklund (2011), Lovelady and El-halwagi (2009), Chew, Tan, Foo, Chui (2009), Taskhiri, Tan, Chui (2011) and Chae, Kim, Yoon, Park, (2010). Martin and Eklund (2011) propose the framework of IS. However the benefits and the material flows of the IS are not quantified. Lovelady and El-halwagi (2009), Chew et al. (2009), Taskhiri et al. (2011) and Chae et al.(2010) develop mathematical models to design optimal network for single resource (either wastewater or process steam) for already existing plants. The results suggest significant savings in both cost and resource for the entire system and the individual plants.

\subsection{Sustainability}

In order to design a sustainable bioethanol supply chain, it is necessary to comprehensively understand various sustainability standards. According to You et al. (2012), sustainability consists of three spheres: 1) economic, 2) environmental, and 3) social aspects. They indicate that any business can be sustainable only if all the aspects are improved simultaneously. Consequently, a number of policies have been promoted by federal agencies to improve all the three aspects for bioethanol production. In order to improve the economic aspect of bioethanol production, numerous tax incentives or exemptions are given by federal agencies to bioethanol producers. For example, the US government provides tax exempt of 56 cents for every gallon of $1^{\text {st }}$ generation bioethanol produced (Wheals, Basso, Alves, \& Amorim, 1999) and $\$ 1.01$ for every gallon of $2^{\text {nd }}$ 
generation bioethanol produced (Credit Suisse Report, 2012). In the past 20 years, a number of environmental standards have been encouraged to reduce environmental impacts. For example, the emissions policy indicates that US should reduce its GHG emissions by $20 \%-40 \%$ below 1990 level by 2020 (Romm, 2009). Furthermore, in recent years, numerous sustainability standards have been introduced to improve social aspect. For example, the renewable fuel standard (RFS) mandates $55 \%$ of the bioethanol demand to be met from 2 nd generation bioethanol in order to reduce the use of irrigation land for energy purposes (Schnepf, 2011). The United States Environmental Protection Agency (USEPA) Executive Order 13423 enforces 30\% reduction in energy intensity by the year 2015 for all systems consuming energy. In addition to energy intensity, USEPA Executive Order 13423 mandates 16\% reduction in water intensity by the year 2012 . Therefore, as the emphasis on sustainability continues to grow, it is necessary to design a bioethanol supply chain that maximizes economic benefits under environmental, social and energy intensity restrictions.

\subsection{Uncertainties}

The bioethanol supply chain is exposed to number of uncertainties that will significantly impact the performance of bioethanol supply chain. In past, researchers have considered designing bioethanol supply chain under uncertainties. Marvin et al. (2012) conducted Monte Carlo simulation to design a $1^{\text {st }}$ generation bioethanol supply chain under price uncertainties. Awudu and Zhang (2012) develop a stochastic production planning model for corn based bioethanol plants under bioethanol demand and price uncertainties. Osmani and Zhang (2013) develop a stochastic MILP model to design a 2nd generation bioethanol supply chain. They include biomass yield, biomass purchase price, bioethanol demand, and bioethanol price uncertainties. Chen and Fan (2011) develop a mixed integer stochastic programming model under demand and supply 
uncertainties. Dal-Mas et al (2011) design a $1^{\text {st }}$ generation bioethanol supply chain under corn price and bioethanol selling price uncertainties. 


\section{CHAPTER 3. DESIGN OF THE OPTIMAL INDUSTRIAL SYMBIOSIS SYSTEM TO IMPROVE BIOETHANOL PRODUCTION}

\subsection{Abstract}

The emergence of environmental and sustainability regulations, such as Kyoto protocol, Energy Policy Act and the increasingly limited availability of fossil fuels has brought the notion of gradually substituting petroleum products with bioethanol into the limelight. Even though, bioethanol is one of the cleanest sources of energy, a major concern of bioethanol production is its economic feasibility. Industrial symbiosis is one of the sustainable strategies that can help to reduce bioethanol production and logistic costs. In industrial symbiosis, traditionally separate plants collocate in order to efficiently utilize resources, reduce wastes and increase profits for the entire industrial symbiosis and each players in the industrial symbiosis. This paper focuses on developing optimal configurations of bioenergy-based industrial symbiosis under certain constraints, such that the bioethanol production cost (or profit) is reduced (or increased). A decision framework that combines the Linear Programming models and large scale Mixed Integer Linear Programming model is proposed to determine the optimal configuration of bioenergy-based industrial symbiosis and to design the optimal network flows of various products in the bioenergybased industrial symbiosis. A case study has been conducted to study the efficiency and effectiveness of the proposed model and the results suggest significant increase in profitability for biorefinery plant and the rest of the players in the bioenergy-based industrial symbiosis system. Sensitivity analysis is also conducted to provide deep understanding of the proposed bioenergybased industrial symbiosis system and to identify the factors that might impact the performance of biorefinery plant in bioenergy-based industrial symbiosis. 


\subsection{Introduction}

In recent years, the use of biofuel for transportation and other purposes has been encouraged extensively as it is both renewable and environmentally friendly source of energy (Leao, Hamcher, Oliveira, 2011). In fact, many countries view biofuel as possible substitute or alternative for petroleum products due to the growing environmental concerns and limited availability of petroleum products (Leao et al., 2011). The emergence of the environmental and sustainability regulations such as Kyoto protocol, Energy policy Act (EPAct) has increased attention towards finding alternative renewable and eco-friendly sources of energy (instead of fossil fuels). One of the major steps undertaken to achieve this goal is substitution of biofuel for petroleum products. For example, the EPAct 2005 Renewable Fuel Standard and the presidential initiative, targets $20 \%$ of the petroleum usage to be substituted with biofuel within 10 years (Huang et al., 2010). Bioethanol and biodiesel are major forms of biofuel. This work only focuses on bioethanol production.

While bioethanol is one of the cleanest sources of energy, the major concern of bioethanol production is its economic feasibility. Lambert and Middleton (2010) suggest that cellulosic bioethanol production is marginally feasible under current bioethanol prices and anticipated technologies, but emphasize that it would be viable if the bioethanol prices increased and the conversion cost reduced. Huang et al. (2010) suggest that cellulosic bioethanol production can only sustain when the production cost is below $\$ 1.10$ per gallon. They claim that this is feasible only if an efficient supply chain is designed. A considerable amount of research has been conducted to develop different strategies to reduce the bioethanol production cost. Kaylen et al. (2000) anticipate that with current lignocellulosic bioethanol production technologies, bioethanol can compete with gasoline only if high value co-products are produced in addition to bioethanol. 
Corsona et al. (2011) develop a mixed integer non-linear programming (MINLP) model to design a sustainable supply chain for sugar based bioethanol production. They conclude that the inclusion of sustainability into the model results in economic, operative and design changes for the supply chain.

In order to address the issue of higher bioethanol production and logistic costs, the current paper proposes Industrial Symbiosis (IS) strategy. IS is a subset of industrial ecology where traditionally standalone companies collaborate or collocate for sharing service, utility, and resources in order to reduce waste and costs, add profits, and reduce the environmental impact (Laybourn and Morrissey, 2009; Veiga and Magrini, 2009). The concept of IS is analogous to that of closed loop supply chain. In closed loop supply chain, one plant's output will be the input for other plants, which improves environmental and economic benefits through efficient reuse of resources (Quariguasi Frota Neto et al., 2009; Easwaran and Üster, 2010; Abdallah et al., 2012; Kenné et al., 2012). Collaboration and the synergistic possibilities offered by geographic proximity are the major keys to the success of IS (Boons et al., 2011). Martin and Eklund (2011) suggest that IS creates a "win-win situation" for all companies in the coalition from both environmental and economic perspectives. They discuss the environmental benefits of an Handelo bioenergy symbiosis park where by-products and utilities are integrated among a biorefinery plant, a combined heat and power (CHP) plant and a biogas plant. Jacob (2006) conducts quantitative assessment of kalundborg IS and finds improvements in both economic and environmental aspects. Beers et al. (2007) and Park et al. (2008) study various IS developments. Their studies suggest that industrial synergy is one of the sustainable strategies and the governments of various nations are gradually considering IS as a future strategy to improve resource utilization and reduce wastes. 
Many researchers have conducted research to design optimal network flow of products within IS in order to improve economic and environmental benefits. It includes the works of Martin and Eklund (2011), Lovelady and El-halwagi (2009), Chew et al. (2009), Taskhiri et al. (2011), and Chae et al. (2010). Martin and Eklund (2011) propose the framework of IS. However the benefits and the material flows of the IS are not quantified. Lovelady and El-halwagi (2009), Chew et al. (2009), Taskhiri et al. (2011) and Chae et al.(2010) develop mathematical models to design optimal network for single resource (either wastewater or process steam) for already existing plants. The results suggest significant savings in both cost and resource for the entire system and the individual plants.

While IS is one of the best strategies to gain economic and environmental benefits, many important issues existing in IS have not been answered in literature. For example, there are many ways to form IS. If given a set of candidate plants and a set of constraints, what is the optimal configuration to form a new IS in order to reduce the bioethanol production and logistic costs while increasing the profitability of biorefinery plant. In addition, a multi-product network design is common and important in IS. To the best of our knowledge, none of the up-to-date literature has tackled the problem of mathematically determining the optimal configuration of the IS system to improve bioethanol production costs and design the optimal multi-product flows in IS . Since, the objective of the paper is to improve bioethanol production cost through IS, the IS in this paper is called as Bioenergy based Industrial Symbiosis (BBIS).

In order to bridge the gap in literature, this chapter proposes a scientific approach to determine the best configuration of the BBIS system under certain constraints. A decision framework that combines Linear Programming (LP) models and large scale Mixed Integer Linear Programming (MILP) model is proposed to decide the optimal configuration of the BBIS system 
that includes: 1) deciding the best possible combination of plants to form the BBIS, and 2) determining the optimal multi-product network of various materials in the BBIS. A case study is conducted to illustrate the effectiveness of the proposed framework and gain managerial insights on the BBIS system.

\subsection{Problem statement}

This paper addresses the issue of developing the optimal configuration of BBIS in order to reduce bioethanol production and logistic costs and increase the profitability of biorefinery plant. Meanwhile, the profitability of other plants in the BBIS is also increased.

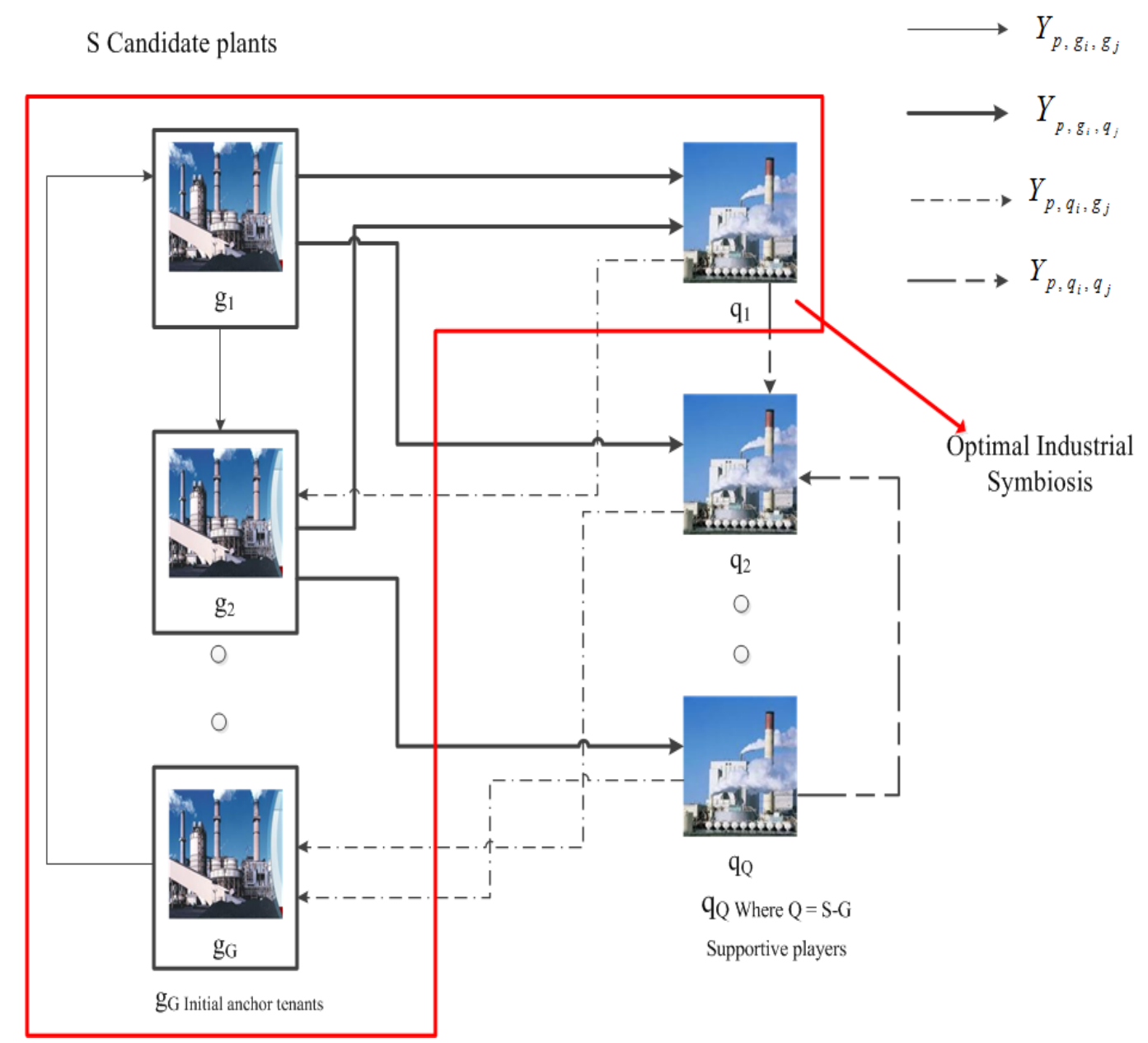

Figure 4. Structure of the problem 
Figure 4 is an illustration of the structure of the problem. It consists of a set of candidate plants $S(S \in\{G \cup Q\})$ that bid to form the BBIS in order to increase profitability and resource utilization while reducing wastes. The candidate plants are classified into two sets of categories: 1) a set of initial anchor tenants represented by $G \in\left\{g_{1}, g_{2}, g_{3}, \ldots . g_{G}\right\}$ and 2) a set of supportive players represented by $Q \in\left\{q_{1}, q_{2}, q_{3}, \ldots q_{Q}\right\}$. According to Hardy and Graedel (2002), most of ecoindustrial parks are formed around a focal plant, which has relatively high connectance with other plants, and such plants are called "anchor tenants". In this paper, anchor tenants are the initiative players and should be included in the IS. The reason for classifying each of the players into categories depends on the criterion that is being dealt. For example, the goal of this paper is to increase the profitability of the biorefinery plant and hence, the biorefinery plant is considered as one of the anchor tenants. Supportive players are those players that are optional to be selected in the IS formation. These plants can be of any type that can form symbiotic links (SLs) with the anchor tenants. Here, the SL is the transfer or exchange of particular product between two plants in IS. The inclusion of such plants in IS would result in increased profits for all plants due to reduced production and logistic costs. For product type $p$, let $i$ be the index for supply plant and $j$ be the index for the demand plant. Then the SL in IS exists in four possible ways;

1) Between two anchor tenants which is given by $Y_{p, g_{i}, g_{j}}$

2) Between key player and supportive player which is given by $Y_{p, g_{i}, q_{j}}$

3) Between supportive player and key player which is given by $Y_{p, q_{i}, g_{j}}$

4) And between two supportive players which is given by $Y_{p, q_{i}, q_{j}}$

With such a structure, the proposed model (which is the combination of LP and large scale MILP formulation) aims to determine the optimal configuration of IS (in the red box in Figure 4) 
that includes determining: 1) the type of supportive plants that should be included in the BBIS system along with the anchor tenants under certain constraints and 2) the network flows of materials exchanging between the selected plants in the BBIS.

\subsection{Proposed methodology}

An optimization based decision framework is proposed to determine the optimal configuration of BBIS under certain constraints such as space, finance and disruption level. Designing a BBIS requires determining the: 1) type of plants that should be included in the BBIS and 2) the optimal network flow or the SLs of products among the selected plants in the BBIS. The objective is to improve the profit of the biorefinery plant and the entire BBIS. Figure 5 presents the proposed decision framework that enables to determine the optimal BBIS configuration under certain constraints.

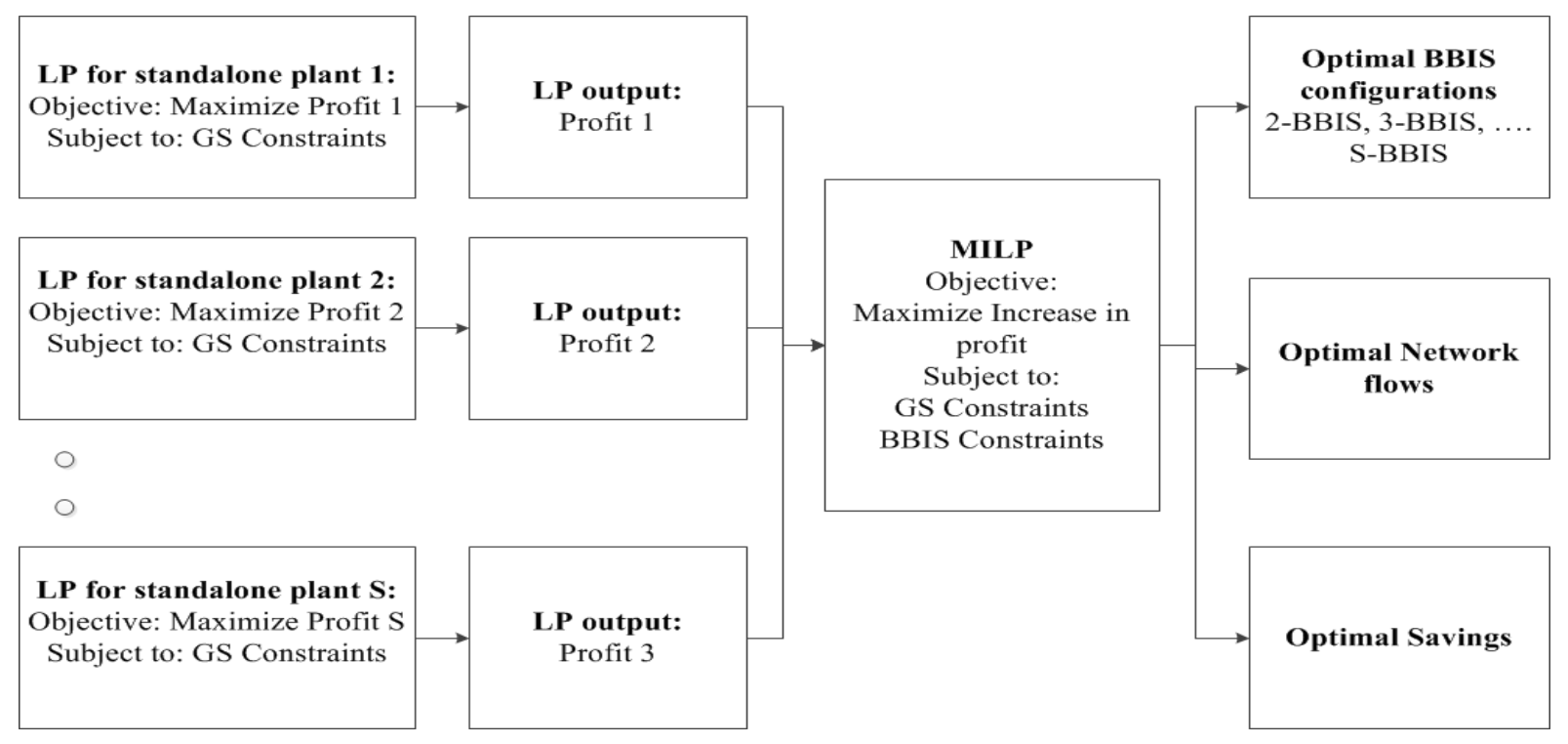

Figure 5. Proposed decision framework

\section{Notations}

Standalone mode nomenclature 


$$
\begin{aligned}
& \text { Input parameters: } \\
& i \quad \text { Index for plant under consideration where } i=1,2,3 \ldots S \\
& k_{i} \quad \text { Index for finished products at each plant } i \text { where } k_{i}=1,2,3 \ldots K_{i} \\
& b_{i} \quad \text { Index for by-products at each plant } i \text { where } b_{i}=1,2,3 \ldots B_{i} \\
& W_{i} \quad \text { Index for waste products at each plant } i \text { where } W_{i}=1,2,3 \ldots W_{i} \\
& l_{i} \quad \text { Index for materials purchased from market by plant } i \text { where } l_{i}=1,2,3 \ldots L_{i} \\
& \text { mkt Index for market } \\
& t \quad \text { Index for time period where } t=1,2,3 \ldots T \\
& \text { op Index for output products } \\
& \text { ip Index for input products } \\
& P_{o p, t}^{i, m k t} \quad \text { Price of output products } o p \text { sold to market by plant } i \text { in time period } t \\
& P C_{o p, t} \quad \text { Production cost of output products } o p \text { produced at plant } i \text { in time period } t \\
& C_{i p, t}^{m k, i} \quad \text { Cost of purchasing input products ip from market by plant } i \text { in time period } t \\
& C_{w_{i}, t}^{i} \quad \text { Cost of disposing waste } w_{i} \text { at plant } i \text { in time period } t \\
& H_{o p, t}^{i} \quad \text { Inventory holding cost for output products } o p \text { at plant } i \text { in time period } t \\
& H_{i p, t}^{i} \quad \text { Inventory holding cost for input products ip at plant } i \text { in time period } t \\
& B_{o p, t}^{i} \quad \text { Inventory backorder cost for output products } o p \text { at plant } i \text { in time period } t \\
& B_{i p, t}^{i} \quad \text { Delay cost for input products ip at plant } i \text { in time period } t \\
& d_{o p, t}^{i, m k t} \quad \text { Market demand for output products op at plant } i \text { in time period } t
\end{aligned}
$$


$P C a p_{o p \in k_{i}}^{i} \quad$ Production capacity of final products at plant $i$

PCa $\dot{\not}_{\text {ombinec }} \quad$ Combined production capacity of final products at plant $i$

$\operatorname{Cap}_{i p, t}^{m k t, i} \quad$ Capacity of input products ip that can be purchased from market by plant $i$ in time period $t$

ICap ${ }_{o p}^{i} \quad$ Inventory Capacity of output products op at plant $i$

ICap $_{i p}{ }^{i} \quad$ Inventory Capacity of input products ip at plant $i$

Decision Variables:

Unrestricted variables

$I_{o p, t}^{i} \quad$ Inventory level of output products $o p$ at plant $i$ in time period $t$

$I_{i p, t}^{i} \quad$ Inventory level of input products $i p$ at plant $i$ in time period $t$

Positive variables

$S_{o p, t}^{i, m k t} \quad$ Amount of output products $o p$ sold to market by plant $i$ in time period $t$

$X p_{o p, t}^{i} \quad$ Amount of output products $o p$ produced at plant $i$ in time period $t$

$X_{i p, t}^{m k, i} \quad$ Amount of input products ip purchased by plant $i$ from market in time period $t$

$X u_{i p, t}^{i} \quad$ Amount of input products ip used by plant $i$ in time period $t$

$I_{o p, t}^{i^{+}} \quad$ Amount of output products $o p$ inventory held at plant $i$ in time period $t$

$I_{i p, t}^{i^{+}} \quad$ Amount of input products ip inventory held at plant $i$ in time period $t$

$I_{o p, t}^{i^{-}} \quad$ Amount of output products $o p$ backordered at plant $i$ in time period $t$ 
$I_{i p, t}^{i^{-}} \quad$ Amount of input products ip procurement delayed at plant $i$ in time period $t$

$W_{w_{i}, t}^{i} \quad$ Amount of waste $w_{i}$ disposed at plant $i$ in time period $t$

$W p_{w_{i}, t}^{\dot{s}} \quad$ Amount of waste $w_{i}$ produced at plant $i$ in time period $t$

BBIS configuration nomenclature

Additional (in addition to standalone) input parameters:

$s \quad$ Set of candidate plants for IS where ${ }_{s}=1,2,3 \ldots S(S \in\{G \cup Q\})$

$g$ Set of anchor tenants that are always included in the coalition where $g=1,2,3,4 \ldots$

G

$q$ Set of supportive players that are optional to use in the coalition where $q=1,2,3 \ldots$

$Q=S-G$

$j \quad$ Index for plant other than considered plant where $j=1,2,3 \ldots S-1$ where $j \neq i$

$k_{j} \quad$ Index for finished products at each plant $j$ where $k_{j}=1,2,3 \ldots K_{j}$

$b_{j} \quad$ Index for by-products at each plant $j$ where $b_{j}=1,2,3 \ldots B_{j}$

$w_{j} \quad$ Index for waste products at each plant $j$ where $w_{j}=1,2,3 \ldots W_{j}$

$n \quad$ Number of plants to be selected where ${ }_{n}=1,2,3 \ldots \mathrm{N}$

$M \quad$ Big M, Largest possible number

$P_{o p, t}^{i, j} \quad$ Price of output products $o p$ sold by plant $i$ to plant $j$ in time period $t$

$C C_{p, t}^{m k, i}$ Cost of input product ip under contract purchased by plant $i$ from market in time period $t$

$C_{i p, t}^{j, i} \quad$ Cost of purchasing input products ip by plant $i$ from plant $j$ in time period $t$ 
$W_{i} \quad$ Weight for each candidate plant based on the decision maker interest

Additional (in addition to standalone) decision variables:

Binary variables

Y Binary variable if plant $i$ is included or not in BBIS

$Y_{j} \quad$ Binary variable if plant $j$ is included or not in BBIS

Unrestricted variables

$X R_{i p \in l_{i}}^{m k t, i} \quad$ Raw material level when purchased with or without contract

Positive variables

$S_{o p, t}^{i, j} \quad$ Amount of output products op sold by plant $i$ to plant $j$ in time period $t$

$S_{i p, t}^{j, i} \quad$ Amount of input products ip of plant $i$ sold by plant $j$ to plant $i$ in time period $t$

$X_{o p, t}^{i, j} \quad$ Amount of output products op of plant $i$ purchased by plant $j$ in time period $t$ $X C_{i p \in I_{i}, t}^{m k t, i} \quad$ Amount of input product ip purchased by plant $i$ from market in time period $t$ under contract

$X_{i p, t}^{j, i} \quad$ Amount of input products ip of plant $j$ purchased by plant $i$ in time period $t$ $X \operatorname{siz} \dot{e}_{o p \in k_{i}, t} \quad$ Size of the plant

\subsubsection{LP model formulation for standalone plants}

The LP formulation is developed for each plant when operating in standalone mode throughout the planning horizon. Equation 3.1 represents the objective function. Equation $3.2-$ Equation 3.11 represent constraints for output products. Equation 3.12 - Equation 3.20 represent 
input product constraints and Equation 3.21 represents waste disposal constraint. All the products are classified into two categories: 1) Discrete and 2) Continuous. Discrete products are those products whose inventory can be stored and continuous products are those products that cannot be stored. Examples of continuous products include process steam, water and electricity.

The objective function Equation 3.1 for each individual plant is to maximize the profit of the entire planning horizon. This is obtained by subtracting the total operational cost from the total revenue obtained by selling output products to markets. The total operational cost includes input product purchase cost, production cost of output products, inventory holding cost, backorder cost, delay cost and waste disposal cost. The total revenue is calculated by $1(\mathrm{a})$ and $1(\mathrm{~b})-1(\mathrm{~h})$ are used to obtain the different costs mentioned above.

$\operatorname{MaxZ}_{i}^{S A}=1(\mathrm{a})-1(\mathrm{~b})-1(\mathrm{c})-1(\mathrm{~d})-1(\mathrm{e})-1(\mathrm{f})-1(\mathrm{~g})-1(\mathrm{~h}) \forall i$

The total revenue obtained by selling the final products and by-products to the market (1(a)) is calculated as follows:

$1(\mathrm{a})=\sum_{o p \in k_{i} \cup b_{i}} \sum_{t} P_{o p, t}^{i, m k t} S_{o p, t}^{i, m k t}$

The total production cost of the final products and by-products produced (1(b)) is calculated as follows:

$1(\mathrm{~b})=\sum_{o p \in k_{i} \cup b_{i}} \sum_{t} P C_{o p, t}^{i} X p_{o p, t}^{i}$

The total inventory holding cost for final products and by-products (1(c)) is calculated as follows:

$1(\mathrm{c})=\sum_{o p \in k_{i} \cup b_{i}} \sum_{t} H_{o p, t}^{i} I_{o p, t}^{i^{+}}$

The backorder cost of output products for the entire time period horizon (1(d)) is calculated as follows: 
$1(\mathrm{~d})=\sum_{o p \in k_{i} \cup b_{i}} \sum_{t} B_{o p, t}^{i} I_{o p, t}^{i^{-}}$

The total cost of input products that are purchased over the entire time period horizon (1(e)) is calculated as follows:

$1(\mathrm{e})=\sum_{i p \in l_{i}} \sum_{t} C_{i p, t}^{m k t, i} X_{i p, t}^{m k t, i}$

The total cost of inventory held for input products (1(f)) is calculated as follows:

$1(\mathrm{f})=\sum_{i p \in I_{i}} \sum_{t} H_{i p, t}^{i} I_{i p, t}^{i^{+}}$

The total cost incurred when supplier fails to deliver input products in time (delay time) $(1(\mathrm{~g}))$ is calculated as follows:

$1(\mathrm{~g})=\sum_{i p \in l_{i}} \sum_{t} B_{i p, t}^{i} I_{i p, t}^{i^{-}}$

The total disposal costs of waste $(1(\mathrm{~h}))$ is calculated as follows:

$1(\mathrm{~h})=\sum_{w_{i}} \sum_{t} C_{w_{i}, t}^{i} W_{w_{i}, t}^{i}$

The LP model is subject to the following constraints:

Equation 3.2 - Equation 3.11 are the constraints for output products for each candidate plant for each time period.

Equation 3.2 is to constraint the amount of final products and by-products sold to the market to be always less than or equal to the demand of the market for any given time period.

$S_{o p \in k_{i} \cup b_{i}, t}^{i, m k} \leq d_{o p \in k_{i} \cup b_{i}, t}^{i, m k t} \forall i, \forall o p, \forall t$

Equation 3.3 forces the amount of discrete final and by-products produced at each plant to be always greater than the total amount of products sold to the market for each time period.

$X p_{o p \in k_{i} \cup b_{i}, t}^{i} \geq S_{o p \in k_{i} \cup b_{i}, t}^{i, m k t} \forall i, \forall o p, \forall t$ 
Equation 3.4 forces the amount of continuous final products and by-products produced to be always equal to the amount of products sold to market for each given time period.

$$
X p_{o p \in k_{i} \cup b_{i}, t}^{i}=S_{o p \in k_{i} \cup b_{i}, t}^{i, m k t} \forall i, \forall o p, \forall t
$$

Equation 3.5 suggest that amount of final and by-products produced during any given time period is always less than the production capacity.

$$
X p_{o p \in k_{i}, t}^{i} \leq P C a p_{o p \in k_{i}}^{i} \forall i, \forall o p, \forall t
$$

Assumptions are made at times where combined production of certain products should be less than certain capacity limit. For example, at biorefinery plant, production of $2^{\text {nd }}$ generation bioethanol such as corn stover, wheat straw and barley straw depends on the availability of bioethanol in nearby areas. So, combined production technology constraint is used and is given Equation 3.6. In such cases Equation 3.5 does not hold for those products.

$$
\sum_{o p \subset k_{i}} X p_{o p \in k_{i}, t}^{i} \leq P C a p_{\text {combined }}^{i} \forall i, \forall t
$$

Equation 3.7 suggest that for discrete final and by-product, the inventory carried from the previous time period plus the amount produced should be equal to the amount sold plus the inventory carried to the next time period at any given time period.

$$
I_{o p \in k_{i} \cup b_{i}, t-1}^{i}+X p_{o p \in k_{i} \cup b_{i}, t}^{i}=S_{o p \in k_{i} \cup b_{i}, t}^{i, m k k}+I_{o p \in k_{i} \cup b_{i}, t}^{i} \forall i, \forall o p, \forall t
$$

Equation 3.8 suggest that for continuous final and by-products, the amount produced should be equal to the amount sold in any given time period.

$$
X p_{o p \in k_{i} \cup b_{i}, t}^{i}=S_{o p \in k_{i} \cup b_{i}, t}^{i, m k} \forall i, \forall o p, \forall t
$$

Equation 3.9 calculates the amount of output product inventory held or backordered during each given time period. The inclusion of both inventory holding cost and backorder cost 
in objective function (Equation 3.1) enforces any one of inventory held or backordered to have value, but not both.

$$
I_{o p \in k_{i} \cup b_{i}, t}^{i}=I_{o p \in k_{i} \cup b_{i}, t}^{i^{+}}-I_{o p \in k_{i} \cup b_{i}, t}^{i^{-}} \forall i, \forall o p, \forall t
$$

Equation 3.10 constraints inventory level of discrete products should be less than the holding capacity.

$$
I_{o p \in k_{i} \cup b_{i}, t}^{i^{+}} \leq I C a p_{o p \in k_{i} \cup b_{i}}^{i} \forall i, \forall o p, \forall t
$$

Equation 3.11 suggest that the amount of by-products and waste products produced in any time period depends on the amount of final product produced in that time period and the rate of conversion when one unit of final product is produced.

$$
X p_{o p \in b_{i} \cup w_{i}, t}^{i}=\sum_{o p \in k_{i}} F\left(X p_{o p \in k_{i}, t}^{i}\right) \forall i, \forall o p \in b, \forall t
$$

Equation 3.12 - Equation 3.20 are the constraints for input products for each time period.

Equation 3.12 suggest that the amount of raw material and operational products purchased should be always less than the capacity that market can provide in any given time period. In the current problem, the capacity of input product that market can provide is assumed to be unlimited.

$$
X_{i p \in l_{i}, t}^{m k t, i} \leq \operatorname{Cap}_{i p \in l_{i}, t}^{m k t, i} \forall i, \forall o p, \forall t
$$

Equation 3.13 suggest that for discrete raw materials and operational products, the amount of products purchased from market is always greater than or equal to the amount of input product used for any given time period.

$$
X u_{i p \in l_{i}, t}^{i} \leq X_{i p \in l_{i}, t}^{m k t, i} \forall i, \forall i p, \forall t
$$

Equation 3.14 suggest that for continuous raw materials and operational products, the amount of products purchased from market should be equal to the amount of products used for each given time period. 


$$
X u_{i p \in l_{i}, t}^{i}=X_{i p \in I_{i}, t}^{m k t, i} \forall i, \forall i p, \forall t
$$

Equation 3.15 suggest that for discrete raw material and operational products, the inventory carried from the previous time period plus the amount purchased should be equal to the amount used plus the inventory carried to the next time period at any given time period.

$$
I_{i p \in l_{i}, t-1}^{i}+X_{i p \in l_{i}, t}^{m k t, i}=X u_{i p \in l_{i}, t}^{i}+I_{i p \in l_{i}, t}^{i} \forall i, \forall i p, \forall t
$$

For continuous products, the amount of products purchased from market should be equal to the amount of products used in any given time period is given by Equation 3.16.

$$
I_{i p \in l_{i}, t}^{i}=I_{i p \in l_{i}, t}^{i^{+}}-I_{i p \in l_{i}, t}^{i^{-}} \forall i, \forall i p, \forall t
$$

Equation 3.17 is an inventory balancing constraint that enables to calculate amount of input product inventory held or delayed by supplier. Including both inventory holding cost and delay cost in objective function (Equation 3.1) enforces any one of the inventory held or delayed to have a value, but not both.

$$
I_{i p \in l_{i}, t}^{i}=I_{i p \in l_{i}, t}^{i^{+}}-I_{i p \in l_{i}, t}^{i^{-}} \forall i, \forall i p, \forall t
$$

For discrete raw materials and operational products, the inventory level should be less than the holding capacity for each time period is given by Equation 3.18.

$$
I_{i p \in l_{i}, t}^{i^{+}} \leq I C a p_{i p \in l_{i}}^{i} \forall i, \forall i p, \forall t
$$

Equation 3.19 suggests that the amount of raw materials and operational products used depends on the amount of final product produced and the unit final product conversion rate for any given time period.

$$
X u_{i p \in l_{i}, t}^{i}=\sum_{o p \in k_{i}} F\left(X p_{o p \in k_{i}, t}^{i}\right) \forall i, \forall i p, \forall t
$$


Assumptions are made to use combined technologies at plants. For example, CHP plant and cement plant often use co-combustion technology to reduce environmental impacts and to gain economic benefits. Such combined technology for input products is given by Equation 3.20. For such products, Equation 3.19 does not hold.

$$
\sum_{i p \subset l_{i}} X u_{i p \in l_{i}, t}^{i}=\sum_{o p \in k_{i}} F\left(X p_{o p \in k_{i}, t}^{i}\right) \forall i, \forall t
$$

The amount of waste produced is equal to the amount of waste disposed for any given time period is given by Equation 3.21.

$$
X p_{o p \in w_{i}, t}^{i}=W_{w_{i}, t}^{i} \forall i, \forall w_{i}, \forall t
$$

\subsubsection{MILP model formulation for BBIS system}

The MILP model is developed to obtain optimal configuration of the BBIS system. Equation 3.22 represents total savings where $22(\mathrm{a})-22(\mathrm{k})$ are the part of objective function. Equation 3.23 is a constraint that enables to consider only those solutions that have savings for each plant. Equation 3.24 forces the inclusion of all the anchor tenants in BBIS. Equation 3.25 gives the decision maker flexibility to select the number of plants that should be included in BBIS. This is provided such that the decision maker can make decisions based on the constraints such as space and financial availability to form BBIS system. Equation 3.26 - Equation 3.37 represent the constraints for output products, and Equation 3.38 - Equation 3.50 represent the constraints for input products.

The objective function is the maximization sum of the savings of all the plants throughout

the planning horizon. $Z_{i}^{B B I S}$ is the profit of each plant in BBIS. It consists of total revenue obtained by selling output products to market and coalition plants (in BBIS) minus total operational cost that include input product purchase cost, production cost of output products, inventory holding 
cost, backorder cost, delay cost and waste disposal cost. $Z_{i}^{S A}$ is the result from LP model (Equation 3.1) which is profits of each plant when operating in standalone mode. $Y_{i}$ is a binary variable that forces standalone plant's profit to be zero if the plant is not selected in the BBIS system.

$\operatorname{Max} Z=\sum_{i=1}^{g} W_{i}\left(Z_{i}^{B B I S}-Z_{i}^{S A} Y_{i}\right)$

where

$Z_{i}^{B B I S}=22(\mathrm{a})+22(\mathrm{~b})-22(\mathrm{c})-22(\mathrm{~d})-22(\mathrm{e})-22(\mathrm{f})-22(\mathrm{~g})-22(\mathrm{~h})-22(\mathrm{i})-22(\mathrm{j})-22(\mathrm{k}) \quad \forall i$

The revenue obtained by selling final products and by-products to the market (22(a)) is calculated as follows:

$22(\mathrm{a})=\sum_{o p \in k_{i} \cup b_{i}} \sum_{t} P_{o p, t}^{i, m k t} S_{o p, t}^{i, m k t}$

The revenue obtained by selling final products, by-products and waste product to the coalition plant (22(b)) is calculated as follows:

22(b) $=\sum_{o p \in k_{i} \cup b_{i} \cup w_{i}} \sum_{t} P_{o p, t}^{i, j} S_{o p, t}^{i, j}$

The total production cost of output product for the entire time period horizon $(22(\mathrm{c}))$ is calculated as follows:

$22(\mathrm{c})=\sum_{o p \in k_{i} \cup b_{i} \cup w_{i}} \sum_{t} P C_{o p, t}^{i} X p_{o p, t}^{i}$

The total inventory holding cost for output products $(22(\mathrm{~d}))$ is calculated as follows:

$22(\mathrm{~d})=\sum_{o p \in k_{i} \cup b_{i} \cup w_{i}} \sum_{t} H_{o p, t}^{i} I_{o p, t}^{i^{+}}$

Total backorder cost for output products in a given time period horizon (22(e)) is calculated as follows:

$22(\mathrm{e})=\sum_{o p \in k_{i} \cup b_{i} \cup w_{i}} \sum_{t} B_{o p, t}^{i} I_{o p, t}^{i^{-}}$ 
Total cost of input products purchased from market (22(f)) is calculated as follows:

$22(\mathrm{f})=\sum_{i p \in\left\{k_{j} \cup b_{j} \cup l_{i}\right\}} \sum_{t} C_{i p, t}^{m k t, i} X_{i p, t}^{m k t, i}$

Total cost of input products purchased from market under contract from market $(22(\mathrm{~g}))$ is calculated as follows:

$22(\mathrm{~g})=\sum_{i p \in\left\{k_{j} \cup b_{j} \cup i_{i}\right\}} \sum_{t} C C_{i p, t}^{m k t, i} X C_{i p, t}^{m k t, i}$

Total cost of input products purchased from coalition plant (22(h)) is calculated as

follows:

$22(\mathrm{~h})=\sum_{i p \in\left\{k_{j} \cup b_{j} \cup w_{j}\right\}} \sum_{t} C_{i p, t}^{j, i} X_{i p, t}^{j, i}$

Total cost of input products that can be held during a given time horizon ( 22(i)) is calculated as follows:

$22(\mathrm{i})=\sum_{i p \in\left\{k_{j} \cup b_{j} \cup w_{j} \cup l_{i}\right\}} \sum_{t} H_{i p, t}^{i} I_{i p, t}^{i^{+}}$

Total delay cost while procuring input products in any time period ( 22(j)) is calculated as follows:

$22(\mathrm{j})=\sum_{i p \in\left\{k_{j} \cup b_{j} \cup w_{j} \cup l_{i}\right\}} \sum_{t} B_{i p, t}^{i} I_{i p, t}^{i^{-}}$

Total cost of waste disposed (22(k)) is calculated as follows:

$22(\mathrm{k})=\sum_{w} \sum_{t} C_{w, t}^{i} W_{w, t}^{i}$

The MILP model subjects to the following constraints:

Equation 3.23 forces to consider solutions whose savings are greater than zero for each given plant. 


$$
Z_{i}^{B B I S}-Z_{i}^{S A} Y_{i} \geq 0 \forall i
$$

Equation 3.24 enforces that anchor tenants are always included in the BBIS.

$$
Y_{i}=1 \forall i \text { if } i \in G
$$

Equation 3.25 enables to select the number of plants that needs to be included in the BBIS.

$$
\sum_{i} Y_{i}=n
$$

Equation 3.26 - Equation 3.37 represent the constraints for output products for each plant during each time period.

Equation 3.26 represent the amount of products sold to market by each plant should be less than the market demand during each given time period. Furthermore, the output products can only be sold if the plant is open.

$$
S_{o p \in k_{i} \cup b_{i}, t}^{i, m k t} \leq d_{o p \in k_{i} \cup b_{i}, t}^{i, m t_{i}} Y_{i} \forall i, \forall o p, \forall t
$$

Equation 3.27 represents the amount of products exchanged within the coalition in any given time period.

$$
S_{o p \in\left\{k_{i} \cup b_{i} \cup w_{i}\right\}, t}^{i, j}=X_{o p \in\left\{k_{i} \cup b_{i} \cup w_{i}\right\}, t}^{i, j} \forall i, \forall j, \forall o p, \forall t
$$

Equation 3.28 forces each plant to sell products only if the coalition plant is open.

$$
S_{o p \in\left\{k_{i} \cup b_{i} \cup w_{i}\right\}, t}^{i, j} \leq M Y_{j} \forall i, \forall o p, \forall t
$$

Equation 3.29 suggests that for discrete products, the amount of output products produced is always greater than the amount of products sold during each time period.

$$
X p_{o p \in\left\{k_{i} \cup b_{i} \cup w_{i}\right\}, t}^{i} \geq S_{o p \in k_{i} \cup b_{i}, t}^{i, m k t}+\sum_{j} S_{o p \in\left\{k_{i} \cup b_{i} \cup w_{i}\right\}, t}^{i, j} \forall i, \forall j, \forall t
$$


Equation 3.30 represents that for continuous products, the amount of output products produced is always equal to the amount of products sold

$$
X p_{o p \in\left\{k_{i} \cup b_{i} \cup w_{i}\right\}, t}^{i}=S_{o p \in k_{i} \cup b_{i}, t}^{i, m k t}+\sum_{j} S_{o p \in\left\{k_{i} \cup b_{i} \cup w_{i}\right\}, t}^{i, j} \forall i, \forall j, \forall t
$$

Equation 3.31 constraints the amount of products produced in any given time period to be always less than the production capacity. Production can only be done if the plant under consideration is open.

$$
X p_{o p \in k_{i}, t}^{i} \leq P C a p_{o p \in k_{i}}^{i} Y_{i} \forall i, \forall o p, \forall t
$$

Equation 3.32 represents that the combined production of output products should be less than the production capacity. Eq. 3.31 does not hold for such output products.

$$
\sum_{o p \subset k_{i}} X p_{o p \in k_{i}, t}^{i} \leq P C a p_{c o m b i n e d}^{i} Y_{i} \forall i, \forall t
$$

Equation 3.33 represents that for discrete products, the amount of inventory carried from previous time period to the current time period plus the amount of products produced is equal to the total amount of products sold and the amount of products carried to the next time period and the amount of products disposed, if the product is a waste product.

$$
I_{o p \in\left\{k_{i} \cup b_{i} \cup w_{i}\right\}, t-1}^{i}+X p_{o p \in\left\{k_{i} \cup b_{i} \cup w_{i}\right\}, t}^{i}=S_{o p \in k_{i} \cup b_{i}, t}^{i, m k t}+\sum_{j} S_{o p \in\left\{k_{i} \cup b_{i} \cup w_{i}\right\}, t}^{i, j}+I_{o p \in\left\{k_{i} \cup b_{i} \cup w_{i}\right\}, t}^{i}+W_{w_{i}, t}^{i} \forall i, \forall o p, \forall t
$$

Equation 3.34 represents that for continuous products, the amount of products produced in each time is equal to the amount of products sold plus the amount of product disposed if the product is a waste product.

$$
X p_{o p \in\left\{k_{i} \cup b_{i} \cup w_{i}\right\}, t}^{i}=S_{o p \in k_{i} \cup b_{i}, t}^{i, m k t}+\sum_{j} S_{o p \in\left\{k_{i} \cup b_{i} \cup w_{i}\right\}, t}^{i, j}+W_{w_{i}, t}^{i} \forall i, \forall o p, \forall t
$$


Equation 3.35 represents inventory level constraint that enables to calculate inventory held or backordered for each time period. Including both inventory holding cost and inventory backorder cost in objective function (Equation 3.22) forces anyone of the inventory held or backorder to have a value, but not both.

$\left.I_{o p \in\left\{k_{i} \cup b_{i} \cup w_{i}\right\}, t}^{i}=I_{o p \in\left\{k_{i} \cup b_{i} \cup w_{i}\right\}}^{i^{+}}\right\}, t-I_{o p \in\left\{k_{i} \cup b_{i} \cup w_{i}\right\}, t}^{i^{-}} \forall i, \forall o p, \forall t$

Equation 3.36 suggests that for discrete products, the amount of inventory carried in any time period should be always less than the capacity of inventory. Furthermore, inventory can only be held if the plant is open.

$I_{o p \in\left\{k_{i} \cup b_{i} \cup w_{i}\right\}, t}^{i^{+}} \leq I C a p_{o p \in\left\{k_{i} \cup b_{i} \cup w_{i}\right\}}^{i} Y_{i} \quad \forall i, \forall o p, \forall t$

The amount of by-products and waste products produced in any time period is given by Equation 3.37.

$X p_{o p \in b_{i} \cup w_{i}, t}^{i}=\sum_{o p \in k_{i}} F\left(X p_{o p \in k_{i}, t}^{i}\right) \forall i, \forall o p \in b_{i} \cup w_{i} \forall t$

Equation 3.38 - Equation 3.50 represent the constraints for input products for each plant during each time period.

Equation 3.38 represent that the amount of input product purchased from market is less than the capacity of the products that market supply in any time period. In the current model, the market supply capacity is assumed to be infinite. Furthermore, market can only provide products if the plant is open.

$X_{i p \in l_{i}, t}^{m k t, i} \leq \operatorname{Cap}_{i p \in I_{i}, t}^{m k t, i} Y_{i} \forall i p, \forall l_{i}, \forall t$

Equation 3.39 - Equation 3.41 represents that input products can be purchased from market with or without contract. Contract purchase from market can be done if both the plants are open; else it can be obtained at market price. 
Equation 3.39 represents that contract purchase can be done if plant $\mathrm{i}$ is open and the amount that can be procured should be less than the capacity that market can provide.

$$
X C_{i p \in l_{i}, t}^{m k t, i} \leq \operatorname{Cap}_{i p \in l_{i}, t}^{m k t, i} Y_{i} \quad \forall i p, \forall l_{i}, \forall t
$$

Equation 3.40 forces contract purchase can only be done if plant $\mathrm{j}$ is open and the amount that can be procured should be less than the capacity that the market can provide.

$$
X C_{i p \in l_{i}, t}^{m k t, i} \leq \operatorname{Cap}_{i p \in l_{i}, t}^{m k t, i} Y_{j} \quad \forall i p, \forall l_{i}, \forall t
$$

Equation 3.41 represents that input products can be procured either with or without contract. The inclusion of both costs in the objective function forces purchase through one of the options, but not both.

$$
X R_{i p \in l_{i}}^{m k t, i}=X_{i p \in l_{i}, t}^{m k t, i}-X C_{i p \in l_{i}, t}^{m k t, i} \forall i p, \forall l_{i}, \forall t
$$

The amount of products purchased by plant $i$ from other plants $j$ in each time period is given by Equation 3.42 .

$$
X_{i p \in\left\{k_{j} \cup b_{j} \cup w_{j}\right\}, t}^{j, i}=S_{i p \in\left\{k_{j} \cup b_{j} \cup w_{j}\right\}, t}^{j, i} \forall i, \forall j, \forall i p, \forall t
$$

Equation 3.43 suggests that input products can only be purchased from coalition plants, if the coalition plant is open.

$$
X_{i p \in\left\{k_{j} \cup b_{j} \cup w_{j}\right\}, t}^{j, i} \leq M Y_{j} \forall i, \forall i p, \forall t
$$

Equation 3.44 suggests that for discrete products, the amount of input products used is less than the total amount of input products purchased.

$$
X u_{i p \in\left\{l_{i} \cup k_{j} \cup b_{j} \cup w_{j}\right\}, t}^{i} \leq X R_{i p \in I_{i}}^{m k t, i}+\sum_{j} X_{i p \in\left\{k_{j} \cup b_{j} \cup w_{j}\right\}, t}^{j, i} \forall i, \forall i p, \forall t
$$

Equation 3.45 represents the amount of input products used is equal to the amount of input products purchased for continuous products. 
$X u_{i p \in\left\{l_{i} \cup k_{j} \cup b_{j} \cup w_{j}\right\}, t}^{i}=X R_{i p \in l_{i}}^{m k t, i}+\sum_{j} X_{i p \in\left\{k_{j} \cup b_{j} \cup w_{j}\right\}, t}^{j, i} \forall i, \forall i p, \forall t$

Equation 3.46 represents that for discrete products, the amount of inventory carried from previous time period to the current time plus the total amount of input products purchased is equal to amount of input products used plus the amount of inventory carried to the next time period.

$$
I_{i p \in\left\{l_{i} \cup k_{j} \cup b_{j} \cup w_{j}\right\}, t-1}^{i}+X R_{i p \in l_{i}}^{m k t, i}+\sum_{j} X_{i p \in\left\{k_{j} \cup b_{j} \cup w_{j}\right\}, t}^{j, i}=X u_{i p \in\left\{l_{i} \cup k_{j} \cup b_{j} \cup w_{j}\right\}, t}^{i}+I_{i p \in\left\{l_{i} \cup k_{j} \cup b_{j} \cup w_{j}\right\}, t}^{i} \forall i, \forall i p, \forall t
$$

The inventory balance of each plant is calculated by Equation 3.47. It calculates the amount of inventory held or delayed by the supplier during each time period. Addition of both inventory holding cost and delay cost in the objective function (Equation 3.22) forces any one of inventory held or delayed to have a value, but not both.

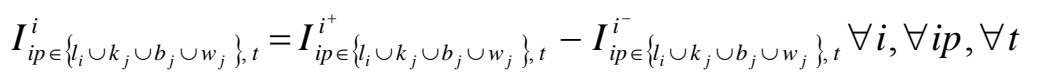

Equation 3.48 forces the amount of inventory held in any given time period to be less than the capacity of the inventory held during that time period. In addition, inventory can only be held if the plant is open.

$$
\left.I_{i p \in\left\{l_{i} \cup k_{j} \cup b_{j} \cup w_{j}\right\}, t}^{i^{+}} \leq \operatorname{ICap}_{i p \in\left\{l_{i} \cup k_{j} \cup b_{j} \cup w_{j}\right.}^{i}\right\} Y_{i} \forall i, \forall i p, \forall t
$$

Equation 3.49 suggests that the amount of input products needed depends on the total amount of final product produced and the unit conversion rate for each time period.

$$
X u_{i p \in\left\{l_{i} \cup k_{j} \cup b_{j} \cup w_{j}\right\}, t}^{i}=\sum_{o p \in k_{i}} F\left(X p_{o p \in k_{i}, t}^{i}\right) \forall i, \forall i p, \forall t
$$

Combined input product technology is given by Equation 3.50. For such products Equation 3.49 does not hold.

$\sum_{i p \subset\left\{l_{i} \cup k_{j} \cup b_{j} \cup w_{j}\right\}} X u_{i p \in\left\{l_{i} \cup k_{j} \cup b_{j} \cup w_{j}\right\}, t}^{i}=\sum_{o p \in k_{i}} F\left(X p_{o p \in k_{i}, t}^{i}\right) \forall i, \forall i p, \forall t$ 


\subsection{Case study}

A case study is conducted to compare the performance of various BBIS configurations in order to demonstrate the effectiveness of the proposed methodology and gain managerial insights. Sensitivity analysis is further conducted to provide deep understanding of the proposed BBIS system.

Figure 6 shows the potential structure of the BBIS system that is studied in this paper. It includes five candidate plants and possible connectance between them. The five candidate plants are: 1) biorefinery plant; 2) combined heat and power (CHP) plant; 3) anaerobic digestion (AD) plant; 4) malt plant; and 5) cement plant.

The biorefinery plant and the CHP plant are the initial anchor tenants. The biorefinery plant is considered as the initial anchor tenant since it is the focus of this paper. The biorefinery plant is a hybrid plant that produces a combination of $1^{\text {st }}$ generation (corn based) and $2^{\text {nd }}$ generation (cellulosic based) bioethanol. In addition, the CHP plant is also considered as the initial anchor tenant because it has high level of connectance with other plants and provides energies such as process steam and electricity to other plants. The CHP plant consists of a municipal wastewater treatment unit (Combined Heat and Power Partnership, 2012). Such structure is considered to reduce the usage of fresh water and increase the sustainability of the system.

The AD plant, cement plant and malt plant are supportive players and are optional to be selected based on various constraints. The $\mathrm{AD}$ plant operates in combination with cattle farms or feedlots. 
The barley farms are the external suppliers or non-BBIS suppliers of barley and barley straw. If malt plant is included in the BBIS, a combined contract to procure barley and barley straw cheaply will be activated between the biorefinery plant and the malt plant.

The potential SLs of products/byproducts are shown by the links between the plants. For example in Figure 6, the SL of lignin pallet suggests that the biorefinery plant has the potential to sell lignin pallets to the CHP plant.

Given such a system of five candidate plants, the objective is to determine the optimal configuration of the Industrial Symbiosis (IS) under certain constraints such that the bioethanol production cost is reduced. This requires determining the type of plants that should be included in the BBIS and designing the optimal networks or SLs of various products, by-products, waste, and utilities in the formed BBIS. 


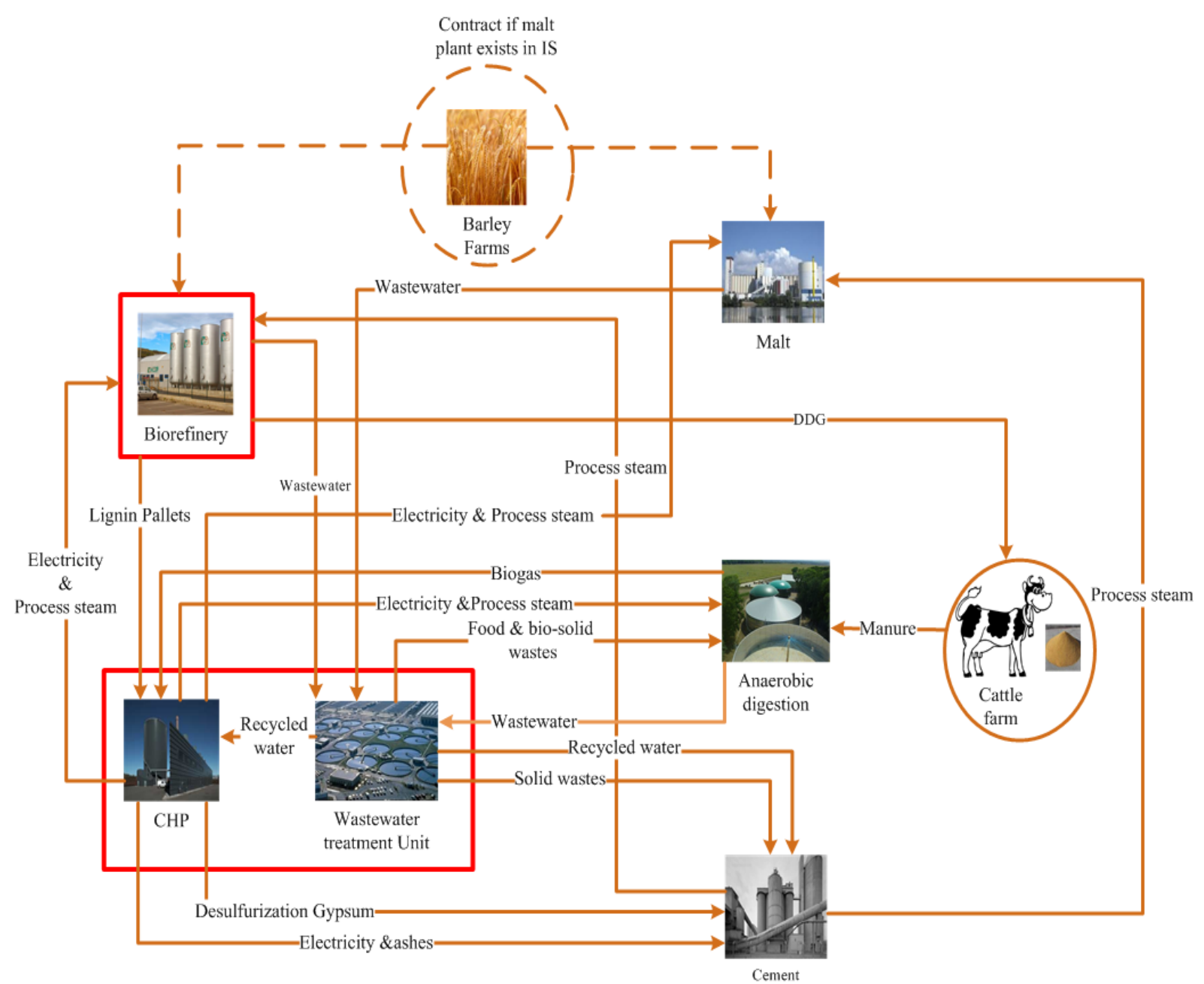

Figure 6. Candidate plants and their potential SLs

*Biorefinery Plant and CHP Plant - anchor tenants (Highlighted by red boxes)

*Dash lines indicate potential combined contract by biorefinery plant and malt plant with barley farms

\subsubsection{Plant configurations}

This section presents the configuration of each plant in detail.

\subsubsection{Biorefinery plant}

The biorefinery plant is a hybrid plant that produces a combination of $1^{\text {st }}$ generation (corn based) and $2^{\text {nd }}$ generation (cellulosic based) bioethanol. The capacity for corn based bioethanol is assumed to be 50 million gallons per year (MMGY) and for cellulosic based bioethanol is assumed to be $10 \mathrm{MMGY}$. This biorefinery plant configuration is called as hybrid (83-17) as it produces 
$83 \%$ corn based bioethanol and $17 \%$ cellulosic based bioethanol. The cellulosic based bioethanol is assumed to be produced from three kinds of raw materials: 1) Corn stover 2) Wheat straw and 3) Barley straw. The production technology for corn based bioethanol is assumed to be dry grind process and hence the by-products are Distilled dried grains (DDG) and liquid $\mathrm{CO}_{2}(\mathrm{SPEB}, 2011)$. A combined production technology is considered for cellulosic bioethanol where any combination of corn stover, wheat straw and barley straw can be processed. The technology for cellulosic bioethanol production is assumed to be matured. Figure 7 shows the input and output products of the biorefinery plant. Table 3 summarizes the configuration of the biorefinery plant in the BBIS.

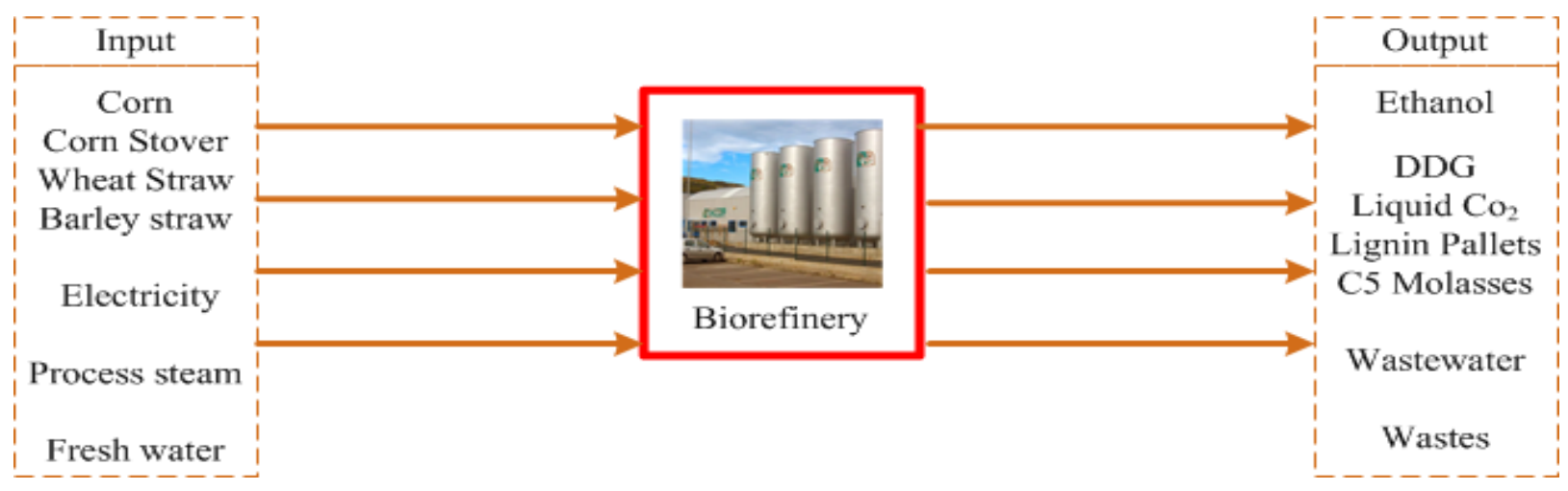

Figure 7. Input and output products of the biorefinery plant

The following assumptions are made for the standalone biorefinery plant:

1. Raw materials that include corn, corn stover, wheat straw and barley straw are procured from the market and the supply capacity of the market is assumed to be infinite for each type of raw material in the initial study. The model is developed such that the capacity for all the raw materials can be set based on the availability.

2. Electricity and freshwater are obtained from the market as required and the supply capacity is assumed to be infinite.

3. Process steam is produced through combustion of fossil fuel (lignite) in the boilers. Fresh water is used to generate process steam. 
4. All the final (ethanol) and by-products (DDG, lignin pallets, C5 molasses and liquid $\mathrm{Co}_{2}$ are sold to the market.

5. All the wastewater and wastes generated are disposed.

Table 3. Configuration of the biorefinery plant in BBIS

\begin{tabular}{|c|c|c|c|c|}
\hline \multirow[t]{2}{*}{ Capacity } & \multicolumn{2}{|c|}{ Output products } & \multicolumn{2}{|c|}{ Input products } \\
\hline & Product & $\begin{array}{l}\text { Potential input } \\
\text { to }\end{array}$ & Product & $\begin{array}{l}\text { Potential } \\
\text { output } \\
\text { from }\end{array}$ \\
\hline $\begin{array}{l}60 \text { MMGY of } \\
\text { ethanol }\end{array}$ & Ethanol & -- & Corn & -- \\
\hline $\begin{array}{l}\text { - } 50 \text { MMGY of } \\
\text { corn based } \\
\text { ethanol }\end{array}$ & DDG & $\mathrm{AD}$ & Corn stover & -- \\
\hline \multirow{6}{*}{$\begin{array}{l}10 \text { MMGY of } \\
\text { cellulosic based } \\
\text { ethanol }\end{array}$} & Liquid Co2 & -- & Wheat straw & -- \\
\hline & $\mathrm{C} 5$ & -- & Barley straw & -- \\
\hline & Molasses & & & \\
\hline & $\begin{array}{l}\text { Lignin } \\
\text { pallets }\end{array}$ & CHP & Electricity & CHP \\
\hline & Wastewater & $\mathrm{CHP}$ & $\begin{array}{l}\text { Process } \\
\text { steam }\end{array}$ & $\begin{array}{l}\text { CHP } \\
\text { Cement }\end{array}$ \\
\hline & Wastes & -- & Fresh water & -- \\
\hline
\end{tabular}

The following assumptions are made for the biorefinery plant in BBIS:

1. Raw materials, corn, corn stover and wheat straw are procured from market and can be procured as much as required.

2. Barley straw can be procured from market at lower costs if malt plant exists in BBIS through combined barley and barley straw contract, else, if malt plant is not included in the BBIS, barley straw can be procured at market price.

3. Electricity and process steam can be procured from the CHP plant resulting in less capital investment for boilers and zero consumption of fossil fuel. 
4. Final products (ethanol) and by-products (DDG, lignin pallets, C5 molasses and liquid $\mathrm{CO}_{2}$ ) can be sold to the market. DDG can also be sold to cattle farm of $\mathrm{AD}$ plant for cattle feeding (Bevill, 2011). Lignin pallets can be sold to CHP plant for co-combustion.

5. All the wastewater generated is sent to the CHP plant wastewater treatment unit for recycling.

6. All the wastes generated are disposed.

\subsubsection{CHP plant}

The CHP plant has electricity generation capacity of 99 Megawatts (MW). It consists of municipal wastewater treatment unit that recycles wastewater obtained from the city or other plants in the BBIS (Combined Heat and Power Partnership, 2012). The capacity of the wastewater treatment unit is assumed to be 32 billion gallons. Through recycling the wastewater, the wastewater treatment unit generates solid wastes, food and bio-solid wastes (Detailed treatment process, 2012). The CHP plant uses recycled water to generate electricity and process steam. The combustion technology used in CHP plant is co-combustion that uses a combination of lignite, biogas and lignin pallets.

According to WBCSD report ${ }^{\mathrm{a}}$ (2002), one of the major concerns of lignite fired CHP plant is that it emits flue gases that cause acid rains. In order to reduce air pollution and acid rains, desulphurizing equipments are used. The equipment uses bases such as quicklime and calcium carbonate to neutralize the acid pollutants. The resultant of this reaction is gypsum. The technology to combat pollution and to produce gypsum is considered in the current study. Figure 8 shows the input and output products of CHP plant. Table 4 describes the configuration of CHP plant in BBIS. 
Table 4. Configuration of the CHP plant in BBIS

\begin{tabular}{|c|c|c|c|c|}
\hline \multirow[t]{2}{*}{ Capacity } & \multicolumn{2}{|c|}{ Output products } & \multicolumn{2}{|c|}{ Input products } \\
\hline & Product & $\begin{array}{l}\text { Potential } \\
\text { input to } \\
\text { plant }\end{array}$ & Product & $\begin{array}{l}\text { Potential } \\
\text { output from } \\
\text { plant }\end{array}$ \\
\hline $99 \mathrm{MW}$ electricity & Electricity & Biorefinery & $\begin{array}{l}\text { Lignin } \\
\text { pallets }\end{array}$ & Biorefinery \\
\hline \multirow{10}{*}{$\begin{array}{l}32 \text { billion gallons } \\
\text { of wastewater } \\
\text { treatment unit }\end{array}$} & & $\mathrm{AD}$ & Wastewater & Biorefinery \\
\hline & & Cement & & Malt \\
\hline & & Malt & Biogas & $\begin{array}{l}\mathrm{AD} \\
\mathrm{AD}\end{array}$ \\
\hline & Process steam & Biorefinery & Lignite & -- \\
\hline & & $\begin{array}{l}\text { Malt } \\
\mathrm{AD}\end{array}$ & Solid waste & -- \\
\hline & Ashes & Cement & & \\
\hline & $\begin{array}{l}\text { Desulphurized } \\
\text { Gypsum }\end{array}$ & Cement & & \\
\hline & Solid wastes & Cement & & \\
\hline & $\begin{array}{l}\text { Food and bio-solid } \\
\text { wastes }\end{array}$ & $\mathrm{AD}$ & & \\
\hline & Recycled water & Cement & & \\
\hline
\end{tabular}

The following assumptions are made for the standalone CHP plant:

1. Lignite, quicklime and calcium carbonate is obtained from the market and have no capacity limit.

2. The output products, electricity and the process steam, are sold to the utility center for district electricity and heating. It is assumed that technology is available to produce process steam at desired temperature and pressure and it costs same for all.

3. The gypsum obtained from the desulphurization process is sold in the market.

4. All the recycled water is used by the CHP plant and the solid, food and biosolid wastes of the treatment are disposed. 


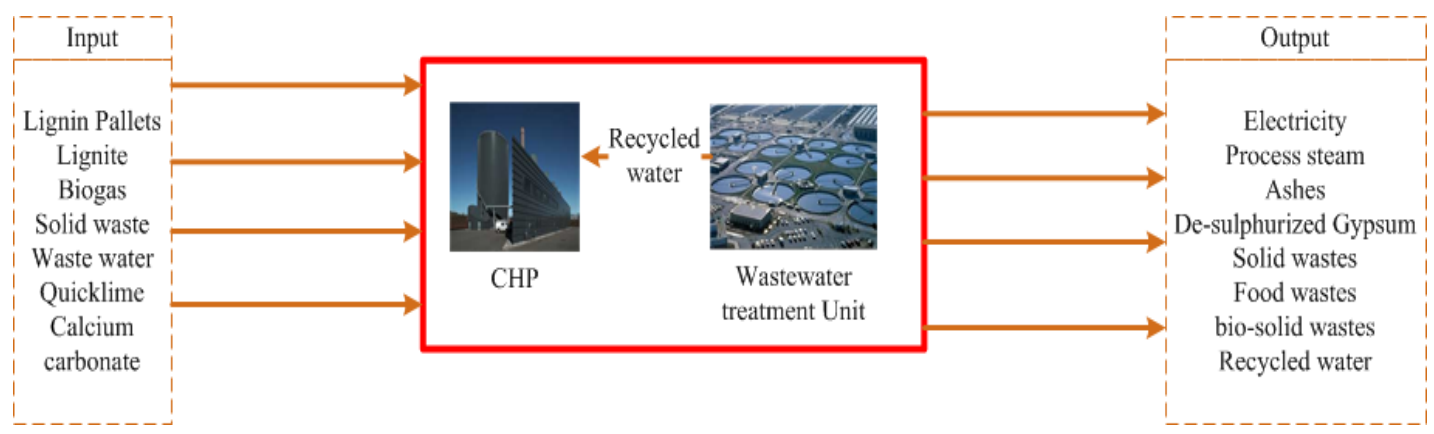

Figure 8. Input and output products of the CHP plant

The following assumptions are made for the CHP plant in BBIS:

1. Lignite, quicklime and calcium carbonate can be obtained from the market as much as required.

2. The output product, electricity can be sold to all the candidate plants in the BBIS and to the district.

3. The output product, process steam can be sold to the biorefinery plant, the malt plant, the $\mathrm{AD}$ plant and for district heating. It is assumed that technology is available to produce process steam at desired temperature and pressure and it costs same for all.

4. Desulpurized gypsum can be sold to the cement plant.

5. Ashes from the the CHP plant combustion process can be sold to the cement plant and/or disposed.

6. Recycled water can be sold to the cement plant for cooling the kiln. Due to economies of scale, the recycle cost of waste water reduces and capacity cost increases. So, both economies of scale benefits and capacity cost are considered.

7. Solid wastes from muncipal wastewater can be sold for combustion purposes to the cement plant and the remaining can be disposed. It requires a pretreatment unit that 
removes moisture content in the solid wastes and hence pretreatment technology cost per ton is included.

8. Lignin pallets from the biorefinery plant can also be used in the combustion of boilers.

9. Food and biosolid wastes can be sent to the AD plant for the production of biogas and biofertilizers (Appels et al., 2011).

10. The source of wastewater for treatment unit can be biorefinery plant, malt plant and the city.

\subsubsection{AD plant}

The AD plant is a hybrid type (Ahring and Angelidaki, 1997) that produces biogas and biofertilizers from two sources; 1) cattle feedlot manure and 2) food and bio-solids (Appels et al., 2011). The cattle feedlot is assumed to have a maintenance capacity of 18,000 cattle heads per year and the capacity of food and bio-solids that can be used is assumed to be 0.3 million tons/annum. The cattle heads are fed and their weights are increased and sold to market (Mark, Schroeder, and Jones, 2000). The cattle feedlot is assumed to be part of the AD plant. Figure 9 illustrates input and outputs required for the $\mathrm{AD}$ plant. Table 5 summarizes the configuration of AD plant in BBIS.

The following assumptions are made for the standalone AD plant:

1. Food and bio-solids can be obtained from the markets that include municipal wastewater treatment centers and other recycling units.

2. Process steam can be generated by using part of the biogas generated. It is assumed that freshwater is used to produce process steam.

3. Electricity can be purchased from the market and the capacity limit is infinite. 
4. Cattle-feed, DDG can be purchased from the market and can be purchased as much as needed.

5. Biogas and bio-fertilizers can be sold to market.

6. Waste is disposed.

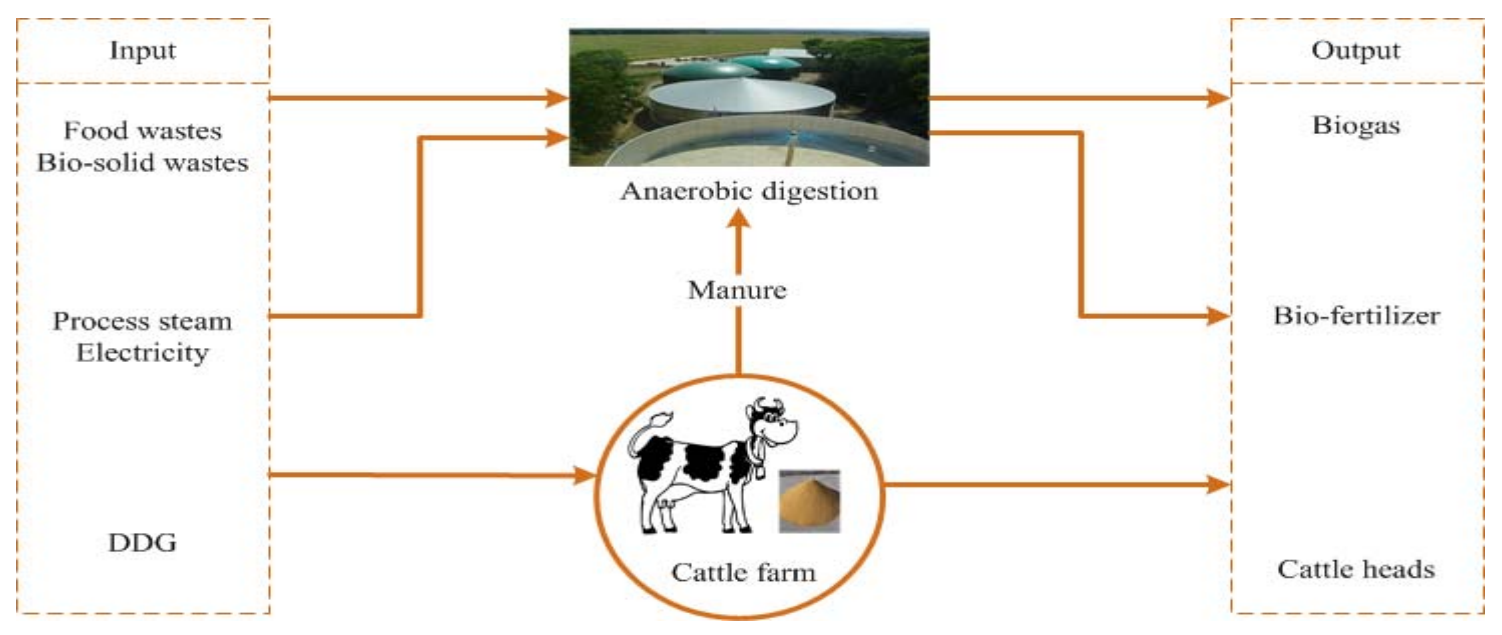

Figure 9. Input and output products for the AD plant

Table 5. Configuration of the AD plant in BBIS

\begin{tabular}{|c|c|c|c|c|}
\hline \multirow[t]{2}{*}{ Capacity } & \multicolumn{2}{|c|}{ Output products } & \multicolumn{2}{|c|}{ Input products } \\
\hline & Product & $\begin{array}{l}\text { Potential } \\
\text { input to plant }\end{array}$ & Product & $\begin{array}{l}\text { Potential } \\
\text { output from } \\
\text { plant }\end{array}$ \\
\hline \multirow{6}{*}{$\begin{array}{l}18000 \text { cattle heads } \\
0.3 \text { million tons of } \\
\text { food and bio-solid } \\
\text { wastes }\end{array}$} & Cattle heads & -- & Cattle heads & -- \\
\hline & Biogas & CHP & DDG & Biorefinery \\
\hline & $\begin{array}{l}\text { Bio- } \\
\text { fertilizers }\end{array}$ & -- & $\begin{array}{l}\text { Food and } \\
\text { bio-solids }\end{array}$ & CHP \\
\hline & Wastewater & CHP & Electricity & $\begin{array}{l}\text { CHP } \\
\text { CHP }\end{array}$ \\
\hline & & & $\begin{array}{l}\text { Process } \\
\text { steam }\end{array}$ & CHP \\
\hline & & & & Cement \\
\hline
\end{tabular}

The following assumptions are made for the AD plant in BBIS:

1. Food and bio-solid wastes can be obtained from the CHP plant.

2. Process steam and electricity can be obtained from the CHP plant. 
3. Cattle feed, DDG can be obtained from the biorefinery plant.

4. Biogas can be sold to market or CHP plant.

5. Bio-fertilizers can be sold to the market.

6. Waste is disposed.

\subsubsection{Cement plant}

The cement plant uses rotary kiln technology. The production process is dry type with a capacity of 0.358 million tons of Ordinary Portland cement (US national average for kiln capacity is 0.45 million tons) (WBCSD report ${ }^{\mathrm{a}}, 2002$ ). The rotary kiln with dry type process is a state-ofart technology in the US. Since ordinary portland cement in dry process is less complex process flow, and consumes zero water and less electricity when compared to other kinds of cement, it is considered in this paper (WBCSD report $\left.{ }^{\mathrm{b}}, 2002\right)$. The combustion technology in kiln is assumed to be co-combustion that uses a combination of wastes and fossil fuels (Cheung, Choy, Hui, Porter, \& Mckay, 2006). The heat in the kiln is recovered through water and the produced process steam can be used for district heating (Sög üt, Oktay, \&Karakoç, 2010). It is assumed that technology is available to obtain process steam at desired temperature and pressure. The cost to obtain different process steam temperature and pressure is assumed to be the same. The portland cement manufactured is assumed to be a combination of fly ash and portland cement $(30 \%$ fly ash \& $70 \%$ portland cement) (Limbachiya, Meddah, Ouchagour, 2012). Figure 10 illustrates the inputs and outputs of cement plant. Table 6 summarizes the configuration of cement plant in BBIS. 


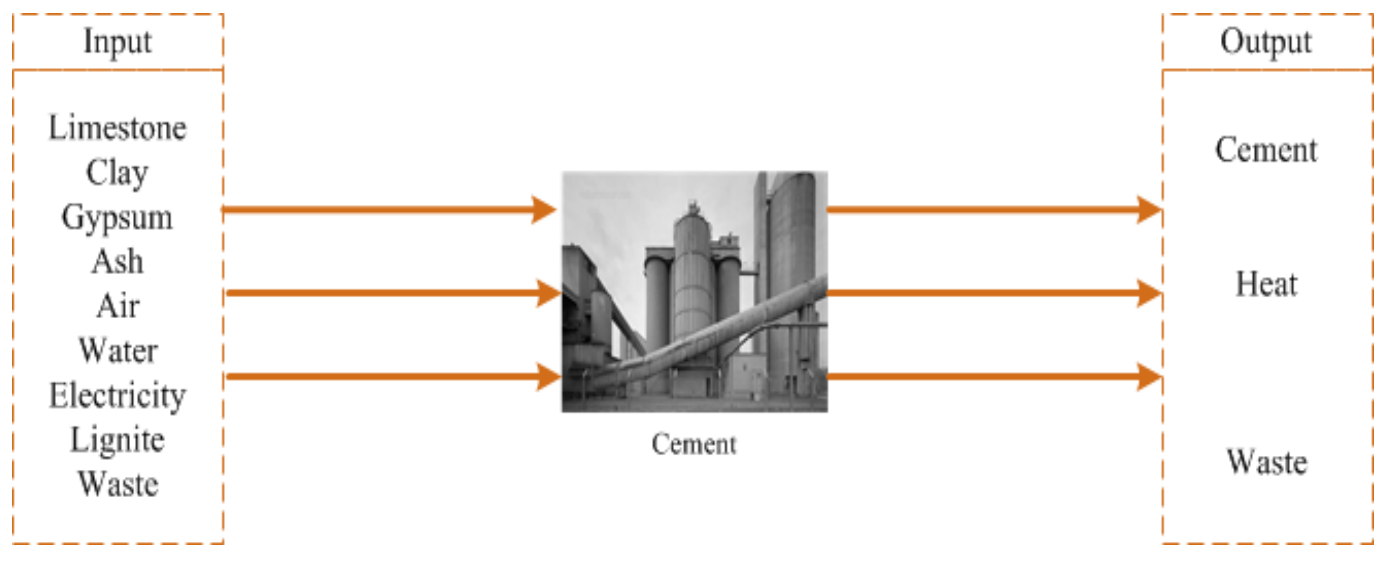

Figure 10. Input and output products of the cement plant

Table 6. Configuration of the cement plant in BBIS

\begin{tabular}{|c|c|c|c|c|}
\hline \multirow[t]{2}{*}{ Capacity } & \multicolumn{2}{|c|}{ Output products } & \multicolumn{2}{|c|}{ Input products } \\
\hline & Product & $\begin{array}{l}\text { Potential } \\
\text { input to }\end{array}$ & Product & $\begin{array}{l}\text { Potential } \\
\text { output from }\end{array}$ \\
\hline \multirow{8}{*}{$\begin{array}{l}0.358 \text { million } \\
\text { tons of cement }\end{array}$} & Cement & -- & Limestone & - \\
\hline & & -- & Clay & -- \\
\hline & $\begin{array}{l}\text { Waste heat or } \\
\text { process steam }\end{array}$ & Bio-refinery & Gypsum & $\mathrm{CHP}$ \\
\hline & & $\begin{array}{l}\text { Malt } \\
\text { AD }\end{array}$ & Air & -- \\
\hline & & & $\begin{array}{l}\text { Lignite } \\
\text { (Combustion) }\end{array}$ & -- \\
\hline & & & $\begin{array}{l}\text { Solid Waste } \\
\text { (Combustion) }\end{array}$ & $\mathrm{CHP}$ \\
\hline & & & Ashes & CHP \\
\hline & & & Electricity & CHP \\
\hline
\end{tabular}

The following assumptions are made for the standalone cement plant:

1. Raw materials (limestone, clay, gypsum and ash) are purchased from market and has no capacity limit. Since, cement plants are commonly built near limestone quarry area, the cost of obtaining is considered lower for individual plants when compared to operating in coalition.

2. Fresh water is obtained from the market for heat recovery and the generated process steam is sold to utility centers for district heating. 
3. Electricity, lignite and waste are purchased from market.

4. Output waste obtained is recycled within the cement plant up to the threshold and the remaining are disposed.

The following assumptions are made for the cement plant in BBIS:

1. Raw materials (limestone, clay) are purchased from market and has no capacity limit. Raw material purchase cost is assumed to higher for the cement plant in BBIS, as it loses the benefits such as increased transportation and inventory cost, when located near limestone quarry.

2. Raw materials (gypsum and ash) can be purchased from the CHP plant and/or market based on the requirements. The gypsum obtained from the CHP plant is desulfurized gypsum.

3. Recycled water from the CHP plant treatment unit can be used for heat recovery and the generated process steam can be sold to the biorefinery plant, the malt plant, the $\mathrm{AD}$ plant and district heating.

4. Solid wastes from the CHP plant water treatment unit can be used for cocombustion (Cheung et al., 2006).

5. Electricity can be obtained from the CHP plant at cheaper prices.

6. Output non-product wastes are recycled up to threshold and the remainings are disposed.

\subsubsection{Malt plant}

The capacity of the malt plant is assumed to be 0.15 million tons per annum. Figure 11 illustrates the inputs and outputs of the malt plant. Table 5 illustrates the configuration of the malt plant in BBIS. 


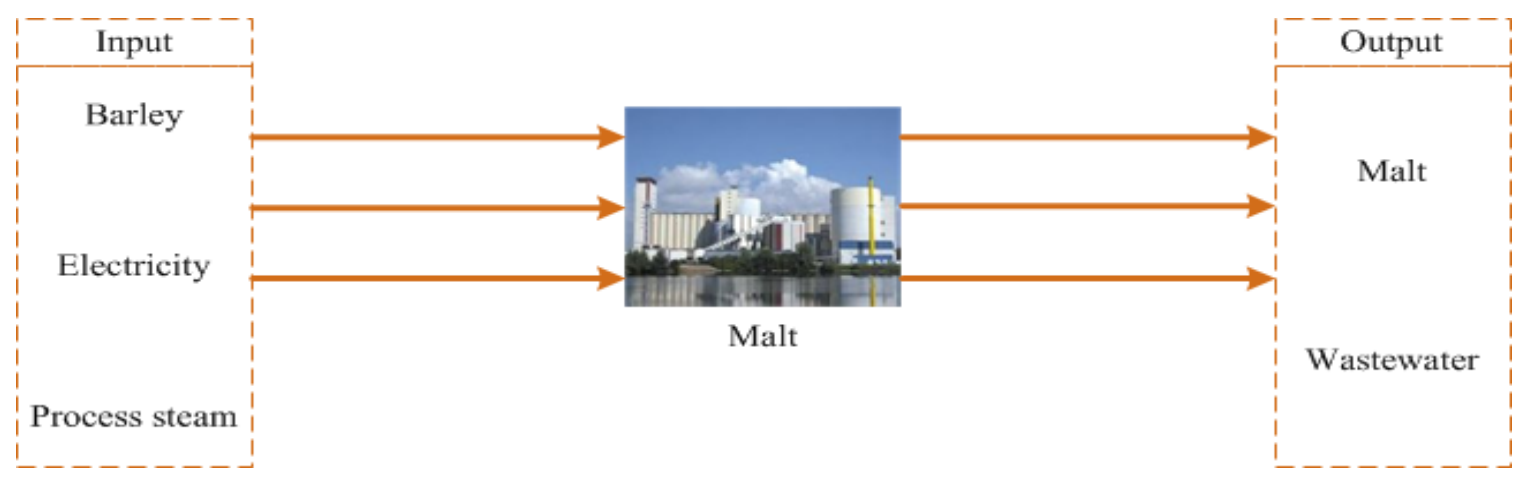

Figure 11. Input and output products of the malt plant

Table 7. Configuration of the malt plant in BBIS

\begin{tabular}{llllll}
\hline Capacity & \multicolumn{2}{c}{ Output products } & & \multicolumn{2}{c}{ Input products } \\
\cline { 2 - 3 } \cline { 5 - 6 } & Product & $\begin{array}{l}\text { Potential } \\
\text { input to }\end{array}$ & & Product & $\begin{array}{l}\text { Potential } \\
\text { output } \\
\text { from }\end{array}$ \\
\hline $\begin{array}{llllll}0.15 \text { million tons of } \\
\text { malt }\end{array}$ & Malt & -- & Electricity & CHP \\
& Wastewater & CHP & & $\begin{array}{l}\text { Process } \\
\text { steam }\end{array}$ & CHP \\
& & & & Fresh water & -- \\
\hline
\end{tabular}

The following assumptions are made for the standalone malt plant:

1. Barley is procured from market and can be obtained as much as required.

2. Process steam is generated with fresh water and combustion of fossil fuels (lignite).

3. Electricity can be procured from the market at infinite capacity.

4. The wastewater generated is assumed to be disposed.

5. Malt produced is sold to the market.

6. Freshwater for malting purpose is obtained from market.

The following assumptions are made for the malt plant in BBIS:

1. Malt plant, if included in BBIS would allow both the biorefinery plant and the malt plant to use a combined contract with barley farm owners, that would allow lower procurement cost of barley straw and barley for both plants.

2. Process steam and electricity can be purchased from the CHP plant. 
3. Wastewater can be sent to wastewater treatment unit of the CHP plant.

4. Malt produced is sold to the market.

5. Freshwater for malting purpose is obtained from market.

Table 8. Cases that are studied

\begin{tabular}{|c|c|}
\hline Cases & Description of case \\
\hline Standalone & $\begin{array}{l}\text { When plants operate in standalone mode without any coalition or } \\
\text { symbiosis }\end{array}$ \\
\hline 2-BBIS & $\begin{array}{l}\text { Two anchor tenants in BBIS from five candidate plants (Biorefinery plant } \\
\text { and CHP plant) }\end{array}$ \\
\hline 3-BBIS & $\begin{array}{l}\text { Two anchor tenants and one supportive player in BBIS from five candidate } \\
\text { plants }\end{array}$ \\
\hline 4-BBIS & $\begin{array}{l}\text { Two anchor tenants and two supportive players in BBIS from five } \\
\text { candidate plants }\end{array}$ \\
\hline 5-BBIS & $\begin{array}{l}\text { Two anchor tenants and three supportive players in BBIS from five } \\
\text { candidate plants }\end{array}$ \\
\hline
\end{tabular}

The decision framework combining LP and MILP models is coded in GAMS and is solved by using the XpressMP solver. In order to derive managerial insight, various cases have been studied in order to find optimal BBIS configurations when there are different constraints in space, finance, and disruption management efforts (Tudor, Adam, \& Bates, 2007; Ji, 2009; Lowe, 1997). Table 8 summarizes all the cases studied.

\subsection{Designing the best BBIS configurations}

This section focuses on finding the optimal BBIS configuration for each specified case to demonstrate the effectiveness of the proposed methodology.

Table 9 presents the results. It is shown that the profits of all the plants are increased through BBIS compared to the standalone mode. In addition, as the number of plants in BBIS increases, the profits of the entire BBIS and each player in the BBIS increase. Figure 12 presents the percentage increase in profits for anchor tenants (the biorefinery plant and the CHP plant) and the entire BBIS for each case. It indicates that the profit of the biorefinery plant under 2-BBIS 
increases significantly compared to the standalone mode. However, under 3-BBIS, 4-BBIS and 5BBIS, the profit of the biorefinery plant does not improve significantly. This implies that the biorefinery plant's profit is improved significantly more by the CHP plant than by other plants. The profit of the CHP plant increases significantly under 3-BBIS compared to 2-BBIS. In 3-BBIS, the AD plant is added as a supportive plant. This implies that the CHP plant's profit is significantly improved by the AD plant.

Figure 13, Figure 14, Figure 15 and Figure 16 present the optimal 2-BBIS, 3-BBIS, 4BBIS, and 5-BBIS configurations, respectively. Table 10 summarizes the number of SLs of each optimal BBIS configuration. In this paper, SL represents a network link between two plants exchanging a particular type of resource, waste, product, or by-product. It can be observed that as the number of plants in the BBIS increases, the number of SLs increases significantly. In addition, it indicates that as the number of SLs increases, the increase in profit also improves considerably.

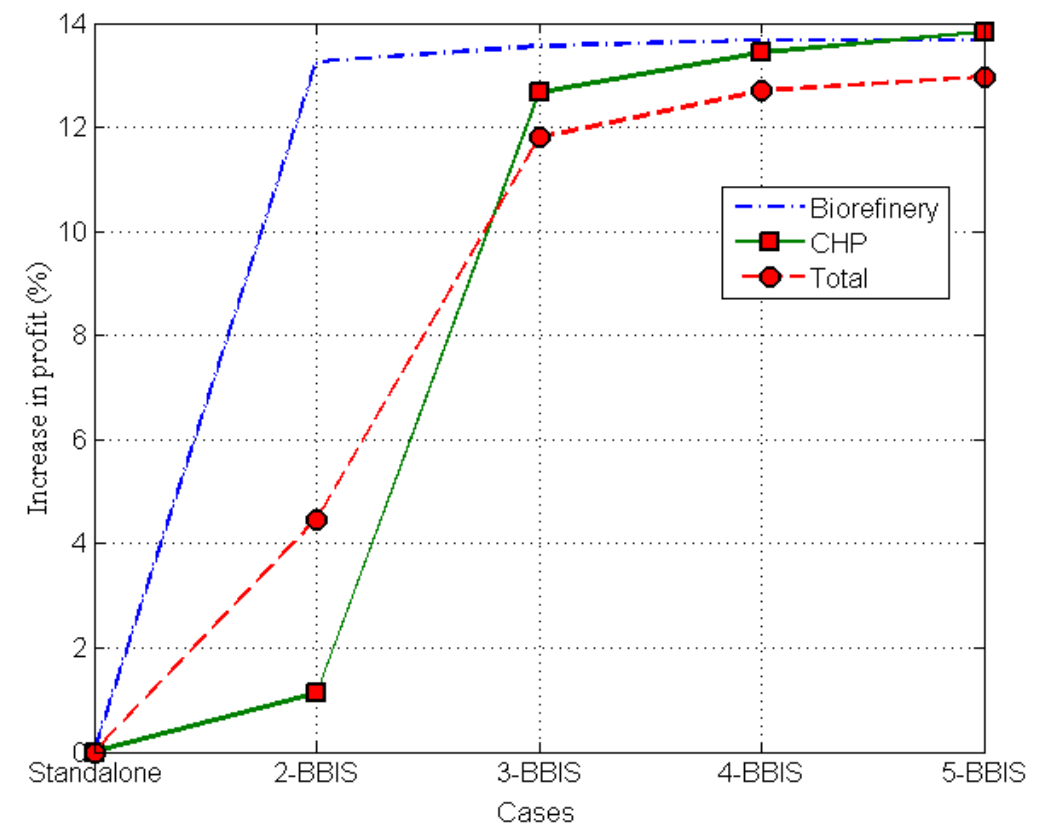

Figure 12. Percentage increase in profit of anchor tenants and BBIS 


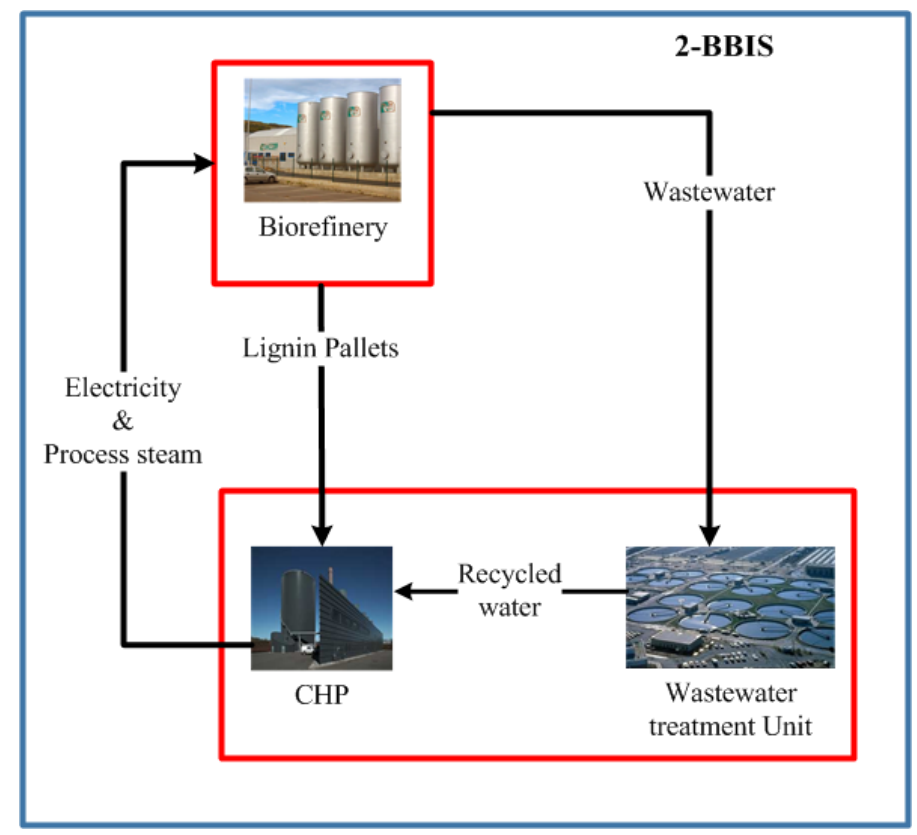

Figure 13. Optimal 2-BBIS configuration

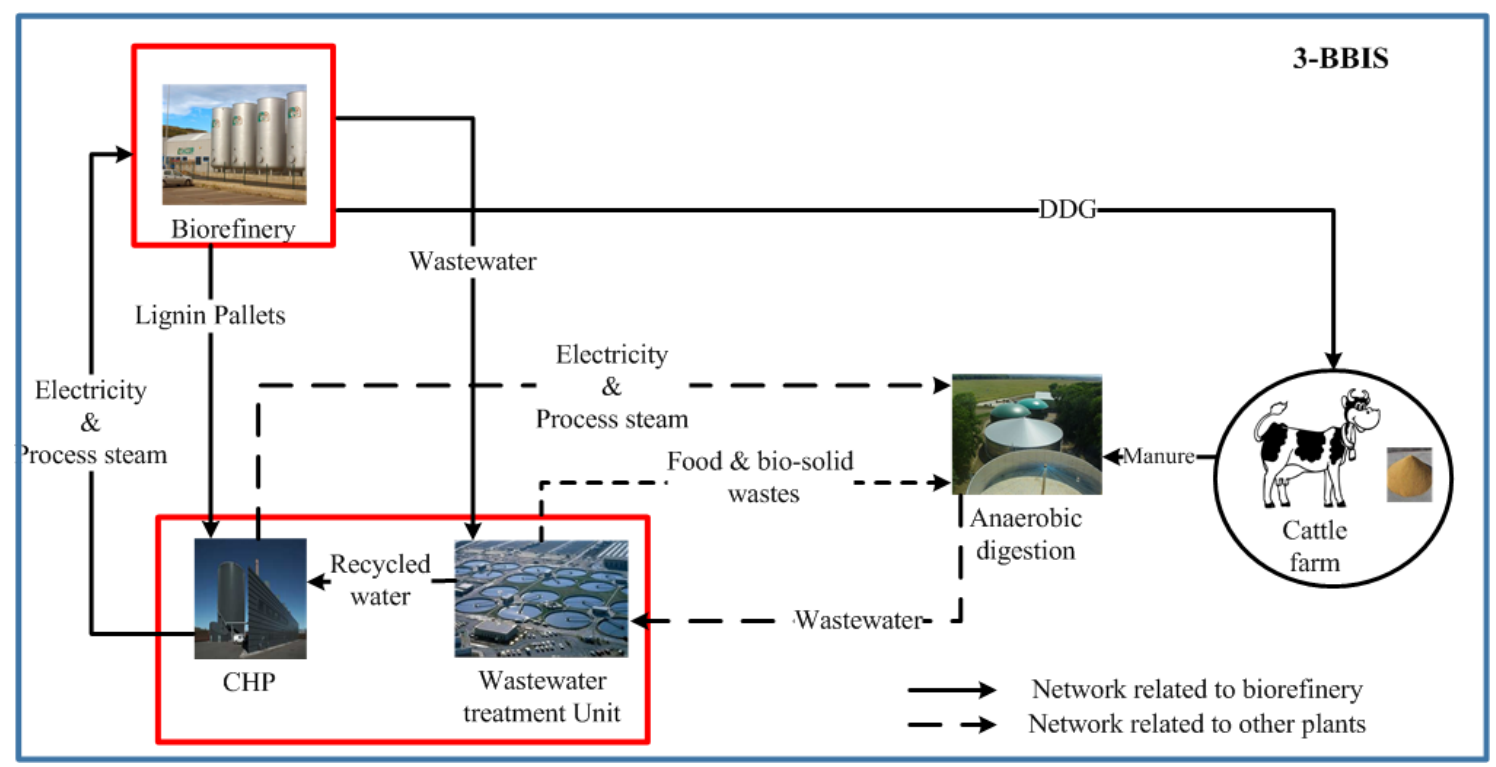

Figure 14. Optimal 3-BBIS configuration 
Table 9. Optimal profits (in million \$) under different cases

* \% Increase stands for percentage increase in profit when compared to standalone

\begin{tabular}{|c|c|c|c|c|c|c|c|c|c|}
\hline \multirow{3}{*}{ Plants } & \multicolumn{9}{|c|}{ Profit (in Millions) } \\
\hline & \multirow{2}{*}{$\begin{array}{c}\text { Standalone } \\
\text { Absolute }\end{array}$} & \multicolumn{2}{|c|}{ 2-BBIS } & \multicolumn{2}{|c|}{ 3-BBIS } & \multicolumn{2}{|c|}{ 4-BBIS } & \multicolumn{2}{|c|}{ 5-BBIS } \\
\hline & & Absolute & $\begin{array}{c}\% \\
\text { Increase }\end{array}$ & Absolute & $\begin{array}{c}\% \\
\text { Increase }\end{array}$ & Absolute & $\begin{array}{c}\% \\
\text { Increase }\end{array}$ & Absolute & $\begin{array}{c}\% \\
\text { Increase }\end{array}$ \\
\hline Biorefinery & $\$ 251.02$ & $\$ 284.29$ & $13.25 \%$ & $\$ 285.07$ & $13.56 \%$ & $\$ 285.34$ & $13.67 \%$ & $\$ 285.34$ & $13.67 \%$ \\
\hline CHP & $\$ 531.97$ & $\$ 537.98$ & $1.13 \%$ & $\$ 599.33$ & $12.66 \%$ & $\$ 603.45$ & $13.43 \%$ & $\$ 605.60$ & $13.84 \%$ \\
\hline $\mathrm{AD}$ & $\$ 18.16$ & --- & --- & $\$ 20.45$ & $12.62 \%$ & $\$ 20.45$ & $12.62 \%$ & $\$ 20.45$ & $12.62 \%$ \\
\hline Cement & $\$ 4.00$ & --- & --- & --- & --- & --- & --- & $\$ 4.20$ & $5.073 \%$ \\
\hline Malt & $\$ 73.17$ & --- & --- & --- & --- & $\$ 76.66$ & $4.77 \%$ & $\$ 76.65$ & $4.77 \%$ \\
\hline $\begin{array}{l}\text { Anchor } \\
\text { tenant } \\
\text { Total }\end{array}$ & $\$ 782.99$ & $\$ 822.27$ & $5.01 \%$ & $\$ 884.40$ & $12.95 \%$ & $\$ 888.79$ & $13.51 \%$ & $\$ 890.94$ & $13.78 \%$ \\
\hline increase & -- & $\$ 39.28$ & $4.47 \%$ & $\$ 103.70$ & $11.80 \%$ & $\$ 111.58$ & $12.70 \%$ & $\$ 113.92$ & $12.97 \%$ \\
\hline
\end{tabular}

Table 10. The number of SLs in each optimal BBIS configurations

\begin{tabular}{lllll}
\hline Case & $\begin{array}{l}\text { Number of SLs } \\
\text { related to } \\
\text { biorefinery }\end{array}$ & $\begin{array}{l}\text { Number of SLs } \\
\text { related to other } \\
\text { plants }\end{array}$ & $\begin{array}{l}\text { Total number of } \\
\text { SLs }\end{array}$ & $\begin{array}{l}\text { Increase in } \\
\text { profit } \\
\text { (Millions) }\end{array}$ \\
\hline 2-BBIS & 4 & 0 & 4 & $\$ 39.28$ \\
3-BBIS & 5 & 4 & 9 & $\$ 103.70$ \\
4-BBIS & 6 & 7 & 13 & $\$ 111.58$ \\
5-BBIS & 6 & 13 & 19 & $\$ 113.92$ \\
\hline
\end{tabular}




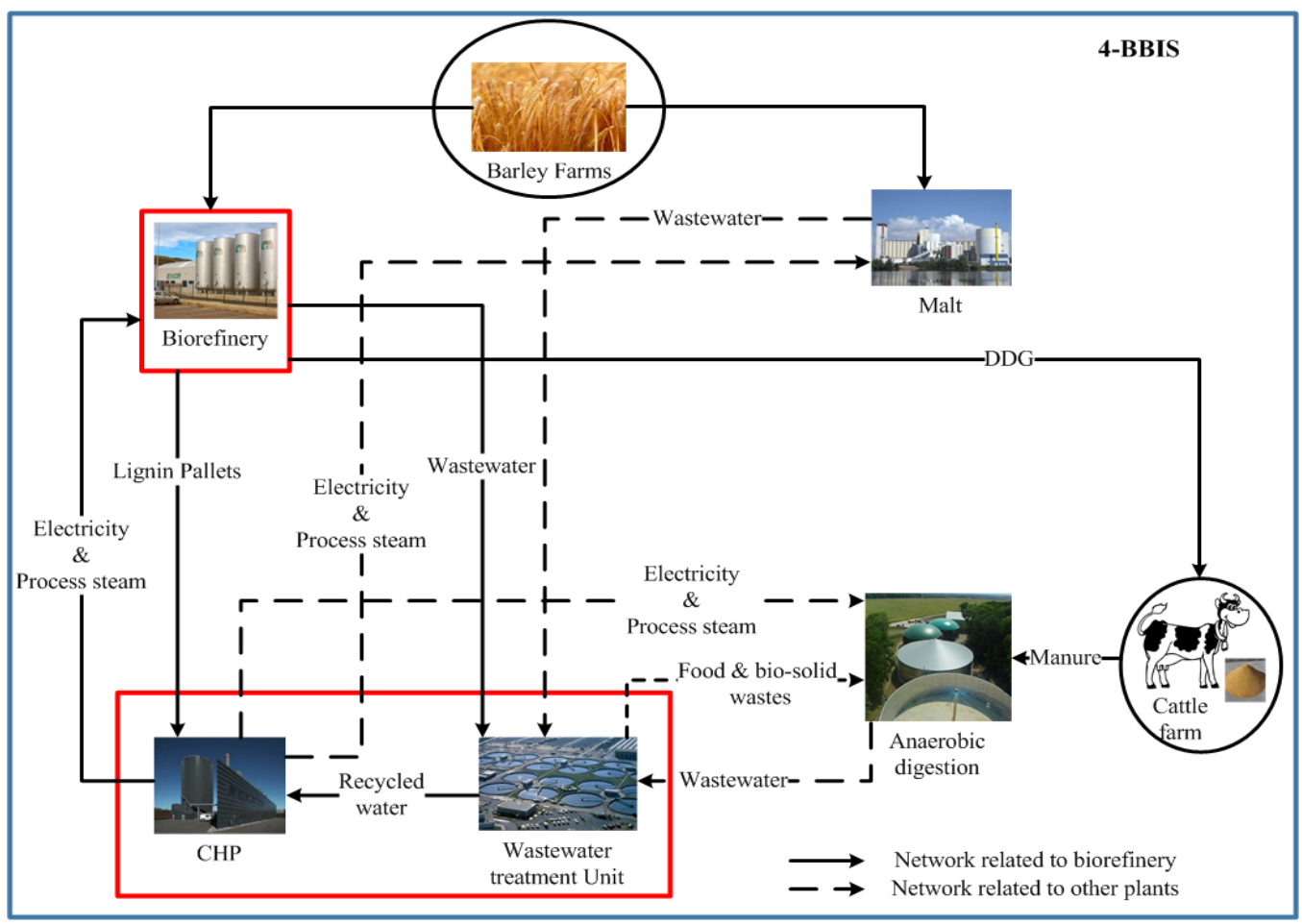

Figure 15. Optimal 4-BBIS configuration

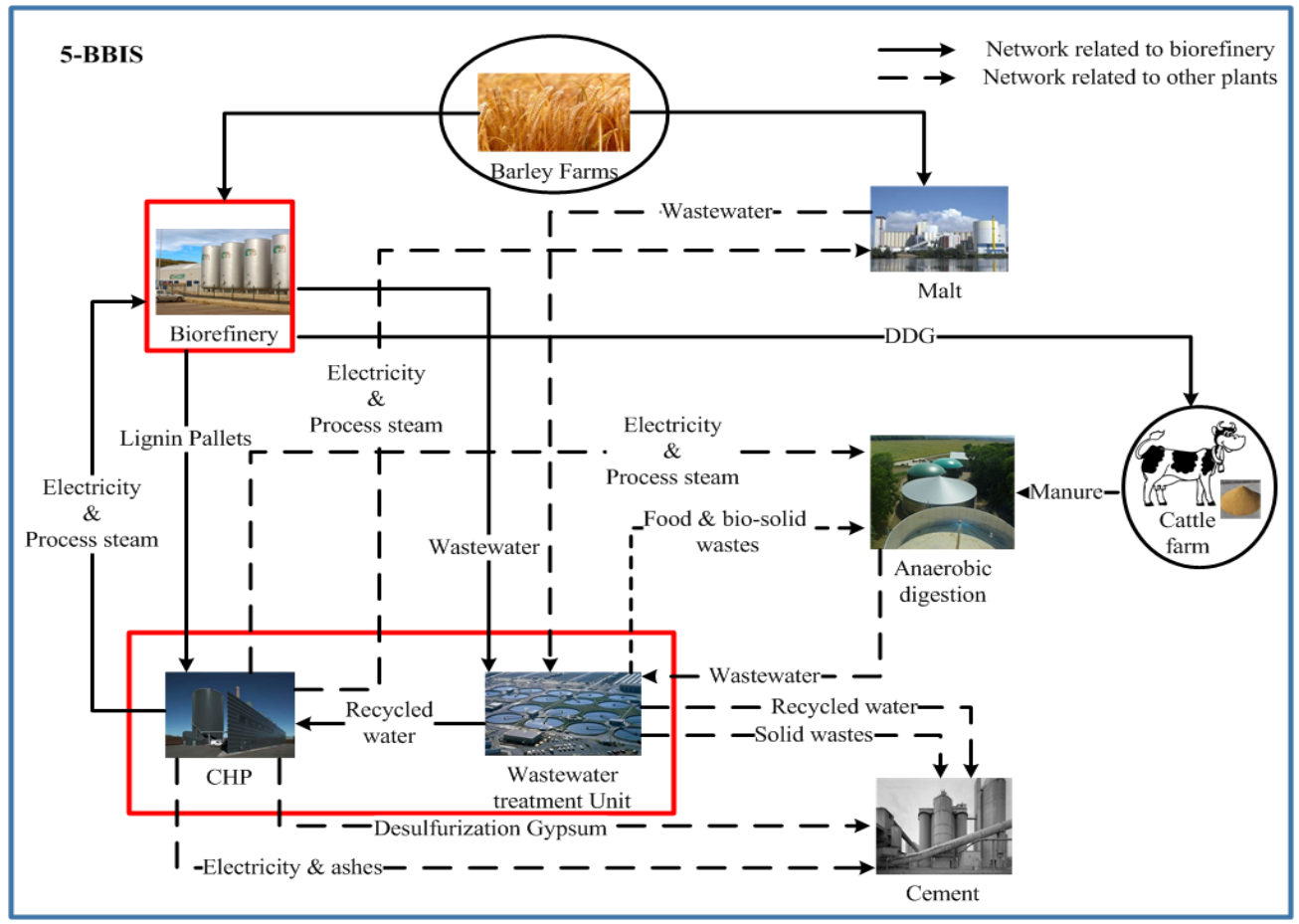

Figure 16. Optimal 5-BBIS configuration 


\subsection{Analyzing the optimal BBIS configurations}

This section focuses on identifying the reasons for the optimal BBIS configurations. It includes identifying the payoff to each plant from the other plants and the primary reasons for those payoffs. Strategies are proposed for decision makers of each plant to exploit IS while designing the supply chain in order to improve profit.

\subsubsection{Symbiotic relationship payoff (SRP)}

In order to understand the mechanism of the optimal BBIS, a metric called Symbiotic Relationship payoff (SRP) is developed to quantitatively measure the benefit of the symbiotic relationship between any two given plants. The SRP of plant $i$ from $j\left(S R P_{j \rightarrow i}\right)$ is defined in Equation 3.51.

$\mathrm{SRP}_{j \rightarrow i}=$ increase in profit of plant $\mathrm{i}$ due to $\mathrm{j}$ in BBIS

Since $S R P_{j \rightarrow i}$ is the measure of the contribution of plants $j$ to a particular plant $i$ in the BBIS, the higher the $S R P_{j \rightarrow i}$, the more plant $i$ will gain. It is noted that SRP is directional. This means the contribution of plant $j$ to plant $i$ is not same as the contribution of plant $i$ to plant $j$. Table 11 presents the SRP matrix for all the optimal BBIS configurations. For example, in 3-BBIS, $S R P_{\mathrm{CHP} \rightarrow \text { Biorefiner } \mathrm{y}}=33.27$ and $S R P_{\mathrm{AD} \rightarrow \text { Biorfiner }} \mathrm{y}=0.78$. This suggests that the CHP plant contributes $\$ 33.27$ million profit increase for the biorefinery plant and the AD plant generates $\$$ 0.78 million additional profit for the biorefinery plant compared to the standalone mode.

Figure 17 presents the pictorial representation of the highest SRP for each plant. The Figure shows: 
1) For the biorefinery plant, the CHP plant generates highest SRP compared to other plants in all the optimal BBIS configurations. This implies that the biorefinery plant would prefer forming symbiosis with the CHP plant if only one plant can be selected.

2) For the CHP plant, the $\mathrm{AD}$ plant provides the highest SRP compared to other plants. Therefore, the CHP plant will prefer collocating with the AD plant if only one plant can be selected.

3) For the $\mathrm{AD}$ plant, the CHP plant generates the highest $\mathrm{SRP}$ and hence the $\mathrm{AD}$ plant would prefer forming symbiosis with the CHP plant if only one plant can be selected.

4) Malt plant would prefer forming symbiosis with the CHP plant if only one plant can be selected as the CHP plant generates the highest SRP.

5) Cement plant would prefer forming symbiosis with the CHP plant if only one plant can be selected as the CHP plant generates the highest SRP.

6) Since, the CHP plant significantly benefits all the plants, it acts as a focal plant for all the plants and hence any candidate plant would like to collocate with it.

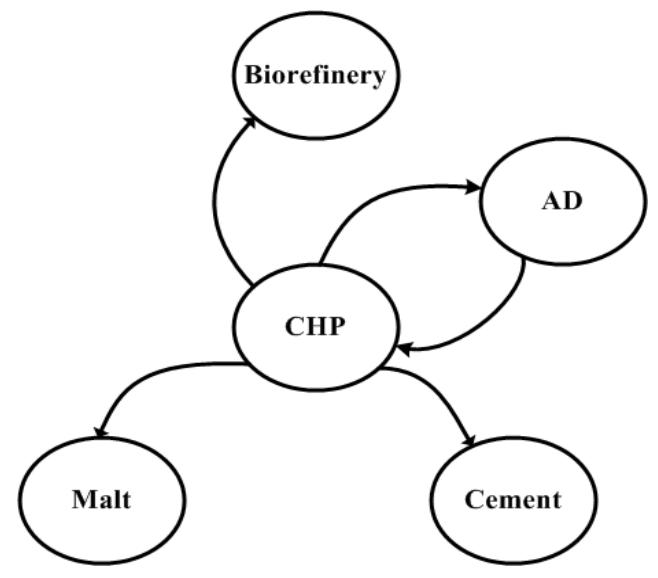

Figure 17. Pictorial representation of the highest SRP for each plant

Compared with the $\mathrm{AD}$ plant, the biorefinery plant is not the best option for the CHP plant to form symbiosis. This implies that if the biorefinery plant wants to form a stable IS, at least three 
plants, which are the biorefinery plant, the CHP plant and the AD plant, should be included in order to attract the CHP plant to participate in the BBIS.

Table 11. SRP matrix (in millions) for all the optimal BBIS configurations

\begin{tabular}{llllll}
\hline & \multicolumn{5}{c}{$i$} \\
\cline { 2 - 6 } & Biorefinery & CHP & AD & Malt & Cement \\
\hline 2-BBIS & & & & \\
\hline Biorefinery & $\$ 0$ & $\$ 6.01$ & -- & -- & -- \\
CHP & $\$ 33.27$ & $\$ 0$ & -- & -- & -- \\
\hline 3-BBIS & & & & & \\
\hline Biorefinery & $\$ 0$ & $\$ 6.01$ & $\$ 0.22$ & -- & -- \\
CHP & $\$ 33.27$ & $\$ 0$ & $\$ 1.97$ & -- & -- \\
AD & $\$ 0.78$ & $\$ 61.35$ & $\$ 0$ & -- & -- \\
\hline 4-BBIS & & & & & \\
\hline Biorefinery & $\$ 0$ & $\$ 6.01$ & $\$ 0.22$ & $\$ 0.47$ & -- \\
CHP & $\$ 33.27$ & $\$ 0$ & $\$ 1.97$ & $\$ 2.87$ & -- \\
AD & $\$ 0.78$ & $\$ 61.35$ & $\$ 0$ & $\$ 0$ & -- \\
Malt & $\$ 0.27$ & $\$ 4.12$ & $\$ 0$ & $\$ 0$ & -- \\
\hline 5-BBIS & & & & & \\
\hline Biorefinery & $\$ 0$ & $\$ 6.01$ & $\$ 0.22$ & $\$ 0.47$ & $\$ 0$ \\
CHP & $\$ 33.27$ & $\$ 0$ & $\$ 1.97$ & $\$ 2.87$ & $\$ 3.99$ \\
AD & $\$ 0.78$ & $\$ 61.35$ & $\$ 0$ & $\$ 0$ & $\$ 0$ \\
Malt & $\$ 0.27$ & $\$ 4.12$ & $\$ 0$ & $\$ 0$ & $\$ 0.21$ \\
Cement & $\$ 0$ & $\$ 2.15$ & $\$ 0$ & $\$ 0.1$ & $\$ 0$ \\
\hline
\end{tabular}

\subsubsection{Significant symbiotic links (SSLs)}

In this section, Significant Symbiotic Links (SSLs) are identified for each plant. SLs can be classified into two categories: 1) Significant Symbiotic Links (SSLs) and 2) Insignificant Symbiotic Links (ISLs). A SSL is a network link that generates significant benefit for any given plant, whereas an ISL is the network link that does not generate significant benefit for any given plant. Significant increase in profits can be generated whenever a SL reduces the cost to produce a product significantly or whenever a low value input is converted to a high value output/product.

Table 12 presents the flow rates of various products between the biorefinery plant and other plants in 5-BBIS. In addition, it presents the contribution of each SL towards the biorefinery 
plant's increase in profit. The SL of process steam contributes the most (93.18\%) increase in profits of the biorefinery plant. In the BBIS, process steam is procured directly from the CHP plant (as by-product). While in standalone mode, a huge cost is incurred in the form of fuel (lignite) to produce process steam. The net result is reduced cost and increased profit for the biorefinery plant in the BBIS compared to operating in the standalone mode. This implies that the biorefinery plant should collocate with the plants that can provide process steam. Therefore, it is a good strategy for the biorefinery plant to collocate with the CHP plant in order to obtain process steam cheaply. This suggests that identifying SSLs will enable for a plant to determine the primary reason to collocate for a given plant when making supply chain decisions. The SSLs can be identified by analyzing the results of the proposed decision framework. Table A.1. - A.4 of Appendix presents all the SLs and their contribution in optimal 5-BBIS configuration that enables to determine the SSLs.

Figure 18 presents the SSLs between different plants in 5-BBIS. It suggests that:

1) The food and bio-solid waste SL between the CHP plant and the AD plant increases the profit of both plants significantly. Therefore, the CHP plant should collocate with the AD plant that produce biogas with food and bio-solid wastes. Similarly, the AD plant should collocate with the CHP plant that can provide food and biosolid as waste.

2) The main reason for the malt plant to collocate with the CHP plant is process steam. This implies that malt plant should collocate with plants that can provide cheaper process steam.

3) The main reason for the cement plant to collocate with the CHP plant is solid wastes. This implies that the cement plant should collocate with plants that provide solid wastes. 
Table 12. Optimal SLs of products involving biorefinery plant in 5-BBIS

*Indicates outside BBIS partnerships or combined contracts.

\begin{tabular}{|c|c|c|c|c|c|}
\hline $\begin{array}{l}\text { Product } \\
\text { Type }\end{array}$ & $\begin{array}{l}\text { Product } \\
\text { sold to }\end{array}$ & $\begin{array}{l}\text { Product sold } \\
\text { by }\end{array}$ & $\begin{array}{l}\text { Average flow } \\
\text { rate }\end{array}$ & $\begin{array}{l}\text { Contribution } \\
\text { to increase in } \\
\text { profit } \\
\text { (In Million \$) }\end{array}$ & $\begin{array}{l}\text { Percentage } \\
\text { contribution to } \\
\text { increase in } \\
\text { profit }\end{array}$ \\
\hline DDG & $\mathrm{AD}$ & Biorefinery & $\begin{array}{l}3000 \\
\text { Pounds/hour }\end{array}$ & $\$ 0.0329$ & $0.0946 \%$ \\
\hline $\begin{array}{l}\text { Lignin } \\
\text { pallets }\end{array}$ & CHP & Biorefinery & $\begin{array}{l}34684 \\
\text { Tons/year }\end{array}$ & $\$ 0.3381$ & $0.972 \%$ \\
\hline Wastewater & $\begin{array}{l}\mathrm{CHP} / \text { Treat } \\
\text { ment }\end{array}$ & Biorefinery & $\begin{array}{l}18835 \\
\text { Gallons/hour }\end{array}$ & $\$ 0.846$ & $2.433 \%$ \\
\hline Electricity & Biorefinery & CHP & $9 \mathrm{MW}$ & $\$ 0.7884$ & $2.268 \%$ \\
\hline $\begin{array}{l}\text { Process } \\
\text { steam }\end{array}$ & Biorefinery & $\mathrm{CHP}$ & $\begin{array}{l}150308 \\
\text { Pounds/hour }\end{array}$ & $\$ 32.29$ & $93.18 \%$ \\
\hline $\begin{array}{l}\text { Barley } \\
\text { Straw }\end{array}$ & Biorefinery & Farms ${ }^{*} /$ Malt & $\begin{array}{l}29000 \\
\text { Tons/year }\end{array}$ & $\$ 0.361$ & $1.0385 \%$ \\
\hline
\end{tabular}

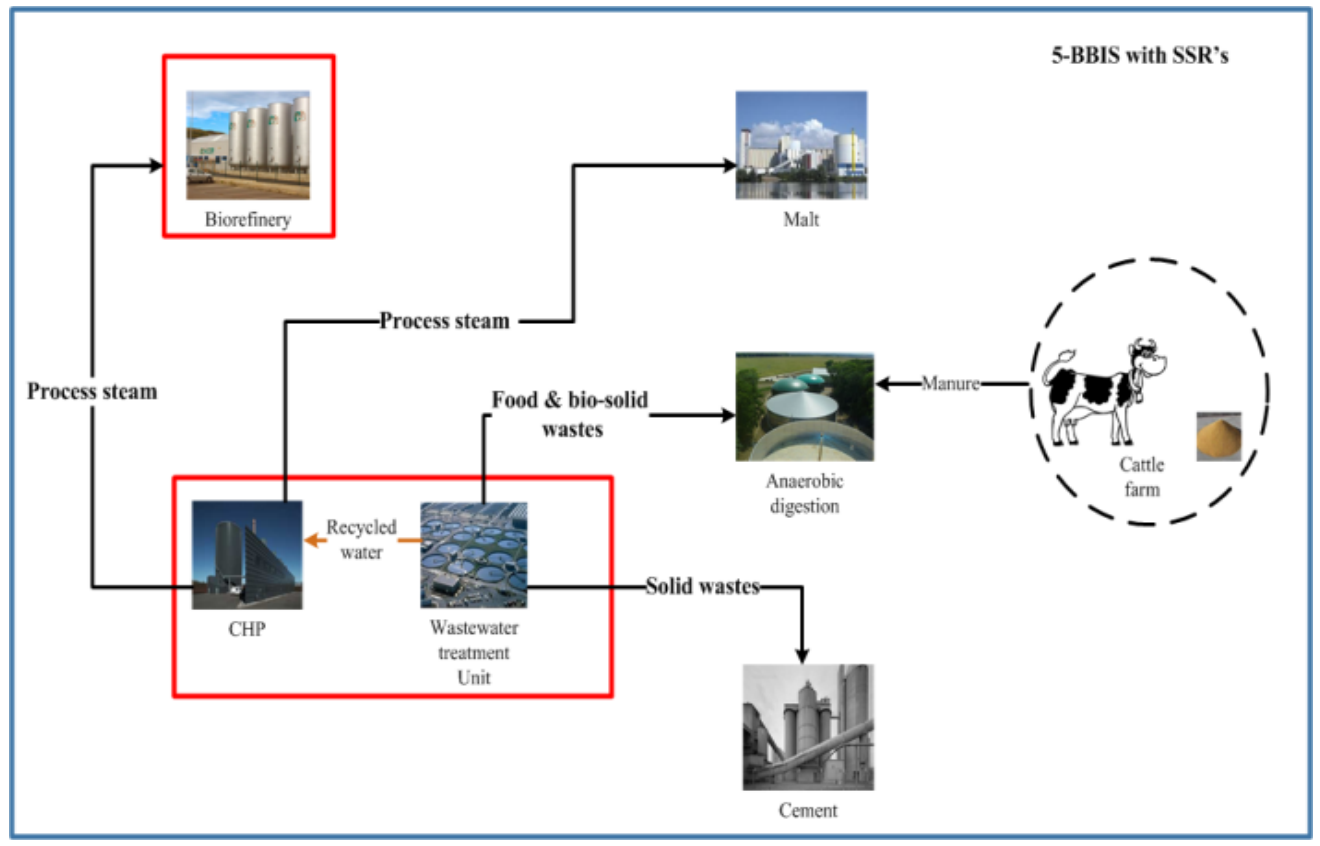

Figure 18. SSLs in 5-BBIS

The conclusions are important for each plant while designing the location of a facility in a supply chain. They provide insights for the decision makers to exploit symbiotic opportunities while designing the supply chain. For example, while designing the bioethanol supply chain, the 
decision makers can exploit the opportunity to collocate with any candidate plant that can provide cheaper process steam. This will enable the biorefinery plant to improve its profit significantly compared to operating in the standalone mode.

\subsection{Sensitivity analyses}

In order to gain more managerial insight for the biorefinery plant, this section conducts the following sensitivity analyses: 1) The impact of the CHP plant's capacity on the biorefinery plant's production; 2) The impact of process steam price on the biorefinery plant's profit; 3) The impact of the capacity of the AD plant's livestock on the biorefinery plant's profit; and 4) The impact of biomass types on the BBIS configurations and profit of the biorefinery plant.

\subsubsection{The impact of the CHP plant's capacity on the biorefinery plant's production}

As the CHP plant generates a high Symbiotic Relationship Payoff (SRP) to the biorefinery plant, sensitivity analysis is conducted to determine the impact of the CHP plant's capacity on the maximum production volume of the biorefinery plant. Figure 19 presents the result of sensitivity analysis by change the CHP plant's capacity from 0 to $90 \mathrm{MW}$. It suggests that the biorefinery plant's maximum production volume is highly influenced when the capacity of the CHP plant is low (0 to 10 Megawatts (MW)). This suggests that the biorefinery plant's production volume decreases if the CHP plant's capacity is lower than the threshold (10 MW) required by the biorefinery plant. This implies that the biorefinery plant should have contingency plan to obtain additional process steam and electricity if it collocate with a CHP plant that has a capacity lower than $10 \mathrm{MW}$. 


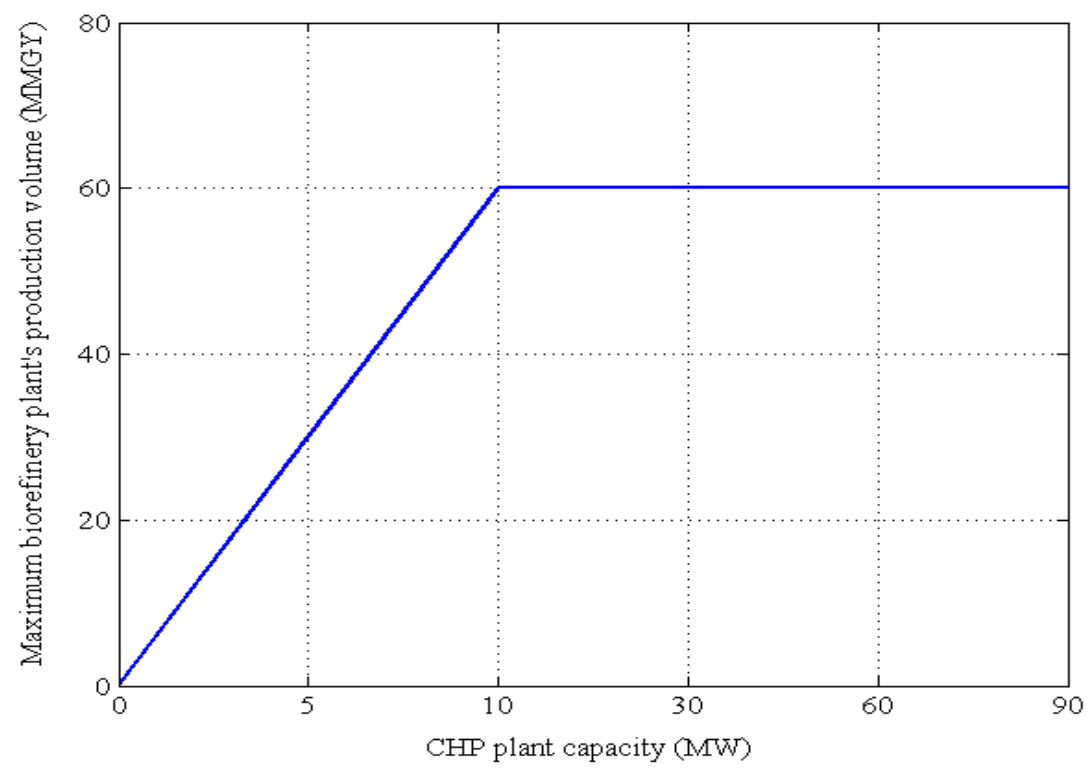

Figure 19. Impact of the CHP plant capacity on the biorefinery plant

\subsubsection{The impact of the process steam price on the biorefinery plant's profit}

Sensitivity analysis is conducted on the Significant Symbiotic Link (SSL) of the biorefinery plant in order to determine the levels at which an SSL is not beneficial. Since process steam is the SSL to the biorefinery plant (from the CHP plant), the effect of the price of the process steam (ranges between $\$ 0.008 /$ pound and $\$ 0.019 /$ pound) is analyzed. Figure 20 shows the impact of process steam prices on the biorefinery plant's profit. It indicates that the biorefinery plant's profit is highly sensitive to the process steam price under different BBIS configurations. In addition, when the process steam price is $\$ 0.0184$ per pound in 2 -BBIS, $\$ 0.0186$ per pound in 3 BBIS and $\$ 0.0188$ per pound in 4-BBIS/5-BBIS, the SL between the CHP plant and the biorefinery plant will not be beneficial. It can be observed that as the number of plants in BBIS increases, the biorefinery plant can pay a higher price for process steam and still make profit. This is because the increase in price of process steam is off-set by the profit generated by the other SLs. 


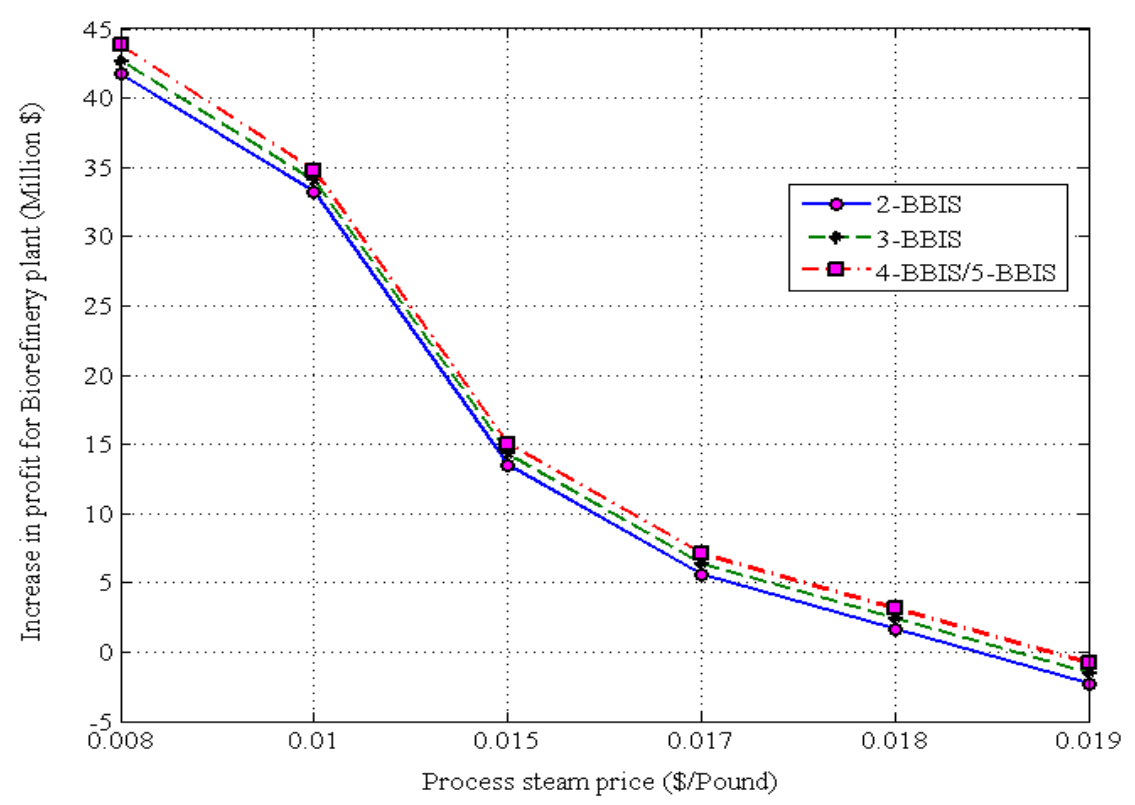

Figure 20. Process steam price impact on the biorefinery plant

\subsubsection{The impact of the capacity of the AD plant's livestock on the biorefinery plant's profit}

Sensitivity analysis is conducted by changing the cattle size of the AD plant in order to determine the impact of the $\mathrm{AD}$ plant's configuration on the biorefinery plant's profit. It is noted that the biorefinery plant and the AD plant are only related through DDG which is a low value product. DDG is the output of the biorefinery plant and input for the AD plant (for cattle feeding). Figure 21 indicates that the biorefinery plant's profit is insensitive to the capacity of the livestock. Therefore, in the BBIS, the cattle size of the AD plant does not influence the profit of the biorefinery plant. 


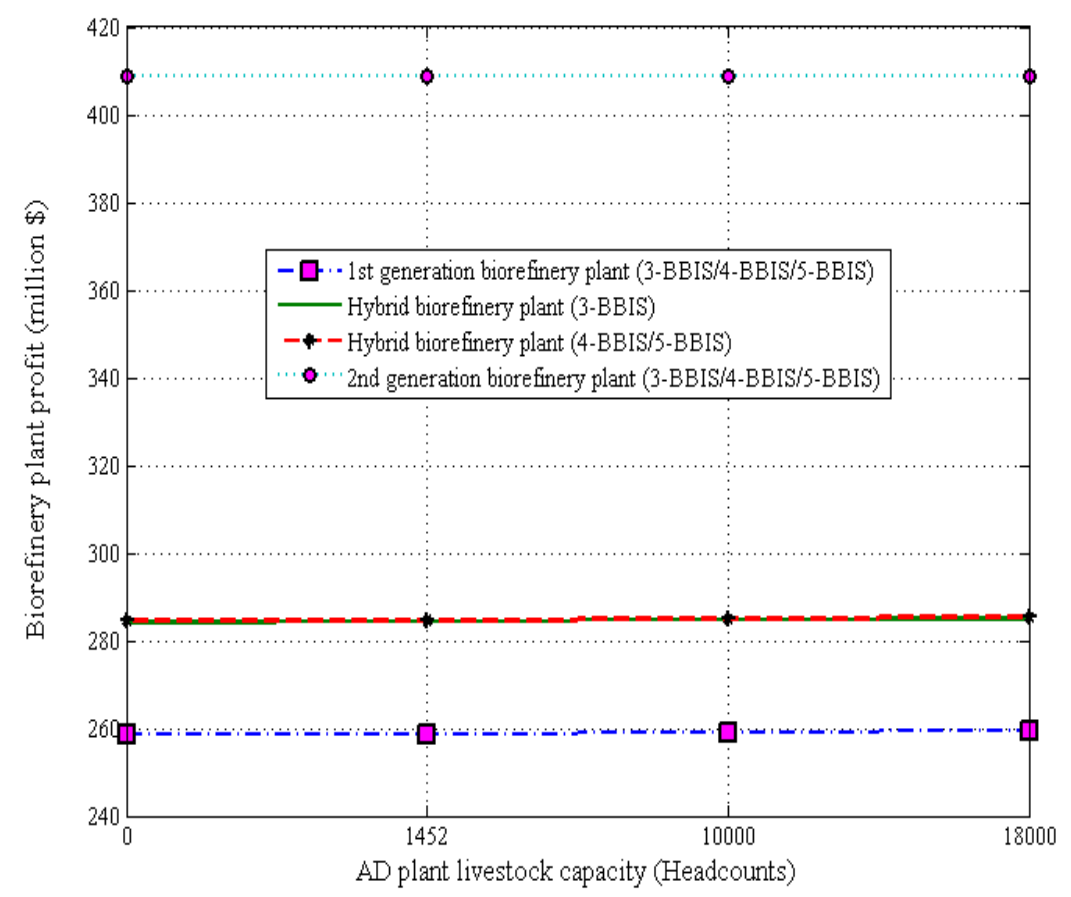

Figure 21. The impact of the livestock capacity on biorefinery plant

\subsubsection{The impact of biomass types on BBIS configurations}

There are three types of biomass that the biorefinery plant can use: 1) $1^{\text {st }}$ generation (all corn), 2) hybrid (mix of $1^{\text {st }}$ generation and $2^{\text {nd }}$ generation), and 3$) 2^{\text {nd }}$ generation (cellulosic). Analysis is conducted to identify whether different biomass input to the biorefinery plant impacts the BBIS configuration and its profit.

The results show that the optimal BBIS configurations do not change for different biomass types. However, the profits change. Figure 22 and Figure 23 present the profit of the biorefinery plant and the CHP plant for each BBIS configuration under different biomass inputs. The results show that $2^{\text {nd }}$ generation biomass improves the profits of both the biorefinery and the CHP plant compared to other biomass types. This indicates that the biorefinery plant should operate with $2^{\text {nd }}$ generation biomass if technology is matured. 


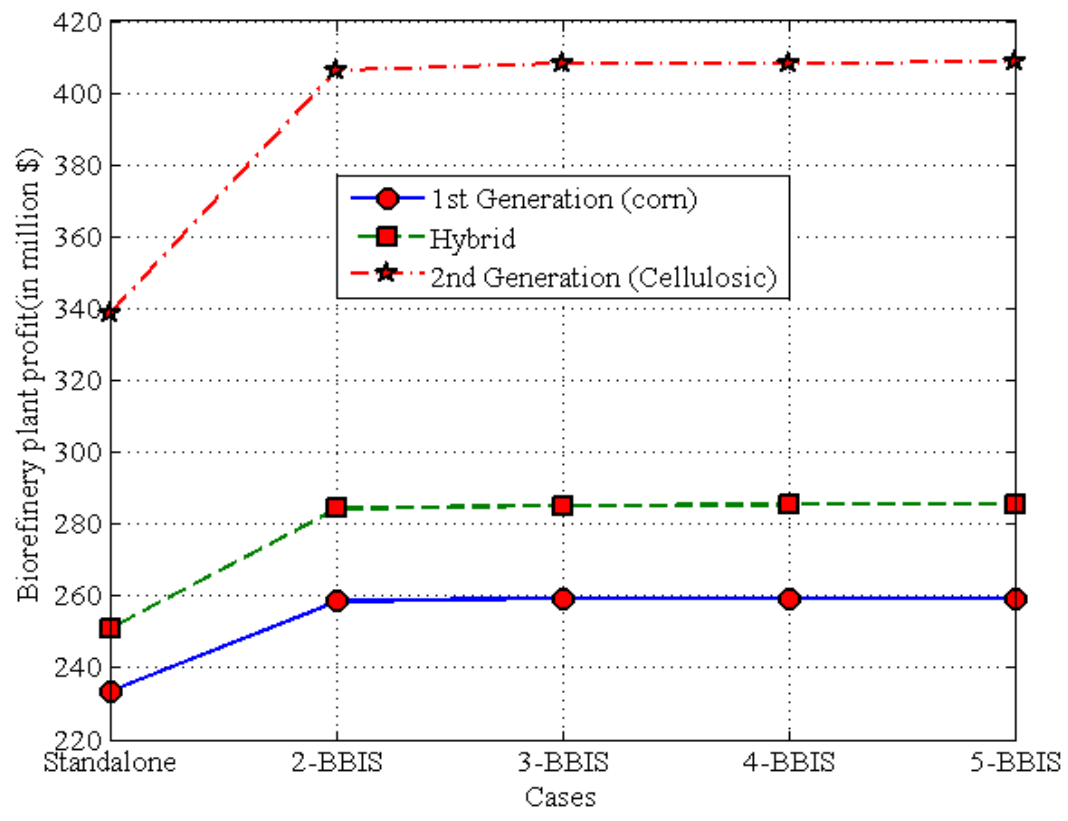

Figure 22. The biorefinery plant profit under different biomass input

Figure 24 presents the cost of bioethanol per gallon for different biomass types under different BBIS cases. It can be observed that for any type of biomass, the cost per gallon can be reduced significantly through BBISs compared to the standalone mode. However, the difference in cost per gallon among different BBIS configurations is considerably low. The cost for $2^{\text {nd }}$ generation bioethanol production decreases significantly in BBIS compared to standalone. This is because higher quantity of process steam and electricity are requires to breakdown the lignin content of the $2^{\text {nd }}$ generation biomass and BBIS can provide cheaper process steam leading to the more cost saving. 


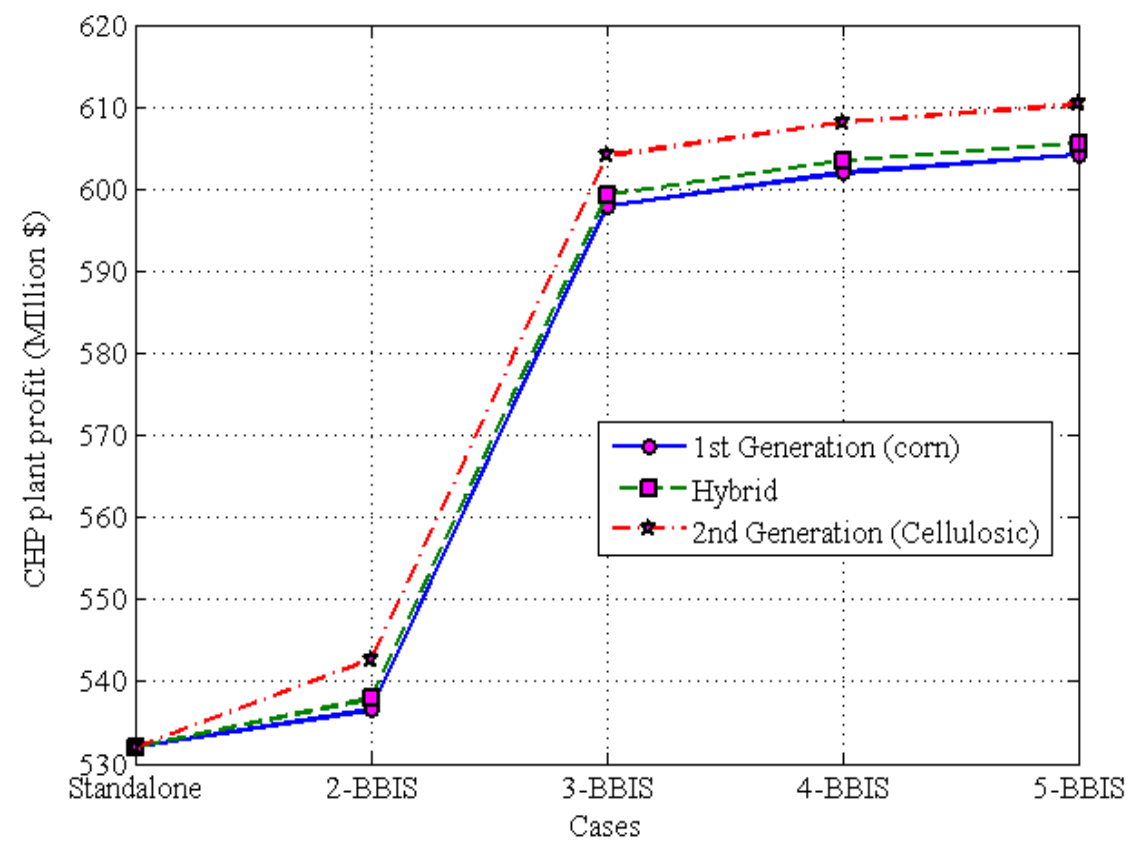

Figure 23. The CHP plant profit under different biomass input

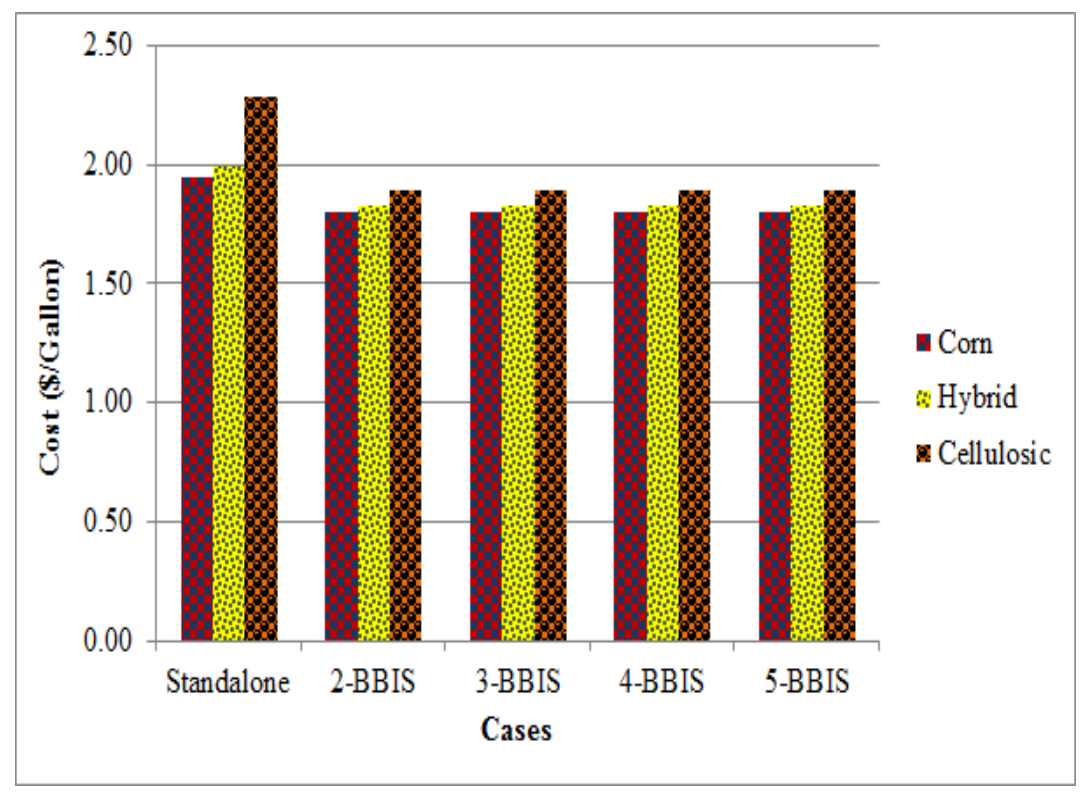

Figure 24. Bioethanol cost (\$/gallon) under various BBIS configurations

Figure 25 presents the profit of bioethanol per gallon under different BBIS configurations. It can be observed that for any type of biomass, the profit per gallon increases significantly through BBIS. However, the difference in profit per gallon among different BBIS configurations is 
considerably low. The profit of the $2^{\text {nd }}$ generation increases significantly compared to the $1^{\text {st }}$ generation because high value co-products are produced with the $2^{\text {nd }}$ generation (assuming that the technology is matured).

In summary, the results show that any BBIS configuration can be designed to improve the biorefinery plant's profit based on the availability of space, finance and disruption management efforts. The 2nd generation biorefinery plant has higher profit than the biorefinery plants using other biomass types. In addition, while designing bioethanol supply chain, bioethanol plant should collocate near to the candidate plants such as CHP plants in order to obtain process steam cheaply. This will especially benefit the 2 nd generation biorefinery plant.

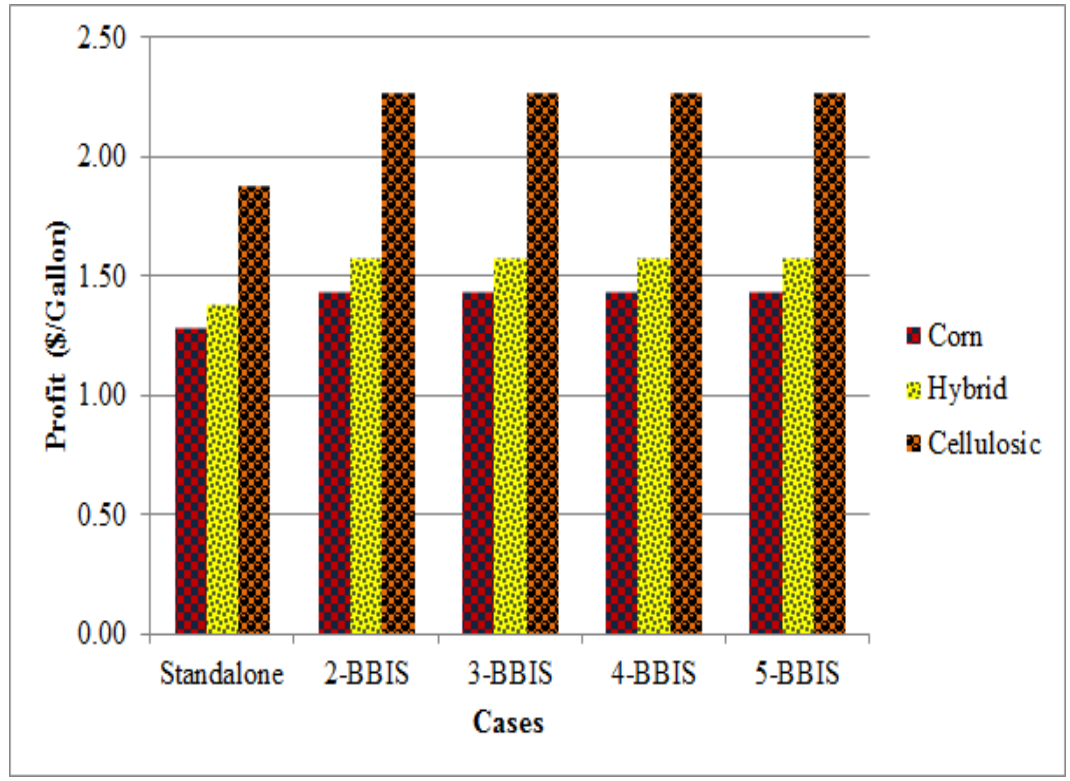

Figure 25. Profit (\$/Gallon) under various BBIS configurations

\subsection{Conclusions}

This research focuses on determining the optimal configuration of the Bioenergy-based Industrial Symbiosis (BBIS) under different constraints such that profitability of the entire BBIS and individual plants in BBIS are increased. A decision framework combining linear programming 
(LP) and large scale mixed integer linear programming (MILP) is proposed to determine the type of plants that should be included in the optimal BBIS. In addition, the model determines the optimal multi-product network flows between the selected plants in BBIS.

This study is mainly conducted from the perspective of the biorefinery plant. A comprehensive case study and sensitivity analyses are conducted to demonstrate the effective of the proposed methodology and gain managerial insight. The results suggest that all the BBIS configurations outperform standalone mode for all the plants. If a new BBIS has to be designed, a minimum of 2-BBIS (collocating with the CHP) is acceptable for biorefinery to improve its profit compared to the standalone mode. In all the BBIS cases, the CHP plant generates highest profit for the biorefinery plant. In all the BBIS cases, the CHP plant acts as a focal point that generates improved benefits for all the plants. However, the AD plant generates highest profit for the CHP plant compared to others. In order to form a stable BBIS, minimum 3-BBIS (the biorefinery plant, the CHP and the AD plant) is necessary to attract the participation of the CHP plant. Process steam is the important factor in improving biorefinery plant's profit. Therefore, decision makers of bioethanol supply chain can look for opportunities to collocate near to the plants that can provide cheaper process steam to the biorefinery plant.

Sensitivity analyses show some important insights: 1) the biorefinery plant's maximum production volume decreases if the CHP plant's capacity is lower than the threshold required by the biorefinery plant. Therefore, contingency plans should be developed to meet the required capacity. 2) The biorefinery plant's profit is highly sensitive to the process steam price. If the process steam price is above some threshold limit in BBIS, then the SL of process steam between the CHP plant and the biorefinery plant will not be beneficial. Therefore, process steam price should be controlled below the threshold in BBIS. 3) The biorefinery plant's profit is insensitive 
to the livestock size of the AD plant. And 4) BBIS configurations remain the same when input biomass types for the biorefinery plant change. However, the $2^{\text {nd }}$ generation biomass improves the profit of biorefinery plant and CHP plant more compared to other biomass types, it should be used for bioethanol production if applicable.

There are many future research directions in designing the optimal BBIS. Future works include, but is not limited to: 1) identifying more cross-sectored candidate plants, to form a more diversified BBIS; 2) identify new markets for by-products of the biorefinery plant, especially the $2^{\text {nd }}$ generation biorefinery plant, in order to transform the current lower value outputs of the biorefinery plant to high value inputs of other plants; and 3) designing sustainability related policies based on environment, social and resource utilization aspects to attract candidates to form BBIS. 


\section{CHAPTER 4. DESIGN OF SUSTAINABLE HYBRID GENERATION BIOETHANOL SUPPLY CHAINS WITH UNCERTAINTIES}

\subsection{Abstract}

This paper focuses on designing a hybrid generation bioethanol supply chain (HGBSC) that will account for economic, environmental and social aspects of sustainability under various uncertainties. A stochastic mixed integer linear programming model is proposed to design an optimal HGBSC. A case study of the state of North Dakota in the United States is used as an application of the proposed model. First, numerous existing sustainability standards are studied. The results suggest that the designs of optimal HGBSC change when different standards are applied. Second, significant trade-off between the economic, environmental and social aspects of sustainability has been observed. Third, sustainability standards are studied under various level of gasoline replacement by bioethanol. The result suggests that strict sustainability regulations are necessary at higher levels of gasoline replacement. Finally, a synchronized decision framework is provided for the policy makers and investors to shift from a lower state of sustainability to a higher state of sustainability.

\subsection{Introduction}

A sustainable energy future calls for a wide range of alternative sources of energy that can reduce fossil fuel dependency (Chen and Fan, 2012). Bioethanol is viewed as one of the potential solutions as it is both renewable and environmental friendly energy source, especially for transportation sector. As a result, $1^{\text {st }}$ generation bioethanol has been produced widely in various nations. However, the wide use of $1^{\text {st }}$ generation bioethanol has given rise to new social issues such as the food versus fuel debate and the extensive use of irrigation land for energy purposes, since 
$1^{\text {st }}$ generation bioethanol is produced from food-based biomass, such as corn and soybean. This results in increased cost of food products and reduced available land (resource) footprint for cultivation of food products. In addition, $1^{\text {st }}$ generation bioethanol production emits higher levels of greenhouse gas (GHG) compared to $2^{\text {nd }}$ generation (Charles, Ryan, Ryan, \& Oloruntoba, 2007). Therefore, $2^{\text {nd }}$ generation bioethanol has gained great attraction from both researchers and investors, because $2^{\text {nd }}$ generation bioethanol can be produced from lignocellulosic-based biomass, such as woody materials, crop residuals, or energy crops that can be cultivated in marginal land and consume less water and fertilizers. It is both environmental and social beneficial to produce and use $2^{\text {nd }}$ generation bioethanol.

In recent years, numerous standards in United States (US) have been developed to promote $2^{\text {nd }}$ generation bioethanol. For example, the renewable fuel standard (RFS) mandates that 36 billion gallons of biofuels should be produced by 2022, and among which, 21 billion gallons should be produced from $2^{\text {nd }}$ generation biomass (Schnepf, 2011). Although $2^{\text {nd }}$ generation bioethanol is being promoted extensively, there are few commercialized $2^{\text {nd }}$ generation bioethanol plants due to lack of mature efficient conversion technologies. Consequently, some portion of bioethanol demand has to be met by $1^{\text {st }}$ generation bioethanol until the $2^{\text {nd }}$ bioethanol production technology matures. Hence, a hybrid generation bioethanol supply chain (HGBSC) is essential to sustainably meet the bioethanol demand. In addition, HGBSC is exposed to number of uncertainties such as bioethanol price, demand and biomass yield. Thus, a robust HGBSC has to be designed by considering the uncertainties.

Review of literature suggests that none of the up-to-date research has focused on designing optimal HGBSC that considers both sustainability and uncertainties. Therefore, this paper will bridge the gap. In this paper, a stochastic mixed integer linear programming (SMILP) model is 
proposed to design the optimal HGBSC where the objective is to maximize economic benefits under environmental and social restrictions. In this study, a GHG emission is used to measure the environmental impact and the amount of irrigation land used for biomass cultivation is used to measure social impact. The SMILP model will determine 1) whether the existing $1^{\text {st }}$ generation bioethanol plants should operate at the current capacity or expansion capacity or should be closed, 2) locations of the new $2^{\text {nd }}$ generation bioethanol plants and their capacities, 3) locations of the biomass cultivation sites, the collection centers of biomass, and 4) transportation modes. A case study of North Dakota (ND) in US is used as an application of the proposed model. The proposed model provides the economic, environmental and social insights under different standards. In addition to providing supply chain and logistic decisions to investors, the proposed model provides tax credit estimates to the policy makers when it is needed to reach a higher state of sustainability from one lower state of sustainability.

The rest of the chapter is organized as follows. Section 4.3 provides comprehensive literature review of the design of bioethanol supply chains. Section 4.4 presents the problem statement where the activities of the bioethanol supply chain is discussed in details. Section 4.5 proposes the mathematical model. Section 4.6 presents a case study setting where the proposed model is applied to the state of ND. Section 4.7 explains a comprehensive analysis of the results and section 4.7 presents sensitivity analysis. Section 4.8 discusses sensitivity analysis and section 4.9 presents conclusion.

\subsection{Literature review}

A considerable amount of research has been conducted to design either a sustainable 1st generation or a $2^{\text {nd }}$ generation bioethanol supply chain, but not both. Zamboni et al. $\left(2009^{\mathrm{a}}\right)$ and Zamboni et al. (2009b) develop a Multi-objective mixed integer linear programming (Mo-MILP) 
model to design a corn-based bioethanol (1st generation) supply chain. The objective is to simultaneously minimize the cost and GHG emissions and the results suggest that supply chain decisions change when GHG emissions are considered. Corsano et al. (2011) develop a mixed integer nonlinear programming (MINLP) model to design a sustainable sugar/ethanol (1st generation) supply chain. The results indicate that including sustainability into the bioethanol supply chain would significantly reduce the profit and change the supply chain design. Zhang et al. (2012) develop a mixed integer linear programming (MILP) model to design the optimal switchgrass based supply chain $\left(2^{\text {nd }}\right.$ generation) to minimize the total cost. Huang et al. (2010) develop an MILP model to design lignocellulosic bioethanol supply chain and conclude that the $2^{\text {nd }}$ generation bioethanol can be compatible at a cost of $\$ 1.10$ per gallon. An et al. (2011) develop a deterministic model to design a lignocellulosic bioethanol supply chain (2nd generation) in order to maximize the profit of bioethanol supply chain. Chen and Fan (2011) designed a biowaste based bioethanol supply chain (2nd generation) and conclude that bio-waste based bioethanol can be feasible solution for future energy requirements. You et al. (2012) develop a Mo-MILP model to design a cellulosic bioethanol supply chain (2nd generation) to simultaneously improve cost, emissions and the number of jobs created. Marvin et al. (2012) design an economically viable lignocellulosic bioethanol supply chain (2nd generation). Bernardi et al. (2013) develop a MoMILP model to design HGBSC that simultaneously improves economic, carbon and water footprint performance. The results suggest that HGBSC design changes when carbon and water utilization aspects are considered.

In order to design a sustainable bioethanol supply chain, it is necessary to comprehensively understand various sustainability standards. According to You et al. (2012), sustainability consists of three spheres: 1) economic, 2) environmental, and 3) social aspects. They indicate that any 
business can be sustainable only if all the aspects are improved simultaneously. Consequently, a number of policies have been promoted by federal agencies to improve all the three aspects for bioethanol production. In order to improve the economic aspect of bioethanol production, numerous tax incentives or exemptions are given by federal agencies to bioethanol producers. For example, the US government provides tax exempt of 56 cents for every gallon of 1st generation bioethanol produced (Wheals et al, 1999) and $\$ 1.01$ for every gallon of 2 nd generation bioethanol produced (Credit Suisse Report, 2012). In the past 20 years, a number of environmental standards have been encouraged to reduce environmental impacts. For example, the emissions policy indicates that US should reduce its GHG emissions by 20\% - 40\% below 1990 level by 2020 (Romm, 2009). Furthermore, in recent years, numerous sustainability standards have been introduced to improve social aspect. For example, the renewable fuel standard (RFS) mandates $55 \%$ of the bioethanol demand to be met from 2 nd generation bioethanol in order to reduce the use of irrigation land for energy purposes (Schnepf, 2011). Therefore, as the emphasis on sustainability continues to grow, it is necessary to design a bioethanol supply chain that maximizes economic benefits under environmental and social restrictions.

In addition, bioethanol supply chain is exposed to number of uncertainties that will significantly impact the performance of bioethanol supply chain. In past, researchers have considered designing bioethanol supply chain under uncertainties. Marvin et al. (2012) conducted Monte Carlo simulation to design a 1st generation bioethanol supply chain under price uncertainties. Awudu and Zhang (2012) develop a stochastic production planning model for corn based bioethanol plants under bioethanol demand and price uncertainties. Osmani and Zhang (2013) develop a stochastic MILP model to design a 2nd generation bioethanol supply chain. They include biomass yield, biomass purchase price, bioethanol demand, and bioethanol price 
uncertainties. Chen and Fan (2011) develop a mixed integer stochastic programming model under demand and supply uncertainties. Dal-Mas designed a 1st generation bioethanol supply chain under corn price and bioethanol selling price uncertainties.

While a number of studies have been conducted to improve economic or environmental benefits for one type of bioethanol supply chain (either 1st generation or 2nd generation) under uncertainties, none of the up-to-date literature has considered designing an HGBSC that accounts for economic, environmental and social aspects under uncertainties. Therefore, this paper proposes a SMILP model to design an optimal HGBSC that accounts for 1) economic, 2) environmental, and 3) social aspects of sustainability under various uncertainties.

\subsection{Problem statement}

This paper focuses on designing an optimal HGBSC that considers economic, environmental and social aspects under various uncertainties. The economic aspect of sustainability refers to the profit of the HGBSC. The environmental aspect of sustainability refers to the GHG emission. The social aspect refers to the amount of irrigation land used for cultivating biomass. It should be noted that production of higher amounts of 1st generation bioethanol will result in social issues such as food versus fuel debate and higher prices for food-based biomass, such as corn, sugar and soybean.

Since the amount of irrigation land used depends on the amount of 1st generation bioethanol produced, the policy makers have found that irrigation land can be easily controlled by restricting the production amount of 1st generation bioethanol. Therefore, in this study, the social aspect is also measured by the amount of 1 st generation bioethanol produced. Figure 26 presents the major logistic activities that take place in both $1^{\text {st }}$ and $2^{\text {nd }}$ generation bioethanol supply chain. Firstly, biomass is cultivated at the biomass cultivation sites. Secondly, biomass is harvested and 
store in collection centers. Then biomass will be transported to the bioethanol conversion plants where biomass is converted to bioethanol. Finally, the converted bioethanol is transported to the bioethanol consumption zones.

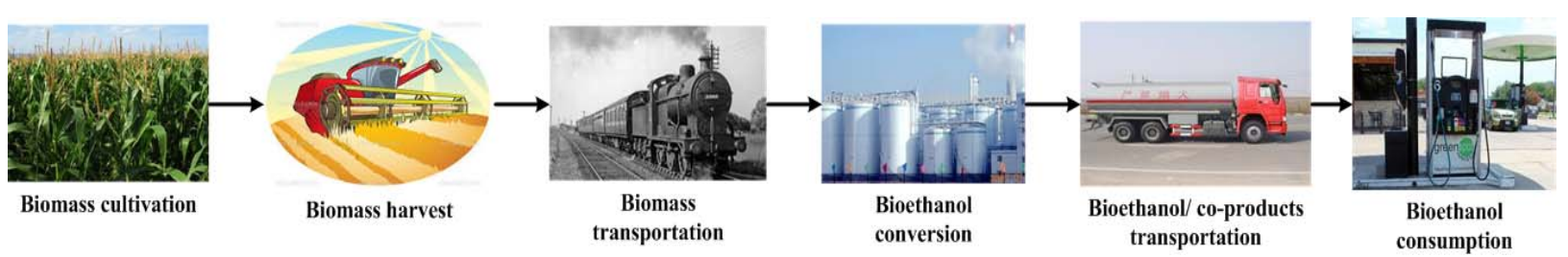

Figure 26. Major logistic activities in any bioethanol supply chain

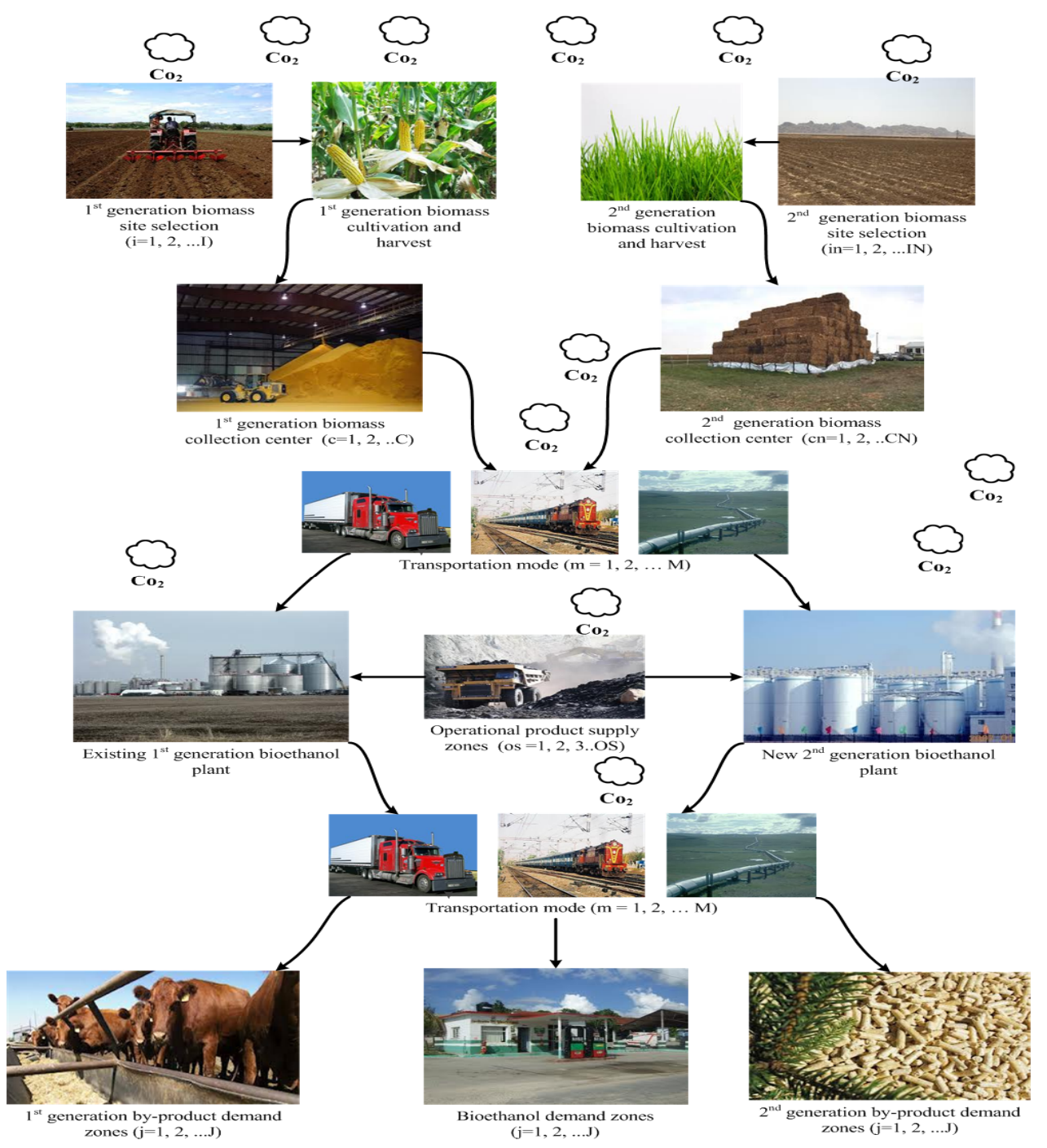

Figure 27. Structure of the HGBSC 
Figure 27 presents the structure of the HGBSC. Let $i$ be the index for $1^{\text {st }}$ generation biomass cultivation sites where type $b$ of $1^{\text {st }}$ generation biomass is cultivated. Let in be the index for $2^{\text {nd }}$ generation biomass cultivation sites where type $b n$ of $2^{\text {nd }}$ generation biomass is cultivated. Let $C$ be the index for $1^{\text {st }}$ generation biomass collection centers and $C n$ be the index for $2^{\text {nd }}$ generation biomass collection centers. Let $r$ be the index for existing $1^{\text {st }}$ generation bioethanol plants. These existing $1^{\text {st }}$ generation plants can: 1) operate with same capacity; 2) operate with expanded capacity; or 3 ) be closed. Let $r n$ be the index for the $2^{\text {nd }}$ generation bioethanol plants. Any opened new plant should operate with $2^{\text {nd }}$ generation biomass. Let $e$ be the index for $1^{\text {st }}$ generation bioethanol and $k$ be the index for corresponding by-products. Let $e n$ be the index for the $2^{\text {nd }}$ generation bioethanol and $k n$ be the index for corresponding by-products. The bioethanol and the by-products are shipped to the demand zone $j$ by using the transportation mode $m$. The transportation modes considered in this study are truck, train and pipelines. Let $O S$ be the index for the operational product supply zones from where operational products $O$ such as electricity and fossil fuels can be procured. Let $t$ be the index for time period. Let $S$ be the number of uncertain scenarios. Three uncertainties are included in this study. They include: 1) bioethanol demand, 2) bioethanol price, and 3) biomass yield. Each uncertainty has three levels: 1) low level, 2) average level and 3) high level. Given such a structure, the objective is to determine optimal HGBSC whose profit is maximized under GHG emission and $1^{\text {st }}$ generation bioethanol production restrictions. The optimal decisions of HGBSC include: 1) whether the existing $1^{\text {st }}$ generation bioethanol plants should operate with the same capacity, expand its capacity or should be closed; 2) optimal locations and capacity for new $2^{\text {nd }}$ generation bioethanol plants; 3 ) optimal collection center locations for both $1^{\text {st }}$ generation and $2^{\text {nd }}$ generation biomass; 4) optimal biomass that should be used and their 
cultivation locations; and 5) optimal transportation modes for biomass and bioethanol, respectively.

\subsection{Proposed methodology}

A SMILP is proposed to design an optimal HGBSC that account for economic, environmental and social aspects of sustainability under various uncertainties. This section presents the mathematical formulation of the proposed SMILP.

\subsubsection{Mathematical formulation}

\subsubsection{Notations}

Indices/Sets

$i \quad$ Index for $1^{\text {st }}$ generation biomass supply zones $(i=1,2,3 \ldots \mathrm{I})$

in Index for $2^{\text {nd }}$ generation biomass supply zones (in $\left.=1,2,3 \ldots \mathrm{IN}\right)$

$i^{\prime} \quad$ Index for supply zones

$c \quad$ Index for $1^{\text {st }}$ generation biomass collection zones $(c=1,2,3 \ldots \mathrm{C})$

cn Index for new $2^{\text {nd }}$ generation collection center zones $(c n=1,2,3 \ldots \mathrm{CN})$

$c^{\prime} \quad$ Index for collection center

$r \quad$ Index for existing $1^{\text {st }}$ generation bioethanol production zones $(r=1,2,3 \ldots \mathrm{R})$

$r n \quad$ Index for new $2^{\text {nd }}$ generation bioethanol production zones $(r n=1,2,3 \ldots \mathrm{RN})$

$r^{\prime} \quad$ Index for bioethanol production zones

$j \quad$ Index for bioethanol demand zones $(j=1,2,3 \ldots \mathrm{J})$

os $\quad$ Index for operational products supply zones $(o s=1,2,3 \ldots \mathrm{OS})$

Index for operational products $(o=1,2,3 \ldots \mathrm{O})$

$t \quad$ Index for Time period $(t=1,2,3 \ldots \mathrm{T})$ 

$e \quad$ Index for $1^{\text {st }}$ generation bioethanol $(e=1,2,3 \ldots \mathrm{E})$
en Index for $2^{\text {nd }}$ generation bioethanol $($ en $=1,2,3 \ldots \mathrm{EN})$
$k \quad$ Index for by-products produced from $1^{\text {st }}$ generation bioethanol production $(k=1$, $2,3 \ldots \mathrm{K})$
$k n \quad$ Index for by-products produced from $2^{\text {nd }}$ generation bioethanol production $(k n=1$, $2,3 \ldots \mathrm{KN})$
$b \quad$ Index for $1^{\text {st }}$ generation biomass $(b=1,2,3 \ldots \mathrm{B})$
bn Index for $2^{\text {nd }}$ generation biomass $(b n=1,2,3 \ldots \mathrm{BN})$
$m \quad$ Index for transportation mode $(m=1,2,3 \ldots \mathrm{M})$
$\xi \quad$ Index for scenario $(\xi=1,2,3 \ldots \mathrm{S})$
$g \quad$ Index for products
$G^{\prime} \quad$ Index for end products $\left\{G^{\prime} \in e \cup e n \cup k \cup k n\right\}$
$G^{\prime \prime} \quad$ Index for end products and biomass $\left\{G^{\prime} \in e \cup e n \cup k \cup k n \cup b \cup b n\right\}$

Parameters

$p_{g t \xi}^{j} \quad$ The price of selling end products $g$ at demand location $j$ in time period $t$ under scenario $\xi$

$\bar{C}_{g}^{r^{\prime j m}} \quad$ The fixed cost of shipping end products $g$ from bioethanol production plant $r^{\prime}$ to demand zone $j$ by transportation mode $m$

$c_{g t}^{r^{\prime j m}} \quad$ The variable cost of shipping end products $g$ from bioethanol production plant $r^{\prime}$ to demand zone $j$ by transportation mode $m$ in time period $t$ 
$\bar{c}_{g}^{c^{\prime} m} \quad$ The fixed cost of shipping biomass $g$ from collection center $c^{\prime}$ to bioethanol production plant $r^{\prime}$ by transportation mode $m$

$c_{g t}^{c^{\prime} m} \quad$ The variable cost of shipping biomass $g$ from collection center $c^{\prime}$ to bioethanol production plant $r^{\prime}$ by transportation mode $m$ in time period $t$

$\mathrm{CO}_{g}^{r^{\prime}} \quad$ The cost of operating bioethanol plant $r^{\prime}$ based on amount of bioethanol $g$ produced

$c e_{g}^{r^{\prime}} \quad$ The cost of expanding bioethanol plant $r^{\prime}$ based on amount of bioethanol $g$ produced

$c c_{g}^{r^{\prime}} \quad$ The cost of closing bioethanol plant $r^{\prime}$ based on amount of bioethanol $g$ produced

$c n^{r^{\prime}} \quad$ The cost of opening new $2^{\text {nd }}$ generation bioethanol plant $r^{\prime}$

$c n^{c^{\prime}} \quad$ The cost of opening a new collection center $c^{\prime}$

$c s_{g t}^{c^{\prime}} \quad$ The cost of storing biomass $g$ at the collection center $c^{\prime}$ in time period $t$

$h c_{g t}^{r^{\prime}} \quad$ The inventory holding cost of products $g$ at bioethanol plant in time period $t$

$b c_{g t}^{r^{\prime}} \quad$ The inventory backorder cost of products $g$ at bioethanol plant in time period $t$

$p c_{g t}^{r^{\prime}} \quad$ The cost of producing end products $g$ at bioethanol plant $r^{\prime}$ in time period $t$

$r c_{g}^{i^{\prime}} \quad$ The cost of renting land at supply zone $i^{\prime}$ for product $g$

$c v t_{g}^{i^{\prime}} \quad$ The cost of cultivating product $g$ at supply zone $i^{\prime}$

$c_{g t}^{i^{\prime} c^{\prime}} \quad$ The cost of harvesting or collecting product $g$ by collection center $c^{\prime}$ from supply zone $i^{\prime}$ in time period $t$ 
$o c_{g t}^{o s r^{\prime}} \quad$ The cost of purchasing operational product $g$ from the operational product supply zone OSby bioethanol plant $r^{\prime}$ in time period $t$

$S C_{g t}^{i} \quad$ The shortage cost of product $g$ at demand zone $j$ in time period $t$

$\tau_{g}^{m} \quad$ The maximum allowable shipping capacity of product $g$ in transportation mode $m$

$\varphi_{g}^{r^{\prime}} \quad$ Current capacity of product $g$ of the existing $1^{\text {st }}$ generation bioethanol plant $r^{\prime}$

$\varphi e_{g}^{r^{\prime}} \quad$ Maximum allowable expansion capacity of product $g$ at plant $r^{\prime}$

$\varphi n_{g}^{r^{\prime}} \quad$ Maximum allowable capacity for end product $g$ at new $2^{\text {nd }}$ generation bioethanol plant $r^{\prime}$

$\varphi_{g}^{c^{\prime}} \quad$ Maximum allowable capacity for end product $g$ at collection center $c^{\prime}$

$\bar{\varphi}_{g}^{c^{\prime}} \quad$ Minimum allowable purchase for existing $1^{\text {st }}$ generation biomass $g$ at collection center $c^{\prime}$

$\operatorname{zmin}_{g}^{r^{\prime}} \quad$ Minimum allowable production at the existing $1^{\text {st }}$ generation biomass $g$ bioethanol plant $r^{\prime}$

ipCap $p_{g t}^{r^{\prime}} \quad$ Maximum allowable inventory capacity for product $g$ at bioethanol plant $r^{\prime}$ in time period $t$

$i b C a p_{g t}^{r^{\prime}} \quad$ Maximum allowable inventory capacity for product $g$ at bioethanol plant $r^{\prime}$ in time period $t$

WCap $p_{g t \xi}^{o s} \quad$ The maximum allowable supply capacity of product $g$ by operational product supplier $O S$ in time period $t$ under scenario $\xi$

$\eta \quad$ Conversion rate 
$\beta_{g t \xi}^{i^{\prime}} \quad$ Total yield of biomass $g$ at location $i^{\prime}$ in time period $t$ under scenario $\xi$

$\delta_{g}^{i^{\prime}} \quad$ Yield rate of biomass $g$ at location $i^{\prime}$

$B_{g}^{i^{\prime}} \quad$ Maximum allowable land for growing biomass $g$ at supply zone $i^{\prime}$

$\vartheta_{\xi} \quad$ Probability of occurrence of scenario $\xi$

$d_{g t \xi}^{j} \quad$ Demand for product $g$ at demand zone $j$ in time $t$ under scenario $\xi$

$g t_{t} \quad$ Total amount of GHG emitted for entire supply chain in time period $t$ under scenario $\xi$

$g_{g t}^{r^{\prime} j m} \quad$ The amount of GHG emitted while shipping end products $g$ from bioethanol plant $r^{\prime}$ to demand zone $j$ by using transportation mode $m$ in time period $t$

$g_{g t}^{r^{\prime}} \quad$ The amount of GHG emitted while producing end products $g$ at bioethanol plant $r^{\prime}$ in time period $t$

$g_{g t}^{c^{\prime} r^{\prime} m} \quad$ The amount of GHG emitted while shipping biomass $g$ from collection center $c^{\prime}$ to bioethanol plant $r^{\prime}$ by using transportation mode $m$ in time period $t$ $g_{g t}^{i^{\prime} c^{\prime}} \quad$ The amount of GHG emitted while harvesting biomass $g$ at location $i^{\prime}$ by collection center $c^{\prime}$ in time period $t$

$g_{g}^{i^{\prime}} \quad$ The amount GHG emitted while cultivating biomass $g$ at supply zone $i^{\prime}$

GP $\quad$ The amount of GHG emissions permitted in time period $t$

a Maximum allowable production of $1^{\text {st }}$ generation bioethanol in percentage 
Decision Variables

Unrestricted Variables

Z Profit

Binary or Discrete Variables

$t_{g}^{r^{\prime} j m}\left\{1\right.$, if product $g$ is shipped from $r^{\prime}$ to $j$ by transportation mode $m$; else 0$\}$

$t_{g}^{c^{\prime} r^{\prime} m} \quad\left\{1\right.$, if product $g$ is shipped from $c^{\prime}$ to $r^{\prime}$ by transportation mode $m$; else 0$\}$

$v_{\text {open }}^{r^{\prime}} \quad\left\{1\right.$, if existing $1^{\text {st }}$ generation bioethanol plant is open; else 0$\}$

$v_{\text {close }}^{r^{\prime}} \quad\left\{1\right.$, if existing $1^{\text {st }}$ generation bioethanol plant is open; else 0$\}$

$v_{\text {new }}^{r^{\prime}} \quad\left\{1\right.$, if new $2^{\text {nd }}$ generation bioethanol plant is open; else 0$\}$

$v^{c^{\prime}} \quad\{1$, if biomass collection is opened; else 0$\}$

Positive Variables

$s_{g t \xi}^{j} \quad$ The amount of end products $g$ sold at demand zone $j$ in time period $t$ under scenario $\xi$

$S L_{g t \xi}^{j} \quad$ The amount of demand for product $g$ not met at demand zone $j$ in time period $t$ under scenario $\xi$

$s_{g t \xi}^{r^{\prime}} \quad$ Total amount of product $g$ sold by bioethanol plant $r^{\prime}$ in time period $t$ under scenario $\xi$

$s_{g t \xi}^{r^{\prime j m}} \quad$ The amount of end products $g$ shipped from bioethanol plant $r^{\prime}$ to demand zone $j$ by transportation mode $m$ in time period $t$ under scenario $\xi$ 
$z_{g t \xi}^{r^{\prime}} \quad$ The amount of end products $g$ produced at bioethanol plant $r^{\prime}$ in time period $t$ under scenario $\xi$

$\bar{z}_{g t \xi}^{r^{\prime}} \quad$ Designed capacity of end products $g$ at bioethanol plant $r^{\prime}$ in time period $t$ under scenario $\xi$

$x_{g t \xi}^{r^{\prime}} \quad$ The amount of biomass $g$ used at bioethanol plant $r^{\prime}$ in time period $t$ under scenario $\xi$

$x p_{g t \xi}^{r^{\prime}} \quad$ The amount of biomass $g$ purchased at bioethanol plant $r^{\prime}$ in time period $t$ under scenario $\xi$

$x p_{g t \xi}^{c^{\prime} r^{\prime} m} \quad$ The amount of biomass $g$ shipped from collection center $c^{\prime}$ to $r^{\prime}$ in time period $t$ under scenario $\xi$

$x c_{g t \xi}^{\prime} \quad$ The amount of biomass $g$ collected or sold by collection center $c^{\prime}$ in time period $t$ under the scenario $\xi$

$x c_{g \xi^{\xi}}^{i^{\prime} c^{\prime}} \quad$ The amount of biomass $g$ shipped from biomass supply zone $i^{\prime}$ to the collection center $c^{\prime}$ in time period $t$ under the scenario $\xi$

$i p_{g t \xi}^{r^{\prime}} \quad$ Inventory holding cost when end products $g$ at bioethanol plant $r^{\prime}$ in time period $t$ under scenario $\xi$

$i b_{g t \xi}^{r^{\prime}} \quad$ Inventory backorder cost when end products $g$ at bioethanol plant $r^{\prime}$ in time period $t$ under scenario $\xi$

$\beta_{g t \xi}^{i^{\prime}} \quad$ The yield of biomass $g$ at location $i^{\prime}$ in time period $t$ under the scenario $\xi$

$y_{g t \xi}^{i^{\prime}} \quad$ Amount of land used for biomass $g$ at location $i^{\prime}$ in time period $t$ under scenario $\xi$ 
$w_{g t \xi}^{r^{\prime}} \quad$ The amount of operational product $g$ used at bioethanol plant $r^{\prime}$ in time period $t$ under scenario $\xi$

$w p_{g t \xi}^{r^{\prime}} \quad$ The amount of operational product $g$ purchased by bioethanol plant $r^{\prime}$ in time period $t$ under scenario $\xi$

$w p_{g t \xi}^{o s r^{\prime}} \quad$ The amount of operational product $g$ shipped from operational product supply zones $O S$ to bioethanol plants $r^{\prime}$ in time period $t$ under scenario $\xi$

$w s_{g t \xi}^{o s} \quad$ The total amount of operational product $g$ sold by operational product supply zone $O S$ in time period $t$ under scenario $\xi$

\subsubsection{Objective function}

Equation 4.1 shows the objective function which is to maximize the total expected profit of the bioethanol supply chain. The profit is obtained by subtracting the total supply chain costs from the total supply chain revenue obtained by selling the end products. The total supply chain cost is the sum of the capital costs (opening or expanding or closing cost), transportation costs, production costs, storage costs, cultivation costs and harvesting costs, shortage cost.

$$
\begin{aligned}
\text { Maximize } Z & =\sum_{j} \sum_{g \in G^{\prime}} \sum_{t} \sum_{\xi} \vartheta_{\xi} p_{g t \xi}^{j} s_{g t \xi}^{j} \\
& -\sum_{r^{\prime} \in r \cup r n} \sum_{j} \sum_{g \in G^{\prime}} \sum_{m} \bar{c}_{g}^{r^{\prime} j m} t_{g}^{r^{\prime j j m}}-\sum_{r^{\prime} \in r \cup r n} \sum_{j} \sum_{g \in G^{\prime}} \sum_{m} \sum_{t} \sum_{\xi} \vartheta_{\xi} c_{g t}^{r^{\prime} j m} s_{g t \xi}^{r^{\prime} j m} \\
& -\sum_{r^{\prime} \in r} \sum_{g \in e} c o_{g}^{r^{\prime}} \varphi_{g}^{r^{\prime}} v_{o p e n}^{r^{\prime}}-\sum_{r^{\prime} \in r} \sum_{g \in e} c e_{g}^{r^{\prime}} \bar{z}_{g t}^{r^{\prime}}+\sum_{r^{\prime} \in r} \sum_{g \in e} \sum_{t} c c_{g}^{r^{\prime}} \varphi_{g}^{r^{\prime}} v_{c l o s e}^{r^{\prime}} \\
& -\sum_{r^{\prime} \in r n} c n^{r^{\prime}} v_{n e w}^{r^{\prime}}-\sum_{r^{\prime} \in r n} \sum_{g \in e n} \sum_{t} c e_{g}^{r^{\prime}} \bar{z}_{g t}^{r^{\prime}} \\
& -\sum_{r^{\prime} \in r \cup r n} \sum_{g \in G^{\prime}} \sum_{t} \sum_{\xi} \vartheta_{\xi} p c_{g t}^{r^{\prime}} z_{g t \xi}^{r^{\prime}}
\end{aligned}
$$




$$
\begin{aligned}
& -\sum_{r^{\prime} \in r \cup r n} \sum_{g \in G^{\prime}} \sum_{t} \sum_{\xi} \vartheta_{\xi} h c_{g t}^{r^{\prime}} i p_{g t \xi}^{r^{\prime}}-\sum_{r^{\prime} \in r \cup r n} \sum_{g \in G^{\prime \prime}} \sum_{t} \sum_{\xi} \vartheta_{\xi} b c_{g t}^{r^{\prime}} b_{g t \xi}^{r^{r^{\prime}}} \\
& -\sum_{c^{\prime} \in c \cup c n} \sum_{r^{\prime} \in r \cup r n} \sum_{g \in b \cup b n} \sum_{m} \bar{c}_{g}^{c^{\prime} r^{\prime} m} t_{g}^{c^{r^{\prime} \prime} m}-\sum_{c^{\prime} \in c \cup c n} \sum_{r^{\prime} \in r \cup r n} \sum_{g \in b \cup b n} \sum_{m} \sum_{t} \sum_{\xi} \vartheta_{\xi} c_{g t}^{c^{\prime} r^{\prime} m} x p_{g t_{\xi}}^{c^{\prime} r^{\prime} m} \\
& -\sum_{c^{\prime} \in \subset \cup c n} c c^{c^{\prime}} v^{c^{\prime}}-\sum_{c^{\prime} \in \subset \cup c n} \sum_{g \in b \cup b n} \sum_{t} \sum_{\xi} \vartheta_{\xi} c s_{g t}^{c^{\prime}} x c_{g t \xi}^{c^{\prime}} \\
& -\sum_{i^{\prime} \in i \cup \text { in }} \sum_{g \in b \cup b n} \sum_{t} \sum_{\xi} r c_{g}^{i^{\prime}} y_{g t \xi}^{i^{\prime}}-\sum_{i^{\prime} \in i \cup i n} \sum_{g \in b \cup b n} \sum_{t} \sum_{\xi} \vartheta_{\xi} c v t_{g}^{i^{\prime}} y_{g t_{\xi}}^{i^{\prime}}-\sum_{i^{\prime} \in i \cup i n} \sum_{c^{\prime} \in c \cup c n} \sum_{t} \sum_{\xi} \vartheta_{\xi} c_{g t}^{i i^{\prime} c^{\prime}} x c_{g t^{\prime} \xi}^{i^{\prime} c^{\prime}} \\
& -\sum_{o s} \sum_{r^{\prime} \in r \cup r n} \sum_{g \in o} \sum_{t} \sum_{\xi} \vartheta_{\xi} O c_{g t}^{o s r^{\prime}} w p_{g t_{\xi}}^{o s r^{\prime}} \\
& -\sum_{j} \sum_{g \in G^{\prime}} \sum_{t} \sum_{\xi} \vartheta_{\xi} S C_{g t}^{j} S L_{g t \xi}^{j}
\end{aligned}
$$

\subsubsection{Subject to}

The estimated amount of GHG emitted during any time period over all the scenarios is given by Equation 4.2. The total amount of GHG emitted is the sum of the GHG emitted while transporting raw materials and products, GHG emitted while producing bioethanol (at bioethanol plant) and GHG emitted while producing biomass (at biomass cultivation sites).

$$
\begin{aligned}
& g t_{t}=\sum_{r^{\prime} \in r \cup r n} \sum_{j} \sum_{g \in G^{\prime}} \sum_{m} \sum_{\xi} \vartheta_{\xi} g_{g t}^{r^{\prime} j m} s_{g t t^{\prime}}^{r^{\prime} j m} \\
& +\sum_{r^{\prime} \in r \cup r n} \sum_{g \in G^{\prime}} \sum_{\xi} \vartheta_{\xi} g_{g t}^{r^{\prime}} z_{g t \xi}^{r^{\prime}} \\
& +\sum_{c^{\prime} \in c \cup c n} \sum_{r^{\prime} \in r \cup r n} \sum_{g \in b \cup b n} \sum_{m} \sum_{\xi} \vartheta_{\xi} g_{g t}^{c^{\prime} r^{\prime} m} x p_{g t_{\xi}}^{c^{\prime} r^{\prime} m} \\
& +\sum_{c^{\prime} \in \subset \cup c n} \sum_{r^{\prime} \in r \cup r n} \sum_{g \in b \cup b n} \sum_{m} \sum_{\xi} \vartheta_{\xi} g_{g t}^{c^{\prime} r^{\prime} m} x p_{g t^{\prime} \xi}^{c^{\prime} r^{\prime} m} \\
& +\sum_{i} \sum_{g \in b \cup b n} \sum_{\xi} \vartheta_{\xi} g_{g}^{i} \beta_{g t \xi}^{i} \\
& +\sum_{o s^{\prime} \in o s \cup o s n} \sum_{r^{\prime} \in r \cup r n} \sum_{g \in o \cup o n} \sum_{m} \vartheta_{\xi} g_{g t_{\xi}^{o r^{\prime}}}^{o r^{\prime}} w p_{g t_{\xi}}^{o r^{\prime} r^{\prime}} \forall t
\end{aligned}
$$


Equation 4.3 enforces GHG emissions to be less than the permit limit.

$g t \leq G P_{t} \forall t$

Equation 4.4 forces the amount of end products sold at each demand zone to be less or equal to the demand.

$S_{g t \xi}^{j}+S L_{g t \xi}^{j}=d_{g t \xi}^{j} \forall j, \forall g \in G^{\prime}, \forall t, \forall \xi$

Equation 4.5 and Equation 4.6 represent the total amount of end products shipped from all bioethanol plants should be equal to the total amount of end products obtained at demand zones.

$$
\begin{aligned}
& s_{g t \xi}^{j}=\sum_{r^{\prime} \in r \cup r n} \sum_{m} s_{g t \xi}^{r^{\prime} j m} \forall j, \forall g \in G^{\prime}, \forall t, \forall \xi \\
& s_{g t \xi}^{r^{\prime}}=\sum_{j} \sum_{m} s_{g t \xi}^{r^{\prime} j m} \forall r^{\prime} \in r \cup r n, \forall g \in G^{\prime}, \forall t, \forall \xi
\end{aligned}
$$

Equation 4.7, Equation 4.8 and Equation 4.9 enforce social restrictions. Equation 4.7 enforces a maximum of $a \%$ of demand should be fulfilled from $1^{\text {st }}$ generation bioethanol. Equation 4.8 enforces at least $(1-a) \%$ of demand should be fulfilled from $2^{\text {nd }}$ generation bioethanol. Equation 4.9 forces that the total demand satisfied should be obtained from the combination of $1^{\text {st }}$ generation and $2^{\text {nd }}$ generation bioethanol.

$$
\begin{aligned}
& \sum_{r^{\prime} \in r} \sum_{m} s_{g t \xi}^{r^{\prime} j m} \leq a \% \sum_{j} s_{g \in e \cup e n t \xi}^{j} \forall g \in e, \forall t, \forall \xi \\
& \sum_{r^{\prime} \in r n} \sum_{m} s_{g t \xi}^{r^{\prime} j m} \geq(1-a) \% \sum_{j} s_{g \in e \cup e n t \xi}^{j} \forall g \in e n, \forall t, \forall \xi \\
& \sum_{r^{\prime} \in r \cup r n} \sum_{m} s_{g t \xi}^{r^{\prime} j m}=\sum_{j} s_{g t \xi}^{j} \forall g \in e \cup e n, \forall t, \forall \xi
\end{aligned}
$$

Equation 4.10 indicates that the amount of end products shipped from bioethanol plants to the demand zones should be always less than the maximum allowable capacity of the carrier or transportation mode. 
$s_{g t \xi}^{r^{\prime} j m} \leq \tau_{g}^{m} t_{g}^{r^{\prime} j m} \forall r^{\prime} \in r \cup r n, \forall g \in G^{\prime}, \forall j, \forall m, \forall t, \forall \xi$

Equation 4.11, Equation 4.12 and Equation 4.13 are transportation mode constraints for both $1^{\text {st }}$ generation and $2^{\text {nd }}$ generation bioethanol plants. They indicate that transportation mode can only exist if the bioethanol plant is open. Otherwise, there should no transportation mode.

$$
\begin{aligned}
& \sum_{m} t_{g}^{r^{\prime} j m} \leq M v_{\text {open }}^{r^{\prime}} \forall r^{\prime} \in r, \forall g \in G^{\prime}, \forall j \\
& \sum_{m} t_{g}^{r^{\prime} j m} \leq M\left(1-v_{\text {close }}^{r^{\prime}}\right) \forall r^{\prime} \in r, \forall g \in G^{\prime}, \forall j \\
& \sum_{m} t_{g}^{r^{\prime} j m} \leq M v_{\text {new }}^{r^{\prime}} \forall r^{\prime} \in r n, g \in e \cup e n \cup k \cup k n, \forall j
\end{aligned}
$$

Equation 4.14 represents that the existing $1^{\text {st }}$ generation plant should be either kept open or closed, but not both

$$
v_{\text {open }}^{r^{\prime}}+v_{\text {close }}^{r^{\prime}}=1 \forall r^{\prime} \in r
$$

Equation 4.15 - Equation 4.18 and Equation 4.19 represent the production constraints for existing $1^{\text {st }}$ generation and new $2^{\text {nd }}$ generation bioethanol plants respectively. Equation 4.15 enforces production to be greater than the amount sold. Equation 4.16 forces production to be less than the maximum allowable where the maximum allowable capacity is less current capacity and the expanded capacity. Equation 4.17 forces minimum production if the existing $1^{\text {st }}$ generation plant is open. Equation 4.18 indicates that production cannot be done if the existing $1^{\text {st }}$ generation plant is closed. Equation 4.19 enforces production to be less than the maximum allowable capacity if the new $2^{\text {nd }}$ generation plant is opened.

$$
\begin{aligned}
& z_{g t \xi}^{r^{\prime}} \geq s_{g t \xi}^{r^{\prime}} \forall g \in G^{\prime}, \forall r^{\prime} \in r \cup r n, \forall t, \forall \xi \\
& z_{g t \xi}^{r^{\prime}} \leq \varphi_{g}^{r^{\prime}} v_{\text {open }}^{r^{\prime}}+\bar{z}_{g t}^{r^{\prime}} \quad \forall r^{\prime} \in r, g \in e, \forall t, \forall \xi
\end{aligned}
$$




$$
\begin{aligned}
& z_{g t \xi}^{r^{\prime}} \geq \mathrm{zmin}_{\mathrm{g}}^{\mathrm{r}^{\prime}} v_{o p e n}^{r^{\prime}} \forall r^{\prime} \in r, \forall g \in e, \forall t, \forall \xi \\
& z_{g t \xi}^{r^{\prime}} \leq \varphi_{g}^{r^{\prime}}\left(1-v_{\text {close }}^{r^{\prime}}\right)+\bar{z}_{g t}^{r^{\prime}} \forall r^{\prime} \in r, g \in e, \forall t, \forall \xi \\
& z_{g t \xi}^{r^{\prime}} \leq \varphi n_{g}^{r^{\prime}} v_{\text {new }}^{r^{\prime}} \forall r^{\prime} \in r n, \forall g \in e n, \forall t, \forall \xi
\end{aligned}
$$

Equation 4.20 and Equation 4.21 are expansion constraints. They suggest that expansion can only be done if the plant is open.

$$
\begin{aligned}
& \bar{z}_{g t}^{r^{\prime}} \leq \varphi e_{g}^{r^{\prime}} v_{o p e n}^{r^{\prime}} \forall r^{\prime} \in r, g \in e, \forall t \\
& \bar{z}_{g t}^{r^{\prime}} \leq \varphi e_{g}^{r^{\prime}}\left(1-v_{\text {close }}^{r^{\prime}}\right) \forall r^{\prime} \in r, g \in e, \forall t, \forall \xi
\end{aligned}
$$

Equation 4.22 represents that the amount of by-products produced depends on the final product (bioethanol) production and the conversion rate.

$$
z_{g \in k \cup k n t \xi}^{r^{\prime}}=\eta z_{g \in e \cup e n t \xi}^{r^{\prime}} \forall g \in k \cup k n, \forall r^{\prime} \in r \cup r n, \forall t, \forall \xi
$$

Equation 4.23 is a material balancing constraint where the amount of end products produced plus the inventory level should be equal to the end products sold plus the inventory carried to the next time period in any given time period under any scenario.

$$
z_{g t \xi}^{r^{\prime}}+i p_{g t-1 \xi}^{r^{\prime}}-i b_{g t-1 \xi}^{r^{\prime}}=s_{g t \xi}^{r^{\prime}}+i p_{g t \xi}^{r^{\prime}}-i b_{g t \xi}^{r^{\prime}} \quad \forall r^{\prime} \in r \cup r n, \forall g \in G^{\prime}, \forall t, \forall \xi
$$

Equation 4.24 - Equation 4.27 are inventory holding and backorder constraints for end products. They indicate that the inventory can be held or backordered if the existing $1^{\text {st }}$ generation bioethanol plants is open and the amount held or backordered should be less than the maximum allowable capacity.

$$
\begin{aligned}
& i p_{g t \xi}^{r^{\prime}} \leq i p \operatorname{Cap}_{g t}^{r^{\prime}} v_{o p e n}^{r^{\prime}} \forall r^{\prime} \in r, \forall g \in e \cup k, \forall t, \forall \xi \\
& i p_{g t \xi}^{r^{\prime}} \leq i p \operatorname{Cap}_{g t}^{r^{\prime}}\left(1-v_{\text {close }}^{r^{\prime}}\right) \forall r^{\prime} \in r, \forall g \in e \cup k, \forall t, \forall \xi \\
& i b_{g t \xi}^{r^{\prime}} \leq i b C a p_{g t}^{r^{\prime}} v_{o p e n}^{r^{\prime}} \forall r^{\prime} \in r, \forall g \in e \cup k, \forall t, \forall \xi
\end{aligned}
$$


$i b_{g t \xi}^{r^{\prime}} \leq i b C a p_{g t}^{\prime}\left(1-v_{c l o s e}^{r^{\prime}}\right) \forall r^{\prime} \in r, \forall g \in e \cup k, \forall t, \forall \xi$

Equation 4.28 and Equation 4.29 are inventory holding and backorder constraints for new $2^{\text {nd }}$ generation bioethanol plant. They indicate that inventory can be held or backordered if the plant is open and the amount held or backordered should be less than the maximum allowable capacity.

$$
\begin{aligned}
& i p_{g t \xi}^{r^{\prime}} \leq i p C a p_{g t}^{r^{\prime}} v_{n e w}^{r^{\prime}} \forall r^{\prime} \in r n, \forall g \in e n \cup k n, \forall t, \forall \xi \\
& i b_{g t \xi}^{r^{\prime}} \leq i b C a p_{g t}^{r^{\prime}} v_{n e w}^{r^{\prime}} \forall r^{\prime} \in r n, \forall g \in e n \cup k n, \forall t, \forall \xi
\end{aligned}
$$

Equation 4.30 and Equation 4.31 represents the conversion rates for both $1^{\text {st }}$ generation and $2^{\text {nd }}$ generation bioethanol. It indicates that the amount of end products produced depends on the amount of $2^{\text {nd }}$ generation biomass used.

$$
\begin{aligned}
& z_{g \in e \cup k t \xi}^{r^{\prime}}=\eta x_{g \in b t \xi}^{r^{\prime}} \forall r^{\prime} \in r, \forall g \in e \cup k, \forall t, \forall \xi \\
& z_{g \in e n \cup k n t \xi}^{r^{\prime}}=\eta x_{g \in b n t \xi}^{r^{\prime}} \forall r^{\prime} \in r n, \forall g \in e n \cup k n, \forall t, \forall \xi
\end{aligned}
$$

The amount of biomass purchased at any given bioethanol plant is greater than or equal to the amount of biomass used in any given time period under any given scenario. This is given by Equation 4.32.

$$
x p_{g t \xi}^{r^{\prime}} \geq x_{g t \xi}^{r^{\prime}} \forall r^{\prime} \in r \cup r n, \forall g \in b \cup b n, \forall t, \forall \xi
$$

Equation 4.33 is the biomass material balance where the amount purchased plus the inventory level should be equal to the amount used plus the inventory level transferred to the next time period.

$$
x p_{g t \xi}^{r^{\prime}}+i p_{g t-1 \xi}^{r^{\prime}}-i b_{g t-1 \xi}^{r^{\prime}}=x_{g t \xi}^{r^{\prime}}+i p_{g t \xi}^{r^{\prime}}-i b_{g t \xi}^{r^{\prime}} \forall r^{\prime} \in r \cup r n, \forall g \in b \cup b n, \forall t, \forall \xi
$$

Equation 4.34 - Equation 4.37 are biomass inventory holding and delay constraints for existing $1^{\text {st }}$ generation bioethanol plant. They indicate that inventory can only be held or delayed 
if the existing $1^{\text {st }}$ generation bioethanol plant is kept open. In addition, the amount of inventory held or delayed should be less than the maximum allowable capacity.

$$
\begin{aligned}
& i p_{g t \xi}^{r^{\prime}} \leq i p C a p_{g t}^{r^{\prime}} t_{o p e n}^{r^{\prime}} \forall r^{\prime} \in r, \forall g \in b, \forall t, \forall \xi \\
& i p_{g t \xi}^{r^{\prime}} \leq i p C a p_{g t}^{r^{\prime}}\left(1-v_{\text {close }}^{r^{\prime}}\right) \forall r^{\prime} \in r, \forall g \in b, \forall t, \forall \xi \\
& i b_{g t \xi}^{r^{\prime}} \leq i b C a p_{g t}^{r^{\prime}} v_{o p e n}^{r^{\prime}} \forall r^{\prime} \in r, \forall g \in b, \forall t, \forall \xi \\
& i b_{g t \xi}^{r^{\prime}} \leq i b C a p_{g t}^{r^{\prime}}\left(1-v_{\text {close }}^{r^{\prime}}\right) \forall r^{\prime} \in r, \forall g \in b, \forall t, \forall \xi
\end{aligned}
$$

Equation 4.38 and Equation 4.39 are the biomass inventory holding and delay constraints. They indicate the amount of biomass inventory held or delayed should be less than the maximum allowable.

$$
\begin{aligned}
& i p_{g t \xi}^{r^{\prime}} \leq i p C a p_{g t}^{r^{\prime}} v_{\text {new }}^{r^{\prime}} \forall r^{\prime} \in r n, \forall g \in b n, \forall t, \forall \xi \\
& i b_{g t \xi}^{r^{\prime}} \leq i b C a p_{g t}^{r^{\prime}} v_{n e w}^{r^{\prime}} \forall r^{\prime} \in r n, \forall g \in b n, \forall t, \forall \xi
\end{aligned}
$$

Equation 4.40 - Equation 4.42 represent that the total amount of biomass shipped from collection centers should be equal to the total amount of biomass obtained by bioethanol plants.

$$
\begin{aligned}
& x p_{g t \xi}^{r^{\prime}}=\sum_{c^{\prime} \in c} \sum_{m} x p_{g t \xi}^{c^{\prime} r^{\prime} m} \forall r^{\prime} \in r, g \in b, \forall t, \forall \xi \\
& x p_{g t \xi}^{r^{\prime}}=\sum_{c^{\prime} \in c n} \sum_{m} x p_{g t}^{c^{\prime} r^{\prime} m} \forall r^{\prime} \in r n, g \in b n, \forall t, \forall \xi \\
& x c_{g t \xi}^{c^{\prime}}=\sum_{r^{\prime} \in r} \sum_{m} x p_{g t \xi}^{c^{\prime} m} \forall c^{\prime} \in c \cup c n, \forall g \in b \cup b n, \forall t, \forall \xi
\end{aligned}
$$

Equation 4.43 - Equation 4.46 are the biomass transportation constraints. They indicate that the transportation mode exists if both the collection center and bioethanol plant $\left(1^{\text {st }}\right.$ and $2^{\text {nd }}$ generation) are open.

$$
\sum_{m} t_{g}^{c^{\prime} r^{\prime}} \leq M v_{o p e n}^{r^{\prime}} \forall r^{\prime} \in r, \forall g \in b, \forall c^{\prime}
$$




$$
\begin{aligned}
& \sum_{m} t_{g}^{c^{\prime} r^{\prime} m} \leq M\left(1-v_{\text {close }}^{r^{\prime}}\right) \forall r^{\prime} \in r, \forall g \in b, \forall c^{\prime} \\
& \sum_{m} t_{g}^{c^{\prime} r^{\prime} m} \leq M v_{\text {new }}^{r^{\prime}} \forall r^{\prime} \in r, \forall g \in b, \forall c^{\prime} \\
& \sum_{m} t_{g}^{c^{\prime} r^{\prime} m} \leq M v^{c^{\prime}} \forall c^{\prime} \in c \cup c n, \forall g \in b, \forall r^{\prime}
\end{aligned}
$$

Equation 4.47 - Equation 4.48 are collection center constraints. They indicates that the amount of biomass collected should be less than the maximum allowable.

$$
\begin{aligned}
& x c_{g t \xi}^{c^{\prime}} \leq \varphi_{g}^{c^{\prime}} v^{c^{\prime}} \forall c^{\prime} \in c \cup c n, \forall g \in b \cup b n, \forall t, \forall \xi \\
& x c_{g t \xi}^{c^{\prime}} \geq \bar{\varphi}_{g}^{c^{\prime}} v^{c^{\prime}} \forall c^{\prime} \in c \cup c n, \forall g \in b \cup b n, \forall t
\end{aligned}
$$

Equation 4.49 represents that the amount of biomass collected by collection center is equal to the sum of the biomass sold by the supply zones in any given time period under any given scenario.

$$
x c_{g t \xi}^{c^{\prime}}=\sum_{i^{\prime} \in i \cup i n} x c_{g t \xi}^{i^{\prime} c^{\prime}} \forall c^{\prime} \in c \cup c n, g \in b \cup b n, \forall t, \forall \xi
$$

Equation 4.50 forces the amount of biomass yielded is sold to the collection center in any given time period under any given scenario

$\beta_{g t \xi}^{i^{\prime}}=\sum_{c^{\prime} \in c \cup c n} x c_{g t \xi}^{i^{\prime} c^{\prime}} \forall i^{\prime} \in i \cup i n, g \in b \cup b n, \forall t, \forall \xi$

Equation 4.51 illustrates that the amount of biomass yielded depends on the yield rate and the amount of land used in any given time period under any given scenario.

$$
\beta_{g t \xi}^{i^{\prime}}=\delta_{g}^{i^{\prime}} y_{g t \xi}^{i^{\prime}} \forall i^{\prime} \in i \cup i n, \forall g \in b \cup b n, \forall t, \forall \xi
$$

Equation 4.52 represents that the amount of land used for biomass production should be less than the maximum allowable land at each supply zone in any given time period under any given scenario. 
$y_{g t \xi}^{i^{\prime}} \leq B_{g t}^{i^{\prime}} \forall i^{\prime} \in i \cup i n, \forall g \in b \cup b n, \forall t, \forall \xi$

Equation 4.53 represents that the amount of operational products used depends on the conversion rate and the amount of the final products in any given time period under any given scenario.

$w_{g t \xi}^{r^{\prime}}=\eta z_{g t \xi}^{r^{\prime}} \forall r^{\prime} \in r \cup r n, g \in O, \forall t, \forall \xi$

Equation 4.54 represents the amount of operational products purchased is equal to the amount of operational products used in any given time period under any given scenario.

$w p_{g t \xi}^{r^{\prime}}=w_{g t \xi}^{r^{\prime}} \forall r^{\prime} \in r \cup r n, \forall g \in O, \forall t, \forall \xi$

Equation 4.55 and Equation 4.56 are operational product constraints. They indicate that the total operational products purchased by bioethanol plant should be equal to the operational products sold by the operational product suppliers.

$$
\begin{aligned}
& w p_{g t \xi}^{r^{\prime}}=\sum_{o s} w p_{g t \xi}^{o s r^{\prime}} \forall r^{\prime} \in r \cup r n, \forall g \in O, \forall t, \forall \xi \\
& w s_{g t \xi}^{o s}=\sum_{r^{\prime} \in r \cup r n} w p_{g t \xi}^{o s r^{\prime}} \forall o s, \forall g \in O, \forall t, \forall \xi
\end{aligned}
$$

Equation 4.57 represents that the amount of operational products sold by operational product supplier should be less than maximum capacity in any given time period under any given scenario.

$$
w s_{g t \xi}^{o s} \leq W C a p_{g t \xi}^{o s} \forall o s, \forall g \in O, \forall t, \forall \xi
$$

\subsection{Case study}

In order to illustrate the effectiveness of the proposed model, this section discusses a HGBSC case in the state of ND in the US. Figure 28 shows the current configuration of bioethanol supply chain in ND State. It indicates the locations of six existing $1^{\text {st }}$ generation bioethanol plants 
(Ethanol Facilities capacity by state and plant, 2012), eight coal mines (North Dakota 100K coal map) and four power plants (powerplantjobs.com). Since coal and electricity are necessary input resources for the production of bioethanol, most of the existing $1^{\text {st }}$ generation bioethanol plants are located near the coal mines and/or power plants. These $1^{\text {st }}$ generation bioethanol plants use corn as input biomass. The end products of the existing $1^{\text {st }}$ generation bioethanol plants are bioethanol and distillers dried grains (DDG). For the existing $1^{\text {st }}$ generation bioethanol plants, three strategic decisions are considered: 1) operating with existing capacity, 2) expanding the capacity or 3) closing. Table 13 presents the current capacities and maximum expansion capacities for the existing $1^{\text {st }}$ generation bioethanol plants. It is assumed that the existing $1^{\text {st }}$ generation bioethanol plant can only be expanded by $25 \%$ of its existing capacity.

The potential biomass inputs for a new $2^{\text {nd }}$ generation bioethanol plants are assumed to be switchgrass and corn stover. According to Zhang et al. (2012) ND's environmental and soil conditions are highly suitable for cultivating switchgrass and hence switchgrass is considered as one of the potential $2^{\text {nd }}$ generation biomass. In addition, since ND has high corn yield (Crops: Corn for grain, 2011), corn stover is considered as the other type of potential $2^{\text {nd }}$ generation biomass. The end products of the new $2^{\text {nd }}$ generation bioethanol plants are bioethanol and lignin pallets. It is assumed that any new plant will only operate with $2^{\text {nd }}$ generation biomass.

Nine agricultural districts are considered as the potential supply or cultivation zones for both $1^{\text {st }}$ generation and $2^{\text {nd }}$ generation biomass. These districts include North West (NW), North Central (NC), North East (NE), West Central (WC), Central (C), East Central (EC), South West (SW), South Central (SC), and South East (SE). The potential zones for collection centers, new $2^{\text {nd }}$ generation plants and demand zones (for both bioethanol and by-products) are assumed to be in the largest city in each specified agricultural district. The maximum capacity of $2^{\text {nd }}$ generation 
bioethanol plant is assumed to be 150 Million Gallon per Year (MMGY). The maximum inventory holding, backorder and/or delay capacity at each of the bioethanol plants for all the products is assumed to be 60 days.

The transportation modes considered in this study are: 1) truck, 2) train and 3) pipeline. Bioethanol can be shipped through all the three transportation modes. Both DDG and lignin pallets (by-products) are assumed to be sold locally and hence truck is considered as the primary transportation mode. The basic transportation mode for corn is truck and train. Switchgrass and corn stover can be transported through truck, train and pipeline.

The study is conducted for one year with three uncertainties. The uncertainties include: 1) demand 2) bioethanol price and 3) biomass yield (that includes corn, corn stover and switchgrass). The scenarios for each uncertainty are discretized with three levels. These levels are low level (LL), average level (AL) and high level (HL) and therefore adding to 27 total uncertain scenarios. The probability of occurrence of each scenario is assumed to be equally likely. The demand considered is $100 \%$ gasoline equivalent in ND. Tables A.5 -A.9 of Appendix present the input parameters used in this study. 


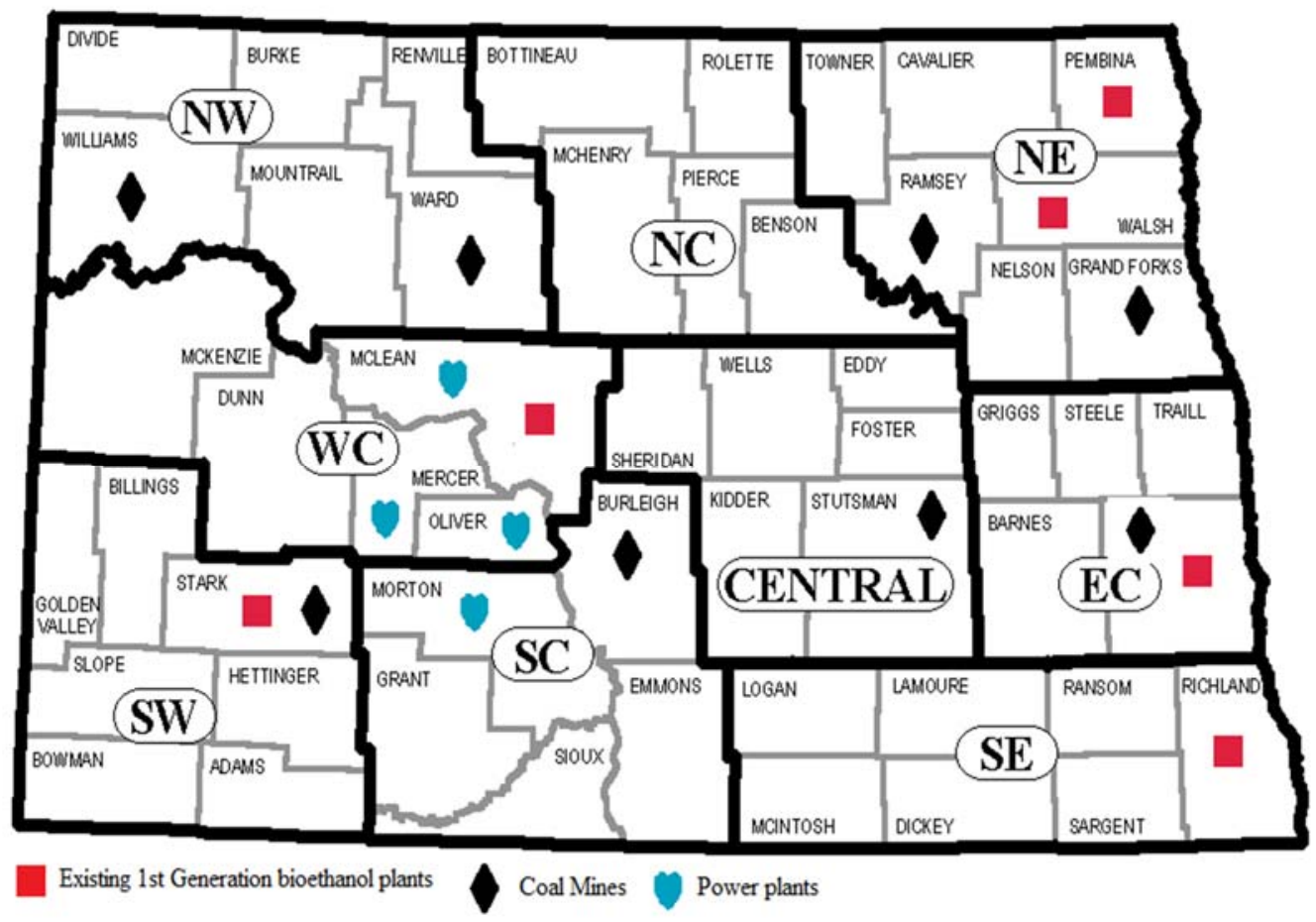

Figure 28. Current configuration of the bioethanol supply chain in ND State

Table 13. Initial and expansion capacities for existing 1st generation bioethanol plants *source: (Ethanol Facilities capacity by state and plant, 2012)

\begin{tabular}{llll}
\hline Plant & $\begin{array}{l}\text { Biomass input } \\
\text { type }\end{array}$ & $\begin{array}{l}\text { current } \\
\text { capacity } \\
\text { (MMGY) }\end{array}$ & $\begin{array}{l}\text { Maximum } \\
\text { expansion } \\
\text { capacity } \\
\text { (MMGY) }\end{array}$ \\
\hline North East (Pembina) & Corn & 28 & 7 \\
North East (Walsh) & Corn & 10 & 2.5 \\
West Central & Corn & 50 & 12.5 \\
East Central & Corn & 150 & 37.5 \\
South West & Corn & 50 & 12.5 \\
South East & Corn & 110 & 27.5 \\
\hline
\end{tabular}

\subsection{Results}

The proposed SMILP model is coded in GAMS and solved with Coin-or Branch and Cut (CBC) solver. The model consists of 56,687 continuous variables and 39 integer variables. Various standards have been studied in order to understand their impact on the optimal design of HGBSC. Table 14 presents the standards considered in this study. 
It should be noted that GHG permit limit is difficult to estimate for the bioethanol supply chain since there is insufficient available literature that estimates the GHG permit for a particular supply chain. Therefore, in order to obtain the permit level, the model is solved without any restrictions (current conditions). This study considered no GHG restrictions and 100\% bioethanol from corn. The GHG emissions obtained are 2.665 million tons. This is assumed as year 2010 level. Since, BES (Table 2) regulates GHG emission to be reduced 30\% below 1990 level, it is necessary to obtain GHG emissions for year 1990. According to U.S. Greenhouse Gas Inventory Report, 2013, the US has reported an increase in GHG emission by $10.5 \%$ in 2010 compared to 1990 level. Therefore, the $1990 \mathrm{GHG}$ emission level is 2.412 million tons $(110.5 \% * 2.412=2.665)$ and $30 \%$ below 1990 level is 1.688 million tons $(70 \% * 2.412=1.668)$.

Table 14. Standards considered in the study *In all the cases, GHG emission cost is incurred

\begin{tabular}{ll}
\hline Standard & Description \\
\hline Renewable Fuel Standard (RFS) & $\begin{array}{l}\text { RFS requires that at least 55\% of the bioethanol demand } \\
\text { should be met from 2 2 }\end{array}$ \\
Base Emissions Standard (BES) & $\begin{array}{l}\text { BES requires the reduction in GHG emissions by 30\% } \\
\text { compared to 1990 level (Romm, 2009) is enforced. } \\
\text { CS requires that the HGBSC meets both standards of RFS }\end{array}$ \\
Combined standard (CS) & $\begin{array}{l}\text { and BES } \\
\text { A2GS requires that all the bioethanol demand is met with }\end{array}$ \\
$\begin{array}{l}\text { All 2 } 2^{\text {nd }} \text { generation Standard } \\
\text { (A2GS) }\end{array}$ & $2^{\text {nd }}$ generation bioethanol. \\
\hline
\end{tabular}

Table 15 presents the economic, environmental and social performance of the optimal HGBSC under different standards. Figure 29, Figure 30 and Figure 31 graphically interpret the results. They indicate:

1) The economic, environmental and social performance of HGBSC depends on the standard applied. This implies that the configurations of optimal HGBSC change when different standards are applied. 
2) BES and CS have the same sustainability performance. This indicates that when a portfolio of standards (RFS and BES) is applied to the design of optimal HGBSC, the optimal decisions and performance of HGBSC will be determined by the stricter standard (BES).

3) RFS performs best in improving economic performance, but the GHG emissions are above the permit limit. This indicates that RFS standard should not be applied alone if higher environmental benefit is expected.

4) A2GS performs best in reducing the GHG emissions and irrigation land usage. However, the profit is reduced significantly. This implies that under current $2^{\text {nd }}$ generation bioethanol production technologies, it is not economically beneficial to switch all the bioethanol production to $2^{\text {nd }}$ generation.

5) Economic performance is indirectly proportional to the environmental and social performance. This implies that HGBSC with higher profits will generate higher GHG emissions and use larger amount of irrigation land.

6) GHG emissions and social performance can be improved by producing higher quantities of $2^{\text {nd }}$ generation. $1^{\text {st }}$ generation performs best in improving economic benefits. Therefore, HGBSC provides a balance among the sustainability aspects.

7) The amount of irrigation land used is directly proportional to the $1^{\text {st }}$ generation bioethanol production and the amount of marginal land used is directly proportional to the amount of $2^{\text {nd }}$ generation bioethanol produced. Therefore, irrigation land can be controlled by $1^{\text {st }}$ generation production and marginal land use can be controlled by $2^{\text {nd }}$ generation bioethanol production. 
Table 15. Sustainability aspects under standards * GHG permit limit considered is 1.688 million Tons

\begin{tabular}{|c|c|c|c|c|}
\hline \multirow[t]{2}{*}{ Standard } & Economic & Environmental & \multicolumn{2}{|l|}{ Social } \\
\hline & $\begin{array}{l}\text { Profit } \\
\text { (Billion \$) }\end{array}$ & $\begin{array}{c}\text { GHG } \\
\text { emissions } \\
\text { (Million Tons) } \\
\end{array}$ & $\begin{array}{c}\text { Bioethanol produced (\%) } \\
\left(1^{\text {st }} \text { Generation, } 2^{\text {nd }}\right. \\
\text { Generation })\end{array}$ & $\begin{array}{l}\text { Land used } \\
\text { (Irrigated, } \\
\text { Marginal) }\end{array}$ \\
\hline RFS & $\$ 0.476$ & 2.059 & $(36.62,63.38)$ & $(37 \%, 33 \%)$ \\
\hline BES & $\$ 0.404$ & 1.623 & $(15.61,84.39)$ & $(16 \%, 43 \%)$ \\
\hline CS & $\$ 0.404$ & 1.623 & $(15.61,84.39)$ & $(16 \%, 43 \%)$ \\
\hline $\mathrm{A} 2 \mathrm{GS}$ & $\$ 0.327$ & 1.266 & $(0,100)$ & $(0 \%, 100 \%)$ \\
\hline
\end{tabular}

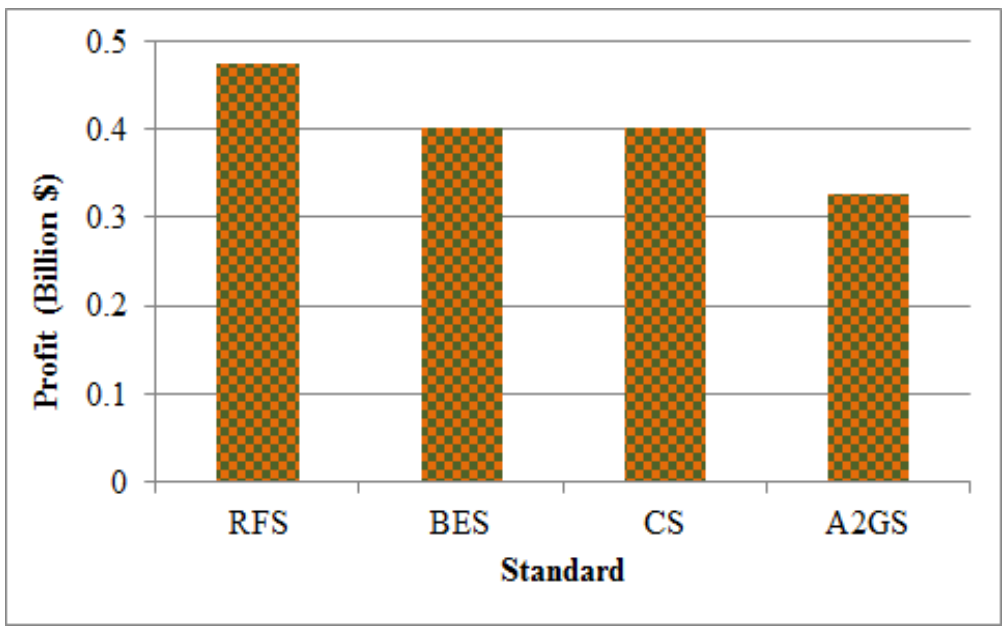

Figure 29. Economic aspect of HGBSC under different standards

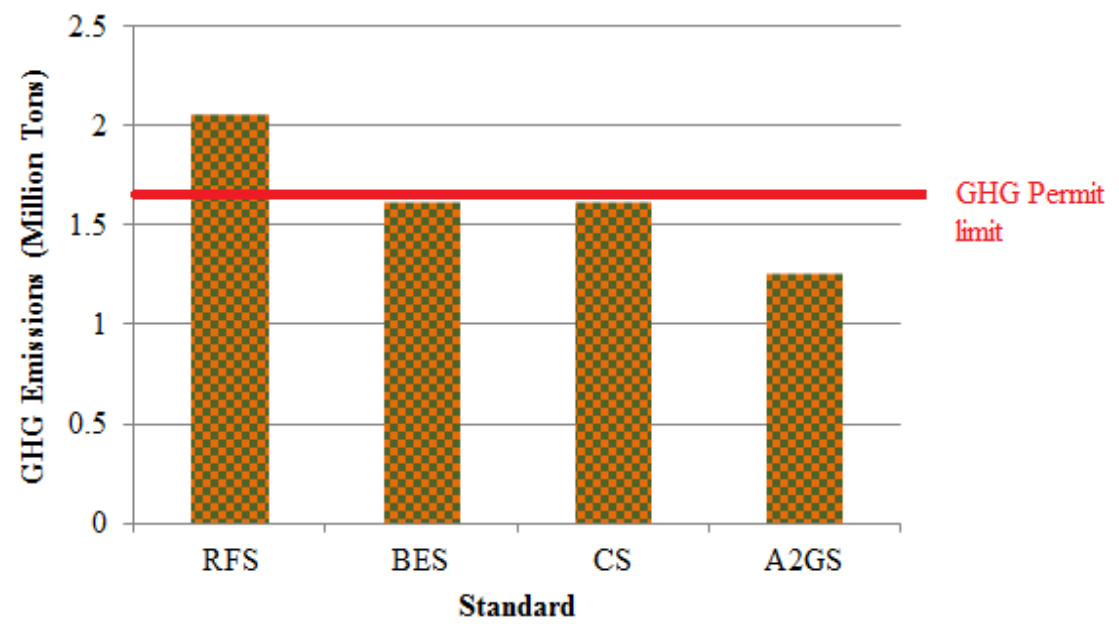

Figure 30. Environmental aspect of HGBSC under different standards 


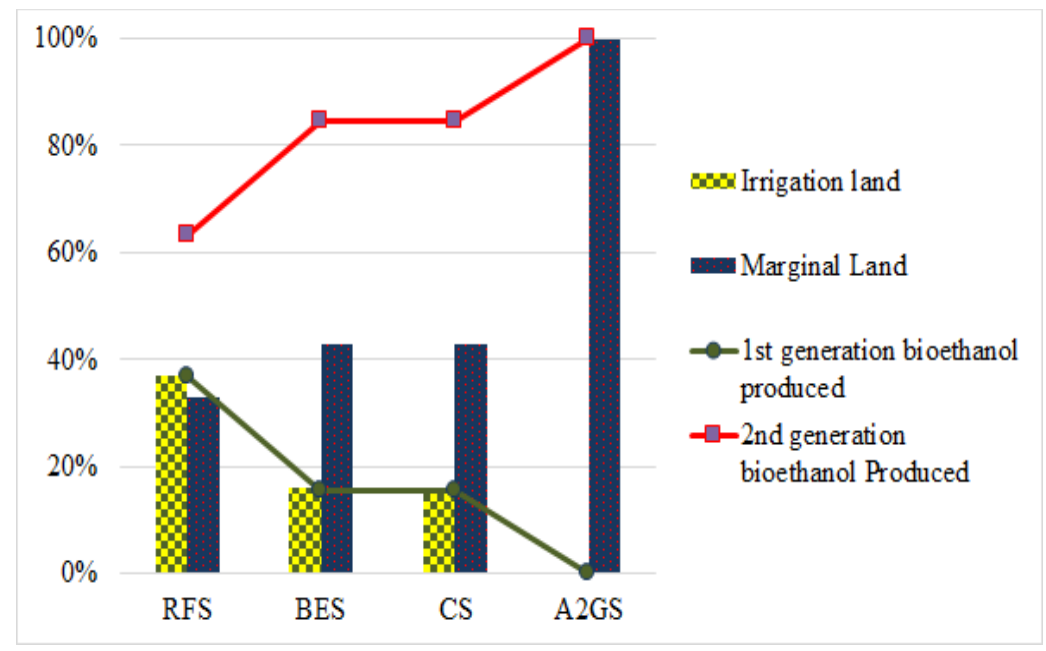

Figure 31. Percentage of irrigation and marginal land used

\subsubsection{Economic analysis under different standards}

This section analyzes the economic performance of HGBSC under different standards. The economic performance of $1^{\text {st }}$ generation and $2^{\text {nd }}$ generation bioethanol production are compared. It includes analysis of profit and costs under different standards.

\subsubsection{Bioethanol and co-product profit}

Figure 32 shows the profit generated by bioethanol and co-products (DDG, Lignin pallets) under each standard. It indicates that even though the profit from bioethanol remains the same under each standard, the profit from co-products reduces as higher amount of $2^{\text {nd }}$ generation bioethanol is produced. Therefore, in order for the $2^{\text {nd }}$ generation bioethanol production to compete with $1^{\text {st }}$ generation bioethanol production, $2^{\text {nd }}$ generation bioethanol production should produce high value co-products compared to $1^{\text {st }}$ generation bioethanol production. 


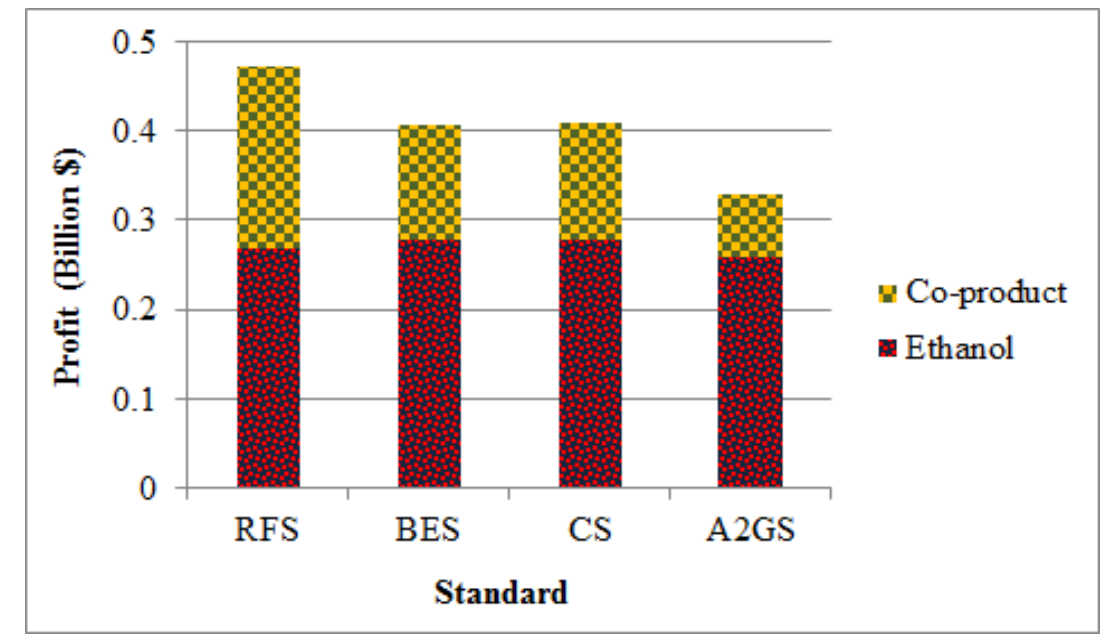

Figure 32. Profit from bioethanol and co-products

\subsubsection{Costs}

This section analyzes all the costs for HGBSC under different standards. The costs include annualized capital cost for existing $1^{\text {st }}$ generation bioethanol plants, new $2^{\text {nd }}$ generation plants and collection centers, the closing cost of $1^{\text {st }}$ generation plants, bioethanol production cost, biomass production cost, transportation cost and storage cost. Table 16 and Figure 33 present all the costs under different standards. It suggests that:

1) The total cost increases when the production quantity of $2^{\text {nd }}$ generation bioethanol increases. This implies that the total cost for $2^{\text {nd }}$ generation bioethanol production is higher compared to $1^{\text {st }}$ generation bioethanol production.

2) Both the capital cost and the closing cost increases in order to shift from existing $1^{\text {st }}$ generation bioethanol supply chain to new $2^{\text {nd }}$ generation bioethanol supply chain. The capital cost is major cost under all standards. In addition, it increases when higher amount of $2^{\text {nd }}$ generation bioethanol is produced. Therefore, in order for $2^{\text {nd }}$ generation to compete with $1^{\text {st }}$ generation, the capital cost of $2^{\text {nd }}$ generation should be reduced significantly. 
3) The bioethanol production cost is significantly higher for $2^{\text {nd }}$ generation bioethanol compared to $1^{\text {st }}$ generation bioethanol. This is because higher amount of operational products such as coal and electricity are consumed by $2^{\text {nd }}$ generation biomass in order to remove moisture content and breakdown the lignin compared to $1^{\text {st }}$ generation.

4) Biomass production cost is less for $2^{\text {nd }}$ generation compared to $1^{\text {st }}$ generation. Since, $2^{\text {nd }}$ generation biomass can grow in marginal land, it does not require resources such as fertilizers, water and irrigation land. This provides an added benefit for the $2^{\text {nd }}$ generation bioethanol compared to $1^{\text {st }}$ generation.

5) Transportation cost does not contribute significantly to the total cost. However, the transportation cost increases as higher amount of $2^{\text {nd }}$ generation bioethanol is produced due to higher density of $2^{\text {nd }}$ generation biomass compared to $1^{\text {st }}$ generation.

6) The storage cost is higher for $2^{\text {nd }}$ generation compared to the $1^{\text {st }}$ generation because of high density of $2^{\text {nd }}$ generation biomass compared to $1^{\text {st }}$ generation biomass.

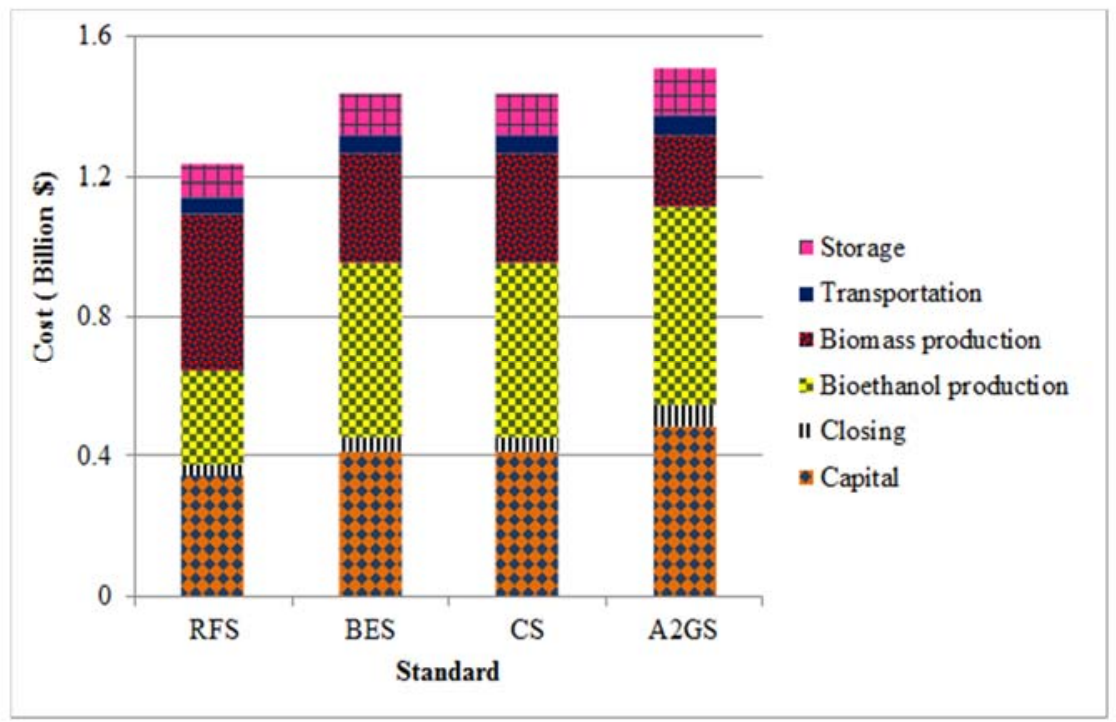

Figure 33. Total bioethanol supply chain cost under different standards 
Table 16. Various costs under different standards

\begin{tabular}{lllll}
\hline Cost & \multicolumn{4}{c}{ Standard } \\
\cline { 2 - 5 } & RFS & BES & CS & A2GS \\
\hline Capital cost & $\$ 0.35$ & $\$ 0.42$ & $\$ 0.42$ & $\$ 0.49$ \\
Closing cost & $\$ 0.03$ & $\$ 0.04$ & $\$ 0.04$ & $\$ 0.06$ \\
Bioethanol production & $\$ 0.27$ & $\$ 0.5$ & $\$ 0.5$ & $\$ 0.57$ \\
Biomass Production & $\$ 0.45$ & $\$ 0.31$ & $\$ 0.31$ & $\$ 0.2$ \\
Transportation & $\$ 0.045$ & $\$ 0.05$ & $\$ 0.05$ & $\$ 0.06$ \\
\hline
\end{tabular}

\subsubsection{Environmental analysis under different standards}

This section provides environmental analysis under different standards. Table 17 and Figure 34 present the GHG emissions under different standards. It indicates that:

1) The major amount of GHG emissions in any standard is generated by bioethanol production and biomass production. Therefore, the GHG emissions when producing biomass and bioethanol should be reduced significantly to design sustainable HGBSC.

2) The GHG emissions of transportation are very low. This implies that shifting transportation modes especially from low cost trucks to highly expensive pipelines will not significantly reduce GHG emissions. Therefore, shift to pipelines will not add any value to the supply chain. The transportation cost and GHG emissions are less because the transportation distances are small in the case study.

3) The amount of GHG emitted in bioethanol production increases slightly as higher quantities of $2^{\text {nd }}$ generation bioethanol are produced. This is because higher quantities of coal are used to remove moisture content from $2^{\text {nd }}$ generation.

4) GHG emitted in biomass production decreases significantly when $2^{\text {nd }}$ generation bioethanol production is increased. This is because $2^{\text {nd }}$ generation biomass does not require any fertilizers resulting in reduced GHG emissions. 
Table 17. GHG emissions under different standards

\begin{tabular}{lllll}
\hline & \multicolumn{4}{c}{ Standard } \\
\cline { 2 - 5 } GHG emissions & RFS & BES & CS & A2GS \\
\hline Bioethanol production & 0.79 & 0.82 & 0.82 & 0.85 \\
Biomass production & 1.21 & 0.76 & 0.76 & 0.38 \\
Transportation & 0.052 & 0.043 & 0.043 & 0.037 \\
\hline
\end{tabular}

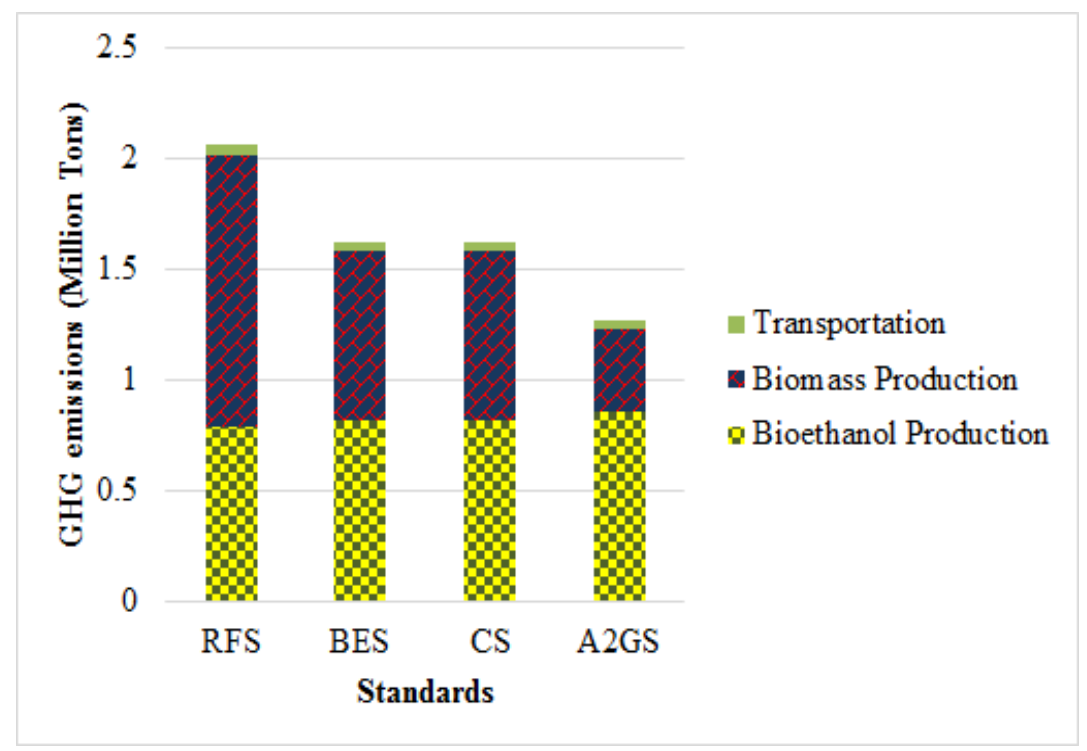

Figure 34. GHG emissions under different standards

\subsubsection{Performances under different percentage of gasoline substitution}

This section studies the sustainability performance of HGBSC when different percentages of gasoline are substituted with bioethanol. It is noted that this analysis is specific to ND. High percentage of gasoline substitution might not be feasible for some states due to biomass supply limit. Figure 35, Figure 36, and Figure 37 present the results. They suggest that:

1) A2GS results in least profit under all levels of gasoline substituted with bioethanol. However, the HGBSC under A2GS is environmentally and socially sustainable compared to other standards because the GHG emission level and the amount of irrigated land used are significantly low. This implies that if environment and social sustainability are 
important performances, then HGBSC should abide by A2GS rather than other standards. A2GS can be promoted by providing tax credits.

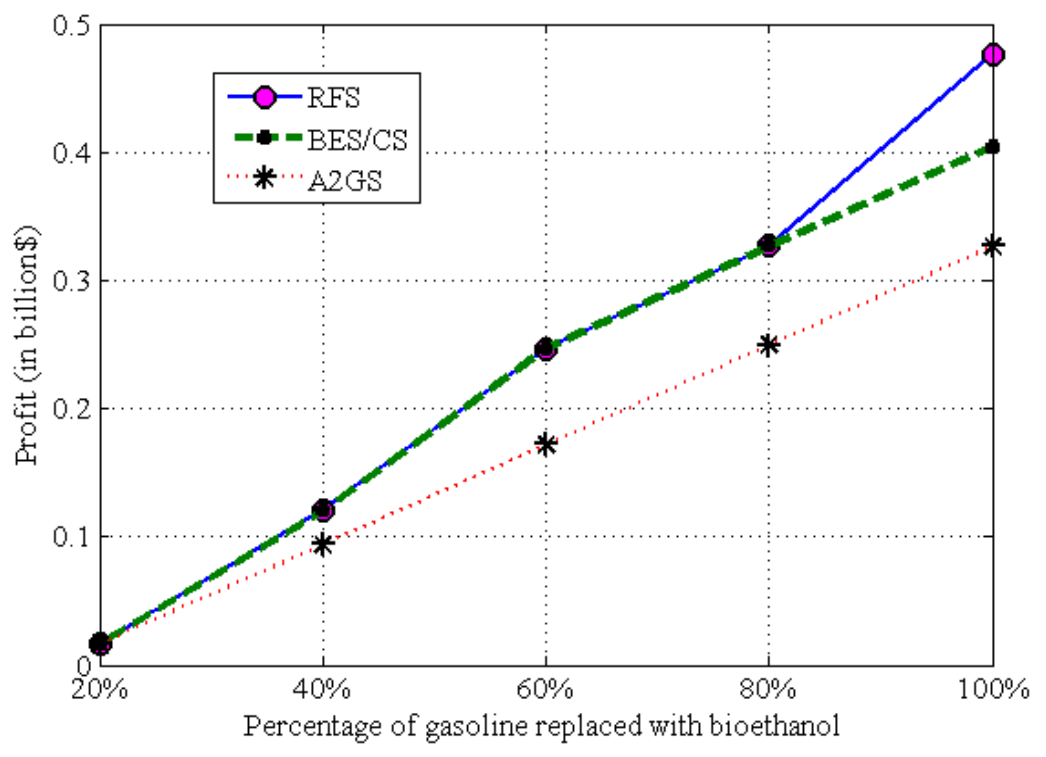

Figure 35. Economic aspect when demand is varied

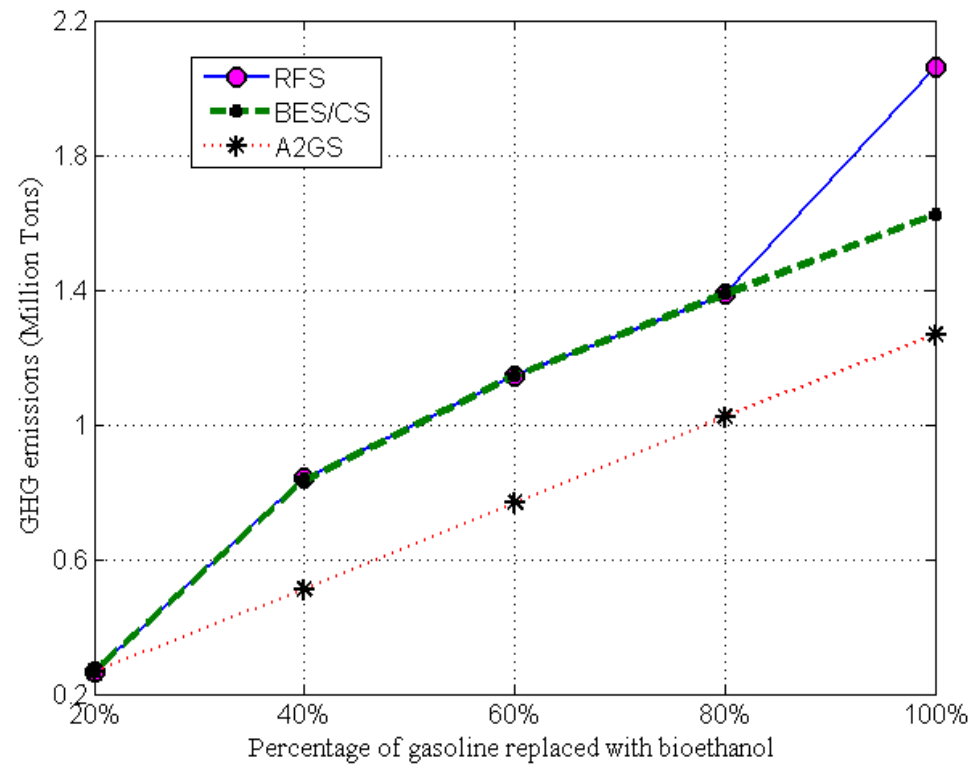

Figure 36. Environmental aspect when demand is varied

2) The sustainability performance for HGBSC under RFS, BES and CS is same for $20 \%, 40 \%$, $60 \%$ and $80 \%$ substitution levels. This indicates that the design of HGBSC is the same for 
RFS, BES and CS standards under these levels. However, when $100 \%$ of the gasoline is substituted with bioethanol, RFS generates higher profit compared to other standards. Meanwhile, the GHG emissions and the amount of $1^{\text {st }}$ generation bioethanol produced are also high. This implies that when the demand is high, RFS might not be environmentally and socially sustainable compared to other standards.

3) The amount of profit lost or gained between different standards at different levels of gasoline substituted with bioethanol can be measured. For example, at $40 \%$ gasoline replaced, the profit lost is $\$ 0.2$ billion ( $\$ 1.2-\$ 1=\$ 0.2$ billion) when compare the result of RFS/BES/CS with that of A2GS. However, the GHG emissions can be reduced to $\$ 0.3$ million tons $(0.8-0.5=0.3$ million tons $))$ and the amount of $1^{\text {st }}$ generation bioethanol produced can be reduced by $100 \mathrm{MMGY}(100-0=100 \mathrm{MMGY})$. This implies that if the policy makers can provide $\$ 0.2$ billion subsidy for the bioethanol supply chain, then the HGBSC can be economically, environmentally and socially sustainable.

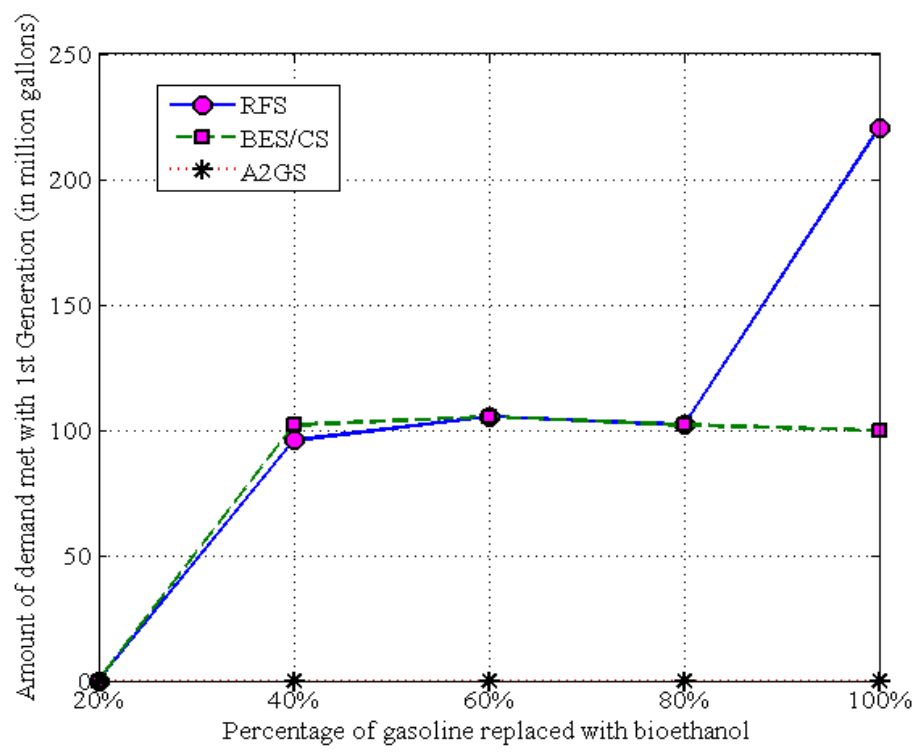

Figure 37. Demand met from $1^{\text {st }}$ generation biomass (social) when demand is varied 


\subsubsection{Tax credit decisions for policy makers}

While the previous studies provided the insights about the performance of HGBSC under existing standards, this section enables to determine the tax credits that the policy makers should provide to the investors in order to attract investors to shift from a lower state of sustainability to a higher state of sustainability in terms of environmental and social benifits. In this section, Pareto analysis for policy makers is conducted to determine the trade-off between the economic, environmental and social aspects of sustainability for HGBSC. It should be noted that the ratio of irrigation land and marginal land used is directly proportional to the ratio of $1^{\text {st }}$ generation and $2^{\text {nd }}$ generation bioethanol produced (see Fig. 6). In addition, the ratio of $1^{\text {st }}$ generation and $2^{\text {nd }}$ generation bioethanol produced can be easily controlled by the investors and hence it is used as a social aspect in this section. Figure 38 presents the Pareto chart indicating the trade-off between the economic, environmental and social aspects of sustainability when $100 \%$ gasoline demand is substituted with bioethanol. The $\mathrm{X}$-axis of the Pareto chart represents the social aspect which is the ratio of $1^{\text {st }}$ generation to $2^{\text {nd }}$ generation bioethanol produced. For example, $(80,20)$ represents that out of every 100 gallons bioethanol produced, 80 gallons are $1^{\text {st }}$ generation bioethanol and 20 gallons are $2^{\text {nd }}$ generation bioethanol. The $\mathrm{Y}$-axis of the Pareto chart represents the economic perfromance and the contours represent different GHG emission limits. For example, the contour "GHG - 40\% below 1990 level" indicates that GHG emission permit limit should be $40 \%$ below the GHG emitted in the year 1990. The chart indicates that:

1) For all the contours, the profit below the breakeven because of two reasons: a) the existing $1^{\text {st }}$ generation bioethanol capacity in ND cannot produce $100 \%$ gasoline requirement and hence it has to rely on importing bioethanol from other state at higher costs, and b) restrictions on GHG emissions forces HGBSC to reduce $1^{\text {st }}$ generation bioethanol 
production (because $1^{\text {st }}$ generation bioethanol generates high GHG emissions) and rely on importing high cost bioethanol from other states in order to reduce GHG emissions.

2) As strict environmental regulations are enforced, $2^{\text {nd }}$ generation bioethanol is highly preferred compared to $1^{\text {st }}$ generation bioethanol. However, the profit is reduced. For example, consider "No GHG restriction", the optimal profit is obtained at state 'A'. The social aspect at state ' $A$ ' is $(60,40)$ which indicates that HGBSC should produce 60 gallons of $1^{\text {st }}$ generation bioethanol and 40 gallons of $2^{\text {nd }}$ generation bioethanol for every 100 gallons of bioethanol produced. However, consider strict environmental regulation "GHG - 30\% below 1990 level", the optimal profit is obtained at state 'B'. The social aspect at state ' $\mathrm{B}$ ' is $(20,80)$ which indicates that HGBSC should produce 20 gallons of $1^{\text {st }}$ generation bioethanol and 80 gallons of $2^{\text {nd }}$ generation bioethanol for every 100 gallons of bioethanol produced. This implies that in order to regulate to "GHG - 30\% below 1990 level”, the HGBSC at state 'A' should reduce $1^{\text {st }}$ generation bioethanol by 40 gallons and increase $2^{\text {nd }}$ generation bioethanol by 60 gallons.

3) In order to produce all bioethanol from $2^{\text {nd }}$ generation, the policy makers should promote "GHG- 40\% below 1990 level". This will enable to become environmentally and socially sustainable. However, the profit is reduced. Therefore, tax credits should be provided by the policy makers to encourage investors to invest in technologies that can reduce GHG emissions significantly.

The Pareto chart also enables to determine the increase or decrease in tax credit required to shift from lower state of sustainability $X$ to another random state of sustainability $y$. Let $z_{x}$ and $z_{y}$ be the profits at states $X$ and, respectively. Let $D_{x}$ and $D_{y}$ be the total estimated demands at 
states $X$ and $y$ respectively. Then the tax credit or exemption $T_{C}$ to become environmentally and socially sustainable is given by Equation 4.58.

$$
T_{C}=\left(\frac{z_{x}}{D_{x}}\right)-\left(\frac{z_{y}}{D_{y}}\right)
$$

For example, consider two states 'A' and ' $\mathrm{B}$ ' in Fig. 13. The profit at state ' $\mathrm{A}$ ' is $\$ 0.463$ billion and the profit state ' $\mathrm{B}$ ' is $\$ 0.354$ billion. The estimated demand at both states ' $A$ ' and 'B' are 700 million gallons. Therefore, the increase tax credit that the government agency should provide to move from lower sustainable state ' $A$ ' to higher sustainable state ' $B$ ' in terms of environmental and social benefits is 0.16 \$/gallon.

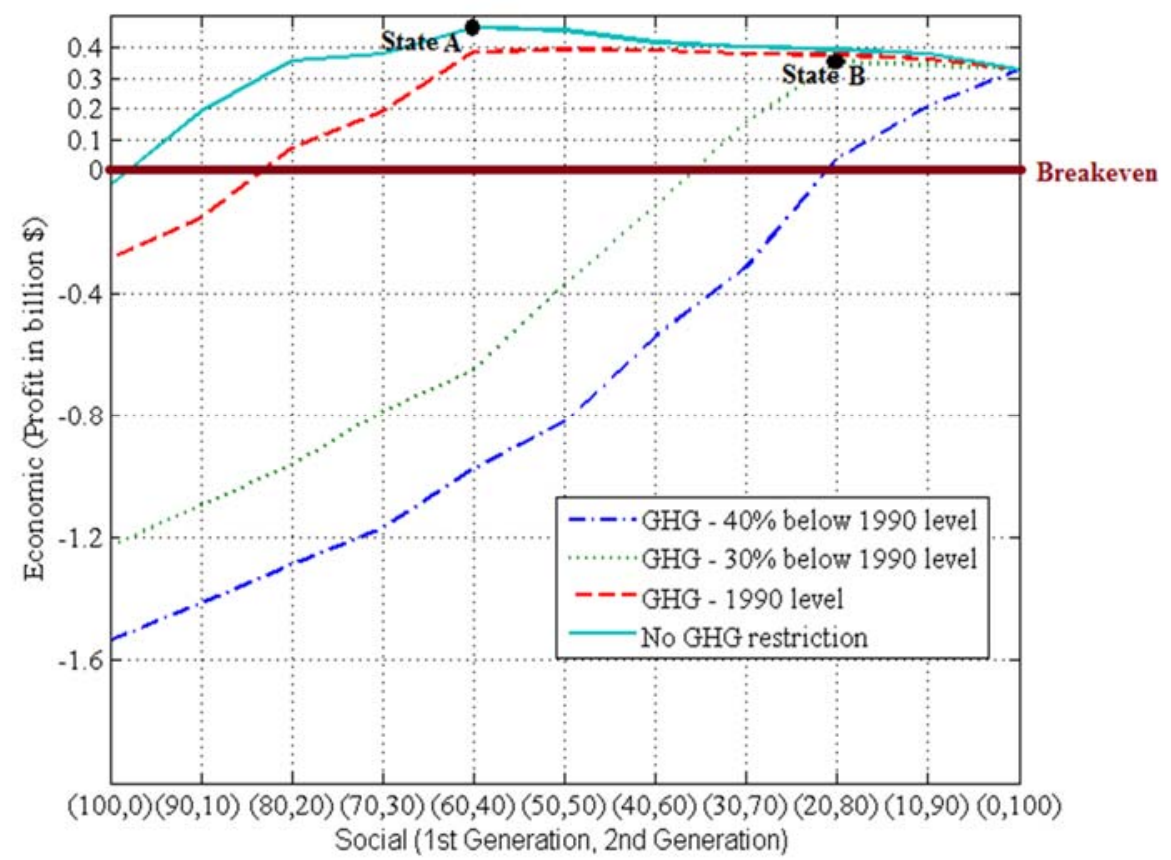

Figure 38. Pareto chart

\subsubsection{Optimal HGBSC decisions}

This section provides insights to the investors to shift from current state 'A' to higher sustainability state ' $\mathrm{B}$ ' in terms of environmental and social benefits (see Fig.13). Figure 39 and 
Figure 40 presents the network topology of biomass supply to bioethanol plant in HGBSC at sustainability states 'A' and ' $B$ ' respectively. They include the optimal $1^{\text {st }}$ generation and $2^{\text {nd }}$ generation biomass cultivation sites, optimal collection center locations for both $1^{\text {st }}$ generation and $2^{\text {nd }}$ generation biomass, optimal $1^{\text {st }}$ generation plants that should be kept open, optimal new $2^{\text {nd }}$ generation plant locations and optimal transportation modes.

Similarly, Figure 41 and Figure 42 presents the network topology of bioethanol plant to demand zones in HGBSC at states ' $\mathrm{A}$ ' and ' $\mathrm{B}$ '. They include the optimal $1^{\text {st }}$ generation bioethanol plants that are kept open and closed, optimal new $2^{\text {nd }}$ generation bioethanol plant locations and the optimal transportation mode for the transportation of bioethanol.

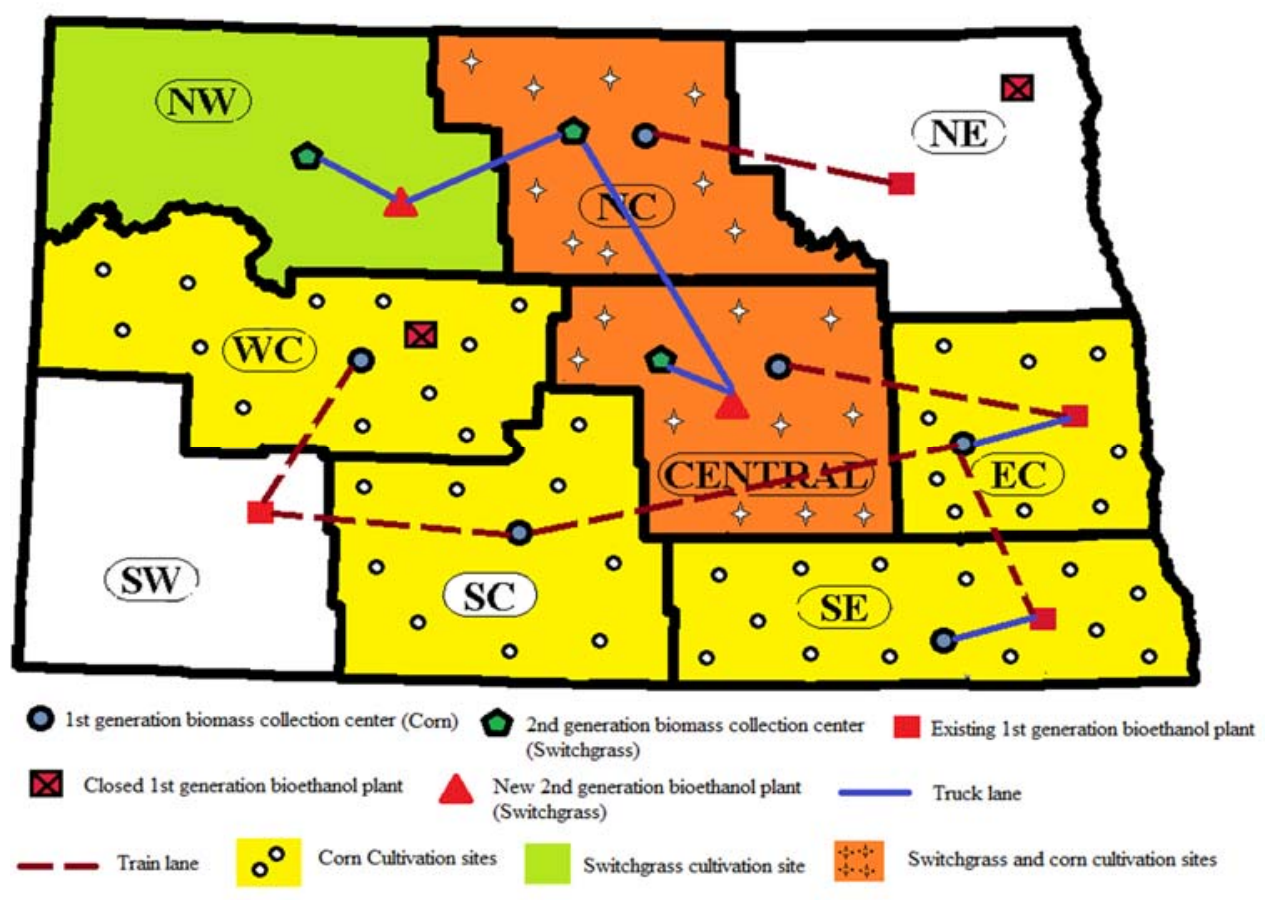

Figure 39. Network topology of biomass supply sites to bioethanol plants in HGBSC at state 'A' 


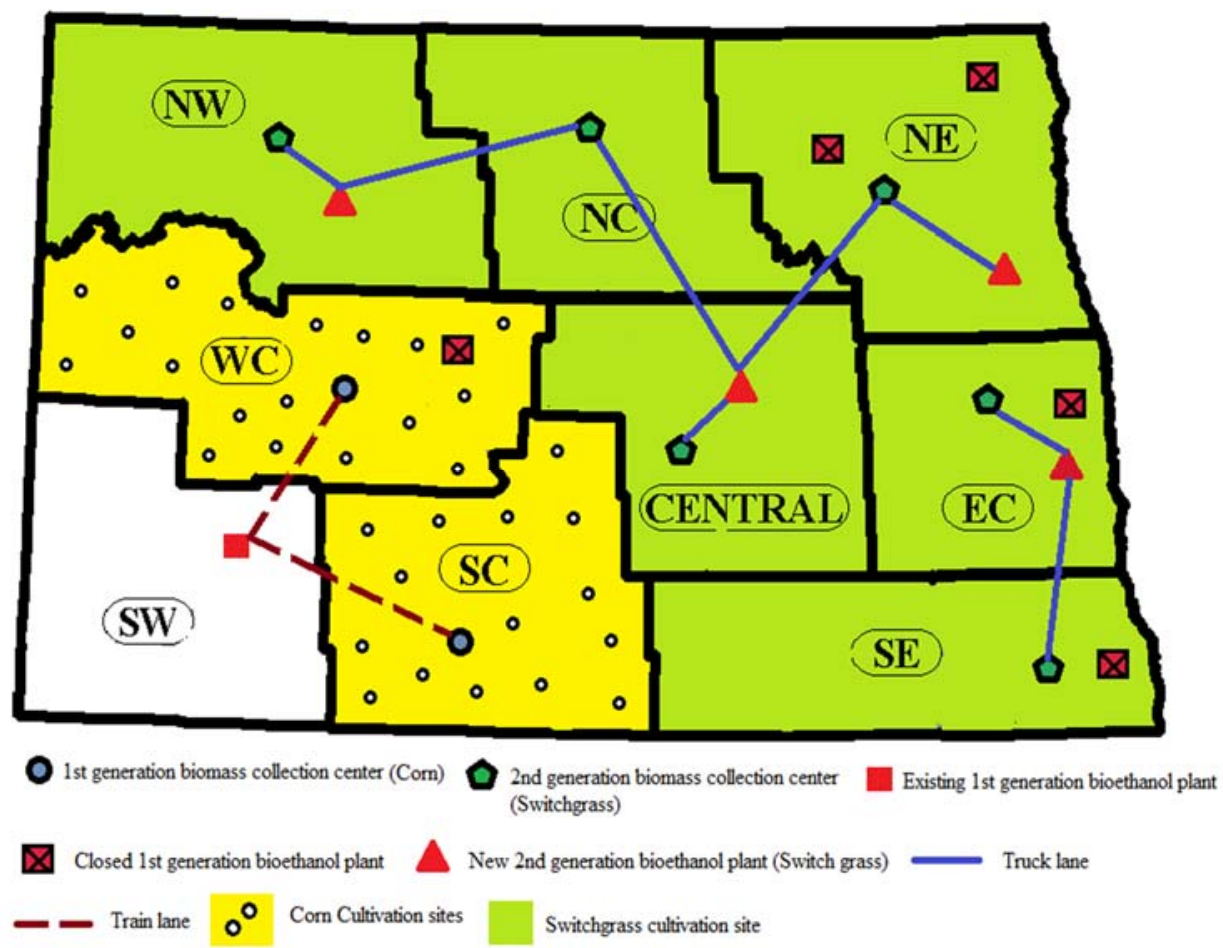

Figure 40. Network topology of biomass supply sites to bioethanol plants in HGBSC at state 'B'

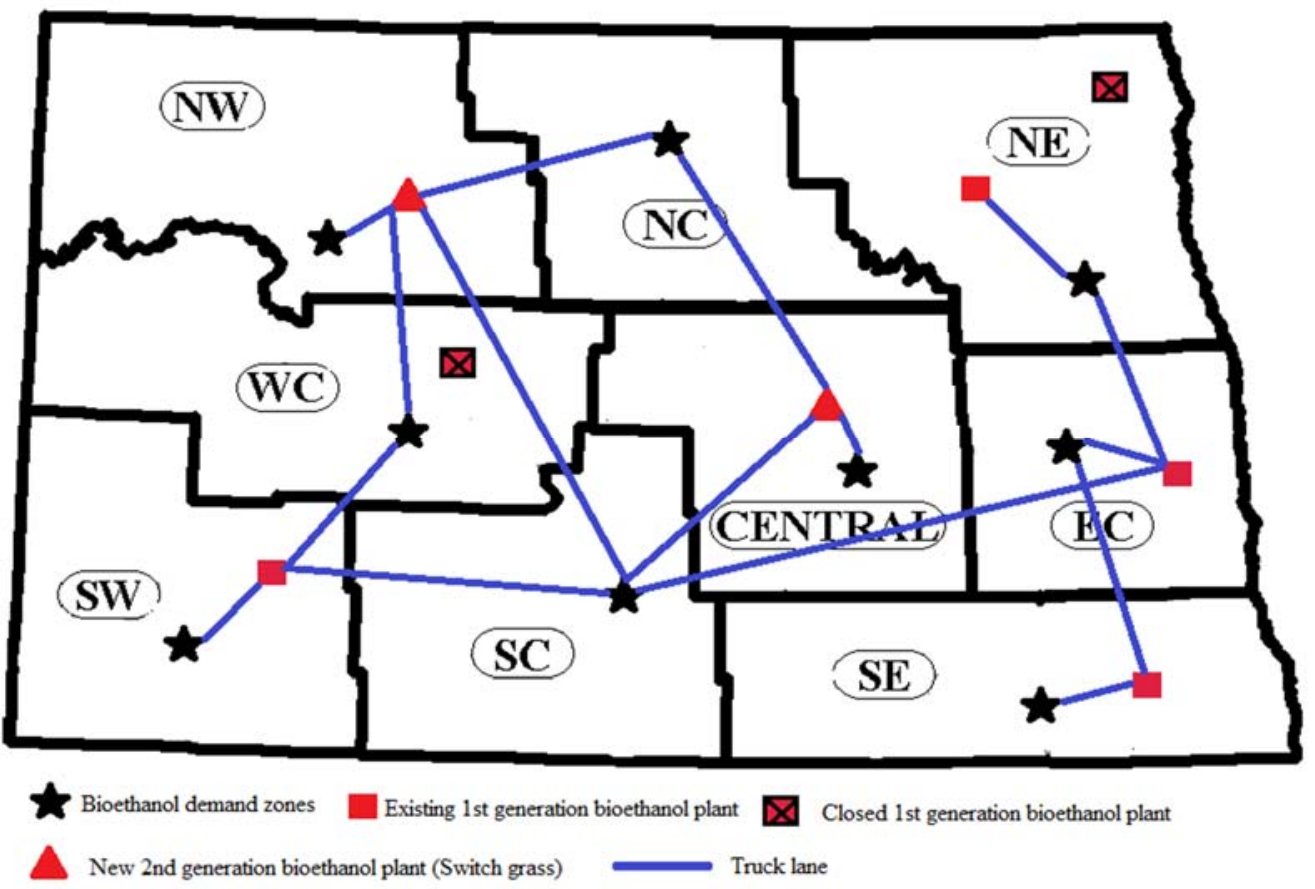

Figure 41. Network topology of bioethanol plants to demand zones in HGBSC at state 'A' 
Table 18 presents the comparison of bioethanol plant configurations. It suggests that HGBSC at state ' $A$ ' relies significantly on the existing $1^{\text {st }}$ generation bioethanol plants. In this HGBSC, all the open existing $1^{\text {st }}$ generation bioethanol plants are expanded. However, compared to the current configuration, two bioethanol plant (NE (Pembina) and WC) are closed. The HGBSC at state 'B' relies significantly on $2^{\text {nd }}$ generation. Almost all the existing $1^{\text {st }}$ generation plants are closed except SW. Therefore, in order to shift from state 'A' to state ' $\mathrm{B}$ ' all the existing $1^{\text {st }}$ generation plants should be closed except that of SW. In addition, new $2^{\text {nd }}$ generation bioethanol plants should be opened in NE and EC and the capacity of C should be increased by 15 MMGY. $(150-135=15)$.

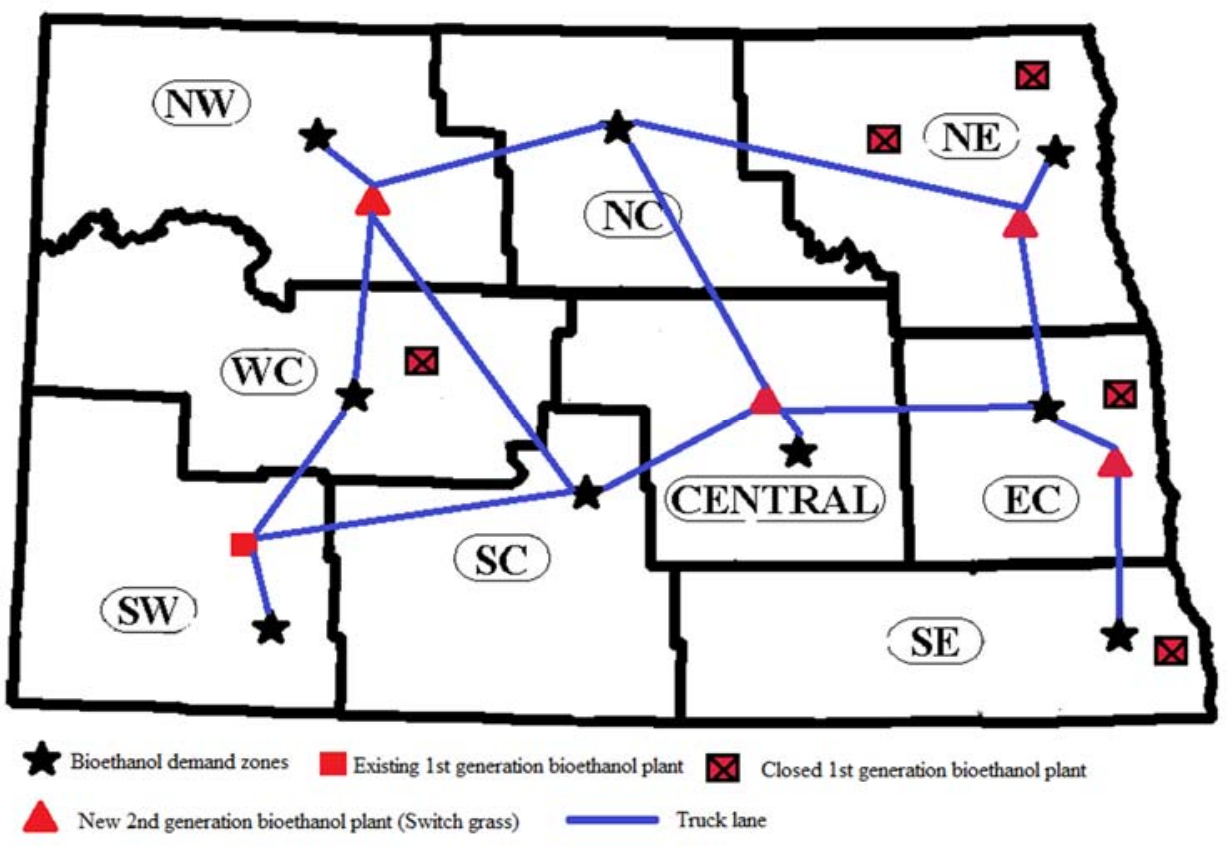

Figure 42. Network topology of bioethanol plants to demand zones in HGBSC at state 'B'

Table 19 and Table 20 present the assignment of collection centers and demand zones to bioethanol plants at sustainability states 'A' and ' $\mathrm{B}$ ' respectively. They indicate that the major assignment remained same for bioethanol plants that exist in both states ' $\mathrm{A}$ ' and 'B'. 
Table 18. Comparison of plant configurations between state ' $\mathrm{A}$ ' and state ' $\mathrm{B}$ '

\begin{tabular}{llll}
\hline Plant & Biomass Type & $\begin{array}{l}\text { Capacity under } \\
\text { 'A' (MMGY) }\end{array}$ & $\begin{array}{l}\text { Capacity under } \\
\text { 'B' (MMGY) }\end{array}$ \\
\hline Existing 1 & st generation bioethanol plants & & \\
\hline NE (Pembina) & Corn & Close & Close \\
NE (Walsh) & Corn & 12.5 & Close \\
WC & Corn & Close & Close \\
EC & Corn & 187.5 & Close \\
SW & Corn & 62.5 & 62.5 \\
SE & Corn & 137.5 & Close \\
\hline New 2 & generation bioethanol plants & & 150 \\
\hline NW & Switchgrass & 150 & 150 \\
NE & Switchgrass & NA & 150 \\
C & Switchgrass & 135 & 150 \\
EC & Switchgrass & NA & \\
\hline
\end{tabular}

Table 19. Optimal assignment of collection centers and demand zones to the bioethanol plants under state 'A'

\begin{tabular}{lll}
\hline $\begin{array}{l}\text { District location of } \\
\text { bioethanol plant }\end{array}$ & $\begin{array}{l}\text { District of biomass } \\
\text { collection center assigned } \\
\text { to bioethanol plant }\end{array}$ & $\begin{array}{l}\text { District of demand zone } \\
\text { assigned to bioethanol } \\
\text { plant }\end{array}$ \\
\hline Existing 1 ${ }^{\text {st }}$ generation bioethanol plant & \\
\hline NE (Walsh) & NC & NE \\
EC & C, EC & NE, EC, SW \\
SW & WC, SC & WC, SW, SC \\
SE & EC, SE & EC, SE \\
\hline New 2 & \\
\hline NW & NWeneration bioethanol plant & NW, NC, WC, SC \\
C & NC, C & NC, C, SC \\
\hline
\end{tabular}

Table 20. Optimal assignment of collection centers and demand zones to the bioethanol plants under state 'B'

\begin{tabular}{|c|c|c|}
\hline $\begin{array}{l}\text { District location of } \\
\text { bioethanol plant }\end{array}$ & $\begin{array}{l}\text { District of biomass } \\
\text { collection center assigned } \\
\text { to bioethanol plant }\end{array}$ & $\begin{array}{l}\text { District of demand zone } \\
\text { assigned to bioethanol } \\
\text { plant }\end{array}$ \\
\hline \multicolumn{3}{|c|}{ Existing $1^{\text {st }}$ generation bioethanol plant } \\
\hline SW & $\mathrm{WC}, \mathrm{SC}$ & WC, SW, SC \\
\hline \multicolumn{3}{|c|}{ New $2^{\text {nd }}$ generation bioethanol plant } \\
\hline NW & $\mathrm{NW}, \mathrm{NC}$ & $\mathrm{NW}, \mathrm{NC}, \mathrm{WC}, \mathrm{SC}$ \\
\hline NE & NE & $\mathrm{NC}, \mathrm{NE}, \mathrm{EC}$ \\
\hline $\mathrm{C}$ & $\mathrm{NC}, \mathrm{NE}, \mathrm{C}$ & $\mathrm{NE}, \mathrm{C}, \mathrm{EC}, \mathrm{SC}$ \\
\hline $\mathrm{EC}$ & $\mathrm{EC}, \mathrm{SE}$ & $\mathrm{EC}, \mathrm{SE}$ \\
\hline
\end{tabular}


Table 21 presents the optimal transportation modes for various products. It can be observed that the optimal transportation modes for various products remained the same in both cases. In addition, pipeline is never preferred as GHG emissions from transportation are low compared to biomass production and bioethanol production. Therefore, pipelines are not preferred as they incur high cost and will not reduce emissions significantly. In addition, corn stover based bioethanol production is never preferred. This is because only small quantity of corn stover is available for bioethanol production as major portion of corn stover is left at cultivation sites for restoring nitrogen.

Table 21. Optimal transportation modes for states 'A' and 'B'

\begin{tabular}{ll}
\hline Product & Transportation mode \\
\hline Bioethanol & Truck \\
$1^{\text {st }}$ generation biomass (corn) & Train \\
$2^{\text {nd }}$ generation biomass (switchgrass) & Truck \\
\hline
\end{tabular}

\subsection{Sensitivity analysis}

Sensitivity analysis is conducted on HGBSC under CS for the following factors: 1) selling price of bioethanol; 2) bioethanol conversion rate from switch grass; and 3) bioethanol production cost produced from switch grass.

\subsubsection{The impact of the bioethanol selling price}

In this section, the impact of the bioethanol selling price on the profit (economic), GHG emissions (environment) and total demand is studied. Figure 43 presents the profit of the HGBSC when bioethanol selling price is increased. It indicates that the profit increases significantly as the bioethanol selling price is increased. Figure 44 and Figure 45 indicates that the GHG emissions and the amount of demand met fluctuate considerably when the bioethanol selling price is low. At lower bioethanol prices, the $1^{\text {st }}$ generation bioethanol plant is kept open in some cases and closed in other cases. This implies that in some cases, it is economical to produce in-state bioethanol and 
in other cases it is economical to outsource from the nearby states under GHG restrictions. However, the GHG emissions remained stable when the bioethanol selling price is high.

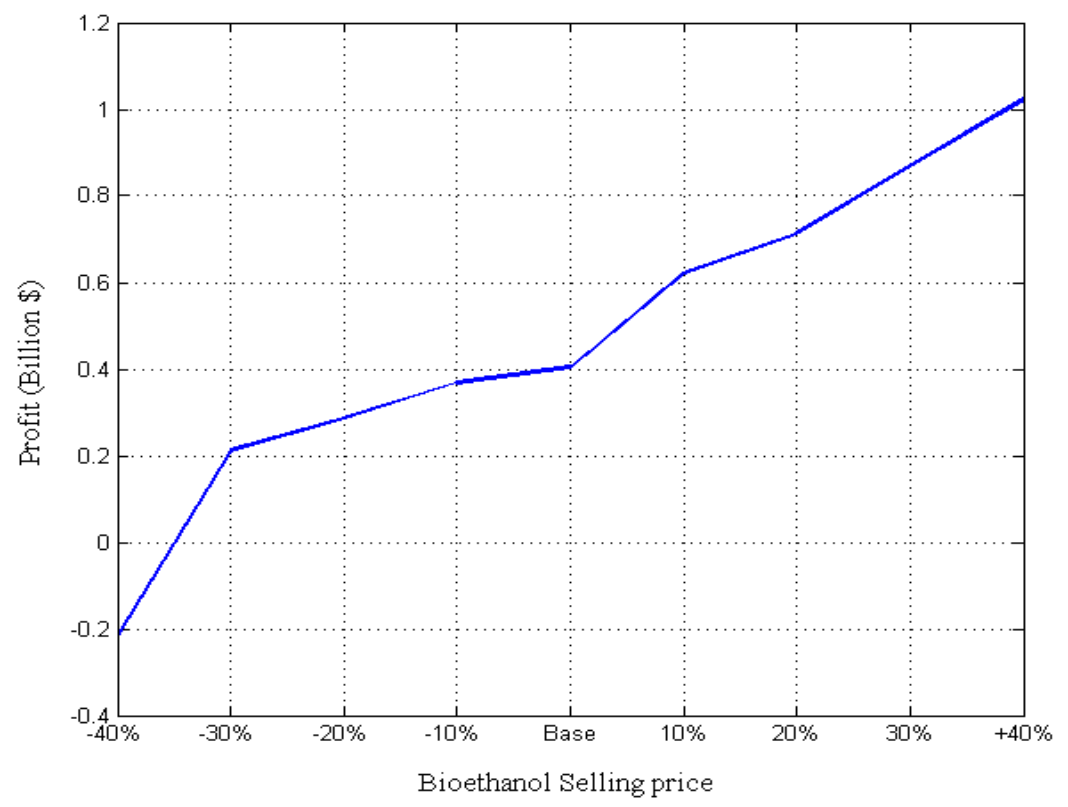

Figure 43. Profit when bioethanol selling price is varied

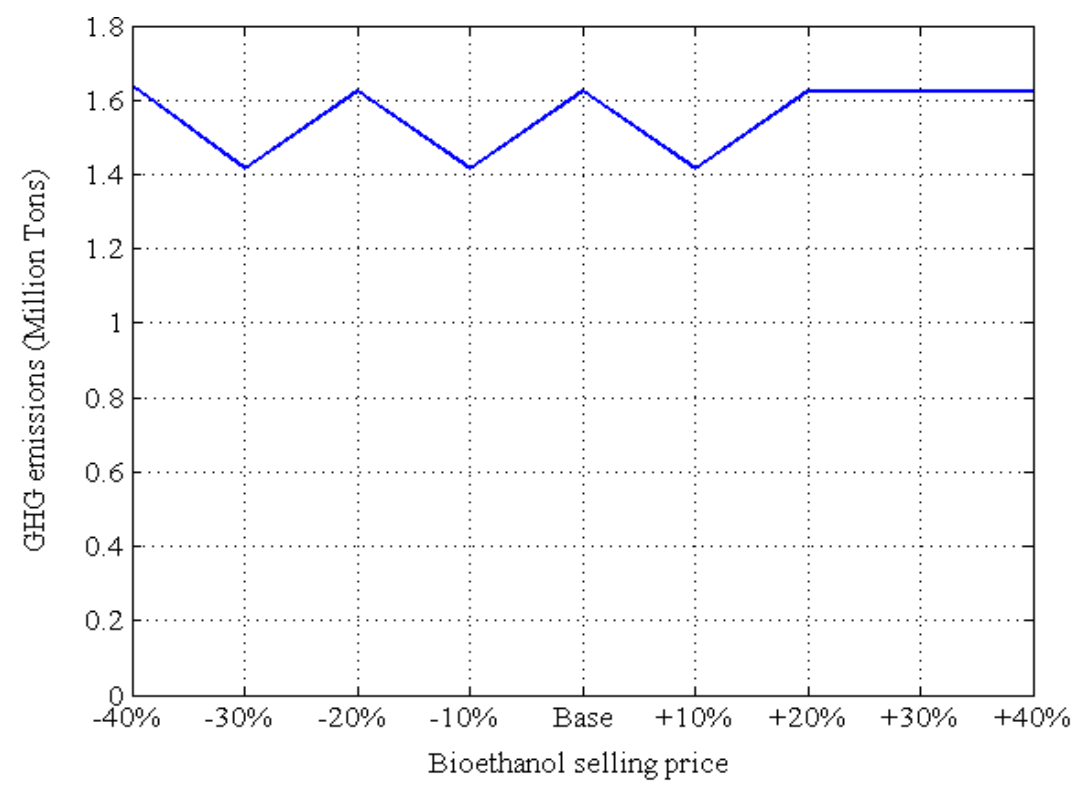

Figure 44. GHG emissions when bioethanol selling price is varied 


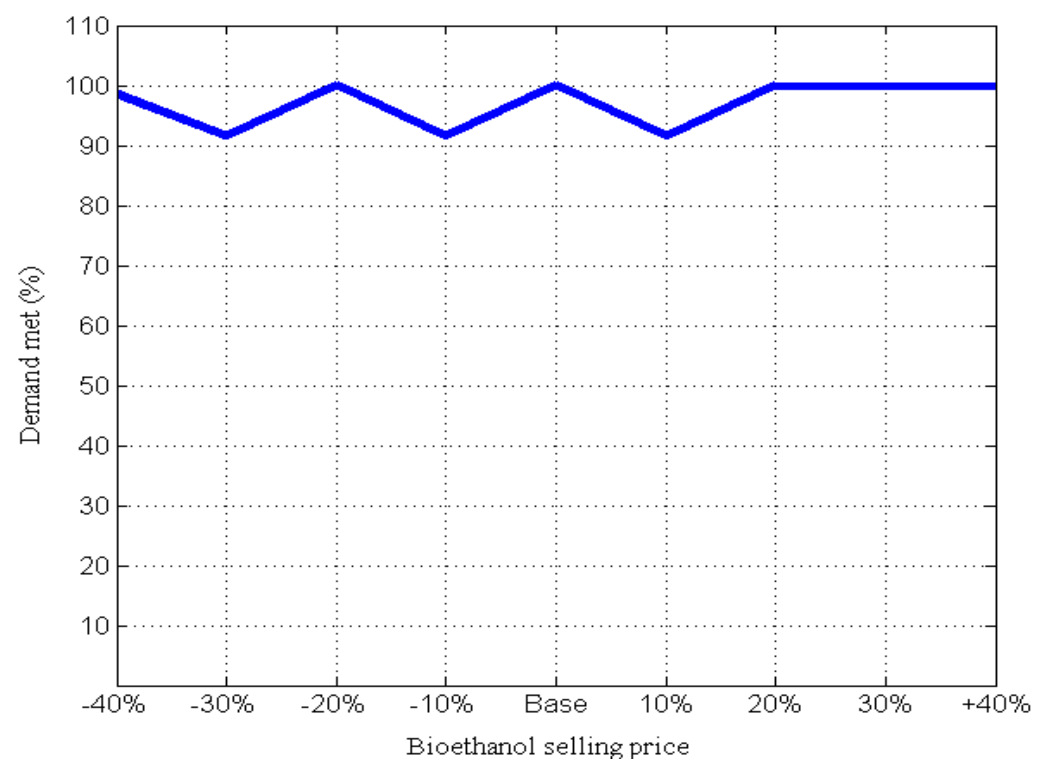

Figure 45. Bioethanol demand met when bioethanol selling price is varied

\subsubsection{The impact of the bioethanol conversion rate from switch grass}

Sensitivity analysis is conducted on the amount of bioethanol produced from the switch grass. Figure 46 and Figure 47 present the profit and the GHG emission from HGBSC when the bioethanol conversion rate from switch grass is varied. It indicates that the profit of HGBSC increases significantly as the conversion rate increases. In addition, the GHG emissions decreases as higher amounts of $2^{\text {nd }}$ generation (section 5.2 indicates that $2^{\text {nd }}$ generation produces lower GHG compared to $1^{\text {st }}$ generation) bioethanol is produced. The GHG emission remained same from -30\% to $-20 \%$ because same proportion of the $1^{\text {st }}$ generation and the $2^{\text {nd }}$ generation is produced for all these levels of conversion rate. However, when the bioethanol conversion rate from switch grass is further increased, the profit increases and GHG emissions decreases. In addition, the amount of irrigation land used decreases as higher quantities of $2^{\text {nd }}$ generation bioethanol is produced. Therefore, improving the conversion technology will enable to improve all the aspects of sustainability. 


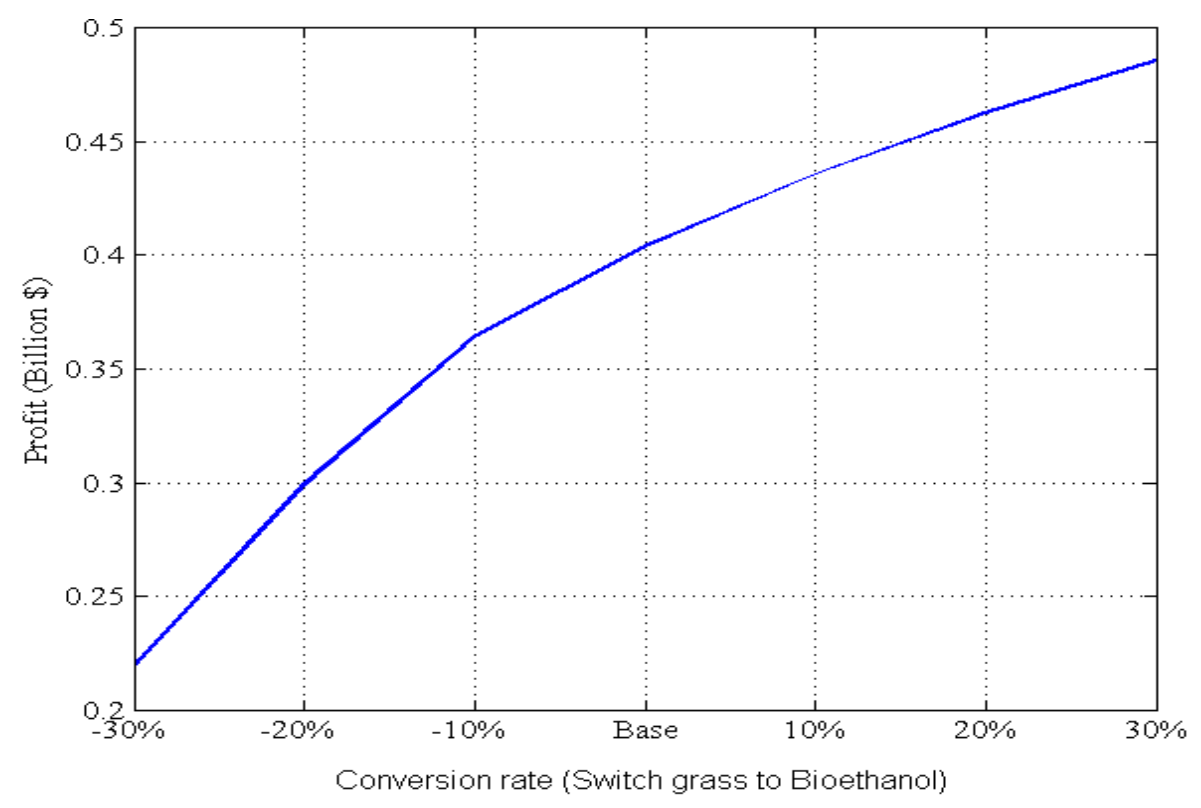

Figure 46. Profit when bioethanol conversion rate is varied

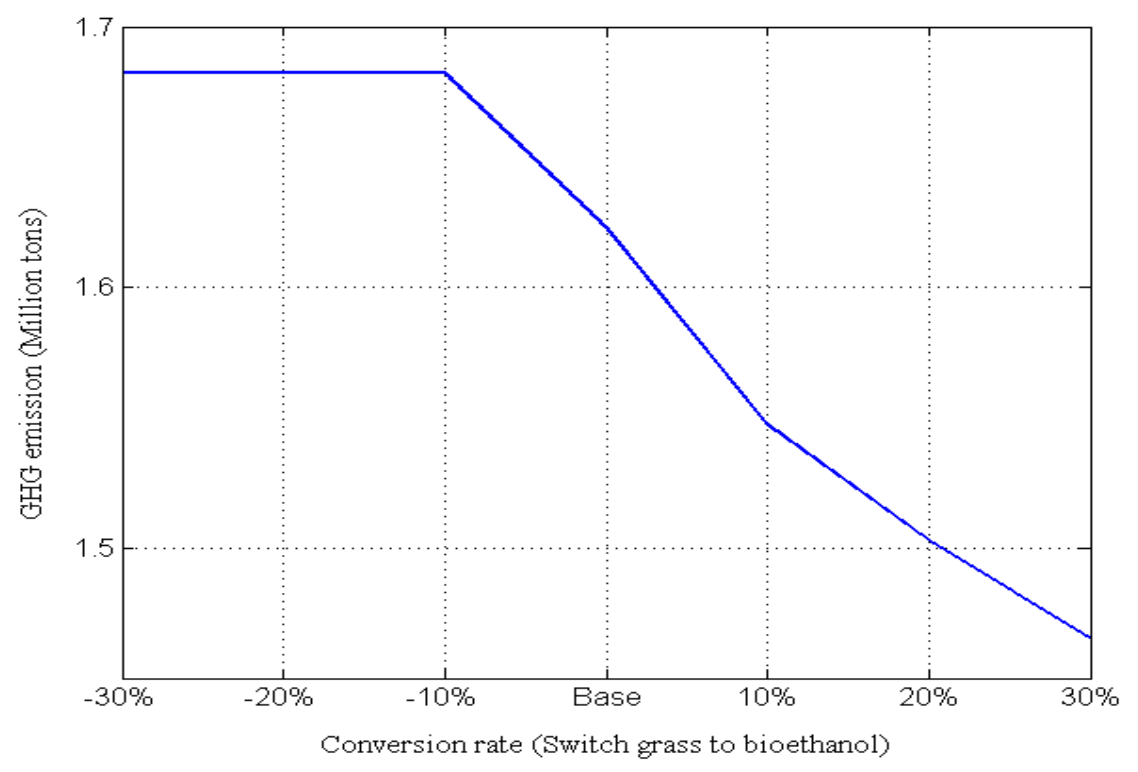

Figure 47. GHG emissions when bioethanol conversion rate is varied

\subsubsection{The impact of the $2^{\text {nd }}$ generation bioethanol production cost}

In this section, sensitivity analysis is conducted on the $2^{\text {nd }}$ generation (switch grass) bioethanol production cost. Figure 48 suggests that the profit decreases significantly as the production cost is increased. However, Figure 49 indicates that GHG emissions reduce when the 
production cost range is $-40 \%$ to $-30 \%$ because a higher amount of switch grass based bioethanol is produced. GHG emissions remain stable between the range $-30 \%$ to $+20 \%$ because at these production costs same ratio of $1^{\text {st }}$ generation and $2^{\text {nd }}$ generation bioethanol are produced. However, when the switch grass production cost is increased, corn based bioethanol is preferred resulting in increased GHG emissions. Therefore, in order to improve profit, GHG emissions and produce more $2^{\text {nd }}$ generation to reduce social impact, the production cost of switch grass based bioethanol should reduce.

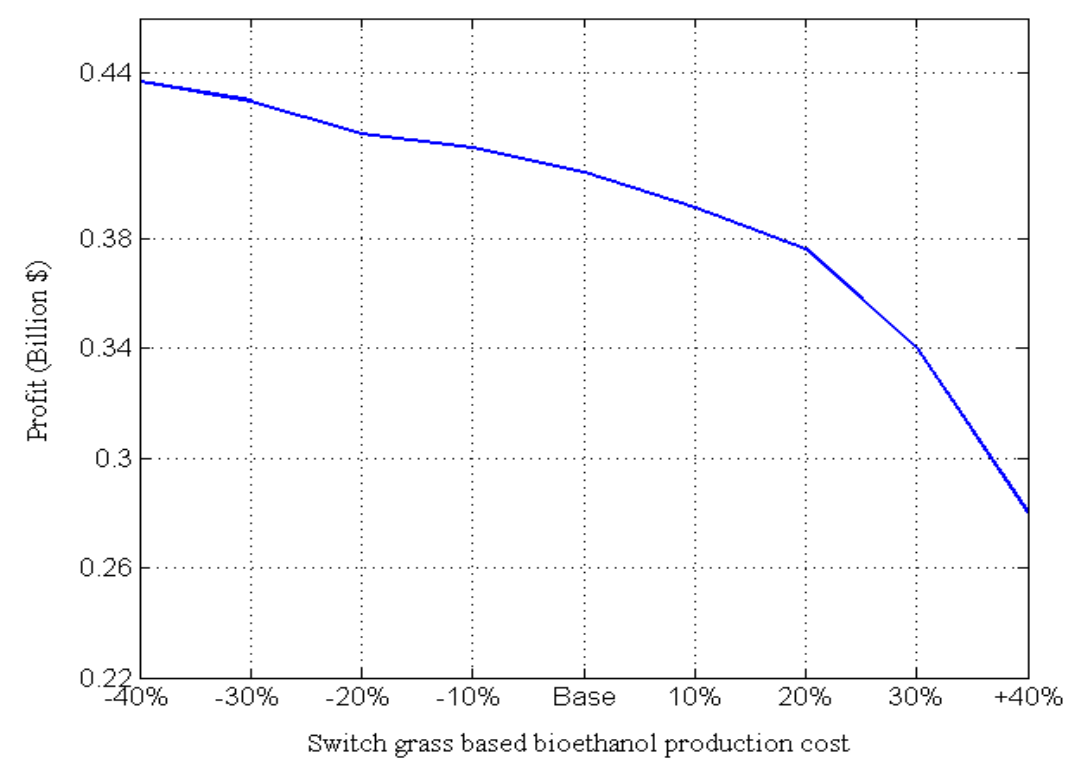

Figure 48. Profit when switchgrass based production cost is varied 


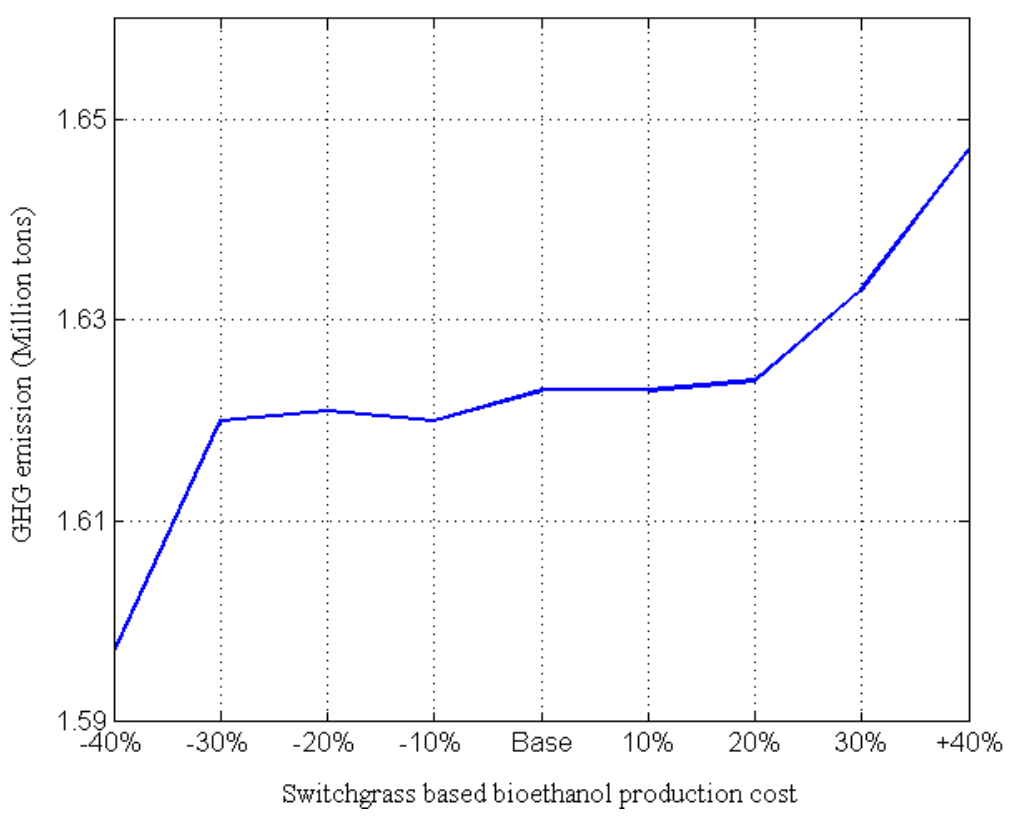

Figure 49. GHG emissions when switchgrass based bioethanol production cost is varied

\subsection{Conclusion}

This paper focuses on designing a sustainable bioethanol supply chain under uncertainties. A SMILP model is proposed to design an optimal HGBSC that accounts for economic, environmental and social aspects of sustainability under uncertainties. The proposed model aims to determine: 1$)$ whether the existing $1^{\text {st }}$ generation bioethanol plant should operate with the same capacity, expand its capacity or should be closed; 2) optimal locations for new $2^{\text {nd }}$ generation bioethanol; 3) the optimal collection center locations for both $1^{\text {st }}$ generation and $2^{\text {nd }}$ generation biomass; 4) optimal biomass that should be used and their harvesting locations; and 5) optimal transportation modes.

A case study of state of the ND in the US is used as an application of the proposed model. The results suggest that the bioethanol supply chain design changes significantly when different aspects of sustainability are addressed. It has been observed that there is significant trade-off 
between the economic, environmental and social aspects of the bioethanol supply chain. Some of the important conclusions are:

1) Economic benefits of HGBSC reduces as strict environmental and social restrictions are enforced. The profit of HGBSC reduces when GHG emissions is reduced. In addition, the profit reduces when the amount of irrigation land used is used.

2) $1^{\text {st }}$ generation based bioethanol supply chain performs best in improving economic aspect. However, it does not help to improve environmental and social aspects.

3) $2^{\text {nd }}$ generation based bioethanol supply chain outperforms $1^{\text {st }}$ generation in improving environmental and social aspects. However, the profit is significantly reduced. Switchgrass is preferred compared to corn stover for $2^{\text {nd }}$ generation bioethanol production because of very low yield rates of corn stover.

4) $2^{\text {nd }}$ generation bioethanol production should produce high value co-products in order to compete with $1^{\text {st }}$ generation in terms of economic performance.

5) The capital cost and the bioethanol production cost contributed significantly to increase the $2^{\text {nd }}$ generation bioethanol supply chain. Therefore, it is essential to find mature technologies that would significantly reduce these costs in order for the $2^{\text {nd }}$ generation to compete with the $1^{\text {st }}$ generation.

6) Pipeline is not preferred because transportation cost and GHG emissions are insignificant in HGBSC. The transportation cost and GHG emissions are less in HGBSC because the geographical area considered is small.

7) Bioethanol production and biomass production played major role in increasing GHG emissions. $2^{\text {nd }}$ generation outperformed $1^{\text {st }}$ generation in reducing GHG emissions 
because low GHG is emitted while producing $2^{\text {nd }}$ generation biomass compared to $1^{\text {st }}$ generation biomass.

8) Tax credits decisions can be made by the policy makers to shift from lower state to higher state of sustainability through the proposed model. In addition, the proposed model provides optimal decisions to the investors to shift from lower state to higher state of sustainability.

The future works includes, but are not limited: 1) a stochastic model will be developed that would include more diversified $2^{\text {nd }}$ generation products, account for availability of gasoline and competition between various bioethanol plants to fulfill the demand and 2) the symbiosis based bioethanol supply chain will be designed that would account for: 1) efficient resource utilization; 2) economic; 3) environment and 3) social aspect of the bioethanol supply chain. 


\section{CHAPTER 5. STOCHASTIC OPTIMIZATION OF SUSTAINABLE SYMBIOSIS BASED HYBRID GENERATION BIOETHANOL SUPPLY CHAINS}

\subsection{Abstract}

The ever increasing concerns such as energy security and climate change calls for a wide range of alternate renewable and eco-friendly sources of energy. As a result, bioethanol has gained great deal of attraction as it is both renewable and environmentally friendly source of energy. In order to gain great benefits from bioethanol, sustainable bioethanol supply chains should be designed to become economically viable, environmentally friendly, and socially beneficial. In addition, bioethanol supply chains should be energy efficient so that they consume lesser input energy and generate higher output energy. Therefore, this paper focuses on designing sustainable hybrid generation based bioethanol supply chain considering industrial symbiosis strategy under uncertainties. In such a bioethanol supply chain, the hybrid generation bioethanol production enables to improve the economic, environmental and social benefits and industrial symbiosis enable to improve energy efficiency. A stochastic model is proposed to design an optimal industrial symbiosis based hybrid generation supply chain considering uncertainties and sustainable constraints. A case study of North Dakota has been considered as an application of the proposed model. The results suggest that $2^{\text {nd }}$ generation bioethanol production improves environmental and social aspects of sustainability. Industrial symbiosis strategy is significantly sustainable compared to standalone in all the aspects of sustainability. Sensitivity analyses are also conducted to provide managerial insights about the proposed model. 


\subsection{Introduction}

The ever increasing concerns such as energy security and climate change calls for alternative renewable and sustainable ways of performing business (Awudu and Zhang, 2012a). As a result, bioethanol has gained a great deal of attraction to replace gasoline because it is considered as both renewable and sustainable source of energy. Currently, $1^{\text {st }}$ generation bioethanol production is commercialized around the world. However, the wide use of $1^{\text {st }}$ generation bioethanol has resulted in new social issues such as food versus fuel debate (use of irrigation land for energy purposes rather than for food) and higher corn price, since $1^{\text {st }}$ generation bioethanol is produced from edible biomass such as corn and sugar.. The need for new types of biomass that can improve environmental and social aspects of sustainability has resulted in the emergence of $2^{\text {nd }}$ generation biomass/bioethanol. This has led to the promotion of $2^{\text {nd }}$ generation bioethanol in recent years. In fact, the Renewable Fuel Standard (RFS) in U.S. enforces that at least $55 \%$ of the bioethanol demand should be met from $2^{\text {nd }}$ generation by the year 2022 . Since $1^{\text {st }}$ generation bioethanol supply chains already exists, and the process of introducing $2^{\text {nd }}$ generation bioethanol should be gradual, there is a need to design hybrid generation bioethanol supply chain (HGBSC) to sustainably meet the bioethanol demand.

In addition, the United States Environmental Protection Agency (USEPA) Executive Order 13423 enforces $30 \%$ reduction in energy intensity by the year 2015 for all systems consuming energy. Therefore, it is necessary to develop strategies that can reduce the energy intensity of HGBSC. Industrial symbiosis (IS) is one of the sustainable strategies that can help to reduce the energy intensity of bioethanol plants. In IS, traditionally separate plants collocate in order to improve resource utilization and reduce wastes, resulting in improved economic, environmental, social, and energy intensity aspects of sustainability (Gonela and Zhang, 2013). There are 
numerous ways to form IS. For instance, a bioethanol plant can collocate near (geographical proximity) to a combined heat and power (CHP) plant or can build its own CHP unit. Different IS configurations provide different benefits of sustainability. Therefore, it is necessary to explore what is the best IS strategy while designing HGBSC. In addition, the HGBSC is exposed to number of uncertainties such as bioethanol demand, bioethanol price and biomass price. Consequently, a robust HGBSC with IS strategy should be designed in order to be less vulnerable to risks.

Literature review shows that none of the up-to-date literature has focused on designing HGBSC by considering IS under uncertainties. Therefore, this paper focuses on exploiting symbiotic opportunities for bioethanol plant location while designing HGBSC and hence the supply chain is called as industrial symbiosis based hybrid generation symbiosis based bioethanol supply chain (ISHGBSC). A stochastic model is proposed to determine which existing $1^{\text {st }}$ generation bioethanol plant should operate with same capacity, expanded capacity or be closed, location of new $2^{\text {nd }}$ generation bioethanol plants and their symbiosis configurations, and the capacities of new bioethanol plants, collection center locations, biomass cultivation locations and transportation modes. A case study of North Dakota (ND) state in the United States (US) is used to study the efficiency and effectiveness of the proposed model. Sensitivity analysis is further conducted to provide deep understanding of the ISHGBSC.

The rest of the chapter is organized as follows. Section 5.3 presents comprehensive literature review. Section 5.4 discusses the problem statement. Section 5.4 presents the proposed methodology. Section 5.6 illustrates the case study configuration. Section 5.7 presents comprehensive analysis of the results and section 5.8 presents sensitivity analysis. Section 5.9 presents the conclusions. 


\subsection{Literature review}

In past, a significant amount of research has been conducted to design economically and environmentally sustainable bioethanol supply chain. These studies have focused on designing either $1^{\text {st }}$ generation bioethanol supply chains or $2^{\text {nd }}$ generation bioethanol supply chains, but not a combination. Dal-Mas et al. (2011), Zamboni et al (2009a), Zamboni et al (2009b), Corsano et al. (2011), and Mele et al. (2001) conduct significant research to design economically and environmentally sustainable $1^{\text {st }}$ generation bioethanol supply chain. Dal-Mas et al. (2011) develop a stochastic model to design a cost effective $1^{\text {st }}$ generation (corn) based bioethanol supply chain. Zamboni et al (2009a) and Zamboni et al (2009b) develop a Mixed Integer Linear Programming (MILP) model to design an economically and environmentally sustainable $1^{\text {st }}$ generation (corn) based bioethanol supply chain. The study indicates that the bioethanol strategic, tactical and operational decisions are highly sensitive to the environmental considerations. In addition, it indicates that the $1^{\text {st }}$ generation bioethanol production can put bioethanol supply chain into risk under proposed European Union (EU) environmental standards. Corsano et al. (2011) develop a Mixed Integer Non-linear Programming (MINLP) model to design a sustainable $1^{\text {st }}$ generation (sugar) based bioethanol supply chain. They include waste recycling element of sustainability and results suggest that the inclusion of the sustainability aspects changes the supply chain design. Mele et al. (2001) develop a Multi-objective Mixed Integer Linear Programming (Mo-MILP) model to design supply chains that combine sugar production and bioethanol production by considering economic and environmental performances. Awudu and Zhang (2012b) develop stochastic production planning model for $1^{\text {st }}$ generation based bioethanol supply chain under demand and supply uncertainties. The objective is to improve the economic benefits. 
While $1^{\text {st }}$ generation has provided economic benefits, wide use of $1^{\text {st }}$ generation bioethanol has created social issues such as food versus fuel debate and irrigation land use for energy purposes. As a result, in recent years significant amount of research is conducted to design sustainable $2^{\text {nd }}$ generation based bioethanol supply chain. Zhang et al. (2012) developed a MILP model to design a cost effective switchgrass based bioethanol supply chain. Huang et al. (2010) develop an MILP model to design an optimal biowaste based bioethanol supply chain. They suggest that $2^{\text {nd }}$ generation bioethanol is feasible when the bioethanol production is below $\$ 1.10$ per gallon. Giarola et al. (2012) design a $2^{\text {nd }}$ generation based bioethanol supply chain under uncertainties that aims to reduce cost under carbon emission trading schemes. Ekşioğlu et al. (2009) develop an MILP model to design a cost effective forest residue based bioethanol supply chain. The study determines the optimal number, size and location of bioethanol plants. Gebreslassie et al. (2012) develop a Stochastic Mixed Integer Linear Programming (SMILP) model to design an economically viable $2^{\text {nd }}$ generation bioethanol supply chain. The objective is to simultaneously maximize profit and minimize risk. You et al. (2012) develop a Multi-objective Mixed Integer Linear programming (Mo-MILP) model to design a cellulosic bioethanol supply chain that will simultaneously reduce cost and GHG emissions, and increase the number of jobs created.

While significant amount of research is conducted to design either $1^{\text {st }}$ generation bioethanol supply chain or $2^{\text {nd }}$ generation bioethanol supply chain, only few research has been conducted to design $2^{\text {nd }}$ generation bioethanol supply chain while considering existing $1^{\text {st }}$ generation bioethanol supply chain. Akgul et al. (2012) develop a Mixed Integer Linear Programming (MILP) model to design a hybrid (first/second generation) bioethanol supply chain to improve economic and environmental performance. However, the study focuses on designing bioethanol supply chain in 
which the configuration of bioethanol plants is hybrid generation. Therefore, none of the up-todate bioethanol supply chain have considered transitioning from existing $1^{\text {st }}$ generation bioethanol to new $2^{\text {nd }}$ generation bioethanol supply chain.

In order to improve economic, environmental, social and energy intensity aspects of sustainability, IS is considered as a good strategy. Chew et al. (2009), Lovelady and El-halwagi (2009), Taskhiri et al. (2011) and Chae et al. (2010) designed an optimal network for single product between the plants in already existing IS. Their study indicates that optimal network of water can improve the water utilization across the IS. Franceschin et al. (2008) conduct pinch technology analysis to reduce water and energy requirements for $1^{\text {st }}$ generation based bioethanol plants. The study incorporates in-house Combined Heat and Power (CHP) Technology and the results suggest that CHP can improve the profit by reducing the production cost. Gonela and Zhang (2013) design optimal Bioenergy based Industrial Symbiosis (BBIS) to reduce bioethanol production cost. They indicate that the profit of a biorefinery plant can be improved significantly when operating in BBIS compared to in standalone mode. While these studies have explored the benefits of IS, none of the up-to-date studies have considered integrating IS with HGBSC. Therefore, this chapterfocuses on integrating HGBSC with IS in order to design ISHGBSC. It is the first chapter that focuses on designing ISHGBSC under uncertainties in order to maximize economic benefits under environmental, social and energy intensity aspects of sustainability constraints.

\subsection{Problem statement}

This paper focuses on designing an optimal ISHGBSC that aims to improve economic benefits considering environmental, social and energy intensity restrictions under uncertainties. In this study, the economic performance measured by the profit generated by the ISHGBSC. Environmental performance is measured and restricted by the amount of $\mathrm{CO}_{2}$ equivalent GHG 
emitted. Social performance is measured and restricted by the amount of irrigation land and water used. Energy intensity is measured and restricted by the energy efficiency which is the ratio of output energy to the input energy.

Figure 50 presents the supply chain and logistic activities taking place in ISHGBSC. Let $b$ be the index for $1^{\text {st }}$ generation biomass type which is cultivated at biomass cultivation site $i$. Let $b n$ be the index for the $2^{\text {nd }}$ generation biomass which is cultivated at the biomass cultivation site in . The $1^{\text {st }}$ generation and $2^{\text {nd }}$ generation biomass are harvested and stored at the $1^{\text {st }}$ generation collection center ${ }_{c}$ and $2^{\text {nd }}$ generation collection center $c$ respectively. The $1^{\text {st }}$ generation biomass is then shipped from the collection centers to the existing $1^{\text {st }}$ generation bioethanol plant $r$. The $2^{\text {nd }}$ generation biomass is shipped from the collection centers to new $2^{\text {nd }}$ generation bioethanol plant $r n$. Table 22 presents the configuration of the bioethanol plants considered in this study.

Table 22. Configurations of bioethanol plants

\begin{tabular}{|c|c|}
\hline $\begin{array}{l}\text { Bioethanol } \\
\text { configuration }\end{array}$ & Description \\
\hline 1G-SA & $\begin{array}{l}\text { Existing } 1^{\text {st }} \text { generation bioethanol plant operating in standalone } \\
\text { (SA) mode. }\end{array}$ \\
\hline 1G-CBIS & $\begin{array}{l}\text { Existing } 1^{\text {st }} \text { generation bioethanol plant operating in collocation } \\
\text { based industrial symbiosis (CBIS) mode. }\end{array}$ \\
\hline 2G-SA & New $2^{\text {nd }}$ generation bioethanol operating in SA mode. \\
\hline 2G-CBIS & New $2^{\text {nd }}$ generation bioethanol plant operating with CBIS mode. \\
\hline 2G-NBBIS & $\begin{array}{l}\text { New } 2^{\text {nd }} \text { generation bioethanol plant operating in New Bioenergy } \\
\text { based Industrial symbiosis (NBBIS) mode }\end{array}$ \\
\hline
\end{tabular}

Figure 51 presents the configuration of $1 \mathrm{G}-\mathrm{SA}$. Under $1 \mathrm{G}-\mathrm{SA}$, the existing $1^{\text {st }}$ generation bioethanol plant produces its own process steam by using coal and freshwater. Coal and fresh water are purchased from operational product supply zones ${ }_{\text {os }}$. The process steam is used to produce bioethanol and Distiller Dried Grains (DDG) that are shipped to demand zones. Figure 52 presents the configuration of 1G-CBIS. In this configuration, the existing bioethanol plant had collocated near to a CHP plant. The existing $1^{\text {st }}$ generation bioethanol plant purchases process 
steam and electricity from the CHP plant to produce bioethanol and DDG that are shipped to the demand zones. Both 1G-SA and 1G-CBIS can operate with three capacity strategies: 1) same capacity, 2) expanded capacity, and 3) close.

Figure 53 presents the configuration of $2 \mathrm{G}-\mathrm{SA}$. Under this configuration, the new $2^{\text {nd }}$ generation bioethanol plant produces process steam by using coal, lignin pallets and freshwater. It should be noted that the combustion process considered is co-combustion where a combination of coal and process steam is used as fuel to generate process steam. The process steam is used to produce bioethanol and lignin pallets. The bioethanol is shipped to the demand zones and the lignin pallets is either used for the combustion purpose or sold to the market. Figure 54 shows the configuration of 2G-CBIS. Under this configuration, the new bioethanol plant is built near to the existing CHP plant. The new $2^{\text {nd }}$ generation bioethanol plant purchases process steam and electricity from the CHP plant to produce bioethanol and lignin pallets. The bioethanol is sold to demand zones and the lignin pallets is either sold to the CHP plant or to the demand zones based on the combustion technology of the CHP plant. Figure 55 presents the configuration of 2GNBBIS. Under this configuration, the new $2^{\text {nd }}$ generation bioethanol plant has its own CHP unit. The CHP unit generates electricity and process steam by using coal, lignin pallets, and freshwater. The combustion process considered is co-combustion where both coal and lignin pallets are used as fuel. While the major amount of electricity and process steam is used by the new $2^{\text {nd }}$ generation bioethanol plant, remaining process steam and electricity are sold to the market. The new $2^{\text {nd }}$ generation bioethanol plant produces bioethanol and lignin pallets where the bioethanol is sold to the market and lignin pallet is either used for combustion or sold to the market. 


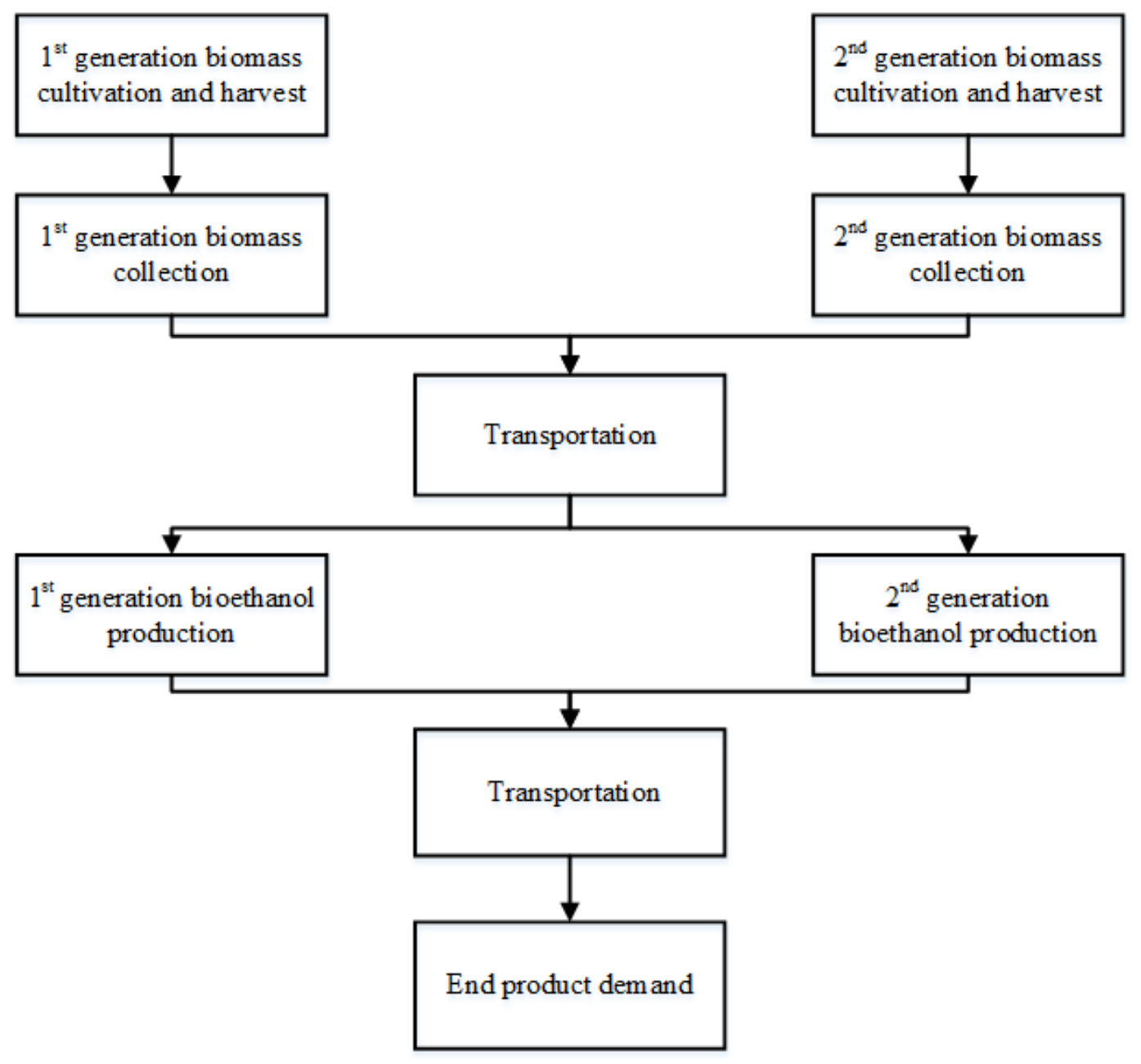

Figure 50. Structure of the problem

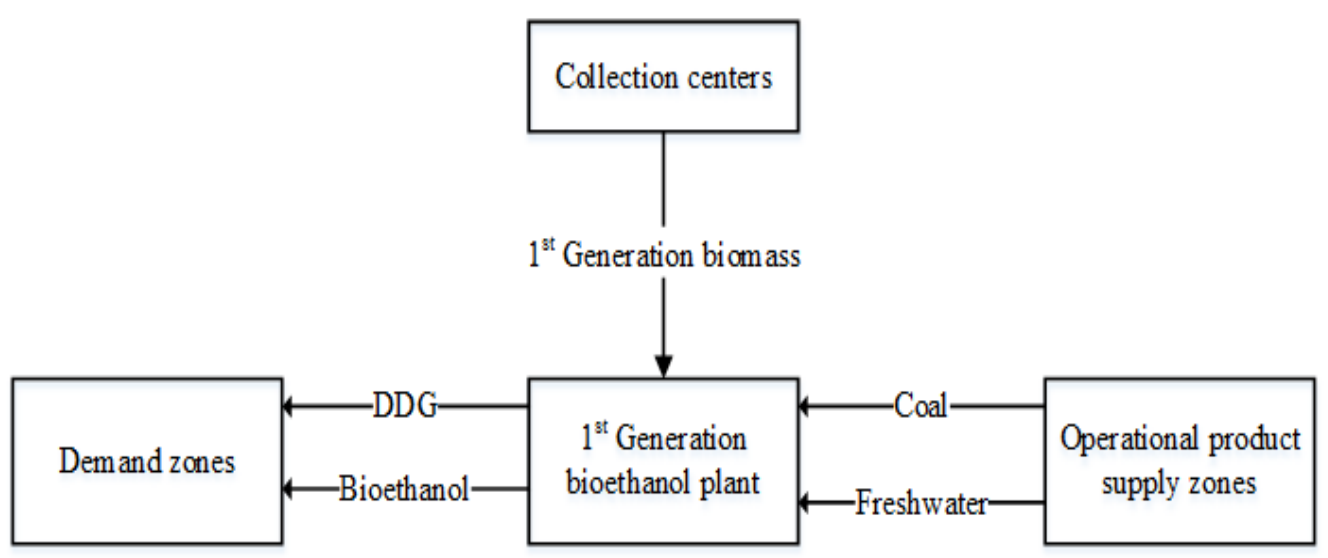

Figure 51. Configuration of 1G-SA 
Let $m$ be the transportation mode through which the products are shipped. Let $t$ be the index of time period and $\xi$ be the uncertain scenarios. The uncertainties considered in this study are bioethanol price, bioethanol demand and biomass yield.

Given such a structure, a stochastic mixed integer linear programming (SMILP) model is proposed to determine the optimal ISHGBSC that aims to maximize the profit under environmental, social and energy intensity restrictions. The proposed model will determine: 1) the type of existing bioethanol plant that should be kept open at the same capacity, expanded, or closed;2) the new $2^{\text {nd }}$ generation bioethanol plant locations and their configurations; 3 ) the optimal collection center locations for both $1^{\text {st }}$ generation and $2^{\text {nd }}$ generation biomass; 4) the optimal cultivation sites for both $1^{\text {st }}$ generation and $2^{\text {nd }}$ generation; and 5) optimal transportation modes for biomass and bioethanol.

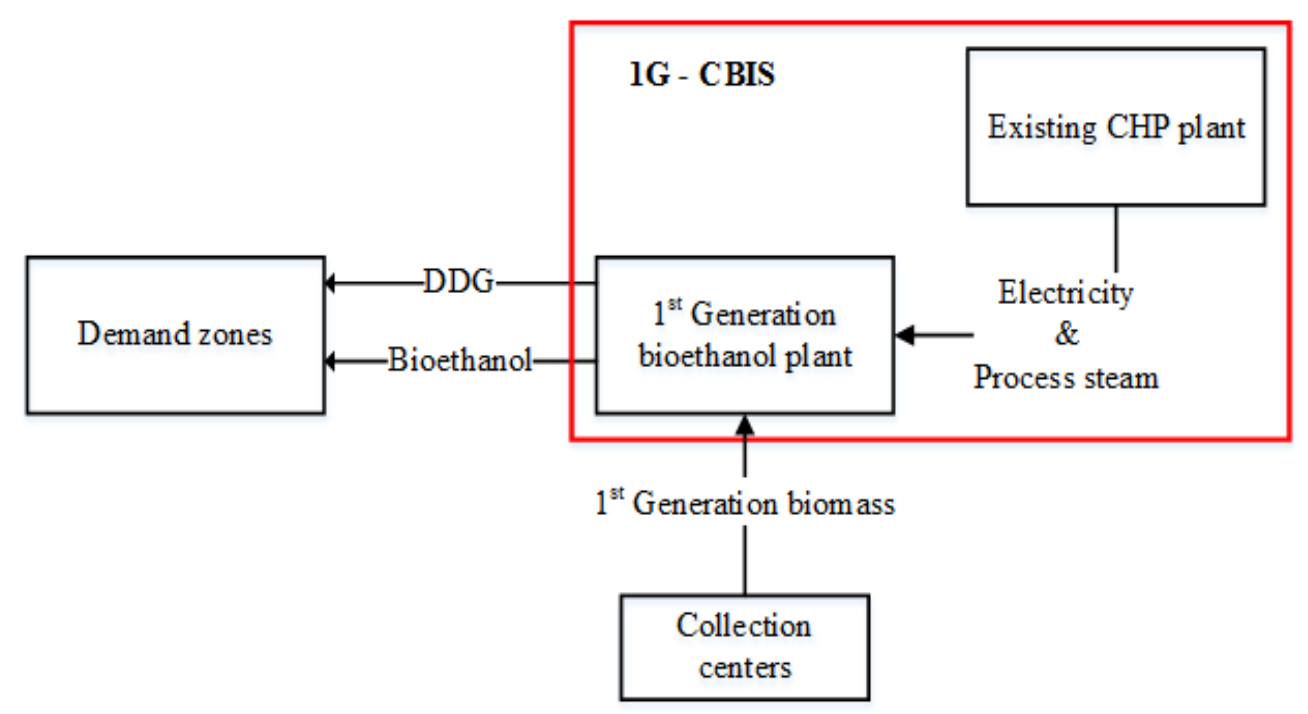

Figure 52. Configuration of 1G-CBIS 


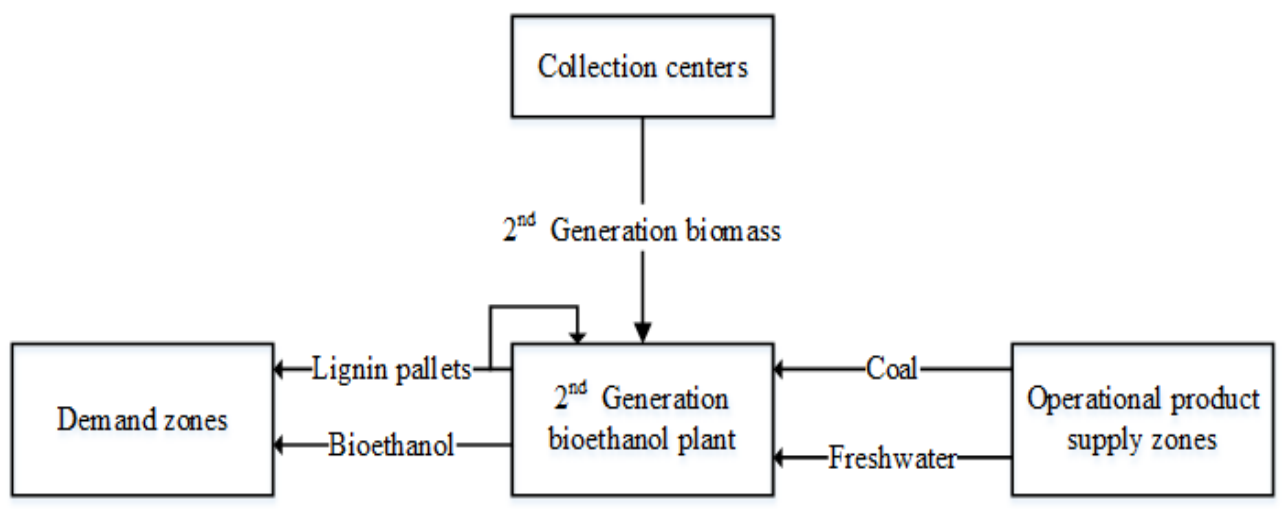

Figure 53. Configuration of 2G-SA

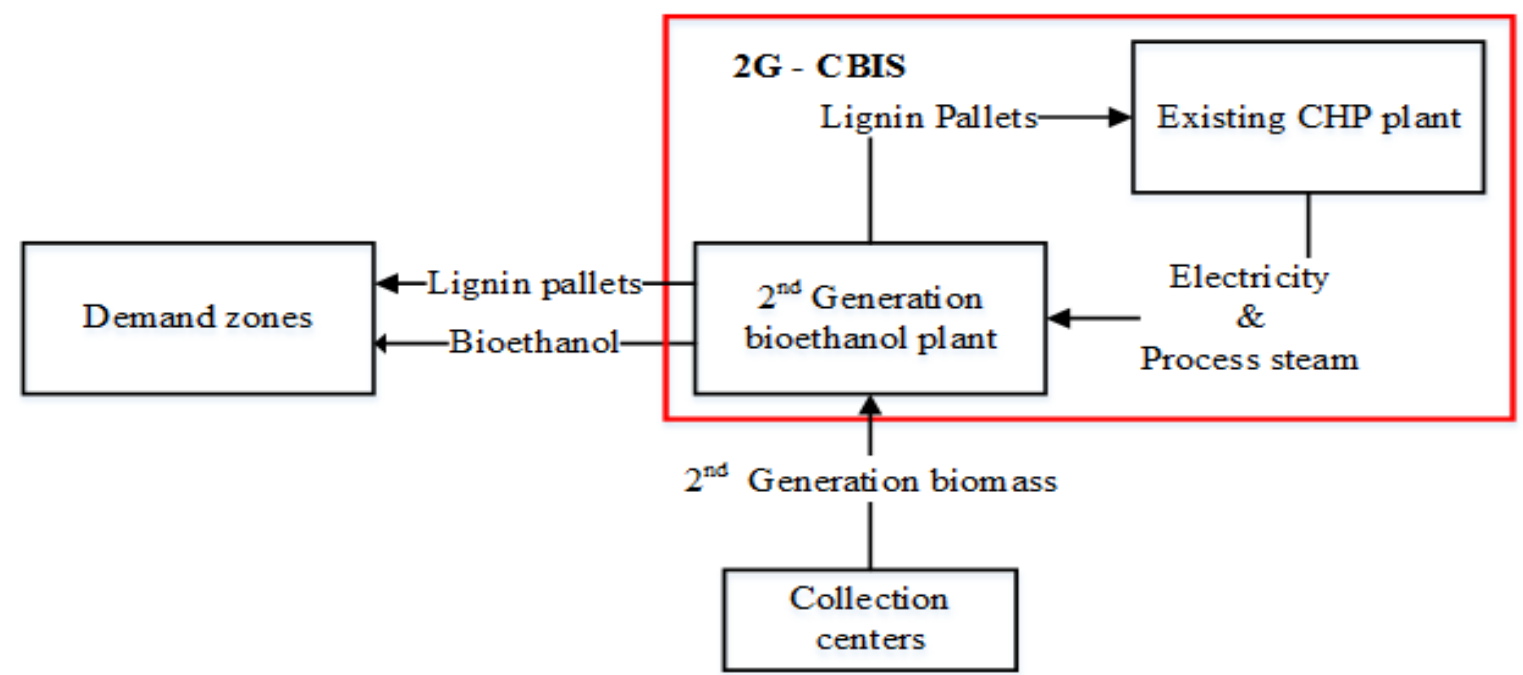

Figure 54. Configuration of 2G-CBIS

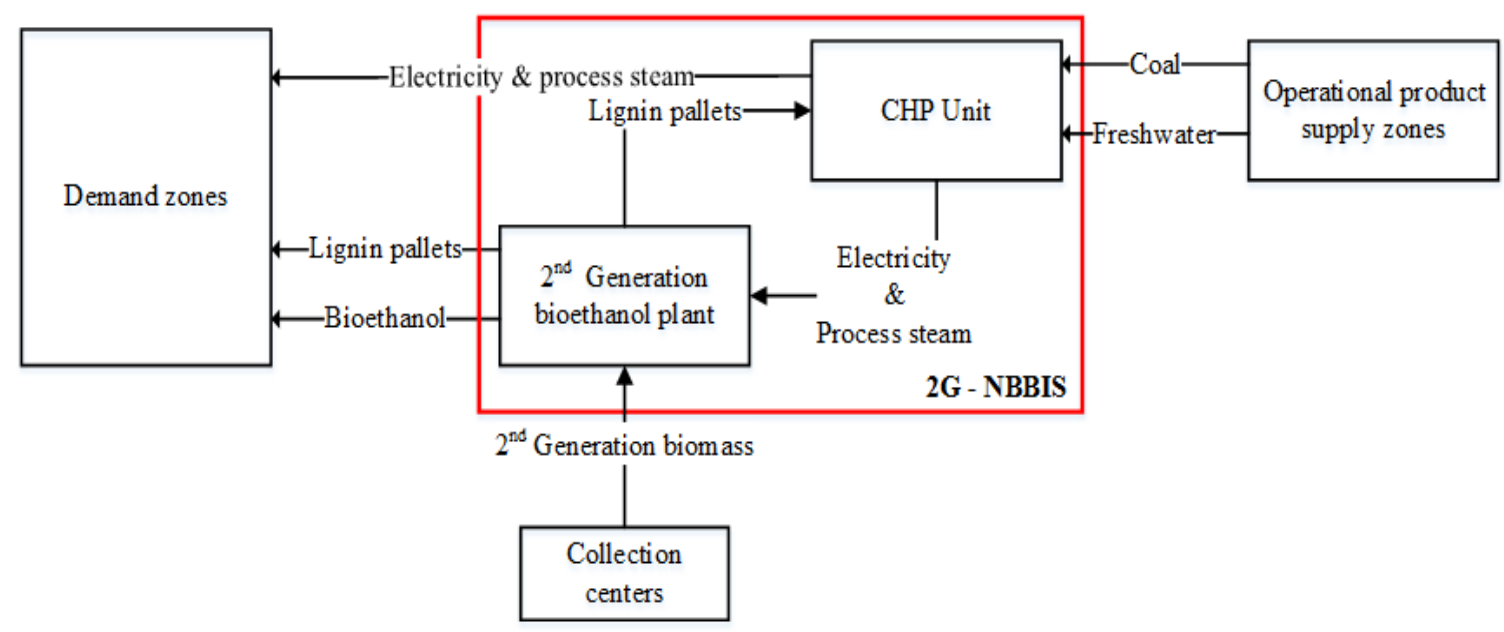

Figure 55. Configuration of 2G-NBBIS 


\subsection{Proposed stochastic model and solution procedure}

This section presents the proposed stochastic model and the solution procedure used to solve the model.

\subsubsection{Proposed stochastic model}

A stochastic model is proposed to design an optimal SHGBSC that considers economic, environmental, social, and energy intensity aspects of sustainability under uncertainties. This section presents the mathematical formulation of the proposed model.

\subsubsection{Notations}

\section{Sets/Indices}

$i \quad$ Index for $1^{\text {st }}$ generation biomass supply zones $(i=1,2,3 \ldots \mathrm{I})$

in Index for $2^{\text {nd }}$ generation biomass supply zones (in $=1,2,3 \ldots \mathrm{IN}$ )

$i^{\prime} \quad$ Index for supply zones

$j \quad$ Index for demand zones $(j=1,2,3 \ldots \mathrm{J})$

$r \quad$ Index for $1^{\text {st }}$ generation bioethanol plants $(r=1,2,3 \ldots \mathrm{R})$

$m^{\prime} \quad$ Index for new $2 \mathrm{G}-\mathrm{SA}\left(m^{\prime}=1,2,3 \ldots R N^{\prime}\right)$

$m^{\prime \prime} \quad$ Index for new 2G-CBIS $\left(r n^{\prime \prime}=1,2,3 \ldots R N^{\prime \prime}\right)$

$r n^{\prime \prime \prime} \quad$ Index for new 2G-BBIS $\left(r n^{\prime \prime \prime}=1,2,3 \ldots R N^{\prime \prime \prime}\right)$

$r n \quad$ Index for $2^{\text {nd }}$ generation bioethanol plants $\left(r n=r n^{\prime} \cup r n^{\prime \prime} \cup r n^{\prime \prime \prime}\right)$

$r^{\prime} \quad$ Index for bioethanol plant locations

$c \quad$ Index for $1^{\text {st }}$ generation biomass collection zones $\left({ }_{c}=1,2,3 \ldots \mathrm{C}\right)$

cn Index for New $2^{\text {nd }}$ generation collection center zones $\left(c_{c n}=1,2,3 \ldots \mathrm{CN}\right)$

$c^{\prime} \quad$ Index for collection centers 
Index for operational product supply zones required for existing $1^{\text {st }}$ generation bioethanol plant $\left({ }_{o s}=1,2,3 \ldots\right.$ OS $)$

osn' Index for operational product supply zones required for new $2^{\text {nd }}$ generation bioethanol plant operating in standalone mode $\left(O S n^{\prime}=1,2,3 \ldots O S N^{\prime}\right)$

osn" Index for operational product supply zones required for new $2^{\text {nd }}$ generation bioethanol plant operating in CBIS $\left(\right.$ osn $\left.^{\prime \prime}=1,2,3 \ldots O S N^{\prime \prime}\right)$

osn'" Index for operational product supply zones required for new $2^{\text {nd }}$ generation bioethanol plant operating in BBIS $\left(\operatorname{osn}^{\prime \prime \prime}=1,2,3 \ldots O S N^{\prime \prime \prime}\right)$

osn'" Index for operational product supply zones required for new $2^{\text {nd }}$ generation bioethanol plant $\left(o s n^{\prime \prime \prime}=o s n^{\prime} \cup o s n^{\prime \prime} \cup o s n^{\prime \prime \prime}\right)$

os $\quad$ Index for operational products

$o^{\prime} \quad$ Index for operational products

$e \quad$ Index for $1^{\text {st }}$ generation bioethanol

en $\quad$ Index for $2^{\text {nd }}$ generation bioethanol

$k \quad$ Index for $1^{\text {st }}$ generation by-products $(k=1,2,3 \ldots \mathrm{K})$

$e^{E} \quad$ Index for electricity as by-product in new BBIS

$k n^{\prime} \quad$ Index for $2^{\text {nd }}$ generation by-products produced when the plant is standalone $\left(k n^{\prime}=1\right.$, $\left.2,3 \ldots K N^{\prime}\right)$

$k n^{\prime \prime} \quad$ Index for $2^{\text {nd }}$ generation by-products produced when the bioethanol plant operates in CBIS mode $\left(k n^{\prime \prime}=1,2,3 \ldots K N^{\prime \prime}\right)$

$k n^{\prime \prime \prime} \quad$ Index for $2^{\text {nd }}$ generation by-products produced when the bioethanol plant operates in BBIS mode $\left(k n^{\prime \prime \prime}=1,2,3 \ldots K N^{\prime \prime \prime}\right)$ 


\begin{tabular}{|c|c|}
\hline$k n$ & Index for $2^{\text {nd }}$ generation by-products $\left(k n=k n^{\prime} \cup k n^{\prime \prime} \cup k n^{\prime \prime \prime}\right)$ \\
\hline$k^{E}$ & Index for by-products of the CHP plant \\
\hline$b$ & Index for $1^{\text {st }}$ generation biomass $(b=1,2,3 \ldots \mathrm{B})$ \\
\hline$b n$ & Index for $2^{\text {nd }}$ generation biomass $(b n=1,2,3 \ldots \mathrm{BN})$ \\
\hline$o$ & Index for existing $1^{\text {st }}$ generation bioethanol plant operation products $\left({ }_{o}=1,2,3 \ldots \mathrm{O}\right)$ \\
\hline$o n^{\prime}$ & $\begin{array}{l}\text { Index for operational products when the new } 2^{\text {nd }} \text { generation bioethanol plant is } \\
\text { operating in standalone mode }\left(o n^{\prime}=1,2,3 \ldots O N^{\prime}\right)\end{array}$ \\
\hline$o n^{\prime \prime}$ & $\begin{array}{l}\text { Index for operational products when the new } 2^{\text {nd }} \text { generation bioethanol plant is } \\
\text { operating in CBIS mode }\left(o n^{\prime \prime}=1,2,3 \ldots O N^{\prime \prime}\right)\end{array}$ \\
\hline$o n^{\prime \prime \prime}$ & $\begin{array}{l}\text { Index for operational products when the new } 2^{\text {nd }} \text { generation bioethanol plant is } \\
\text { operating in new BBIS mode }\left(o n^{\prime \prime \prime}=1,2,3 \ldots O N^{\prime \prime \prime}\right)\end{array}$ \\
\hline on & Index for $2^{\text {nd }}$ generation bioethanol operational products $\left(\right.$ on $\left.=o n^{\prime} \cup o n^{\prime \prime} \cup o n^{\prime \prime \prime}\right)$ \\
\hline$m$ & Index for transportation modes $(m=1,2,3 \ldots \mathrm{M})$ \\
\hline$t$ & Index for time periods $(t=1,2,3 \ldots \mathrm{T})$ \\
\hline$\xi$ & Index for scenarios $(\xi=1,2,3 \ldots \mathrm{S})$ \\
\hline$g$ & Index for products \\
\hline$G^{\prime}$ & Index for all output products $\left\{G^{\prime} \in e \cup e n \cup e^{E} \cup k \cup k n \cup k^{E}\right\}$ \\
\hline$G^{\prime \prime}$ & Index for storable end products and biomass $G^{\prime \prime} \in\{e \cup e n \cup k \cup k n \cup b \cup b n\}$ \\
\hline$G^{\prime \prime \prime}$ & Index for bioethanol and its by products $\left\{G^{\prime \prime \prime} \in e \cup e n \cup k \cup k n\right\}$ \\
\hline
\end{tabular}

Parameters

$P_{g t \xi}^{j} \quad$ Price of selling product $g$ at demand zone $j$ in time period $t$ under scenario $\xi$ 
$\bar{c}_{g}^{r^{\prime} j m} \quad$ Fixed cost of shipping product $g$ from bioethanol plant $r^{\prime}$ to demand zone $j$ by using transportation mode $m$

$c_{g t \xi}^{r^{\prime} j m} \quad$ Variable cost of shipping product $g$ from bioethanol plant $r^{\prime}$ to demand zone $j$ by using transportation mode $m$ in time period $t$ under scenario $\xi$

$\bar{c}_{g}^{c^{\prime} r^{\prime} m} \quad$ Fixed cost of shipping biomass $g$ from collection center $c^{\prime}$ to bioethanol production plant $r^{\prime}$ by transportation mode $m$

$C_{g t}^{c^{\prime} r^{\prime} m} \quad$ Variable cost of shipping biomass $g$ from collection center $c^{\prime}$ to bioethanol production plant $r^{\prime}$ by transportation mode ${ }_{m}$ in time period $t$

$c e_{g}^{r^{\prime}} \quad$ Cost of expanding bioethanol plant $r^{\prime}$ based on amount of bioethanol $g$ produced

$c c_{g}^{r^{\prime}} \quad$ Cost of closing bioethanol plant $r^{\prime}$ based on amount of bioethanol $g$ produced

$p c_{g t}^{r^{\prime}} \quad$ Cost of producing end products $g$ at bioethanol plant $r^{\prime}$ in time period $t$

$h c_{g t}^{r^{\prime}} \quad$ Inventory holding cost of products $g$ at bioethanol plant in time period $t$

$b c_{g t}^{r^{\prime}} \quad$ Inventory backorder cost of products $g$ at bioethanol plant in time period $t$

$o c_{g t}^{o s r^{\prime}} \quad$ Cost of purchasing operational product $g$ from the operational product supply zone os by bioethanol plant $r^{\prime}$ in time period $t$

$C_{t}^{G H G} \quad$ Cost of emitting GHG in time period $t$

$d_{g t \xi}^{j} \quad$ Demand of product $g$ at demand location $j$ in time period $t$ under scenario $\xi$

$B_{g}^{i^{\prime}} \quad$ Maximum allowable land for growing biomass $g$ at supply zone $i^{\prime}$

$\tau_{g}^{m} \quad$ Maximum allowable capacity of the transportation mode $m$ for product $g$

$\varphi_{g}^{r^{\prime}} \quad$ Current capacity of product $g$ of $1^{\text {st }}$ generation bioethanol plant $r^{\prime}$ 
$\varphi e_{g}^{r^{\prime}} \quad$ Maximum allowable expansion capacity of product $g$ at plant $r^{\prime}$

$\varphi n_{g}^{r^{\prime}} \quad$ Maximum allowable capacity for end product $g$ at new $2^{\text {nd }}$ generation bioethanol plant $r^{\prime}$

$\varphi_{g}^{c^{\prime}} \quad$ Maximum allowable capacity for end product at collection center $c^{\prime}$

$\bar{\varphi}_{g}^{c^{\prime}} \quad$ Minimum allowable purchase for existing $1^{\text {st }}$ generation biomass $g$ at collection center $c^{\prime}$

ipCap $\underset{g t}{r^{\prime}}$ Maximum allowable inventory capacity for product $g$ at bioethanol plant $r^{\prime}$ in time period $t$

$i b C a p_{g t}^{r^{\prime}} \quad$ Maximum allowable inventory capacity for product $g$ at bioethanol plant $r^{\prime}$ in time period $t$

$W C a p_{g t \xi}^{o s^{\prime}} \quad$ The maximum allowable supply capacity of product $g$ by operational product supplier os in time period $t$ under scenario $\xi$

$\eta^{r^{\prime}} \quad$ Conversion rate of plant type $r^{\prime}$

$\beta_{g t \xi}^{i^{\prime}} \quad$ Total yield of biomass $g$ at location $i^{\prime}$ in time period $t$ under scenario $\xi$

$\delta_{g}^{i^{\prime}} \quad$ Yield rate of biomass $g$ at location $i^{\prime}$

a Maximum allowable demand that should be fulfilled from $1^{\text {st }}$ generation in percentage $\vartheta_{\xi} \quad$ The probability of occurrence of scenario $\xi$

GHG emissions

$g_{g t}^{r^{\prime} j m}$ The amount of GHG emitted while shipping end products $g$ from bioethanol plant $r^{\prime}$ to demand zone $j$ by using transportation mode ${ }_{m}$ in time period $t$ 
$g_{g t}^{r^{\prime}} \quad$ The amount of GHG emitted while producing end products $g$ at bioethanol plant $r^{\prime}$ in time period $t$

$g_{g t}^{c^{\prime} r^{\prime} m}$ The amount of GHG emitted while shipping biomass $g$ from collection center $c^{\prime}$ to bioethanol plant $r^{\prime}$ by using transportation mode ${ }_{m}$ in time period $t$

$g_{g t}^{i c^{\prime}} \quad$ The amount of GHG emitted while harvesting biomass $g$ at location $i$ by collection center $c^{\prime}$ in time period $t$

$g_{g}^{i} \quad$ The amount GHG emitted while cultivating biomass $g$ at supply zone $i$

$g_{g \xi^{\prime} \xi}^{o r^{\prime}} \quad$ The amount of GHG emitted while shipping operational products $g$ from operational product zones $o s^{\prime}$ to bioethanol plant $r^{\prime}$ by using transportation mode $m$ in time period $t$

$G P_{t} \quad$ The amount of GHG emissions permitted in time period $t$

Resource

$r_{g t}^{r^{\prime} j m} \quad$ The amount of resource used while shipping end products $g$ from bioethanol plant $r^{\prime}$ to demand zone $j$ by using transportation mode $m$ in time period $t$

$r_{g t}^{r^{\prime}} \quad$ The amount of resource used while producing end products $g$ at bioethanol plant $r^{\prime}$ in time period $t$

$r_{g t}^{c^{\prime} r^{\prime} m}$ The amount of resource used while shipping biomass $g$ from collection center $c^{\prime}$ to bioethanol plant $r^{\prime}$ by using transportation mode $m$ in time period $t$

$r_{g t}^{i c^{\prime}} \quad$ The amount of resource used while harvesting biomass $g$ at location $i$ by collection center $c^{\prime}$ in time period $t$

$r_{g}^{i} \quad$ The amount resource used while cultivating biomass $g$ at supply zone $i$ 
$r_{g t \xi}^{o r^{\prime} r^{\prime}} \quad$ The amount of resource used while shipping operational products $g$ from operational product supply zones $\alpha s^{\prime}$ to bioethanol plant $r^{\prime}$ by using transportation mode $m$ in time period $t$

\section{Energy}

$e e_{g} \quad$ Energy content in product $g$

$e e_{g t}^{r^{\prime \prime j m}} \quad$ The amount of energy used while shipping end products $g$ from bioethanol plant $r^{\prime}$ to demand zone $j$ by using transportation mode $m$ in time period $t$

$e e_{g t}^{r^{\prime}} \quad$ The amount of energy used while producing end products $g$ at bioethanol plant $r^{\prime}$ in time period $t$

$e e_{g t}^{c^{\prime} r^{\prime} m}$ The amount of energy used while shipping biomass $g$ from collection center $c^{\prime}$ to bioethanol plant $r^{\prime}$ by using transportation mode $m$ in time period $t$

$e e_{g t}^{i c^{\prime}} \quad$ The amount of energy used while harvesting biomass $g$ at location $i$ by collection center $c^{\prime}$ in time period $t$

$e e_{g}^{i^{\prime}} \quad$ The amount energy used while cultivating biomass $g$ at supply zone $i$

$e e_{g t \xi}^{o r^{\prime} r^{\prime}} \quad$ The amount of resource used while shipping operational products $g$ from operational product supply zones $o s^{\prime}$ to bioethanol plant $r^{\prime}$ by using transportation mode $m$ in time period $t$

$E E_{\text {Permi }}$ The minimum allowable efficiency for the entire bioethanol supply chain

Decision Variables

Binary variables 
$t_{g}^{r^{\prime j m}} \quad 1$, if product $g$ is shipped from bioethanol plant $r^{\prime}$ to $j$ by using the transportation mode $m$; else 0

$t_{g}^{c^{\prime} r^{\prime} m} \quad 1$, if product $g$ is shipped from $c^{\prime}$ to $r^{\prime}$ by transportation mode $m$; else 0

$v_{o p e n}^{r^{\prime}} \quad 1$, if existing $1^{\text {st }}$ generation bioethanol plant is open; else 0

$v_{\text {clost }}^{r^{\prime}} \quad 1$, if existing $1^{\text {st }}$ generation bioethanol plant is close; else 0

$v_{\text {new }}^{r^{\prime}} \quad 1$, if new $2^{\text {nd }}$ generation bioethanol plant is open; else 0

Positive variables

$s_{g t \xi}^{j} \quad$ The amount of product $g$ sold at the demand zone $j$ in time period $t$ under scenario $\xi$

$S L_{g t \xi}^{j} \quad$ The amount of demand for product $g$ not met at demand zone $j$ in time period $t$ under scenario $\xi$

$S_{g t \xi}^{r^{\prime j j m}} \quad$ The amount of product $g$ shipped from bioethanol plant $r^{\prime}$ to demand zone $j$ by using the transportation mode $m$ in time period $t$ under scenario $\xi$

$s_{g t \xi}^{r^{\prime}} \quad$ The total amount of products $g$ sold by plant $r^{\prime}$ in time period $t$ under any given scenario $\xi$

$z_{g t \xi}^{r^{\prime}} \quad$ The amount of end products $g$ produced at bioethanol plant $r^{\prime}$ in time period $t$ under scenario $\xi$

$\bar{z}_{g t \xi}^{r^{\prime}} \quad$ Designed capacity of end products $g$ at bioethanol plant $r^{\prime}$ in time period $t$ under scenario $\xi$ 
$z u_{g t \xi}^{r^{\prime}} \quad$ The amount of end products $g$ produced and used at bioethanol plant $r^{\prime}$ in time period $t$ under scenario $\xi$

$x_{g t \xi}^{r^{\prime}} \quad$ The amount of biomass $g$ used at bioethanol plant $r^{\prime}$ in time period $t$ under scenario $\xi$

$x p_{g t \xi}^{r^{\prime}} \quad$ The amount of biomass $g$ purchased at bioethanol plant $r^{\prime}$ in time period $t$ under scenario $\xi$

$x p_{g t \xi}^{c^{\prime} r^{\prime} m} \quad$ The amount of biomass $g$ shipped from collection center $c^{\prime}$ to $r^{\prime}$ in time period $t$ under scenario $\xi$

$x c_{g t \xi}^{c^{\prime}} \quad$ The amount of biomass $g$ collected or sold by collection center $c^{\prime}$ in time period $t$ under the scenario $\xi$

$x c_{g t \xi}^{i^{\prime \prime} c^{\prime}} \quad$ The amount of biomass $g$ shipped from biomass supply zone $i^{\prime}$ to the collection center $c^{\prime}$ in time period $t$ under the scenario $\xi$

$i p_{g t \xi}^{r^{\prime}} \quad$ Inventory holding cost when end products $g$ at bioethanol plant $r^{\prime}$ in time period $t$ under scenario $\xi$

$i b_{g t \xi}^{r^{\prime}} \quad$ Inventory backorder cost when end products $g$ at bioethanol plant $r^{\prime}$ in time period $t$ under scenario $\xi$

$y_{g t \xi}^{i^{\prime}} \quad$ The amount of land used for biomass $g$ at location $i^{\prime}$ in time period $t$ under scenario $\xi$

$w_{g t \xi}^{r^{\prime}} \quad$ The amount of operational product $g$ used at bioethanol plant $r^{\prime}$ in time period $t$ under scenario $\xi$ 
$w p_{g t \xi}^{r^{\prime}} \quad$ The amount of operational product $g$ purchased by bioethanol plant $r^{\prime}$ in time period $t$ under scenario $\xi$

$w p_{g t \xi}^{o s^{\prime} r^{\prime}} \quad$ The amount of operational product $g$ shipped from operational product supply zones os to bioethanol plants $r^{\prime}$ in time period $t$ under scenario $\xi$

$w s_{g t \xi}^{o s^{\prime}} \quad$ The total amount of operational product $g$ sold by operational product supply zone $o s^{\prime}$ in time period $t$ under scenario $\xi$

$L_{g t \xi}^{r^{\prime}} \quad$ The amount of product $g$ disposed at bioethanol plant $r^{\prime}$ in time period $t$ under scenario $\xi$

$g t_{t} \quad$ The total amount of GHG emitted for entire supply chain in time period $t$ under scenario $\xi$

$r t_{t} \quad$ The total amount of resource used for the entire supply chain in time period $t$

eq The total amount of energy produced for the entire supply chain in time period $t$

et $\quad$ The total amount of energy used for the entire supply chain in time period $t$

EE The energy efficiency of the supply chain

\subsubsection{Objective function}

Equation 5.1 is the objective function which is to maximize the total profit of the bioethanol supply chain. It is obtained by subtracting the total supply chain costs from the total supply chain revenue. The total supply chain revenue is obtained by selling the end products. The total costs include annualized capital cost of both $1^{\text {st }}$ generation and $2^{\text {nd }}$ generation bioethanol plants, annualized capital cost collection centers, production costs, storage costs, cultivation costs and harvesting costs. It should be noted that different IS configurations have different capital costs. 


$$
\begin{aligned}
& \text { Maximize } Z=\sum_{j} \sum_{g \in G^{\prime}} \sum_{t} \sum_{\xi} \vartheta_{\xi} P_{g t \xi}^{j} s_{g t \xi}^{j} \\
& -\sum_{r^{\prime} \in r \cup r n} \sum_{j} \sum_{g \in G^{\prime}} \sum_{m} \bar{c}_{g}^{r^{\prime} j m} t_{g}^{r^{\prime} j m}-\sum_{r^{\prime} \in r \cup r n} \sum_{j} \sum_{g \in G^{\prime}} \sum_{m} \sum_{t} \sum_{\xi} \vartheta_{\xi} c_{g t \xi}^{r^{\prime} j m} s_{g t \xi}^{r^{\prime} j m} \\
& -\sum_{r^{\prime} \in r} \sum_{g \in e} c o_{g}^{r^{\prime}} \varphi_{g}^{r^{\prime}} v_{o p e n}^{r^{\prime}}-\sum_{r^{\prime} \in r} \sum_{g \in e} c e_{g}^{r^{\prime}} \bar{z}_{g t}^{r^{\prime}}-\sum_{r^{\prime} \in r} \sum_{g \in e} \sum_{t} c c_{g}^{r^{\prime}} \varphi_{g}^{r^{\prime}} v_{c l o s e}^{r^{\prime}} \\
& -\sum_{r^{\prime} \in r n^{\prime} \cup r n^{\prime \prime}} c n^{r^{\prime}} v_{\text {new }}^{r^{\prime}}-\sum_{r^{\prime} \in r n^{\prime} \cup r n^{\prime \prime}} \sum_{g \in e n} \sum_{t} c e_{g}^{r^{\prime}} \bar{z}_{g t}^{r^{\prime}} \\
& -\sum_{r^{\prime} \in r n^{\prime \prime \prime}} c n^{r^{\prime}} v_{n e w}^{r^{\prime}}-\sum_{r^{\prime} \in r^{\prime \prime \prime}} \sum_{g \in e n \cup e^{E}} \sum_{t} c e_{g}^{r^{\prime}} \bar{z}_{g t}^{r^{\prime}} \\
& -\sum_{r^{\prime} \in r \cup r n} \sum_{g \in G^{\prime}} \sum_{t} \sum_{\xi} \vartheta_{\xi} p c_{g t}^{r^{\prime}} z_{g t \xi}^{r^{\prime}} \\
& -\sum_{r^{\prime} \in r \cup r n} \sum_{g \in G^{\prime \prime}} \sum_{t} \sum_{\xi} \vartheta_{\xi} h c_{g t}^{r^{\prime}} i p_{g t \xi}^{r^{\prime}}-\sum_{r^{\prime} \in r \cup r n} \sum_{g \in G^{\prime \prime}} \sum_{t} \sum_{\xi} \vartheta_{\xi} b c_{g t}^{r^{\prime}} i b_{g t \xi}^{r^{\prime}} \\
& -\sum_{c^{\prime} \in c \cup c n} \sum_{r^{\prime} \in r \cup r n} \sum_{g \in b \cup b n} \sum_{m} \bar{c}_{g}^{c^{\prime} r^{\prime} m} t_{g}^{c^{c^{\prime} r^{\prime} m}}-\sum_{c^{\prime} \in c \cup c n} \sum_{r^{\prime} \in r \cup r n} \sum_{g \in b \cup b n} \sum_{m} \sum_{t} \sum_{\xi} \vartheta_{\xi} c_{g t}^{c^{\prime} r^{\prime} m} x p_{g t \xi}^{c^{\prime} r^{\prime} m} \\
& -\sum_{c^{\prime} \in c \cup c n} c n^{c^{\prime}} v^{c^{\prime}}-\sum_{c^{\prime} \in c \cup c n} \sum_{g \in b \cup b n} \sum_{t} \sum_{\xi} \vartheta_{\xi} c s_{g t}^{c^{\prime}} x c_{g t \xi}^{c^{\prime}} \\
& -\sum_{i^{\prime} \in i \cup i n} \sum_{g \in b \cup b n} \sum_{t} \sum_{\xi} r c_{g}^{i^{\prime}} y_{g t \xi}^{i^{\prime}}-\sum_{i^{\prime} \in i \cup i n} \sum_{g \in b \cup b n} \sum_{t} \sum_{\xi} \vartheta_{\xi} c v t_{g}^{i^{\prime}} y_{g t \xi}^{i^{\prime}}-\sum_{i^{\prime} \in i \cup i n} \sum_{c^{\prime} \in c \cup c n} \sum_{t} \sum_{\xi} \vartheta_{\xi} c_{g t}^{i^{\prime} c^{\prime}} x c_{g t \xi}^{i^{\prime} c^{\prime}} \\
& -\sum_{o s} \sum_{r^{\prime} \in r \cup r n} \sum_{g \in o} \sum_{t} \sum_{\xi} \vartheta_{\xi} o c_{g t}^{o s^{\prime} r^{\prime}} w p_{g t \xi}^{o s^{\prime} r^{\prime}} \\
& -\sum_{j} \sum_{g \in G^{\prime \prime}} \sum_{t} \sum_{\xi} \vartheta_{\xi} S C_{g t \xi}^{j} S L_{g t \xi}^{j}
\end{aligned}
$$

\subsubsection{GHG emissions constraints}

Equation 5.2 and Equation 5.3 represents the GHG emissions constraints. Equation 5.2 estimates the amount of GHG emitted during any time period over all the scenarios. The estimate

of GHG emission in a given time period is the sum of the GHG emitted while transporting products, GHG emitted while producing bioethanol (at bioethanol plants) and GHG emitted while 
producing biomass. Equation 5.3 ensures GHG emissions to be below than the maximum allowable permit limit in any given time period.

$$
\begin{aligned}
g t_{t}= & \sum_{r^{\prime} \in r \cup r n} \sum_{j} \sum_{g \in G^{\prime \prime}} \sum_{m} \sum_{\xi} \vartheta_{\xi} g_{g t}^{r^{\prime j} m} s_{g t \xi}^{r^{\prime} j m} \\
& +\sum_{r^{\prime} \in r \cup r n} \sum_{g \in G^{\prime}} \sum_{\xi} \vartheta_{\xi} g_{g t}^{r^{\prime}} r_{g t \xi}^{r^{\prime}} \\
& +\sum_{c^{\prime} \in c \cup c n} \sum_{r^{\prime} \in r \cup r n} \sum_{g \in b \cup b n} \sum_{m} \sum_{\xi} \vartheta_{\xi} g_{g t}^{c^{\prime} r^{\prime} m} x p_{g t^{\prime} \xi}^{c^{\prime} r^{\prime} m} \\
& +\sum_{i} \sum_{c^{\prime} \in c \cup c n} \sum_{g \in b \cup b n} \sum_{\xi} \vartheta_{\xi} g_{g t}^{i c^{\prime}} x c_{g t \xi}^{i c^{\prime}} \\
& +\sum_{i} \sum_{g \in b \cup b n} \sum_{\xi} \vartheta_{\xi} g_{g}^{i} \beta_{g t \xi}^{i} \\
& +\sum_{o s^{\prime} \in o s \cup o s n} \sum_{r^{\prime} \in r \cup r n} \sum_{g \in o \cup o n} \sum_{m} \vartheta_{\xi} g_{g t t^{\prime} \xi}^{o r^{\prime} r^{\prime}} w p_{g t_{\xi}}^{o r^{\prime} r^{\prime}} \forall t \\
g t_{t} \leq & \leq P_{t} \forall t
\end{aligned}
$$

\subsubsection{Social aspect constraints}

Equation 5.4 - Equation 5.6 represent the social aspect of sustainability. Equation 5.4 regulates that a maximum of $\mathrm{a} \%$ of the demand is met from $1^{\text {st }}$ generation bioethanol. Equation 5.5 enforces that a minimum of (1-a) \% of demand should be met from $2^{\text {nd }}$ generation bioethanol. Equation 5.6 represents that the total demand should come from a combination of $1^{\text {st }}$ generation and $2^{\text {nd }}$ generation bioethanol.

$$
\begin{aligned}
& \sum_{r^{\prime} \in r} \sum_{m} s_{g t \xi}^{r^{\prime j j m}} \leq a \sum_{j} s_{g \in e \cup e n t \xi}^{j} \forall g \in e, \forall t, \forall \xi \\
& \sum_{r^{\prime} \in r n} \sum_{m} s_{g t \xi}^{r^{\prime} j m} \geq(1-a) \sum_{j} s_{g \in e \cup e n t \xi}^{j} \forall g \in e n, \forall t, \forall \xi \\
& \sum_{r^{\prime} \in r \cup r n} \sum_{m} s_{g t \xi}^{r^{\prime} j m}=\sum_{j} s_{g t \xi}^{j} \forall g \in e \cup e n, \forall t, \forall \xi
\end{aligned}
$$




\subsubsection{Resource utilization constraints}

Equation 5.7 and Equation 5.8 represent the resource utilization constraints. Equation 5.7 represents the estimated amount of resource or energy used during any time period over all the scenarios. The amount of resource or energy used is the sum of resource or energy used while shipping products, resource used while producing bioethanol, and resource or energy used while producing biomass. Equation 5.8 ensures that the estimated amount of resource or energy used in any given time period under any given scenario should be less than the maximum allowable resource permit limit.

$$
\begin{aligned}
& r t_{t}=\sum_{r^{\prime} \in r \cup r n} \sum_{j} \sum_{g \in G^{\prime \prime}} \sum_{m} \sum_{\xi} \vartheta_{\xi} r_{g t}^{r^{\prime} j m} s_{g t t^{\prime}}^{r^{\prime} j m} \\
& +\sum_{r^{\prime} \in r \cup r n} \sum_{g \in G^{\prime}} \sum_{\xi} \vartheta_{\xi} r_{g t}^{r^{\prime}} z_{g t \xi}^{r^{\prime}} \\
& +\sum_{c^{\prime} \in c \cup c n} \sum_{r^{\prime} \in r \cup r n} \sum_{g \in b \cup b n} \sum_{m} \sum_{\xi} \vartheta_{\xi} r_{g t}^{c^{\prime} r^{\prime} m} x p_{g t^{\prime} \xi}^{c^{\prime} r^{\prime} m} \\
& +\sum_{i} \sum_{c^{\prime} \in c \cup c n} \sum_{g \in b \cup b n} \sum_{\xi} \vartheta_{\xi} r_{g t}^{i c^{\prime}} x c_{g t \xi}^{i c^{\prime}} \\
& +\sum_{i^{\prime}} \sum_{g \in b \cup b n} \sum_{\xi} \vartheta_{\xi} r_{g}^{i^{\prime}} \beta_{g t \xi}^{i^{\prime}} \\
& +\sum_{o s^{\prime} \in o s \cup o s n} \sum_{r^{\prime} \in r \cup r n} \sum_{g \in o \cup o n} \sum_{m} \vartheta_{\xi} r_{g \xi^{o r^{\prime}}}^{o r^{\prime}} w p_{g t_{\xi}}^{o s^{\prime} r^{\prime}} \forall t \\
& \sum_{t} r t_{t} \leq \sum_{t} R P_{t}
\end{aligned}
$$

\subsubsection{Energy efficiency constraints}

Equation 5.9 - Equation 5.12 present the energy efficiency constraints. Equation 5.9 enables to estimate the amount of energy produced in each time period. Equation 5.10 estimates the amount of energy used during any time period over all the scenarios. The amount of energy used is the sum of energy used while shipping products, resource or energy used while producing 
bioethanol, and resource or energy used while producing biomass. Equation 5.11 calculates the energy efficiency of ISHGBSC. Equation 5.12 constrains energy efficiency to be above the minimum allowable permit limit.

$$
\begin{aligned}
& e o_{t}=\sum_{g \in G^{\prime}} \sum_{j} \sum_{\xi} \vartheta_{\xi} e e_{g} s_{g t \xi}^{j} \\
& e t_{t}=\sum_{r^{\prime} \in r \cup r n} \sum_{j} \sum_{g \in G^{\prime \prime}} \sum_{m} \sum_{\xi} \vartheta_{\xi} e e_{g t}^{r^{\prime j} m} S_{g t \xi}^{r^{\prime j j m}} \\
& +\sum_{r^{\prime} \in r \cup r n} \sum_{g \in G^{\prime}} \sum_{\xi} \vartheta_{\xi} e e_{g t}^{r^{\prime}} z_{g t \xi}^{r^{\prime}} \\
& +\sum_{c^{\prime} \in \subset \cup c c} \sum_{r^{\prime} \in r \cup r n} \sum_{g \in b \cup b n} \sum_{m} \sum_{\xi} \vartheta_{\xi} e e_{g t}^{c^{c^{\prime} r^{\prime} m}} x p_{g t_{\xi}}^{c^{r^{\prime} m}} \\
& +\sum_{i} \sum_{c^{\prime} \in c \cup c n} \sum_{g \in b \cup b n} \sum_{\xi} \vartheta_{\xi} e e_{g t}^{i c^{\prime}} x c_{g t \xi}^{i c^{\prime}} \\
& +\sum_{i^{\prime}} \sum_{g \in b \cup b n} \sum_{\xi} \vartheta_{\xi} e e_{g}^{i^{\prime}} \beta_{g t \xi}^{i^{\prime}} \\
& +\sum_{o s^{\prime} \in o s \cup o s n} \sum_{r^{\prime} \in r \cup r n} \sum_{g \in o \cup o n} \sum_{m} \vartheta_{\xi} e e_{g t t^{o s}}^{o r^{\prime}} w p_{g t t^{\prime}}^{o r^{\prime}} \forall t \\
& E E=\frac{\sum_{t} e o_{t}}{\sum_{t} e t_{t}}
\end{aligned}
$$

$E E \geq E E_{\text {Permit }}$

\subsubsection{Demand constraints}

Equation 5.13 represents the sum of end products sold and unmet demand should be equal to the demand.

$S_{g t \xi}^{j}+S L_{g t \xi}^{j}=d_{g t \xi}^{j} \forall j, \forall g \in G^{\prime \prime \prime}, \forall t, \forall \xi$ 


\subsubsection{Transportation constraints}

\subsection{End products}

Equation 5.14 - Equation 5.19 are the transportation constraints for end products. Equation 5.14 and Equation 5.15 enforce that all the end products shipped from all bioethanol plants are equal to the sum of all end products received at all the demand zones. Equation 5.16 indicates that the amount of products shipped from the bioethanol plant to the demand zone should be less than the capacity of the carrier or transportation mode. Equation 5.17 and Equation 5.18 indicate that the transportation mode between bioethanol plant and demand zone can only exist if the existing plant is open. Otherwise, there should be no transportation. Equation 5.19 is the transportation mode constraint for new bioethanol plant and indicates that transportation mode can only exist if the new bioethanol plant is opened.

$$
\begin{aligned}
& s_{g t \xi}^{j}=\sum_{r^{\prime} \in r \cup r n} \sum_{m} s_{g t \xi}^{r^{\prime} j m} \forall j, \forall g \in G^{\prime \prime \prime}, \forall t, \forall \xi \\
& s_{g t \xi}^{r^{\prime}}=\sum_{j} \sum_{m} s_{g t \xi}^{r^{\prime} j m} \forall r^{\prime} \in r \cup r n, \forall g \in G^{\prime \prime \prime}, \forall t, \forall \xi \\
& s_{g t \xi}^{r^{\prime} j m} \leq \tau_{g}^{m} t_{g}^{r^{\prime} j m} \forall g \in G^{\prime \prime \prime}, \forall r^{\prime} \in r \cup r n, \forall j, \forall m, \forall t, \forall \xi \\
& \sum_{m} t_{g}^{r^{\prime} j m} \leq M v_{o p e n}^{r^{\prime}} \forall r^{\prime} \in r, \forall g \in G^{\prime \prime \prime}, \forall j \\
& \sum_{m} t_{g}^{r^{\prime} j m} \leq M\left(1-v_{\text {close }}^{r^{\prime}}\right) \forall r^{\prime} \in r, \forall g \in G^{\prime \prime \prime}, \forall j \\
& \sum_{m} t_{g}^{r^{\prime} j m} \leq M v_{\text {new }}^{r^{\prime}} \forall r^{\prime} \in r n, g \in G^{\prime \prime \prime}, \forall j
\end{aligned}
$$

\subsection{Input products}

Equation 5.20 - Equation 5.28 are the transportation constraints for the input products of bioethanol plants. Equation 5.20 - Equation 5.22 enforce the total amount of biomass sold by all 
collection centers to be equal to the total amount of biomass purchased by all bioethanol plants. Equation 5.20 is for existing $1^{\text {st }}$ generation bioethanol plant and Equation 5.21 is for new $2^{\text {nd }}$ generation bioethanol plant. Equation 5.22 is for the collection centers. Equation 5.23 and Equation 5.24 enforce the total amount of operational products sold by all operational product supply zones, such as coal, electricity, and freshwater, to be equal to the total amount of biomass purchased by all bioethanol plants. Equation 5.25 and Equation 5.26 indicate that transportation modes can only exist if the existing $1^{\text {st }}$ generation bioethanol plant is open. Otherwise, transportation cannot exist. Equation 5.27 indicates that transportation mode can only exist if new $2^{\text {nd }}$ generation plant is opened. Similarly, Equation 5.28 indicates that transportation mode can only exist if the collection center is open.

$$
\begin{aligned}
& x p_{g t \xi}^{r^{\prime}}=\sum_{c^{\prime} \in C} \sum_{m} x p_{g t \xi}^{c^{\prime} r^{\prime} m} \forall r^{\prime} \in r, g \in b, \forall t, \forall \xi \\
& x p_{g t \xi}^{r^{\prime}}=\sum_{c^{\prime} \in c n} \sum_{m} x p_{g t}^{c^{\prime} r^{\prime} m} \forall r^{\prime} \in r n, g \in b n, \forall t, \forall \xi \\
& x c_{g t \xi}^{c^{\prime}}=\sum_{r^{\prime} \in r} \sum_{m} x p_{g t_{\xi}}^{c^{\prime} r^{\prime} m} \forall c^{\prime} \in c \cup c n, \forall g \in b \cup b n, \forall t, \forall \xi \\
& w p_{g t \xi}^{r^{\prime}}=\sum_{o s^{\prime} \in o s \cup o s n} w p_{g t^{\prime} \xi^{\prime}}^{o r^{\prime}} \forall r^{\prime} \in r \cup r n, \forall g \in O \cup o n, \forall t, \forall \xi \\
& w s_{g t \xi}^{o s^{\prime}}=\sum_{r^{\prime} \in r \cup r n} w p_{g t_{\xi}}^{o r^{\prime}} \forall 0 s^{\prime} \in O S \cup o s n, \forall g \in O \cup o n, \forall t, \forall \xi \\
& \sum_{m} t_{g}^{c^{r^{\prime} m}} \leq M v_{\text {open }}^{r^{\prime}} \forall r^{\prime} \in r, \forall g \in b, \forall c^{\prime} \\
& \sum_{m} t_{g}^{c^{\prime} r^{\prime} m} \leq M\left(1-v_{\text {close }}^{r^{\prime}}\right) \forall r^{\prime} \in r, \forall g \in b, \forall c^{\prime} \\
& \sum_{m} t_{g}^{c^{\prime} r^{\prime} m} \leq M v_{n e w}^{r^{\prime}} \forall r^{\prime} \in r, \forall g \in b, \forall c^{\prime} \\
& \sum_{m} t_{g}^{c^{\prime} r^{\prime} m} \leq M v^{c^{\prime}} \forall c^{\prime} \in c \cup c n, \forall g \in b, \forall r^{\prime}
\end{aligned}
$$




\subsubsection{Existing $1^{\text {st }}$ generation bioethanol constraint}

Equation 5.29 forces that the existing $1^{\text {st }}$ generation plant can either be open or closed, but not both.

$$
v_{\text {open }}^{r^{\prime}}+v_{\text {close }}^{r^{\prime}}=1 \forall r^{\prime} \in r
$$

\subsubsection{Bioethanol plant production constraints}

Equation 5.30 - Equation 5.37 are the production constraints for all bioethanol plant configurations. Equation 5.30 enforces bioethanol production to be greater than the amount of end products sold for all bioethanol plant configurations. Equation 5.31 is the end product constraint for $2 \mathrm{G}-\mathrm{NBBIS}$. It indicates that electricity and process steam produced by the CHP unit of $2 \mathrm{G}-$ NBBIS should be either used or sold to the demand zones or disposed. No inventory can be held for electricity and process steam. Equation 5.32 constrains the bioethanol production at the existing $1^{\text {st }}$ generation bioethanol plant. It indicates that bioethanol production should less than existing capacity and the expansion capacity. Equation 5.33 constrains the production of certain amount of bioethanol if the existing bioethanol plant is open. Equation 5.34 and Equation 5.35 indicates that production cannot be done if the existing $1^{\text {st }}$ generation bioethanol plant is closed. Equation 5.36 constrains the production of bioethanol at 2G-SA and 2G-CBIS. It indicates that the bioethanol production should be less than the maximum allowable production capacity. Equation 5.37 is the production constraint for 2G-NBBIS. It constrains both bioethanol production and CHP unit capacity. It indicates that bioethanol production should be less than the maximum allowable bioethanol capacity. In addition, Electricity generated by CHP unit should be less than the maximum allowable.

$$
\begin{aligned}
& z_{g t \xi}^{r^{\prime}} \geq s_{g t \xi}^{r^{\prime}}, \forall g \in G^{\prime \prime \prime}, \forall r^{\prime} \in r \cup r n, \forall t, \forall \xi \\
& z_{g t \xi}^{r^{\prime}}=s_{g t \xi}^{r^{\prime}}+z u_{g t \xi}^{r^{\prime}}+L_{g t \xi}^{r^{\prime}} \forall g \in e^{E} \cup k^{E}, \forall r^{\prime} \in r n^{\prime \prime \prime}, \forall t, \forall \xi
\end{aligned}
$$




$$
\begin{aligned}
& z_{g t \xi}^{r^{\prime}} \leq \varphi_{g}^{r^{\prime}} v_{o p e n}^{r^{\prime}}+\bar{z}_{g t}^{r^{\prime}} \forall r^{\prime} \in r, g \in e, \forall t, \forall \xi \\
& z_{g t \xi}^{r^{\prime}} \geq \operatorname{zmin}_{\mathrm{g}}^{\mathrm{r}^{\prime}} v_{\text {open }}^{r^{\prime}} \forall r^{\prime} \in r, \forall g \in e, \forall t, \forall \xi \\
& z_{g t \xi}^{r^{\prime}} \leq \varphi_{g}^{r^{\prime}}\left(1-v_{\text {close }}^{r^{\prime}}\right)+\bar{z}_{g t}^{r^{\prime}} \forall r^{\prime} \in r, g \in e, \forall t, \forall \xi \\
& z_{g t \xi}^{r^{\prime}} \leq \varphi e_{g}^{r^{\prime}}\left(1-v_{\text {close }}^{r^{\prime}}\right) \forall r^{\prime} \in r, g \in e, \forall t, \forall \xi \\
& z_{g t \xi}^{r^{\prime}} \leq \varphi n_{g}^{r^{\prime}} v_{\text {new }}^{r^{\prime}} \forall r^{\prime} \in r n^{\prime} \cup r n^{\prime \prime}, \forall g \in e n, \forall t, \forall \xi \\
& z_{g t \xi}^{r^{\prime}} \leq \varphi n_{g}^{r^{\prime}} v_{\text {new }}^{r^{\prime}} \forall r^{\prime} \in r n^{\prime \prime \prime}, \forall g \in e n \cup e^{E}, \forall t, \forall \xi
\end{aligned}
$$

\subsubsection{Existing 1st generation bioethanol plant expansion constraints}

Equation 5.38 and Equation 5.39 suggests that expansion can only be done if the existing $1^{\text {st }}$ generation bioethanol plant is open, otherwise, expansion cannot be done.

$$
\begin{aligned}
& \bar{z}_{g t}^{r^{\prime}} \leq \varphi e_{g}^{r^{\prime}} v_{o p e n}^{r^{\prime}} \forall r^{\prime} \in r, g \in e, \forall t \\
& \bar{z}_{g t}^{r^{\prime}} \leq \varphi e_{g}^{r^{\prime}}\left(1-v_{\text {close }}^{r^{\prime}}\right) \forall r^{\prime} \in r, g \in e, \forall t
\end{aligned}
$$

\subsubsection{Conversion constraints}

Equation 5.40 - Equation 5.44 presents the conversion rates for end product produced and input products used.

\subsection{End products produced}

Equation 5.40 and Equation 5.41 are co-product production constraints. Equation 5.40 indicates that for 1G-SA, 1G-CBIS, 2G-SA and 2G-CBIS, the product production depends on the amount of bioethanol produced. However, for 2G-NBBIS, the amount of by-products produced depends on both bioethanol production and electricity production. This is given by Equation 5.41

$$
z_{g \in k \cup k n t \xi}^{r^{\prime}}=\eta^{r^{\prime}} z_{g \in e \cup e n t \xi}^{r^{\prime}} \forall g \in k \cup k n^{\prime} \cup k n^{\prime \prime}, \forall r^{\prime} \in r \cup r n^{\prime} \cup r n^{\prime \prime}, \forall t, \forall \xi
$$


$z_{g \in k n^{\prime \prime} \cup k^{E} t \xi}^{r^{\prime}}=\eta^{r^{\prime}} Z_{g \in e n \cup e^{E} t \xi}^{r^{\prime}} \forall g \in k n^{\prime \prime \prime} \cup k^{E}, \forall r^{\prime} \in r \cup r n^{\prime \prime \prime}, \forall t, \forall \xi$

\subsection{Input products used}

Equation 5.42 and Equation 5.43 suggests that the amount of bioethanol and by-products produced depends on the amount of biomass used and its conversion rate. Equation 5.44 indicates that amount of bioethanol and by-products used depends on the amount of operation products such as coal, process steam, electricity used.

$$
\begin{aligned}
& z_{g \in e \cup k t \xi}^{r^{\prime}}=\eta^{r^{\prime}} x_{g \in b t \xi}^{r^{\prime}} \forall r^{\prime} \in r, \forall g \in e \cup k, \forall t, \forall \xi \\
& z_{g \in e n \cup k n t \xi}^{r^{\prime}}=\eta^{r^{\prime}} x_{g \in b n t \xi}^{r^{\prime}} \forall r^{\prime} \in r n, \forall g \in e n \cup k n, \forall t, \forall \xi \\
& w_{g t \xi}^{r^{\prime}}=\eta^{r^{\prime}} z_{g t \xi}^{r^{\prime}} \forall r^{\prime} \in r \cup r n, g \in O \cup o n, \forall t, \forall \xi
\end{aligned}
$$

\subsubsection{Material Balancing constraints}

Equation 5.45 - Equation 5.48 are the material balancing constraints. Equation 5.45 is a material balancing constraints for end products in each time period over all scenarios. The amount of biomass purchased should always be greater than the amount of biomass used over all scenarios. This is given by Equation 5.46. Equation 5.47 represents biomass material balancing in each time period over all given scenarios. Equation 5.48 indicates the material balancing constraint for operational products such as process steam electricity and coal.

$$
\begin{aligned}
& z_{g t \xi}^{r^{\prime}}+i p_{g t-1 \xi}^{r^{\prime}}-i b_{g t-1 \xi}^{r^{\prime}}=s_{g t \xi}^{r^{\prime}}+i p_{g t \xi}^{r^{\prime}}-i b_{g t \xi}^{r^{\prime}} \forall r^{\prime} \in r \cup r n, \forall g \in G^{\prime \prime \prime}, \forall t, \forall \xi \\
& x p_{g t \xi}^{r^{\prime}} \geq x_{g t \xi}^{r^{\prime}} \forall r^{\prime} \in r \cup r n, \forall g \in b \cup b n, \forall t, \forall \xi \\
& x p_{g t \xi}^{r^{\prime}} \geq x_{g t \xi}^{r^{\prime}} \forall r^{\prime} \in r \cup r n, \forall g \in b \cup b n, \forall t, \forall \xi \\
& w p_{g t \xi}^{r^{\prime}}=w_{g t \xi}^{r^{\prime}} \forall r^{\prime} \in r \cup r n, \forall g \in O \cup o n, \forall t, \forall \xi
\end{aligned}
$$




\subsubsection{Inventory constraints}

Equation 5.49 - Equation 5.60 presents the inventory holding, backorder and delay constraints

\subsection{End products}

Equation 5.49 and Equation 5.50 enforces that end product inventory can only be held when the existing $1^{\text {st }}$ generation bioethanol plant is open. Otherwise, inventory cannot be held. Equation 5.51 and Equation 5.52 indicates that end product inventory can only be backordered if the existing $1^{\text {st }}$ generation bioethanol plant is kept open. Else, inventory cannot be backordered. Similarly, Equation 5.53 and Equation 5.54 indicates that end product inventory can be held or backordered only if the new $2^{\text {nd }}$ generation plant is open.

$$
\begin{aligned}
& i p_{g t \xi}^{r^{\prime}} \leq i p C a p_{g t}^{r^{\prime}} v_{o p e n}^{r^{\prime}} \forall r^{\prime} \in r, \forall g \in e \cup k, \forall t, \forall \xi \\
& i p_{g t \xi}^{r^{\prime}} \leq i p \operatorname{Cap}_{g t}^{r^{\prime}}\left(1-v_{\text {close }}^{r^{\prime}}\right) \forall r^{\prime} \in r, \forall g \in e \cup k, \forall t, \forall \xi \\
& i b_{g t \xi}^{r^{\prime}} \leq i b \operatorname{Cap}_{g t}^{r^{\prime}} v_{o p e n}^{r^{\prime}} \forall r^{\prime} \in r, \forall g \in e \cup k, \forall t, \forall \xi \\
& i b_{g t \xi}^{r^{\prime}} \leq i b \operatorname{Cap}_{g t}^{r^{\prime}}\left(1-v_{\text {close }}^{r^{\prime}}\right) \forall r^{\prime} \in r, \forall g \in e \cup k, \forall t, \forall \xi \\
& i p_{g t \xi}^{r^{\prime}} \leq i p \operatorname{Cap}_{g t}^{r^{\prime}} v_{\text {new }}^{r^{\prime}} \forall r^{\prime} \in r n, \forall g \in e n \cup k n, \forall t, \forall \xi \\
& i b_{g t \xi}^{r^{\prime}} \leq i b \operatorname{Cap}_{g t}^{r^{\prime}} v_{\text {new }}^{r^{\prime}} \forall r^{\prime} \in r n, \forall g \in e n \cup k n, \forall t, \forall \xi
\end{aligned}
$$

\subsection{Input products}

Equation 5.55 and Equation 5.56 enforces that biomass inventory can only be held when the existing $1^{\text {st }}$ generation bioethanol plant is open. Otherwise, inventory cannot be held. Equation 5.57 and Equation 5.58 indicates that biomass inventory can only be backordered if the existing $1^{\text {st }}$ generation bioethanol plant is kept open. Else, inventory cannot be backordered. Similarly, 
Equation 5.59 and Equation 5.60 indicates that biomass inventory can be held or backordered only if the new $2^{\text {nd }}$ generation bioethanol plant is open.

$$
\begin{aligned}
& i p_{g t \xi}^{r^{\prime}} \leq i p C a p_{g t}^{r^{\prime}} v_{o p e n}^{r^{\prime}}, \forall r^{\prime} \in r, \forall g \in b, \forall t, \forall \xi \\
& i p_{g t \xi}^{r^{\prime}} \leq i p C a p_{g t}^{r^{\prime}}\left(1-v_{c l o s e}^{r^{\prime}}\right) \forall r^{\prime} \in r, \forall g \in b, \forall t, \forall \xi \\
& i b_{g t \xi}^{r^{\prime}} \leq i b C a p_{g t}^{r^{\prime}} v_{o p e n}^{r^{\prime}} \forall r^{\prime} \in r, \forall g \in b, \forall t, \forall \xi \\
& i b_{g t \xi}^{r^{\prime}} \leq i b C a p_{g t}^{r^{\prime}}\left(1-v_{\text {close }}^{r^{\prime}}\right) \forall r^{\prime} \in r, \forall g \in b, \forall t, \forall \xi \\
& i p_{g t \xi}^{r^{\prime}} \leq i p C a p_{g t}^{r^{\prime}} v_{n e w}^{r^{\prime}} \forall r^{\prime} \in r n, \forall g \in b n, \forall t, \forall \xi \\
& i b_{g t \xi}^{r^{\prime}} \leq i b C a p_{g t}^{r^{\prime}} v_{\text {new }}^{r^{\prime}} \forall r^{\prime} \in r n, \forall g \in b n, \forall t, \forall \xi
\end{aligned}
$$

\subsubsection{Collection center constraints}

Equation 5.61 - Equation 5.64 are collection center constraints. Equation 5.61 and Equation 5.62 are the minimum and maximum allowable biomass that can be collected or harvested and stored at the collection center. Equation 5.63 and Equation 5.64 indicates that all the yield is collected by the collection center.

$$
\begin{aligned}
& x c_{g t \xi}^{c^{\prime}} \leq \varphi_{g}^{c^{\prime}} v^{c^{\prime}} \forall c^{\prime} \in c \cup c n, \forall g \in b \cup b n, \forall t, \forall \xi \\
& x c_{g t \xi}^{c^{\prime}} \geq \bar{\varphi}_{g}^{c^{\prime}} v^{c^{\prime}} \forall c^{\prime} \in c, \forall g \in b, \forall t \\
& x c_{g t \xi}^{c^{\prime}}=\sum_{i^{\prime} \in i \cup i n} x c_{g t \xi}^{i^{\prime}} c^{\prime} \forall c^{\prime} \in c \cup c n, g \in b \cup b n, \forall t, \forall \xi \\
& \beta_{g t \xi}^{i^{\prime} \xi}=\sum_{c^{\prime} \in c \cup c n} x c_{g t \xi}^{i^{\prime} c^{\prime}} \forall i^{\prime} \in i \cup i n, g \in b \cup b n, \forall t, \forall \xi
\end{aligned}
$$

\subsubsection{Biomass yield constraints}

Equation 5.65 and Equation 5.66 constrains the biomass yield constraints. They indicate that the biomass yield is constrained by the conversion rate and the maximum allowable land used. 
$\beta_{g t \xi}^{i^{\prime}}=\delta_{g}^{i^{\prime}} y_{g t \xi}^{i^{\prime}} \forall i^{\prime} \in i \cup i n, \forall g \in b \cup b n, \forall t, \forall \xi$

$y_{g t \xi}^{i^{\prime}} \leq B_{g t}^{i^{\prime}} \forall i^{\prime} \in i \cup i n, \forall g \in b \cup b n, \forall t, \forall \xi$

5.5.1.17. Operational product supply zones constraint

Equation 5.67 is a capacity constraint for all the operational product supply zones.

$w s_{g t \xi}^{o s^{\prime}} \leq W C a p_{g t \xi}^{o s^{\prime}} \forall o s^{\prime} \in O S \cup o s n, \forall g \in O \cup o n, \forall t, \forall \xi$

\subsubsection{Solution procedure}

Sampling average approximation (SAA) is used as the solution technology in order to reduce the computational time and to solve the problem efficiently. The SAA algorithm is described as follows (Kleywegt, Shapiro, and Homem-de-Mello, 2002).

Input Stochastic optimization problem $\underset{\psi}{\operatorname{Max}} f(\psi)$ with large number of scenarios $S$

Step 1: $\quad$ Select initial A sample sets of size B (randomly drawn without replacement from the total $S$ scenarios) such that $A B=S$. Choose B to be sufficiently small, such that $A$ is sufficiently large number of replications. If say $S=1000$, then B can be:

$B=\{1,2,4,5,8,10,20,25,40,50,100,125,200,250,500,1000\}$.

Step 2: $\quad$ For $a=1,2,3 . . A$, do steps 2.1, 2.2 and 2.3

2.1. Start with $A$ sample sets of size $B=1$, and $A=S / B$.

2.2. Solve the problem with a sample size of $B$ in order to obtain the objective function value $\hat{Z}_{B}^{a}$ and ${ }_{\varepsilon}$ optimal solution $\hat{\psi}_{B}^{a}$

2.2. Estimate the upper bound $Z^{*}=\sum_{a=1}^{A} \hat{Z}_{B}^{a} /$ Aand the optimality gap $f\left(\hat{\psi}_{B}^{a}\right)-\mu^{*}$ and variance

2.3. If the optimality gap and variance are sufficiently small, go to step 4 
Step 3: If the optimality gap is too large, increase the sample size to the next possible level of $B$ and create $A=(S / B)$ sample sets and return to step 2

Step 4: $\quad$ Choose the best solution among all the candidate solution $\hat{\psi}_{B}^{a}$ Step 5: Stop

\subsection{Case study configuration}

This section presents the configuration of the case study. A case study of North Dakota (ND) in the United States (US) is used to illustrate the efficiency and effectiveness of the proposed stochastic model. Figure 56 presents the current configuration of bioethanol supply chain in ND State. There are nine agricultural districts, six existing $1^{\text {st }}$ generation bioethanol plants, four existing CHP plants, and eight coal mines in the current configuration. Table 23 presents the configuration of existing $1^{\text {st }}$ generation bioethanol plants and their maximum expansion capacities. Currently ND has five 1G-SA plants and one 1G-CBIS plant. These existing $1^{\text {st }}$ generation bioethanol plants can operate with three capacity strategies: 1) same capacity, 2) expanded capacity, or 3) close. The maximum expansion capacity is assumed maximum $25 \%$ of the existing capacity. It can be observed that the existing $1^{\text {st }}$ generation bioethanol plants are located near to the coal mines. This suggests that cheaper input energy is one of the important factors in determining bioethanol plant locations. It is assumed that all the new plants are $2^{\text {nd }}$ generation due to the high GHG emitted by $1^{\text {st }}$ generation (compared to $2^{\text {nd }}$ generation) and social issues created by the $1^{\text {st }}$ generation. The new $2^{\text {nd }}$ generation plants can be of three types: 1) 2G-SA, 2) 2G-CBIS, and 3) 2G-NBBIS. The potential locations for 2G-SA and 2G-NBBIS plants are the largest cities in each of the nine agricultural districts, and the potential locations for 2G-CBIS plants are the four locations that have CHP plant. The nine agricultural districts are: 1) North West (NW), 2) North Central (NC), 3) North East (NE), 4) West central (WC), 5) Central (C), 6) East Central (EC), 7) 
South West (SW), 8) South Central (SC), and 9) South East (SE). The potential locations for 2GCBIS are: 1) WC (McLean), 2) WC (Mercer 1), 3) WC (Mercer 2), and 4) WC (Oliver). The detailed configurations of 1G-SA, 1G-CBIS, 2G-SA, 2G-CBIS and 2G-NBBIS have been discussed in section 2 . The maximum capacity of $2^{\text {nd }}$ generation bioethanol plant is assumed to be 150 MMGY. The maximum CHP unit capacity for 2G-NBBIS is assumed to be $35 \mathrm{MW}$. The potential locations for collection centers are assumed to be in the largest city in each of the agricultural district.

All the existing $1^{\text {st }}$ generation bioethanol plants operate with corn and produce bioethanol and distillers dried grains (DDG). All the $2^{\text {nd }}$ generation bioethanol plants operate with switchgrass and generate bioethanol and lignin pallets. Switch grass is considered as biomass for $2^{\text {nd }}$ generation bioethanol production since the soil and environmental conditions in ND are highly suitable for cultivating switch grass (Zhang et al, 2012).

Three types of transportation modes are considered in the study: 1) truck, 2) train, and 3) pipeline. Bioethanol can be transported through all the three transportation modes. DDG and lignin pallets are assumed to be sold locally and hence truck is used as the primary transportation mode. Corn is assumed to be shipped by truck or train. Switch grass is assumed to be shipped by truck, train, or pipeline. Coal is transported through truck, train, or pipeline. The primary transportation mode for process steam is assumed to be pipeline.

Four types of uncertainties are included in the study. They include: 1) bioethanol demand, 2) bioethanol price, 3) $1^{\text {st }}$ generation biomass yield, and 4) $2^{\text {nd }}$ generation biomass yield. Three levels of uncertainties are considered for each parameter: 1) low level, 2) mean level, and 3) high level. Therefore, these add to 81 scenarios. The probability of each of these scenarios happening is assumed to be equal. 
Given such a structure the model aims to determine the optimal ISHGBSC in order to maximize profit, considering GHG emissions, $1^{\text {st }}$ generation bioethanol produced, water used and energy intensity restrictions under uncertainties. The proposed model aims to determine : 1) whether the existing $1^{\text {st }}$ generation plant should operate with same capacity, expanded capacity, or should be closed, 2) the type of existing bioethanol plants that should be kept open, expanded or closed, 3) new $2^{\text {nd }}$ generation bioethanol plant locations and their configurations, 4) the optimal collection center locations for both $1^{\text {st }}$ generation and $2^{\text {nd }}$ generation biomass, 5) the optimal cultivation sites for both $1^{\text {st }}$ generation and $2^{\text {nd }}$ generation, and 6) the optimal transportation modes. Readers can refer to the Tables A.10 - Tables A.14 of appendix for the input parameters.

Table 23. Initial and maximum expansion capacities for existing $1^{\text {st }}$ generation bioethanol plants

\begin{tabular}{lllll}
\hline Plant & Type & $\begin{array}{l}\text { Biomass } \\
\text { input type }\end{array}$ & $\begin{array}{l}\text { current } \\
\text { capacity } \\
\text { (MMGY) }\end{array}$ & $\begin{array}{l}\text { Maximum } \\
\text { expansion capacity } \\
\text { (MMGY) }\end{array}$ \\
\hline NE (Pembina) & 1G-SA & Corn & 28 & 7 \\
NE (Walsh) & 1G-SA & Corn & 10 & 2.5 \\
WC & 1G-CBIS & Corn & 50 & 12.5 \\
EC & 1G-SA & Corn & 150 & 37.5 \\
SW & 1G-SA & Corn & 50 & 12.5 \\
SE & 1G-SA & Corn & 110 & 27.5 \\
\hline
\end{tabular}

Source: Ethanol Facilities capacity by state and plant, 2012 


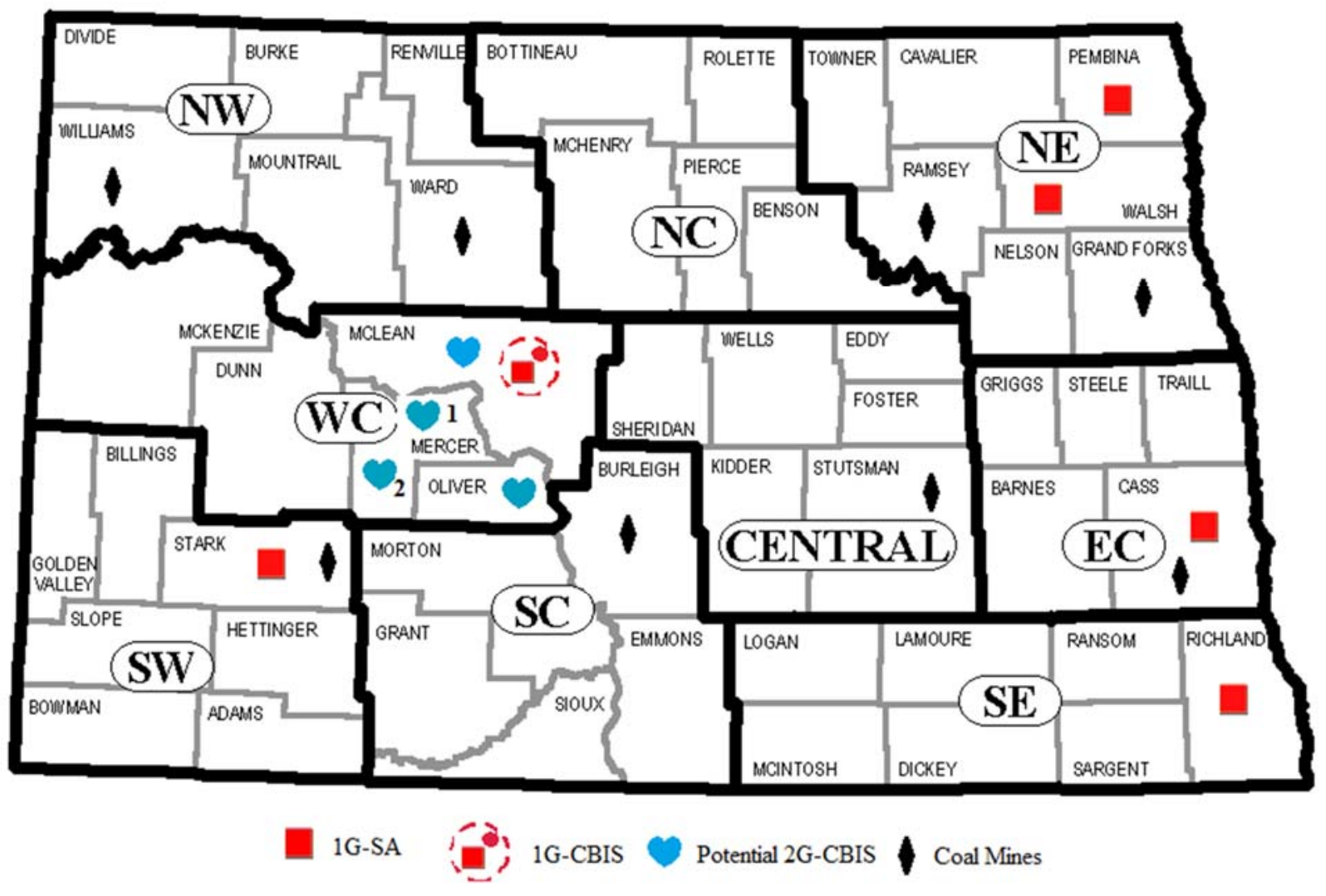

Figure 56. Current configuration of bioethanol supply chain in ND

\subsection{Results of the case study}

The proposed stochastic model and SAA algorithm is coded in GAMS. It consists of 61 discrete variables and 271,446 continuous variables. Various standards of sustainability are considered as constraints in the proposed model to determine whether the optimal configuration of ISHGBSC changes if different standard is applied. Table 24 presents the various standards that are studied.

Table 25 presents the permit limits for GHG emissions, energy efficiency, and water usage. In order to obtain the permit limits, the proposed model is solved without any restrictions. Once, the GHG emissions, irrigation land used, energy efficiency and water used are obtained under current conditions, these values are recalculated to obtain the permit limits. The permit limit for 
GHG emissions are obtained by calculating the 1990 level. US has reported an increase in GHG emissions by $10.5 \%$ in 2010 compared to 1990 level (U.S. Greenhouse Gas Inventory Report, 2013). Therefore, the 1990 level is 2.699 million tons $(2.983 * 100 / 110.5=2.699)$. The permit limit of $30 \%$ below 1990 level (BES) is obtained to be 1.889 million tons. Therefore the maximum allowance of GHG emissions in any time period is 1.889 million tons. The energy efficiency under current conditions is 1.93 . Since, the energy intensity has to be reduced by $30 \%$, the energy efficiency should be increased by $42 \%(1 / 0.7-1 / 1=1.42-1=0.42)$. Therefore, in order to align with EES standard, the minimum allowable efficiency of the ISHGBSC should be $2.74(1.42 * 1.93$ $=2.74)$. The water intensity under current conditions is 655.30 billion gallons. Since WIS mandates the reduction of water intensity by $16 \%$, the permit limit for water intensity is 550 billion gallons $(84 \% * 655.30=550$ billion gallons $)$.

Table 24.Various standards applied to ISHGBSC

\begin{tabular}{ll}
\hline Standard & Description \\
\hline Renewable Fuel Standard & $\begin{array}{l}\text { RFS enforces at least } 55 \% \text { of the bioethanol should come } \\
\text { from } 2^{\text {nd }} \text { generation biomass. The driver of the policy is to } \\
\text { reduce the amount of irrigation land used. }\end{array}$ \\
Base Emissions Standard & $\begin{array}{l}\text { BES enforces that the GHG emissions should be reduced to } \\
30 \% \text { below } 1990 \text { level. }\end{array}$ \\
(BES) & EES suggests increasing the energy efficiency by $42 \%$ \\
Energy Efficiency & compared to current state. \\
Standard* (EES) & WIS suggests reducing the use of water by $16 \%$. \\
Water Intensity Standard & \\
(WIS) & CS is a combination of RFS, BES, EES and WIS. \\
Combined Standard (CS) & A2GS enforces that all bioethanol production are from $2^{\text {nd }}$ \\
All $2^{\text {nd }}$ Generation & generation. \\
Standard (A2GS)
\end{tabular}

* Reduction in energy intensity by $30 \%$ is equivalent to increasing the efficiency by $42 \%(1 / 0.7-1$ $=0.42=42 \%$ )

Table 25. Sustainability measures under current conditions and estimated permit limits

\begin{tabular}{lll}
\hline Sustainability metrics & Current conditions & Permit limit \\
\hline GHG emissions & 2.983 Million tons & 1.889 Million tons \\
Energy Efficiency & 1.93 & Atleast 2.74 \\
Water Intensity & 655.30 Billion gallons & 550 Billion gallons \\
\hline
\end{tabular}


Table 26 and Figure 57-61 show the results. The results show that ISHGBSC under EES and CS standards meet the permit limits of GHG emissions, irrigation land used and water used, and energy intensity. However, the profits of ISHGBSC under these standards are least. The configurations of ISHGBSC under EES and CS are almost the same suggesting that the energy efficiency standard is the most restrict sustainable standard in determining the optimal configuration of ISHGBSC. The optimal configurations of ISHGBSC under RFS, BES, WIS, and A2GS violate one or more sustainable requirements.

Profit is directly proportional to GHG emissions. The more the GHG emits, the higher the profit is. Profit is inversely proportional to energy efficiency, the higher the energy efficiency of the ISHGBSC, the less the profit. The GHG emission is indirectly proportional to the energy efficiency. The higher the energy efficiency, the less the GHG emission. Water usage is directly proportional to the amount of the cultivation land used. The more the cultivation land used, the more the water used.

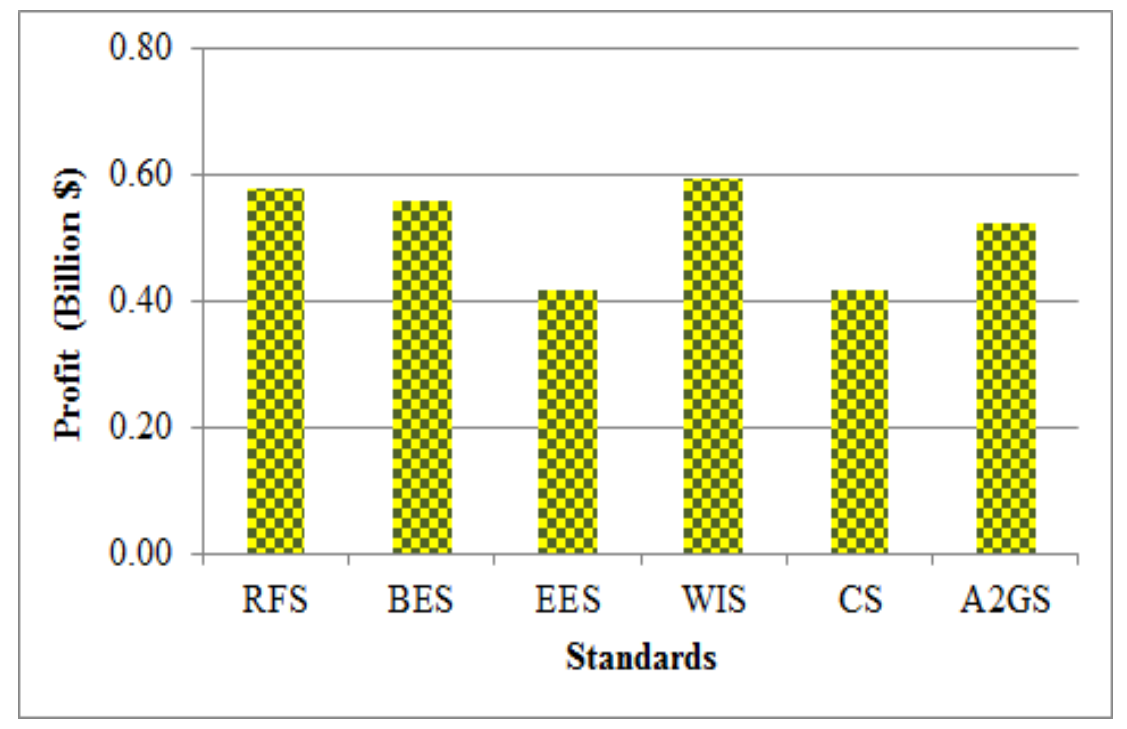

Figure 57. Profit of ISHGBSC under different standards 
Table 26. Performances of various standards under different sustainable metrics

\begin{tabular}{|c|c|c|c|c|c|}
\hline \multirow[t]{2}{*}{ Standard } & \multirow{2}{*}{$\begin{array}{c}\begin{array}{c}\text { Economic } \\
\text { metric }\end{array} \\
\text { Profit } \\
(\text { Billion \$) }\end{array}$} & \multirow{2}{*}{$\begin{array}{c}\begin{array}{c}\text { Environment } \\
\text { metric }\end{array} \\
\text { GHG } \\
\text { (Million Tons) }\end{array}$} & \multicolumn{2}{|c|}{ Social metric } & \multirow{2}{*}{$\begin{array}{c}\text { Energy metric } \\
\text { Energy Efficiency }\end{array}$} \\
\hline & & & $\begin{array}{c}\text { Irrigation land } \\
\text { used } \\
(\%)\end{array}$ & $\begin{array}{c}\text { Water intensity } \\
\text { (Billion Gallons) }\end{array}$ & \\
\hline RFS & $\$ 0.580$ & 2.085 & $31.21 \%$ & 448.04 & 1.91 \\
\hline BES & $\$ 0.559$ & 1.737 & $15.47 \%$ & 361.04 & 1.90 \\
\hline EES & $\$ 0.417$ & 1.25 & $17.13 \%$ & 353.57 & 2.74 \\
\hline WIS & $\$ 0.594$ & 2.341 & $46.37 \%$ & 529.90 & 1.94 \\
\hline $\mathrm{CS}$ & $\$ 0.417$ & 1.25 & $17.13 \%$ & 353.57 & 2.74 \\
\hline $\mathrm{A} 2 \mathrm{GS}$ & $\$ 0.523$ & 1.487 & $0 \%$ & 273.29 & 1.74 \\
\hline
\end{tabular}

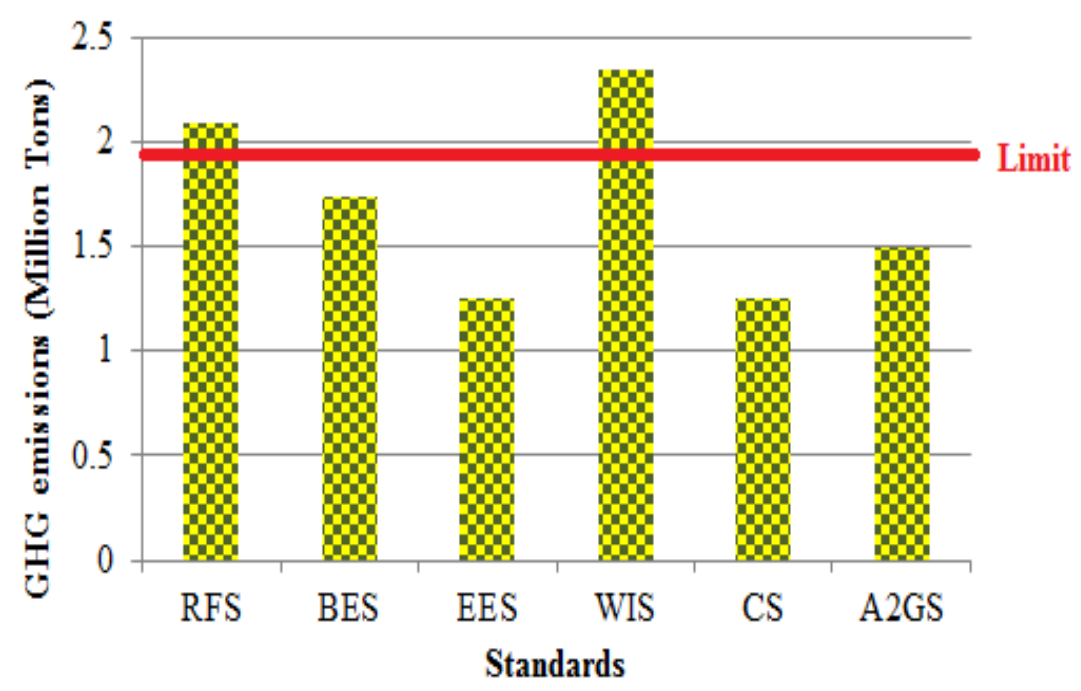

Figure 58. GHG emissions of ISHGBSC under different standards 


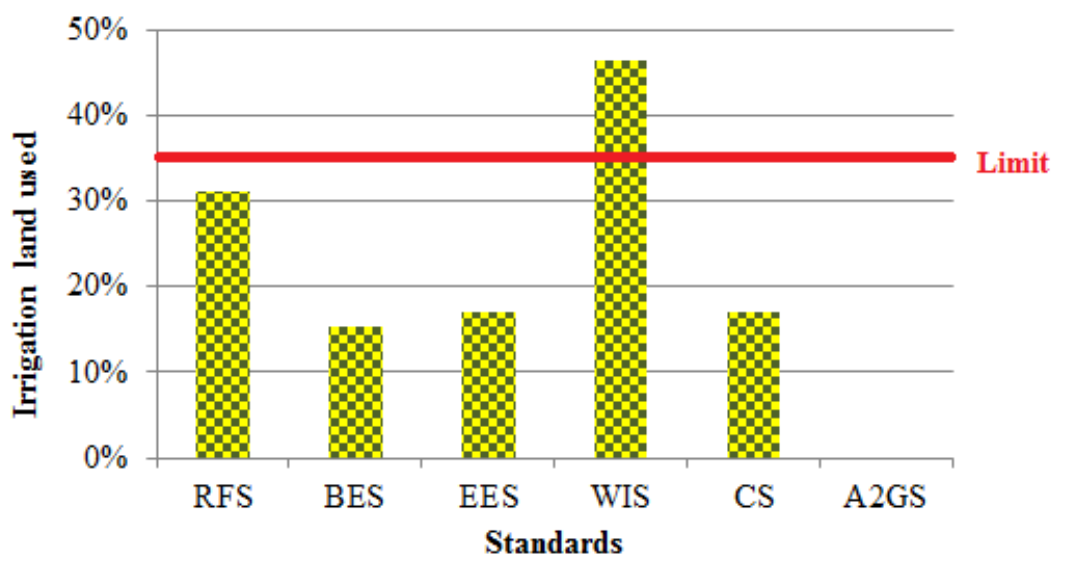

Figure 59. Irrigation land used by ISHGBSC under different standards

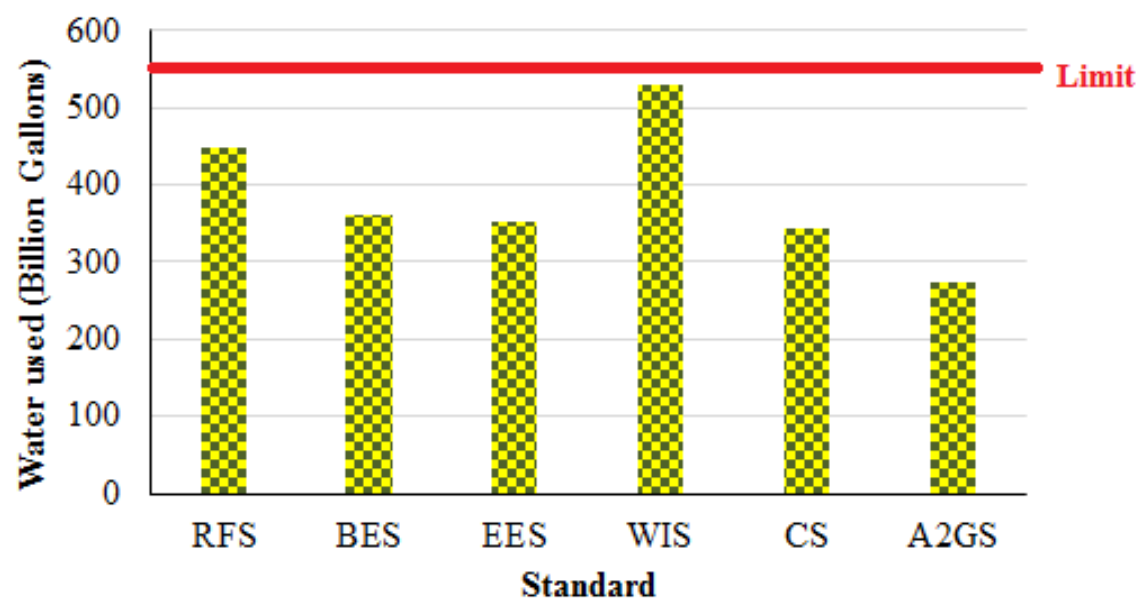

Figure 60. Water used by SHGBSC under different standards

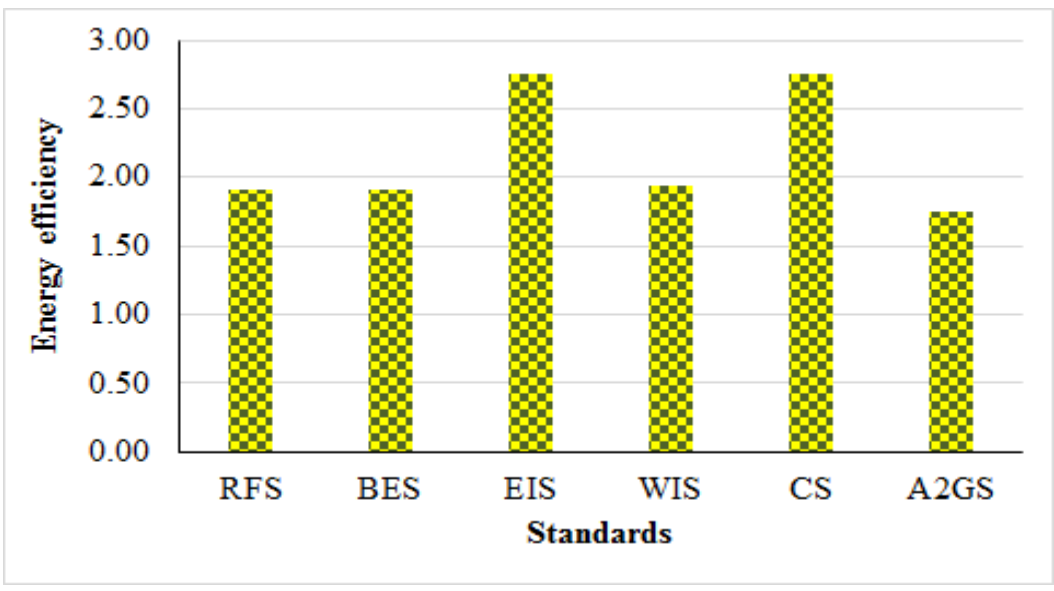

Figure 61. Energy efficiency by ISHGBSC under different standards 


\subsubsection{Bioethanol production from various bioethanol plant configurations under various standards}

This section presents the bioethanol produced from various bioethanol plant configurations. Table 27 and Figure 62 show the bioethanol produced by ISHGBSC under different standards. They indicate that whenever a strict standard (BES, EES, or CS) is applied, the bioethanol production volume of $1 \mathrm{G}-\mathrm{CBIS}$ is larger than that of $1 \mathrm{G}-\mathrm{SA}$. This implies that $1 \mathrm{G}-$ CBIS is more sustainable in terms of reducing GHG emissions and increasing energy efficiency compared to $1 \mathrm{G}-\mathrm{SA}$.

Under all standards, 2G-SA is never selected as the configuration of new $2^{\text {nd }}$ generation bioethanol plant. This indicates that $2 \mathrm{G}-\mathrm{SA}$ is dominated by $2 \mathrm{G}-\mathrm{CBIS}$ and $2 \mathrm{G}-\mathrm{NBBIS}$ under different sustainability standards.

The higher production of 2G-CBIS under CS standard indicates that 2G-CBIS is more preferable than 2G-NBBIS in terms of improving environmental, social and energy efficiency aspects of sustainability. However, 2G-NBIS is more preferable compared to 2G-CBIS in terms of improving economic, environment and social aspects of sustainability.

The amount of bioethanol produced from second generation configuration $(2 \mathrm{G})$ is higher than that from first generation configuration $(1 \mathrm{G})$ under different standards, This implies that $2 \mathrm{G}$ configurations are more sustainable compared to $1 \mathrm{G}$.

Table 27. Bioethanol produced from each bioethanol plant configurations (Million gallons)

\begin{tabular}{lllllll}
\hline $\begin{array}{l}\text { Bioethanol } \\
\text { plant } \\
\text { configuration }\end{array}$ & RFS & BES & EES & WIS & CS & A2GS \\
\hline 1G-SA & 139.87 & 46.57 & 53.09 & 226.98 & 53.09 & 0 \\
1G-CBIS & 50.90 & 49.21 & 62.5 & 52.87 & 62.5 & 0 \\
2G-SA & 0 & 0 & 0 & 0 & 0 & 0 \\
2G-CBIS & 70.29 & 69.97 & 443.22 & 79.42 & 443.22 & 70.23 \\
2G-NBBIS & 305.04 & 403.68 & 0 & 204.43 & 0 & 502.54 \\
\hline
\end{tabular}




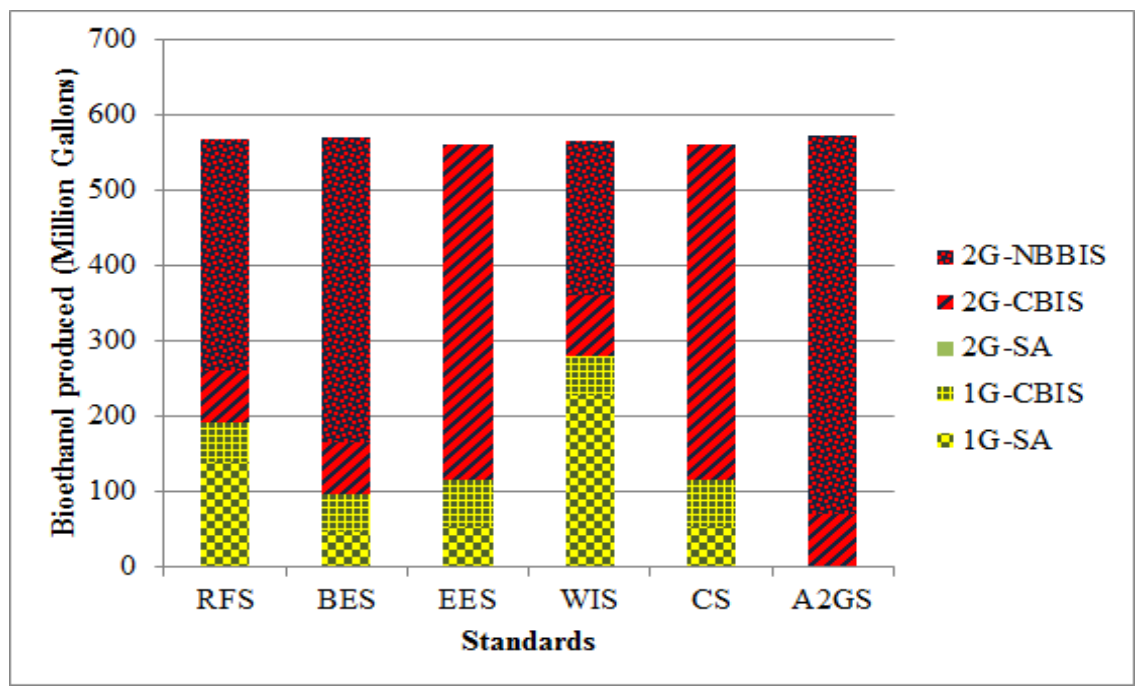

Figure 62. Bioethanol produced by ISHGBSC under different standards

\subsubsection{Economic analysis of ISHGBSC}

This section presents the revenue and cost analysis of ISHGBSC under different standards. This provides economic insights about different plant configurations.

\subsubsection{Revenue analysis}

Figure 63 and Table 28 present the revenue generated by bioethanol, DDG, lignin, process steam and electricity under different standards. It should be noted that 1) DDG is the by-product of $1 \mathrm{G}-\mathrm{SA}$ and $1 \mathrm{G}-\mathrm{CBIS}, 2$ ) lignin is the by-product of 2G-SA, 2G-CBIS and 2G-NBBIS, and 3) process steam and electricity are produced by 2G-NBBIS. Fig. 14 indicates that under all the standards the revenue generated by the bioethanol remained the same, and is the highest contributor to revenue.

Under RFS, BES, WIS and A2GS, the revenues generated from co-products are the same. This indicates that 2G-NBBIS can generate co-products (electricity and process steam) that are competent with co-products (DDG) of 1G. In addition, for EES and CS standards, revenue from co-products (lignin pallets) of 2G-CBIS are not competent with that from 1 G (DDG). 
In summary, DDG and electricity are high value co-products. Lignin pallets and process steam are low value co-products.

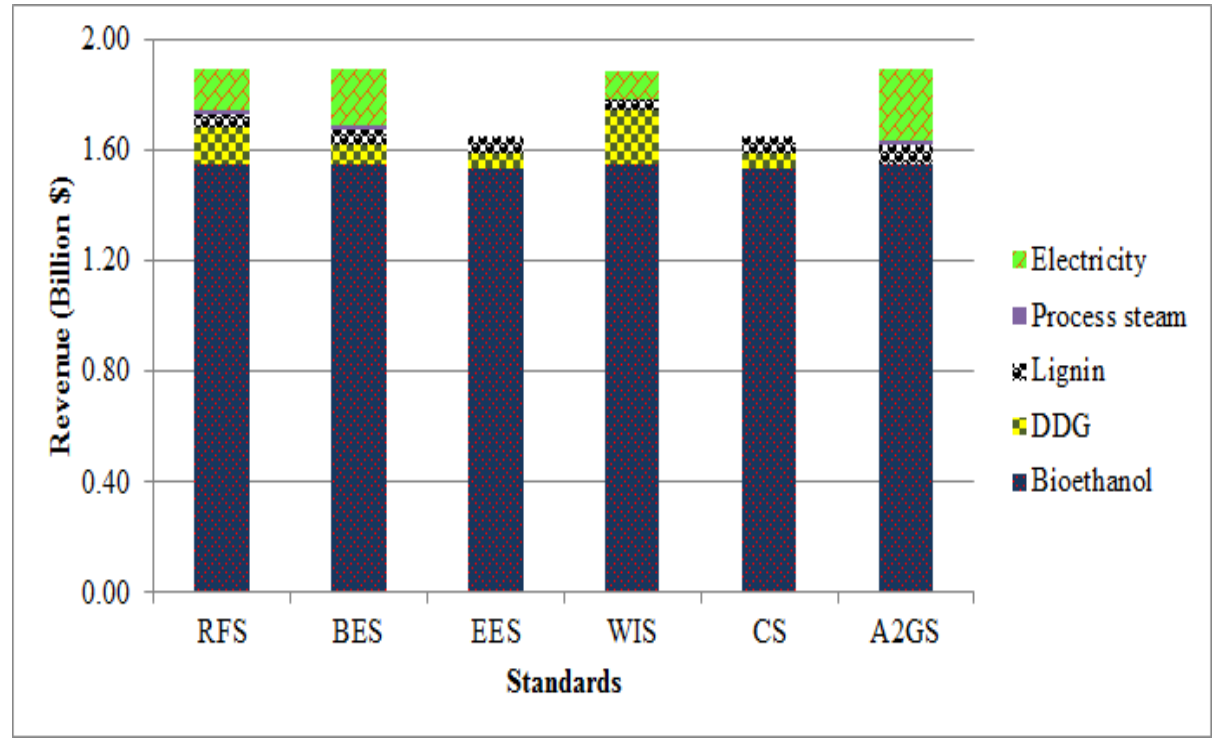

Figure 63. Revenue analysis for ISHGBSC under different standards

Table 28. Revenue (in billions) of ISHGBSC from different end products under different standards

\begin{tabular}{lllllll}
\hline \multicolumn{1}{c}{ Product } & \multicolumn{6}{c}{ Standard } \\
\cline { 2 - 7 } & \multicolumn{1}{c}{ RFS } & \multicolumn{1}{c}{ BES } & EIS & \multicolumn{1}{c}{ WIS } & \multicolumn{1}{c}{$\mathrm{CS}$} & \multicolumn{1}{c}{ A2GS } \\
\hline Bioethanol & $\$ 1.55$ & $\$ 1.55$ & $\$ 1.549$ & $\$ 1.55$ & $\$ 1.549$ & $\$ 1.55$ \\
DDG & $\$ 0.135$ & $\$ 0.066$ & $\$ 0.072$ & $\$ 0.194$ & $\$ 0.066$ & $\$ 0$ \\
Lignin pallets & $\$ 0.048$ & $\$ 0.060$ & $\$ 0.057$ & $\$ 0.036$ & $\$ 0.060$ & $\$ 0.073$ \\
Process steam & $\$ 0.009$ & $\$ 0.012$ & $\$ 0$ & $\$ 0.006$ & $\$ 0$ & $\$ 0.016$ \\
Electricity & $\$ 0.152$ & $\$ 0.203$ & $\$ 0$ & $\$ 0.101$ & $\$ 0$ & 0.255 \\
Total & $\$ 1.893$ & $\$ 1.893$ & $\$ 1.669$ & $\$ 1.887$ & $\$ 1.669$ & $\$ 1.894$ \\
\hline
\end{tabular}

\subsubsection{Cost analysis}

Figure 64 and Table 29 present the various costs of ISHGBSC under different standards. It indicates that the capital cost contributes significant amount in the total cost under all the standards. Table 6 shows that higher amount of bioethanol is produced from 2G-NBBIS than from 2G-CBIS under standards of RFS, BES, and A2GS. Fig. 15 shows the capital costs of these standards are relatively high compared to other standards. This is because that the capital cost of $2 \mathrm{G}-\mathrm{NBBIS}$ is 
higher than that of 2G-CBIS because of additional set-up cost of CHP unit. 2G-CBIS reduces capital cost. However, the production and logistics cost increases significantly. 2G-NBBIS provides the benefit of production and logistics cost.

It is noted from Table 6 and Fig. 15 that the production cost is less whenever higher quantities of bioethanol is produced from 2G-NBBIS rather than from 2G-CBIS. This indicates that the production cost is less for $2 \mathrm{G}-\mathrm{NBBIS}$ compared to $2 \mathrm{G}-\mathrm{CBIS}$. This is because $2 \mathrm{G}-\mathrm{NBBIS}$ can obtain cheaper process steam due to its CHP unit. However, under 2G-CBIS, the process steam is purchased from a third party resulting in a higher price.

The Figure also shows that biomass production cost reduces as high amounts of $2^{\text {nd }}$ generation bioethanol is produced because $2^{\text {nd }}$ generation biomass production do not incur fertilizer costs, water costs and other irrigation related costs. The storage cost and transportation cost are significantly less. However, they increase when higher quantities of $2^{\text {nd }}$ generation bioethanol are produced because of the high density of $2^{\text {nd }}$ generation biomass compared to $1^{\text {st }}$ generation biomass. The closing cost of the existing $1^{\text {st }}$ generation bioethanol plant increases as higher quantities of $2^{\text {nd }}$ generation is produced.

Table 29. Costs (in billions) from different logistic activities in ISHGBSC under different standards

\begin{tabular}{lllllll}
\hline \multirow{2}{*}{ Logistic activities } & \multicolumn{6}{c}{ Standard } \\
\cline { 2 - 7 } & \multicolumn{1}{c}{ RFS } & \multicolumn{1}{c}{ BES } & EIS & WIS & CS & A2GS \\
\hline Slack & $\$ 0$ & $\$ 0$ & $\$ 0.01$ & $\$ 0$ & $\$ 0.01$ & $\$ 0$ \\
Capital & $\$ 0.475$ & $\$ 0.574$ & $\$ 0.290$ & $\$ 0.371$ & $\$ 0.290$ & $\$ 0.674$ \\
Closing & $\$ 0.03$ & $\$ 0.045$ & $\$ 0.045$ & $\$ 0.017$ & $\$ 0.045$ & $\$ 0.06$ \\
Transportation & $\$ 0.074$ & $\$ 0.088$ & $\$ 0.138$ & $\$ 0.064$ & $\$ 0.138$ & $\$ 0.10$ \\
$\begin{array}{l}\text { Bioethanol } \\
\text { production }\end{array}$ & $\$ 0.266$ & $\$ 0.204$ & $\$ 0.337$ & $\$ 0.246$ & $\$ 0.337$ & $\$ 0.196$ \\
Biomass production & $\$ 0.409$ & $\$ 0.302$ & $\$ 0.316$ & $\$ 0.508$ & $\$ 0.316$ & $\$ 0.202$ \\
Storage & $\$ 0.0984$ & $\$ 0.117$ & $\$ 0.114$ & $\$ 0.080$ & $\$ 0.114$ & $\$ 0.137$ \\
Total & $\$ 1.313$ & $\$ 1.333$ & $\$ 1.252$ & $\$ 1.292$ & $\$ 1.252$ & $\$ 1.370$ \\
\hline
\end{tabular}




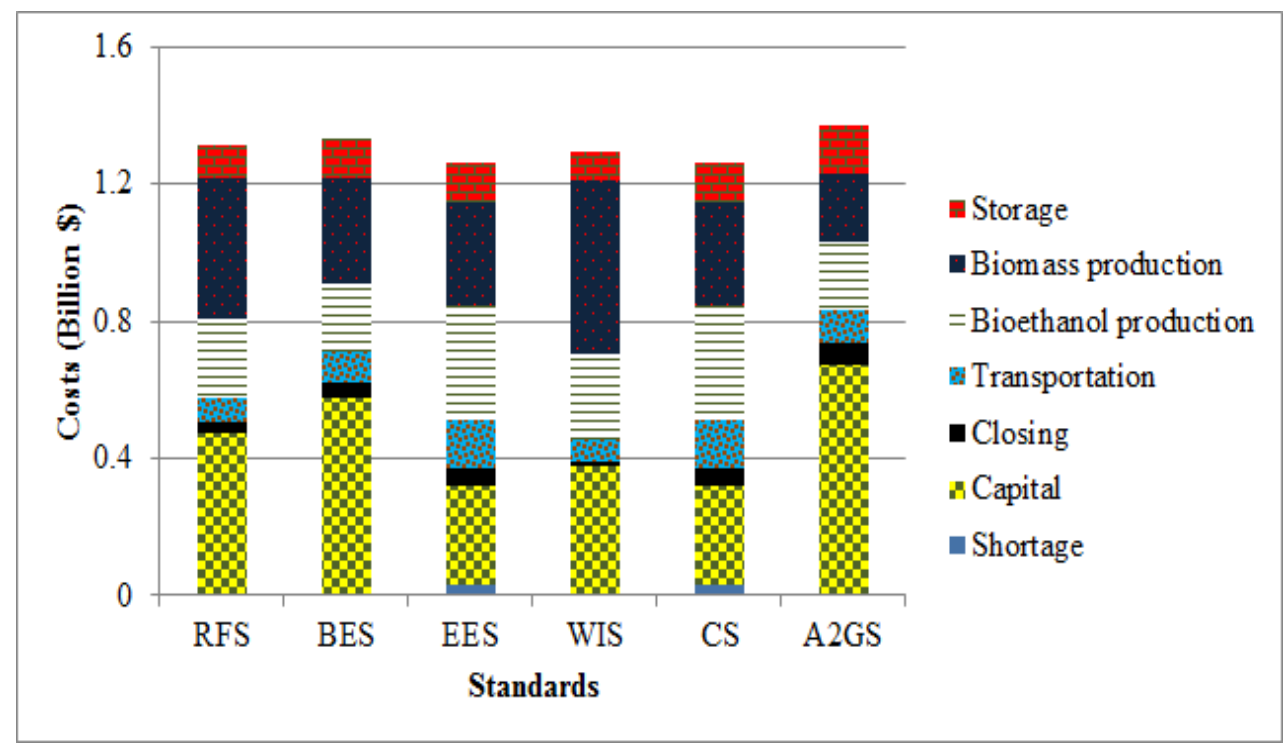

Figure 64. Cost analysis for ISHGBSC under different standards

\subsubsection{Environmental analysis of ISHGBSC}

Figure 65 presents the GHG emissions under different standards. It shows that biomass production and bioethanol production contributed significantly to GHG emissions; GHG emissions from transportation are relatively less due to the small geographic area.

It is noted from Table 27and Figure 65 that GHG emissions reduce significantly when high quantities of bioethanol is produced from 2G-CBIS (e.g., under EES and CS). This indicates that 2G-CBIS can significantly reduce GHG emissions compared to other configurations. The GHG emissions from biomass production reduce significantly when higher quantities of $2^{\text {nd }}$ generation bioethanol are produced.

In summary, GHG emissions can be reduced either by producing $2^{\text {nd }}$ generation bioethanol or by using CBIS for plant location. Producing higher quantities of $2^{\text {nd }}$ generation bioethanol will significantly reduce $\mathrm{GHG}$ as $2^{\text {nd }}$ generation does not require fertilizers that generate high GHG emissions. Using 2G-CBIS configuration can significantly reduce GHG emissions from bioethanol production as bioethanol plants do not have to produce its own process steam. 


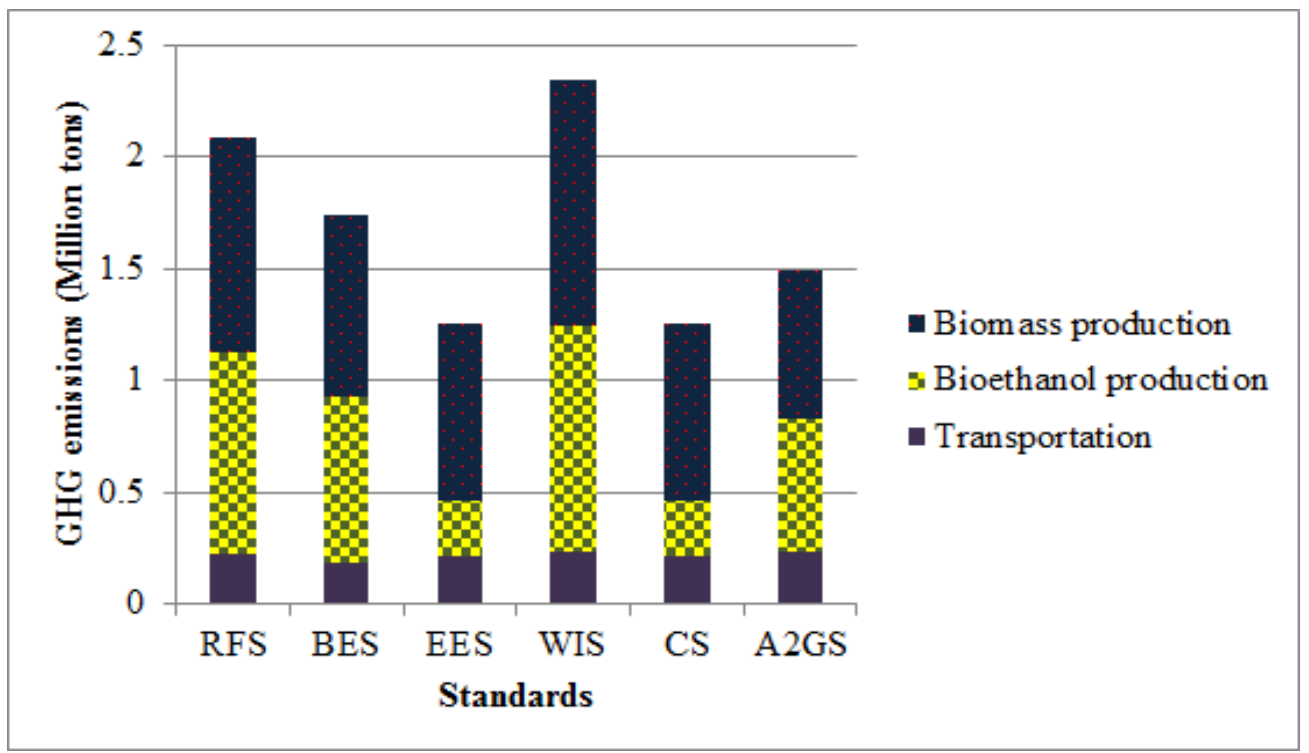

Figure 65. GHG emissions by ISHGBSC under different standards

\subsubsection{Social analysis of ISHGBSC}

This section presents the analysis of social aspect of sustainability. It include the analysis of irrigation land and water used.

Figure 66 presents the results of amount of irrigated and marginal land used. It indicates that under WIS standard, the amount of irrigation land used is significantly high. According to Table 27, under WIS, high portion of bioethanol is produced from first generation biomass. If no irrigation land can be used for bioethanol production, ISHGBSC under A2GS is the only solution. In addition, the amount of irrigation land used under RFS, BES, EES and CS is below the permit limits (refer to Figure 59) and hence ISHGBSC can socially sustain under these standards.

Figure 67 presents the amount of water used in ISHGBSC. It suggests that the major proportional of water is used in biomass production. The amount of water used in bioethanol production is significantly less. In addition, the amount of water used is directly proportional to the amount of cultivation land used. The higher the cultivation land used, the higher the water consumed. 


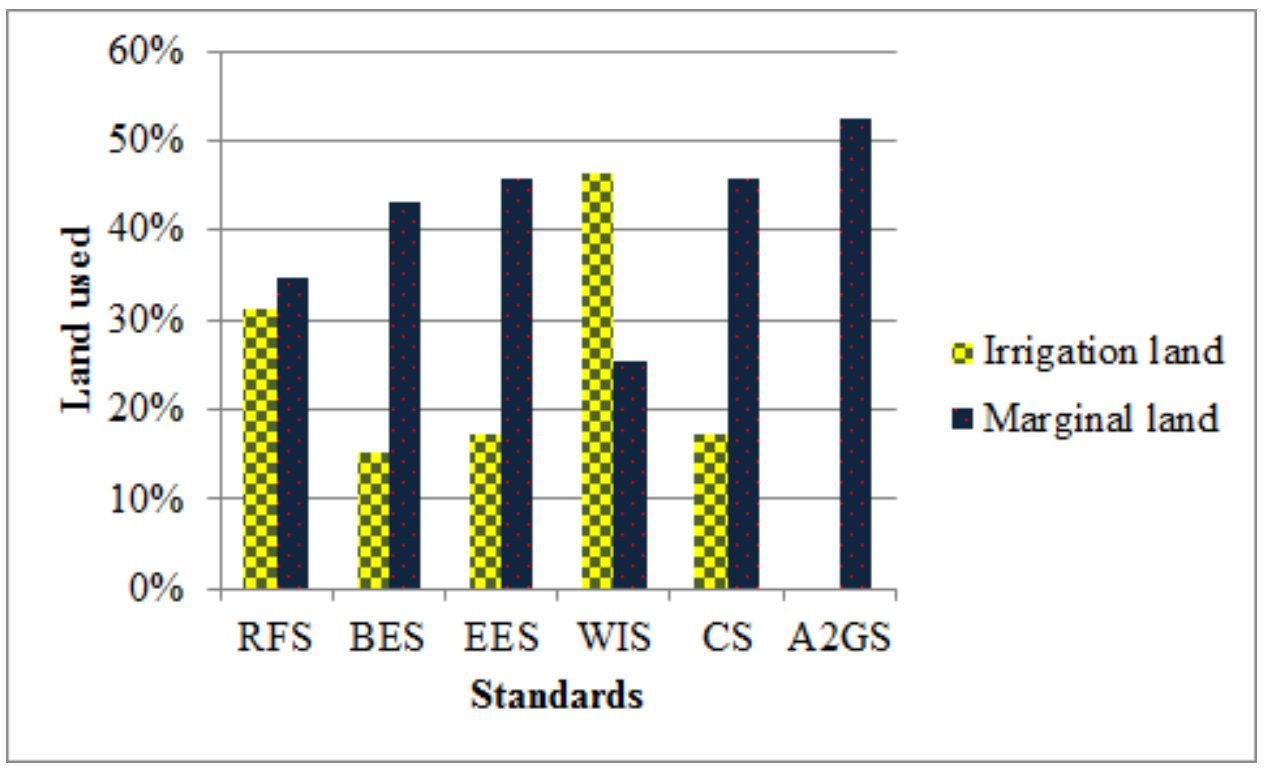

Figure 66. Land used by ISHGBSC under different standards

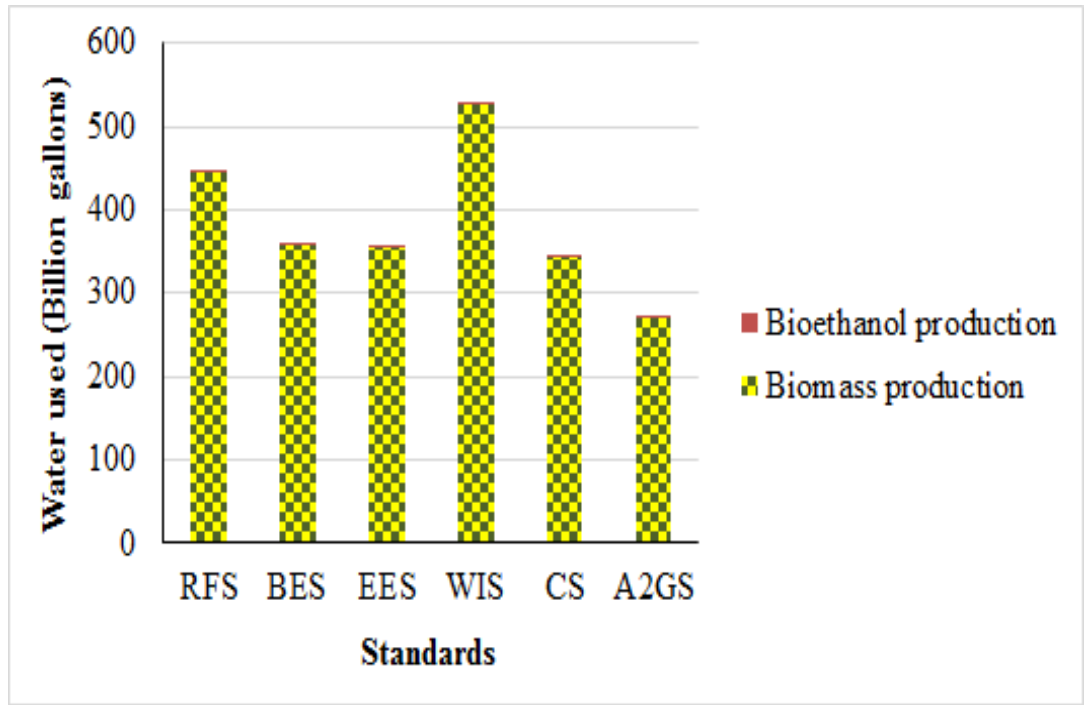

Figure 67. Water used by ISHGBSC under different standards

In summary, social aspect can only be improved by producing higher quantities of $2^{\text {nd }}$ generation. 


\subsubsection{Energy efficiency analysis of ISHGBSC}

This section presents the analysis of energy efficiency. The energy estimates for all the products are provided in the Table A5 of appendix. . To estimate the energy for DDG and lignin pallets, the values are obtained in calories and are converted to million metric British thermal unit (MMBTU). Figure 61 and Table 26 presents the energy efficiency.

Figure 68-69 present the output energy produced and input energy used under different standards. They indicate that the energy output from bioethanol is significantly high and remained same in all the cases. 2G-NBBIS generates high energy co-products since it generates electricity, process steam, and lignin pallets compared to 2G-CBIS which only generates lignin pallets. Major portion of energy is consumed in producing bioethanol production. However, 2G-CBIS enables to reduce energy input significantly as it uses recovers the lost heat by collocating near to the CHP plant. The energy input in biomass production and product transportation is significantly less.

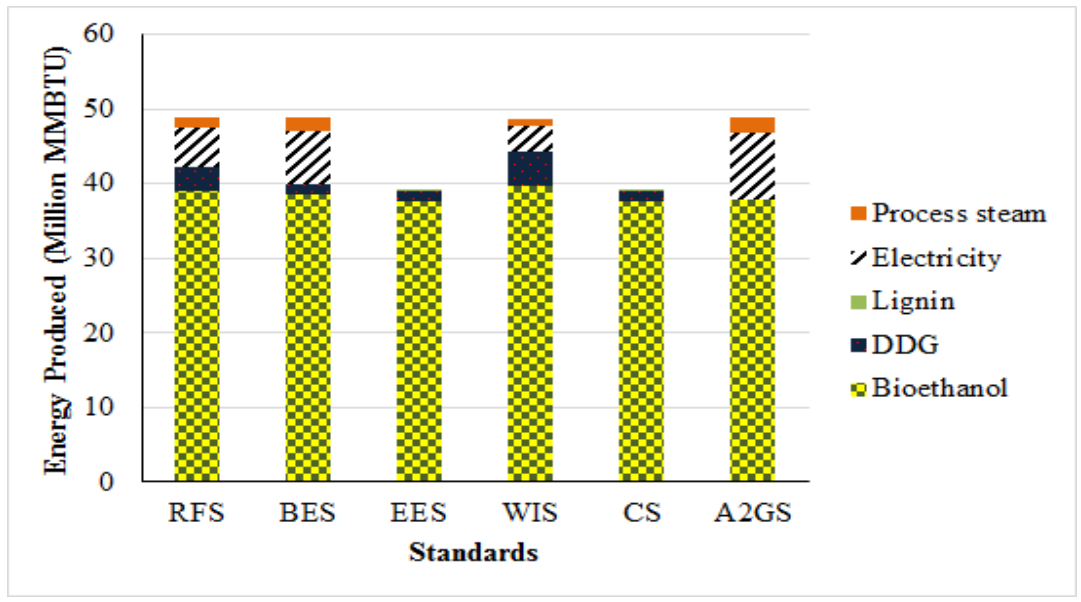

Figure 68. Energy produced by ISHGBSC under different standards 


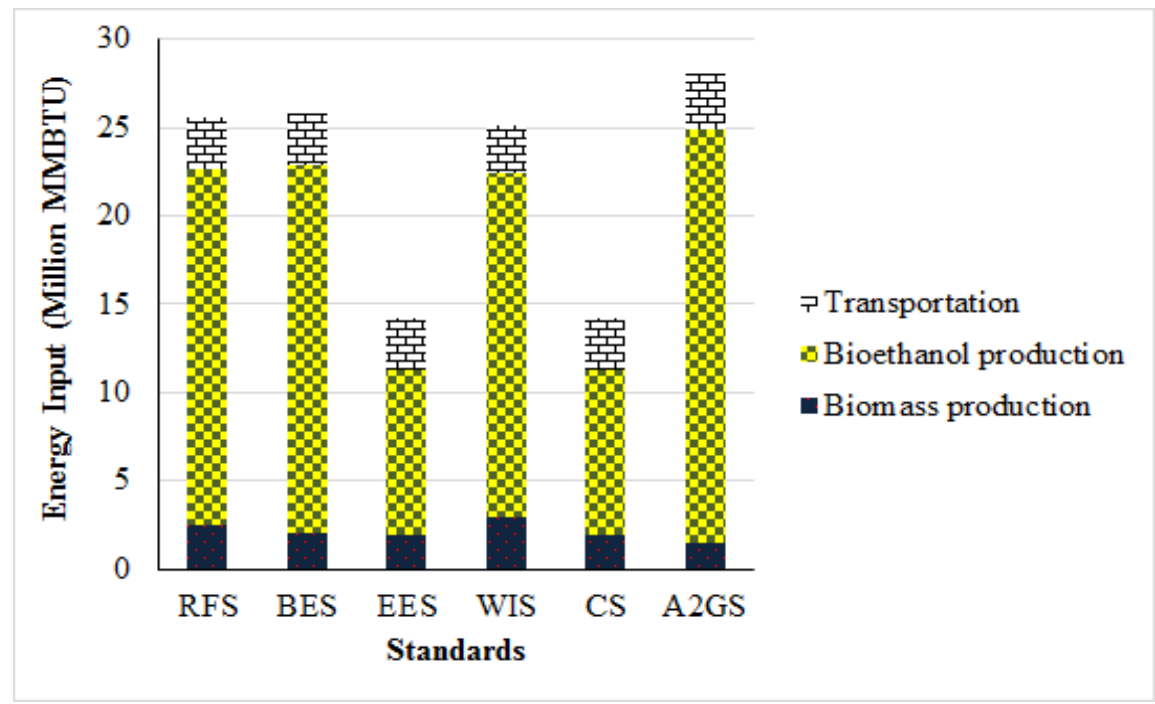

Figure 69. Energy used by ISHGBSC under different standards

In summary, 2G-CBIS is the best strategy to improve energy efficiency. 2G-NBBIS is not sustainable under strict energy regulations.

\subsubsection{Comparison of ISHGBSC under RFS and CS}

This section compares the configurations of ISHGBSC under RFS and CS. While RFS focuses on improving environmental and social aspects of sustainability, CS focuses on improving environmental, social and energy efficiency. Therefore, comparison is conducted to find whether the designs of ISHGBSC change when different standards are applied and to provide reasons for the changes. Figure 70 and Figure 71 present the network topology of biomass supplies to bioethanol plants in ISHGBSC under RFS and CS, respectively. They include the optimal cultivation sites for both $1^{\text {st }}$ generation and $2^{\text {nd }}$ generation biomass, the optimal collection center locations, the optimal $1^{\text {st }}$ generation plant configurations that are kept open, the optimal new $2^{\text {nd }}$ generation bioethanol plant configurations and their locations, and the optimal transportation modes. Similarly, Figure 72 and Figure 73 present the network topology of bioethanol plants to demand zones in ISHGBSC under RFS and CS, respectively. They include the optimal existing $1^{\text {st }}$ 
generation bioethanol plants with location strategies, new $2^{\text {nd }}$ generation bioethanol plants with optimal location strategies, bioethanol demand zones, and the optimal transportation modes. The results suggest that there is significant difference between the ISHGBSC designs under RFS and CS. Table 30 presents the optimal plant locations, configurations and capacities for ISHGBSC under RFS and CS, respectively. It indicates that ISHGBSC under RFS relies heavily on 1G-SA and 2G-NBBIS to meet the bioethanol demand. However, ISHGBSC under CS relies heavily on 2G-CBIS. Since, the goal of RFS standard is to improve the environmental and social benefits, major portion of demand should be met with $2^{\text {nd }}$ generation bioethanol. Within $2^{\text {nd }}$ generation bioethanol, 2G-NBBIS is highly preferred as it generates high profit compared to 2G-SA and 2GCBIS. A small amount of bioethanol production is met with $2 \mathrm{G}-\mathrm{CBIS}$ as the capital cost is low. Under CS standard that regulates to environmental, social and energy efficiency aspect, production of bioethanol from 2G-CBIS is highly preferred. Under this standard, the environmental and social aspects are improved by shifting from $1^{\text {st }}$ generation bioethanol production to $2^{\text {nd }}$ generation bioethanol production. In order to regulate to energy efficiency aspect, the production of 2G-CBIS is highly preferred compared to 2G-NBBIS. Table 31 presents the optimal assignment of collection centers, demand zones and coal mines to the bioethanol plant in ISHGBSC under RFS and CS. It indicates that the optimal assignments of the collection centers and demand zones for ISHGBSC under RFS and CS changes significantly. In addition, the cultivation zones of $1^{\text {st }}$ generation and $2^{\text {nd }}$ generation biomass also changes significantly.

The logistics of ISHGBSC under RFS is simple compared to the CS. This is because of the logistic benefit provided by 2 G-NBBIS as 2 G-NBBIS can be located in any place based on the bioethanol demand and biomass supply. However, under CS, where bioethanol production is heavily relied on 2G-CBIS, the logistic benefits are lost. In addition, it can be observed from the 
Figures that the optimal transportation depends on the product and the distance. For bioethanol, truck is preferred under short and medium raged distances. However, train is preferred for long distances. For switch grass, truck is preferred for short and medium ranged distances and train is preferred for long distances. For corn, truck is preferred for short distances and train is preferred for medium and long distances.

In summary, the bioethanol investors should focus on improving all the aspects of sustainability rather than focusing on few aspects of sustainability.

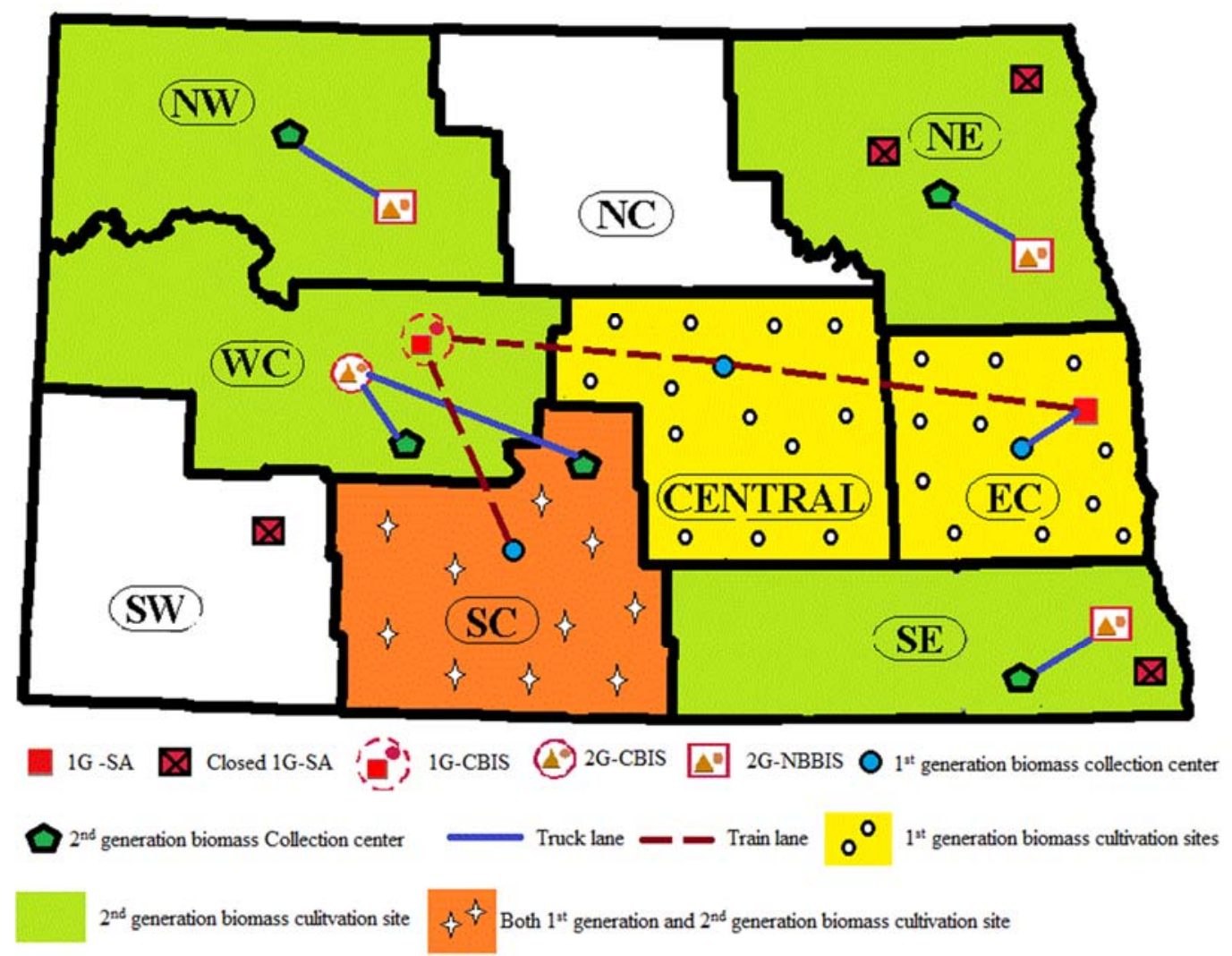

Figure 70. Network topology of biomass supply to bioethanol plant in ISHGBSC under RFS 


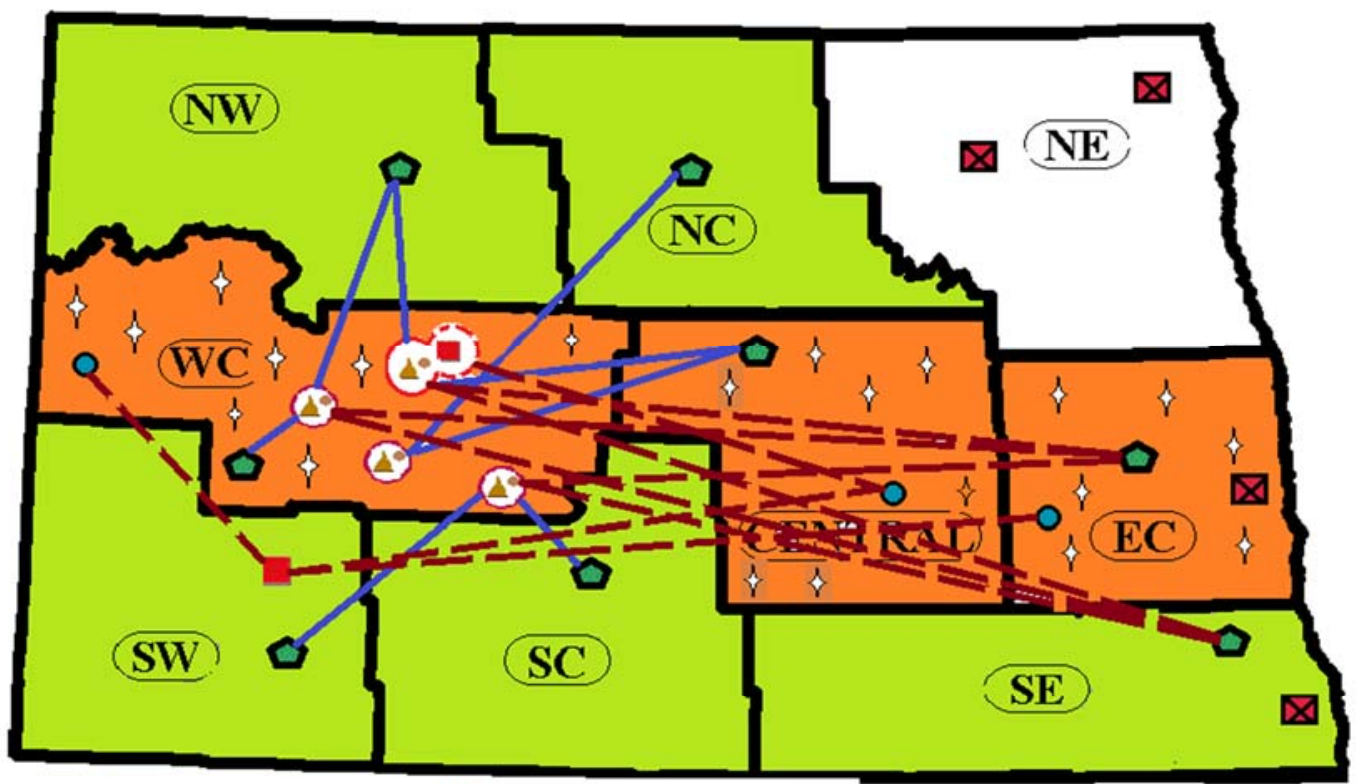

1G-SA $\triangle$ Closed 1G-SA 2 G-CBIS

1st generation biomass collection center (Corn) 2nd generation biomass collection center

Truck lane

- Train lane $\& 4$ Both $1^{\text {st }}$ generation and $2^{\text {nd }}$ generation biomass cultivation site

$2^{\text {nd }}$ generation biomass culitvation site

Figure 71. Network topology of biomass supply to bioethanol plant in ISHGBSC under CS

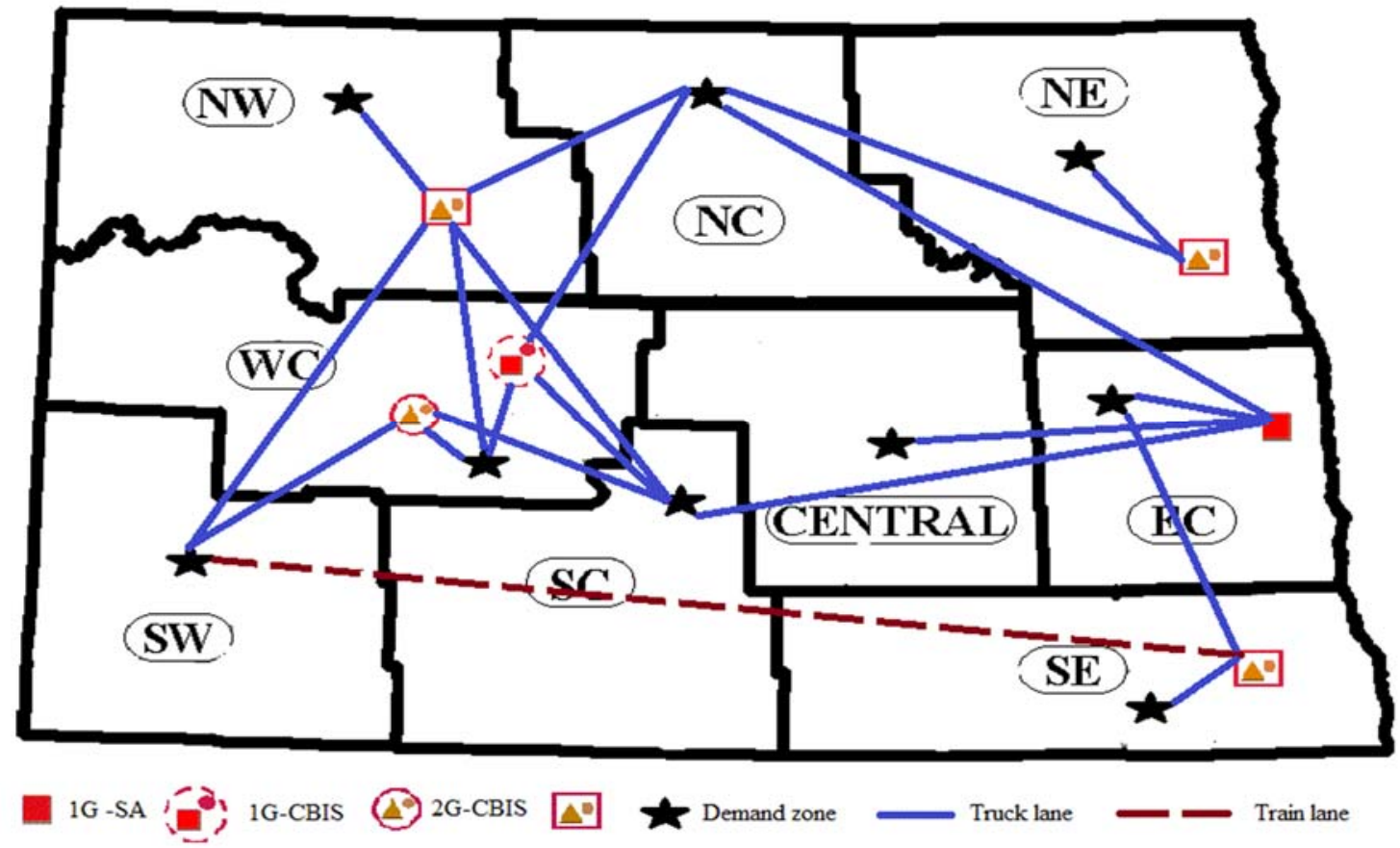

Figure 72. Network topology of bioethanol plant to demand zone in ISHGBSC under RFS 


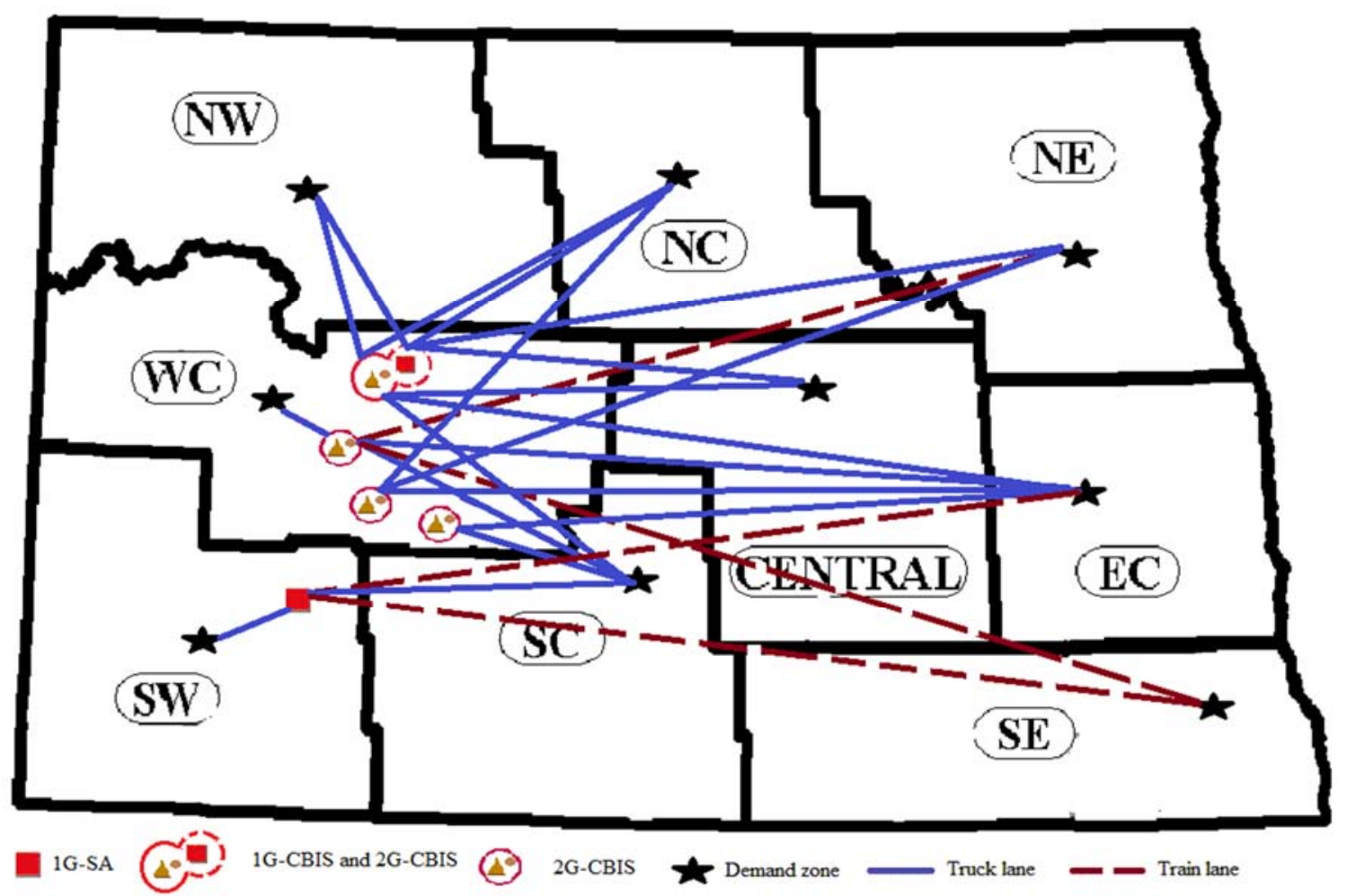

Figure 73. Network topology of bioethanol plant to demand zone in ISHGBSC under CS

Table 30. Optimal plant locations, configurations and capacities for ISHGBSC under RFS and CS

\begin{tabular}{lccccc}
\hline $\begin{array}{l}\text { District } \\
\text { location of } \\
\text { bioethanol } \\
\text { plant }\end{array}$ & \multicolumn{2}{c}{ Configuration } & & \multicolumn{2}{c}{ Capacity (MMGY) } \\
& \multicolumn{2}{c}{} & & & \\
\cline { 2 - 3 } \cline { 5 - 6 } \cline { 5 - 6 } NE (Pembina) & RFS & CS & & RFS & CS \\
NE (Walsh) & 1G-SA & 1G-SA & & Close & Close \\
WC & 1G-CBIS & 1G-CBIS & & Close & Close \\
EC & 1G-SA & 1G-SA & & 62.5 & 62.5 \\
SW & 1G-SA & 1G-SA & & Close & Close \\
SE & 1G-SA & 1G-SA & & Close & Close \\
NW & 2G-NBBIS & -- & & 150 & -- \\
NE & 2G-NBBIS & -- & & 150 & -- \\
WC (Mercer 1) & 2G-CBIS & 2G-CBIS & & 65 & 150 \\
SE & 2G-NBBIS & -- & & 150 & -- \\
WC (Mclean) & -- & 2G-CBIS & & -- & 150 \\
WC (Mercer 2) & -- & 2G-CBIS & & -- & 150 \\
WC (Oliver) & -- & 2G-CBIS & & -- & 150 \\
\hline
\end{tabular}


Table 31. Optimal assignment of collection centers, demand zones to the bioethanol plant in ISHGBSC under RFS and CS

\begin{tabular}{|c|c|c|c|c|}
\hline \multirow{2}{*}{$\begin{array}{c}\text { District location } \\
\text { of bioethanol } \\
\text { plant } \\
\end{array}$} & \multicolumn{2}{|c|}{ Collection center } & \multicolumn{2}{|c|}{ Demand zone } \\
\hline & RFS & $\mathrm{CS}$ & RFS & $\mathrm{CS}$ \\
\hline \multicolumn{5}{|c|}{ Existing $1^{\text {st }}$ generation bioethanol plant } \\
\hline WC & $\mathrm{C}, \mathrm{SC}$ & $\mathrm{C}$ & $\mathrm{NC}, \mathrm{WC}, \mathrm{SC}$ & NW, NC, NE, C \\
\hline $\mathrm{EC}$ & $\mathrm{C}, \mathrm{EC}$ & -- & $\mathrm{NC}, \mathrm{C}, \mathrm{EC}, \mathrm{SC}$ & -- \\
\hline SW & -- & $\mathrm{WC}, \mathrm{C}, \mathrm{EC}$ & -- & $\mathrm{EC}, \mathrm{SW}, \mathrm{SC}, \mathrm{SE}$ \\
\hline \multicolumn{5}{|c|}{ New $2^{\text {nd }}$ generation bioethanol plant } \\
\hline NW & NW & -- & $\begin{array}{c}\mathrm{NW}, \mathrm{NC}, \mathrm{WC}, \mathrm{SW}, \\
\mathrm{SC}\end{array}$ & -- \\
\hline NE & $\mathrm{NE}$ & -- & $\mathrm{NC}, \mathrm{NE}$ & -- \\
\hline WC (Mercer 1) & WC, SC & NW,WC & $\mathrm{WC}, \mathrm{SW}, \mathrm{SC}$ & $\begin{array}{l}\text { NE, WC, EC, } \\
\text { SC, SE }\end{array}$ \\
\hline $\mathrm{SE}$ & SE & -- & $\mathrm{EC}, \mathrm{SW}, \mathrm{SE}$ & -- \\
\hline WC (Mclean) & -- & NW & -- & $\mathrm{NW}, \mathrm{NC}, \mathrm{C}, \mathrm{SC}$ \\
\hline WC (Mercer 2) & -- & $\mathrm{NC}, \mathrm{C}$ & -- & $\mathrm{NC}, \mathrm{NE}, \mathrm{EC}$ \\
\hline WC (Oliver) & -- & $\mathrm{SW}, \mathrm{SC}$ & -- & EC, SW, SC, SE \\
\hline
\end{tabular}

\subsection{Sensitivity analysis}

Sensitivity analyses is conducted on the following in order to gain managerial insights: 1) the impact of corn price on ISHGBSC with different standards, and 2) the impact of $2 \mathrm{G}$ NBBIS/CHP unit capacity on sustainability.

\subsubsection{The impact of corn price on ISHGBSC with different standards}

This section presents the impact of corn price on the sustainability and design of ISHGBSC under different standards.

Figure 74 represents the profit of ISHGBSC with IS strategy under different standards when the corn price is increased. It indicates that:

1) The profit of the all the standards except are highly sensitive to the corn price.

2) The RFS, BES, WIS converges to the A2GS suggesting that all the corn based plants are shutdown when the corn price is increased. 


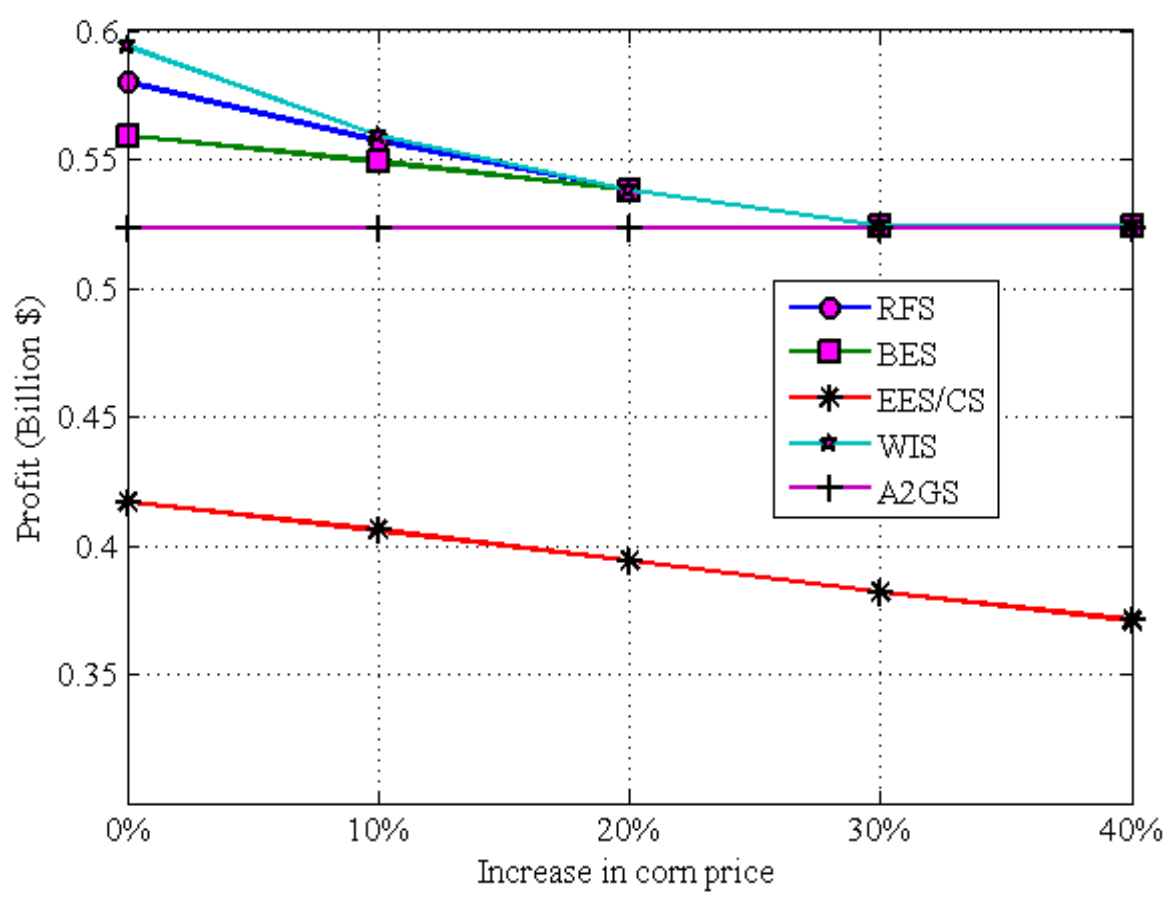

Figure 74. Profit of ISHGBSC under different standards when corn price is increased Figure 75 presents the profit of ISHGBSC under different standards when corn price is increased. It indicates that:

1) Under RFS, BES and WIS, GHG emissions can be significantly reduced when the corn price increases as the design of ISHGBSC converges to A2GS (where all the bioethanol is produced from $2^{\text {nd }}$ generation).

2) Under EES/CS, the GHG emissions are stable and least when compared to other standards.

Figure 76 and Figure 77 presents the social aspect of sustainability under different standards when the corn price is increased. It indicates that:

1) When the corn price is increased by more than $30 \%$, RFS, BES and WIS converges to A2GS resulting in reduced social issues. 
2) Under EES and CS standard, ISHGBSC relies on $1^{\text {st }}$ generation or corn based bioethanol even when the corn price is increased. Therefore, it indicates that EES and CS can create social issues even though corn price increases. This is because the 2G-CBIS is not economically competent enough and hence the ISHGBSC has to rely on $1^{\text {st }}$ generation bioethanol production even when the corn price is high. Therefore, CBIS strategy shows the potential to create social issues at higher corn prices at is it not economically competent enough with $1^{\text {st }}$ generation.

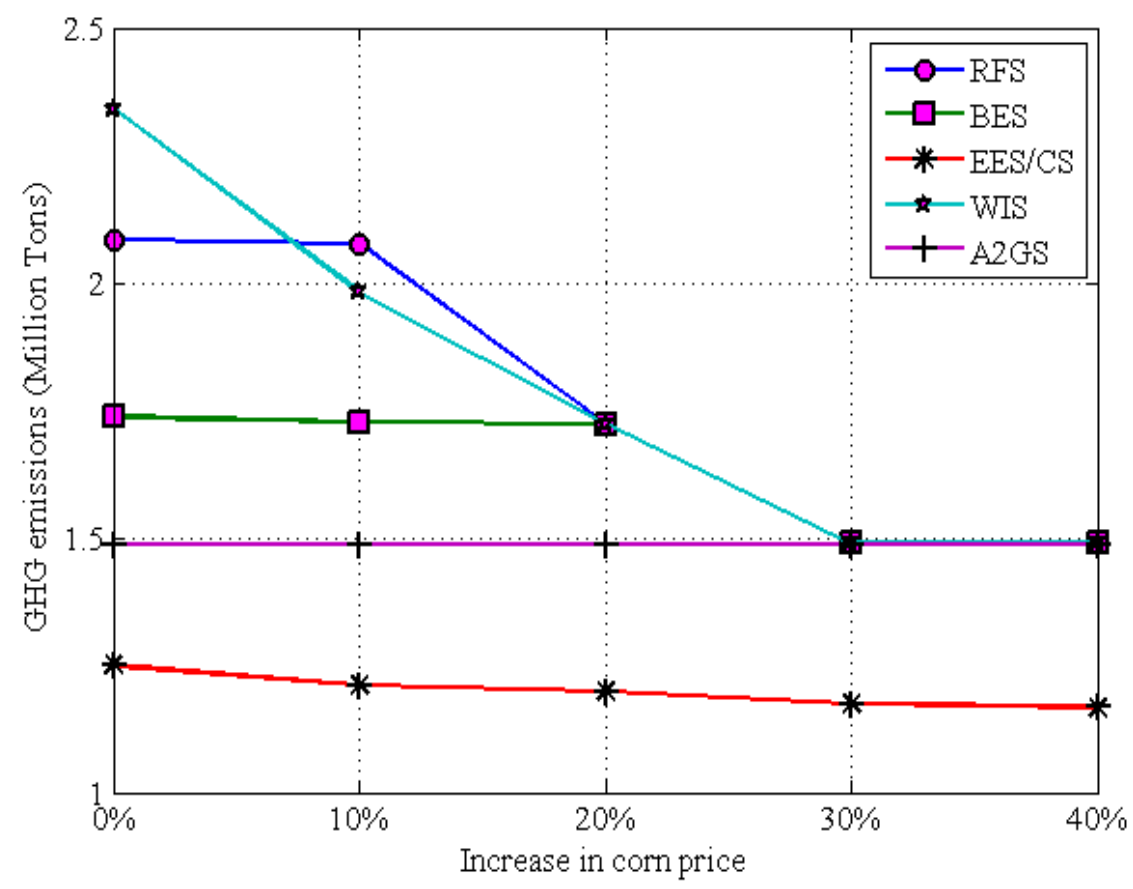

Figure 75. GHG emissions of ISHGBSC under different standards when corn price is increased Figure 78 presents the energy efficiency of the ISHGBSC under different standards when corn price is increased. It indicates that:

1) Energy efficiency of RFS, BES and CS decreases when the production is shifted from hybrid to A2GS suggesting that the energy efficiency of existing $1^{\text {st }}$ generation is higher than 2G-NBBIS. 
2) The energy efficiency under EIS and CS is stable and highest compared to other standards.

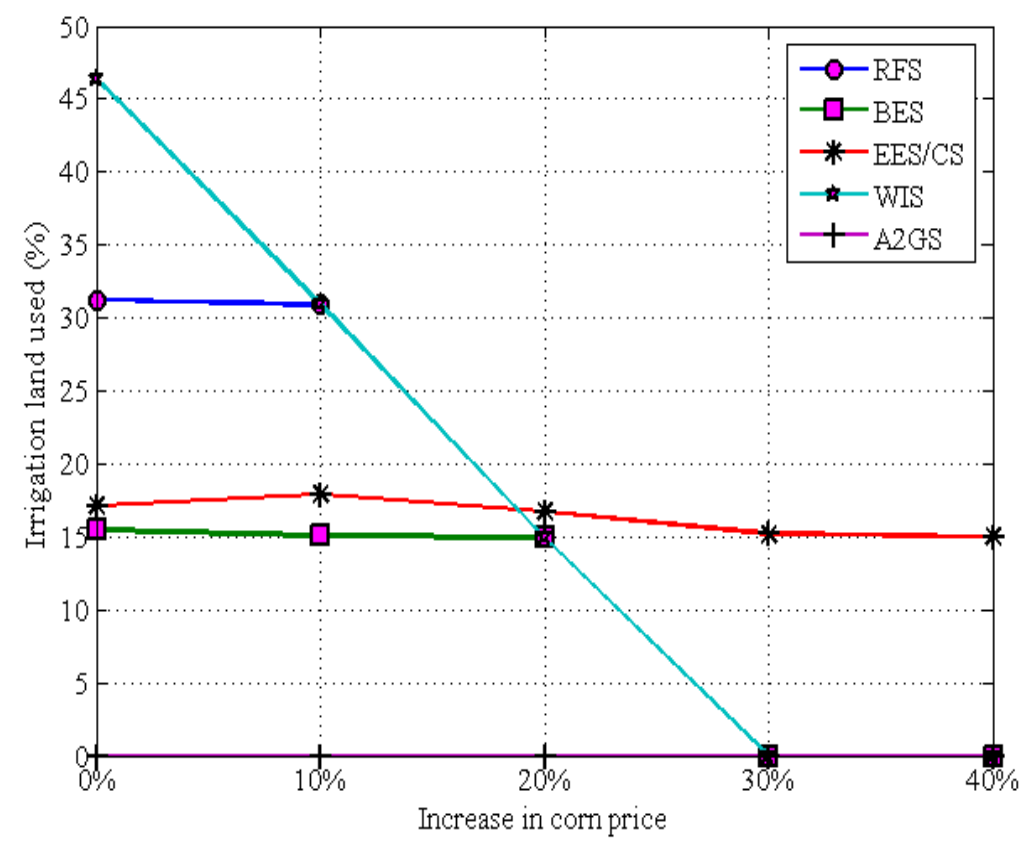

Figure 76. Irrigation land used by ISHGBSC under different standards when corn price is increased

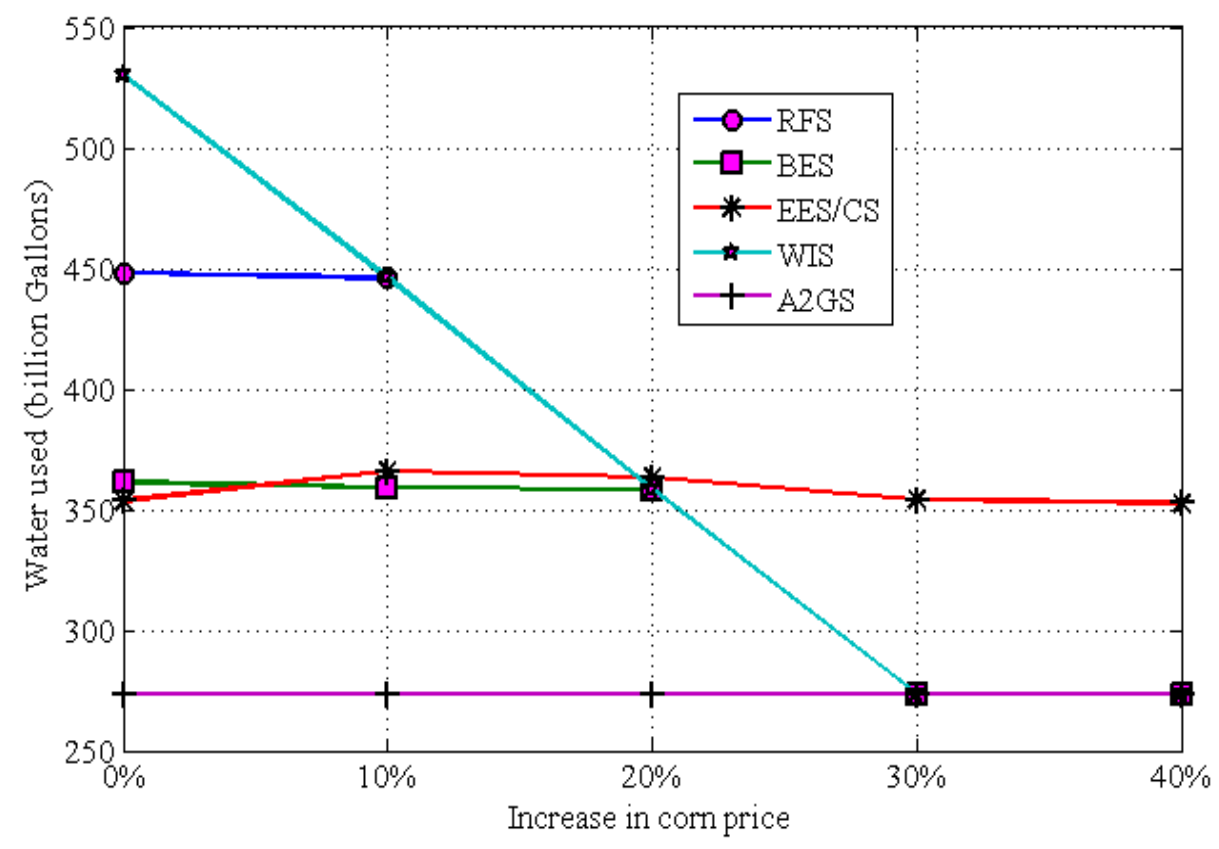

Figure 77. Water used by ISHGBSC under different standards when corn price is increased 


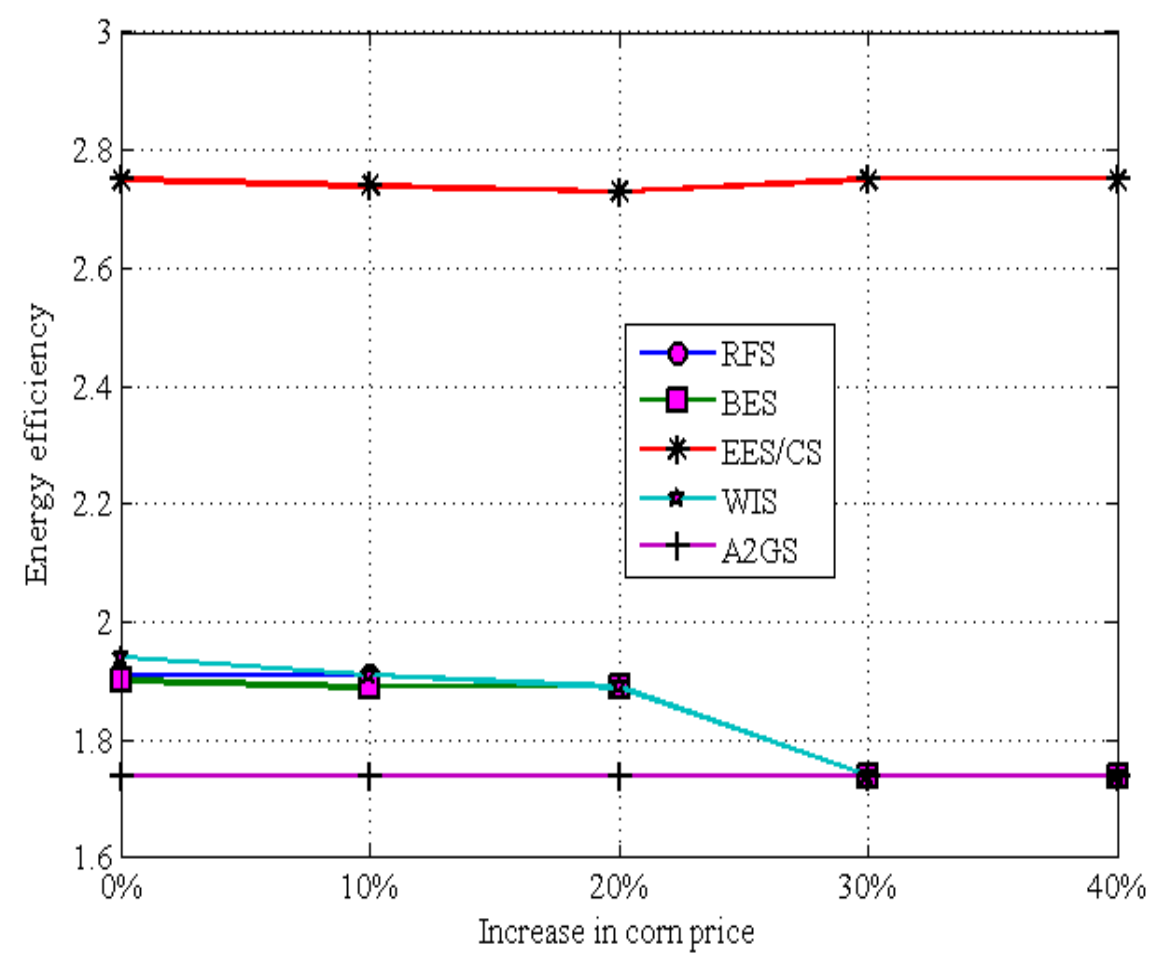

Figure 78. Energy efficiency of ISHGBSC under different standards when corn price is increased

\subsubsection{The impact of 2G-NBBIS/CHP unit capacity on sustainability}

This section presents the impact of 2G-NBBIS/CHP unit capacity on various aspects of sustainability. Figure 79-83 present the results. They indicate that:

1) The profit and GHG emissions for RFS, BES, WIS and A2GS increases when the CHP unit capacity is increased above $25 \mathrm{MW}$. This indicates that 2G-NBBIS can be generate economic benefit when the CHP unit is above 25 MW capacity. However, the GHG emissions is also high.

2) Under RFS, BES, WIS, the social aspect, amount of irrigation land and water used reduces when the capacity of CHP unit is increased above $25 \mathrm{MW}$. This indicates that 2G-NBBIS enables to reduce social impact because it generates competitive profits compared to $1^{\text {st }}$ generation bioethanol production. 
3) Under RFS, BES, WIS and A2GS, the energy efficiency decreases as the CHP unit capacity is increased. This indicates that $2 \mathrm{G}-\mathrm{NBBIS}$ can reduce the energy efficiency of the ISHGBSC.

4) ISHGBSC under EES and CS are not impacted because the supply chain do not rely on 2G-NBBIS.

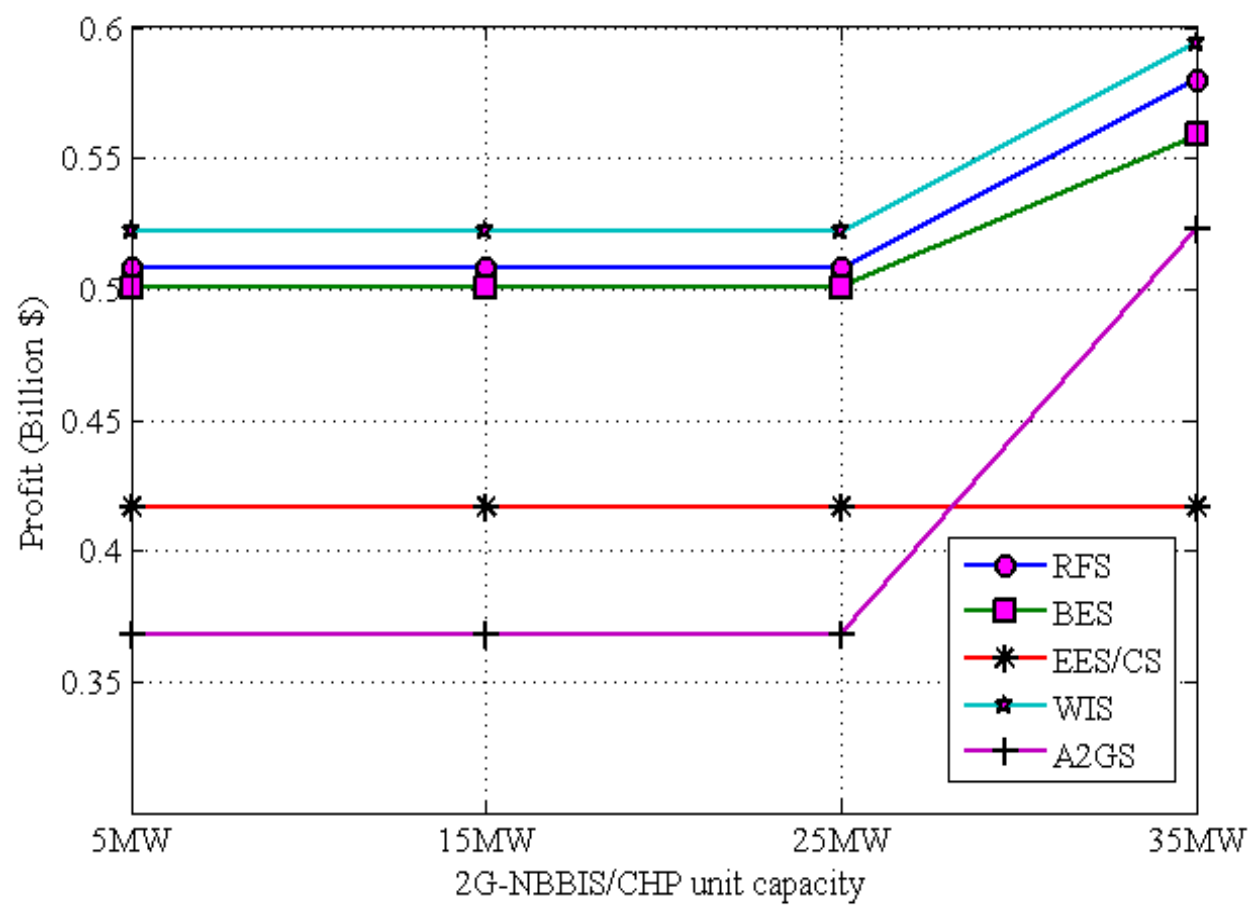

Figure 79. Profit of ISHGBSC when CHP unit capacity of 2G-NBBIS is increased 


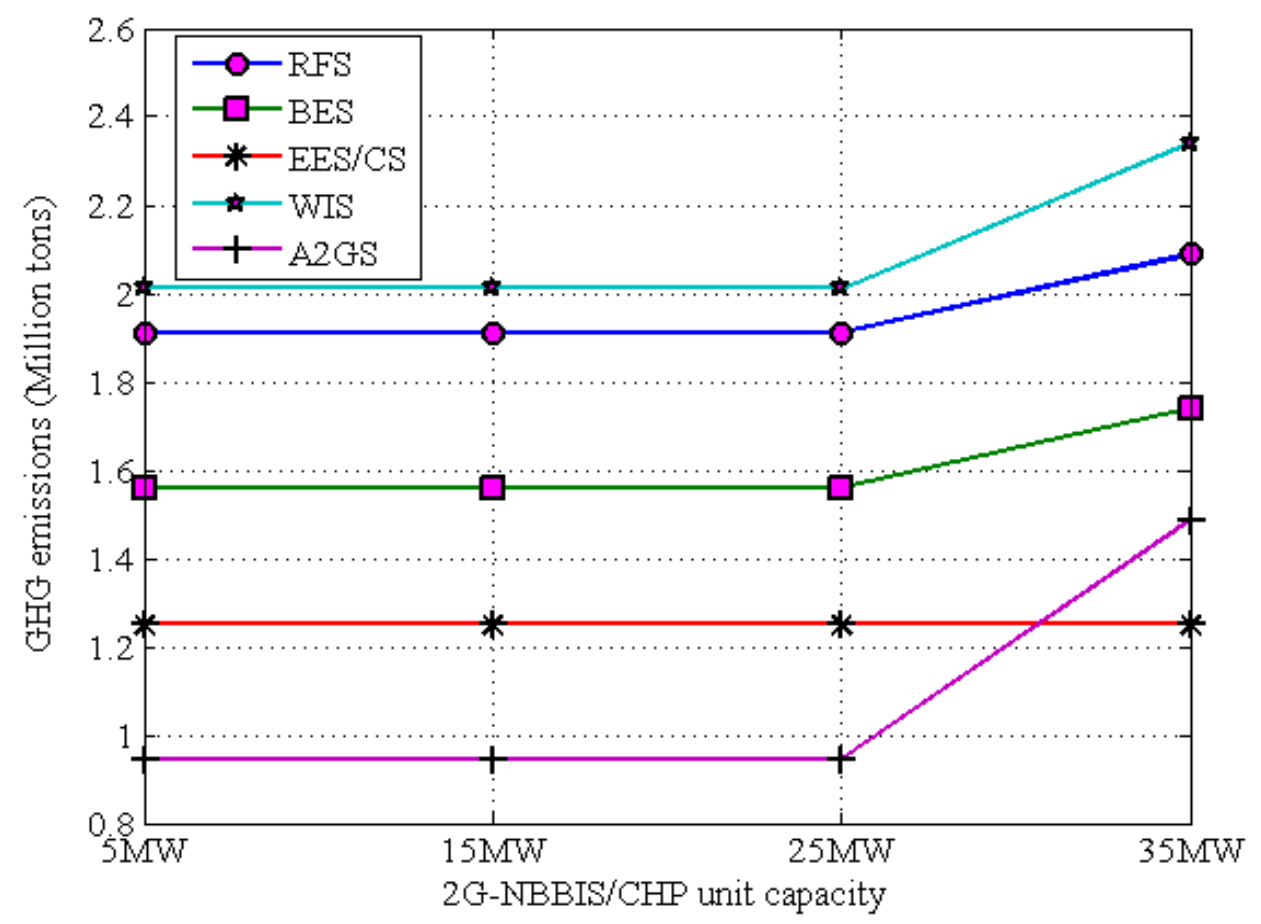

Figure 80. GHG emissions of ISHGBSC when the CHP unit capacity of 2G-NBBIS is increased

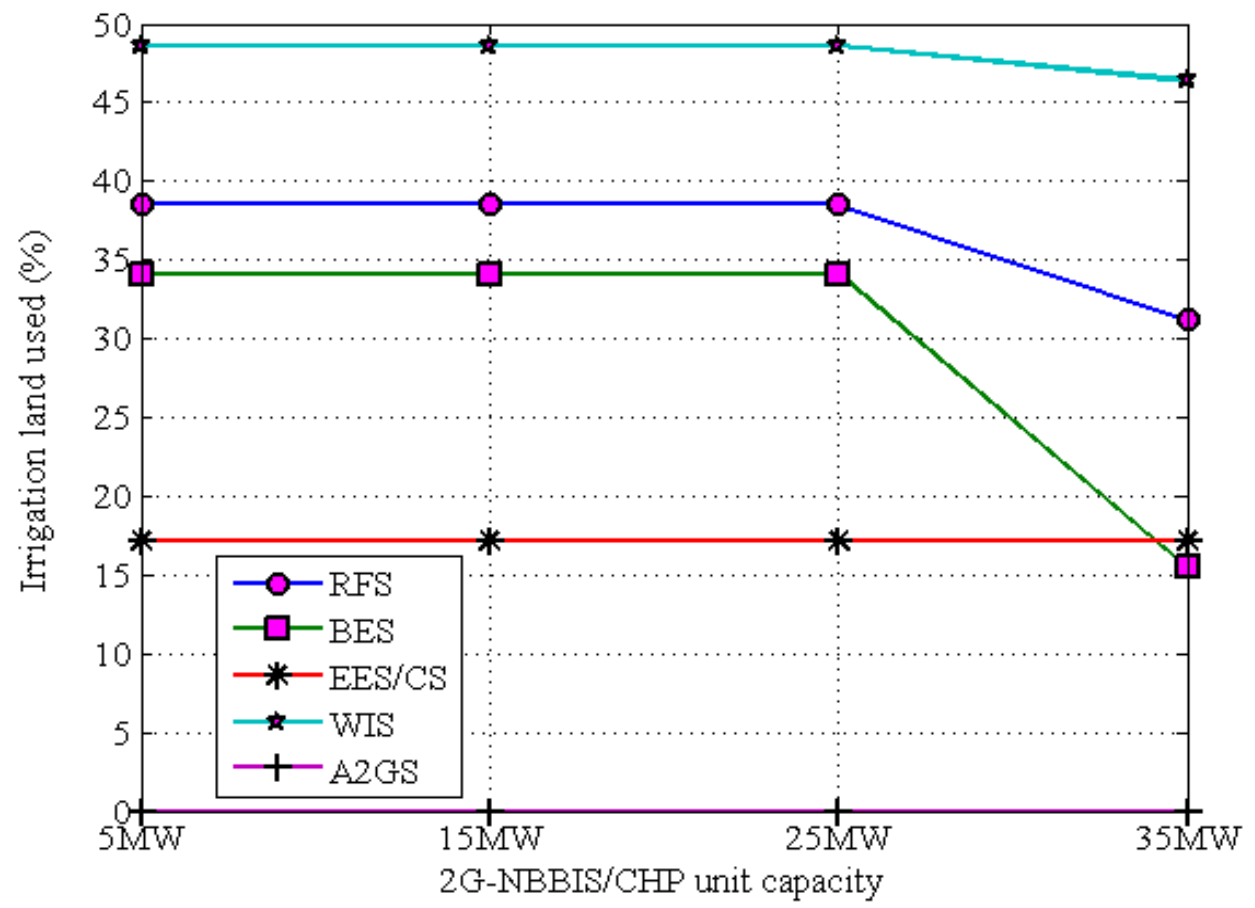

Figure 81. Irrigation land used by ISHGBSC when CHP unit capacity of 2G-NBBIS is increased 


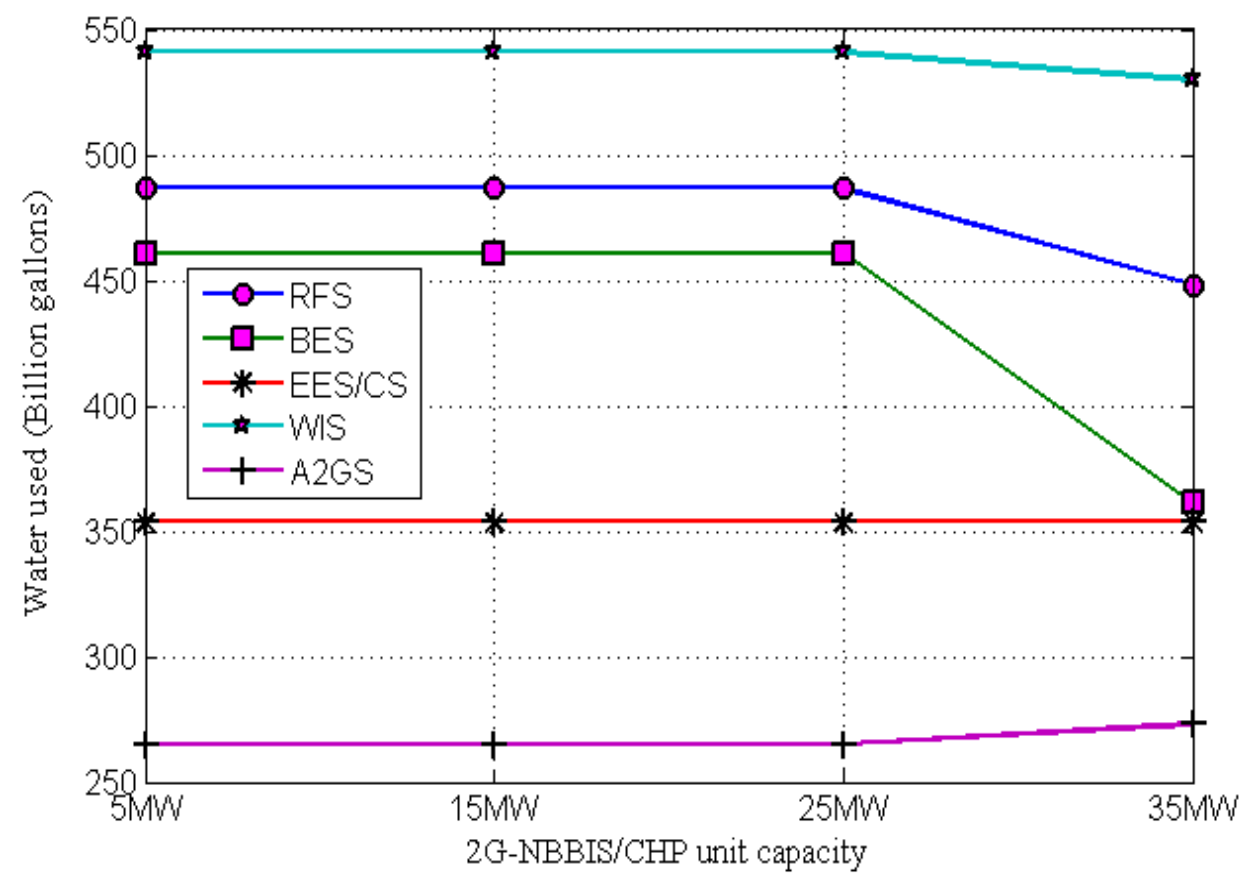

Figure 82. Water used by ISHGBSC when CHP unit capacity of 2G-NBBIS is increased

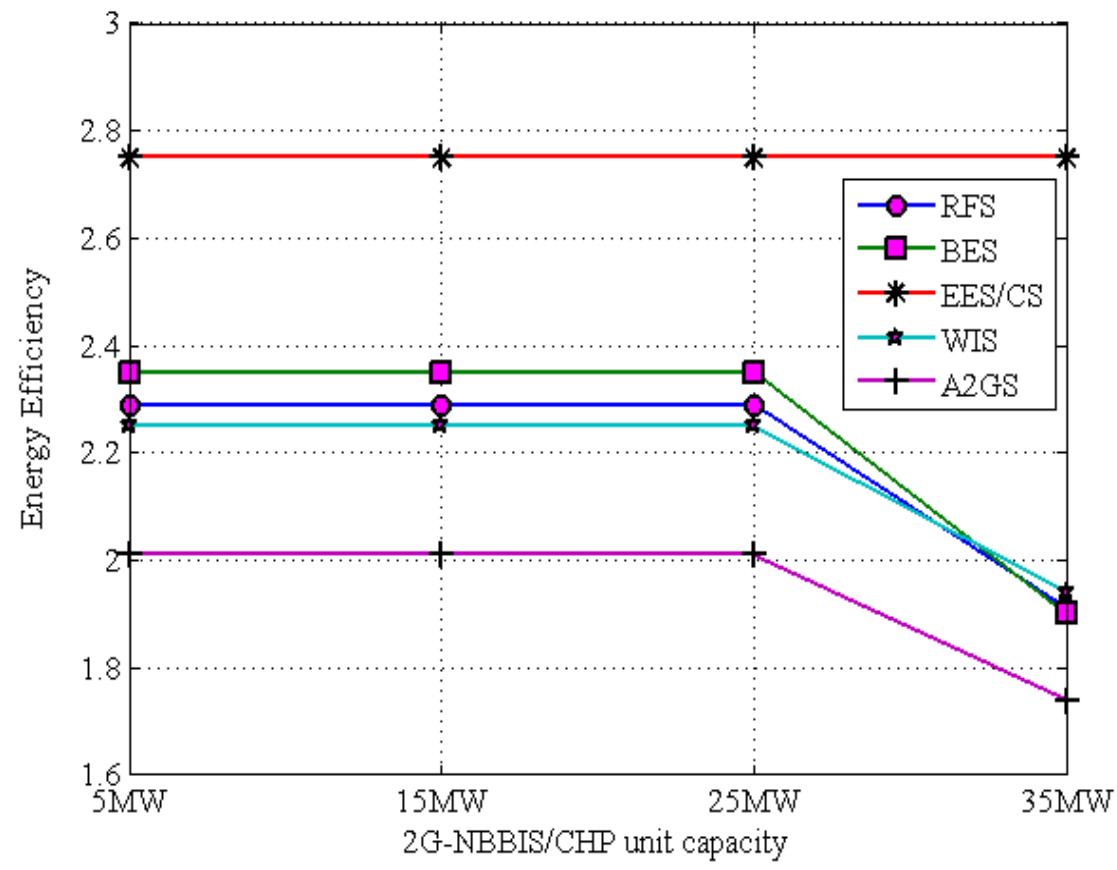

Figure 83. Energy efficiency of ISHGBSC when CHP unit capacity of 2G-NBBIS is increased 


\subsection{Conclusion}

This paper considers different IS configurations to design hybrid generation bioethanol supply chain. A SMILP model is proposed to design optimal ISHGBSC in order to achieve economic benefits under environmental, social and energy efficiency restrictions. In addition, uncertainties such as bioethanol demand, bioethanol price and biomass yield are considered in the study. Different sustainable standards are considered in the constraints. A case study of ND is used as application of the proposed model and SAA is used as the solution technology. The case study results show: 1) the optimal design of ISHGBSC changes significantly when different standards are applied; 2) 2G-SA is always dominated by 2 G-CBIS and 2G-NBBIS and hence should not be considered in sustainable design; 3)1G-CBIS is more sustainable in improving economic, environmental, and energy intensity aspects compared to $1 \mathrm{G}-\mathrm{SA}$. However, there is no difference in social aspect; 4) 2G-NBBIS is sustainable in improving economic, environmental and social aspects. However, it fails to apply with energy intensity restriction under EES; 5) Whenever 2GNBBIS has to be established, it should operate with high capacities to gain economies of scale; 6) CBIS cannot generate economic benefits, compared to NBBIS, due to low value co-products and higher logistic costs; and 7) IS provides sustainability flexibility in reducing GHG emissions and social aspects.

Sensitivity analyses conducted on the model suggests that: 1) 2G-CBIS can generate social issues at higher prices as it cannot compete with existing $1^{\text {st }}$ generation bioethanol production economically; and 2) 2G-NBBIS can be economically beneficial if the CHP unit capacity is above threshold.

Future directions include, but are not limited to: 1) incorporating various conversion technologies such as biochemical and thermochemical into ISHGBSC; 2) identifying strategies to 
make 2G-CBIS economically competitive; and 3) designing ISHGBSC that will consider more diversified $2^{\text {nd }}$ generation biomass. 


\section{CHAPTER 6. CONCLUSIONS AND FUTURE RESEARCH}

This chapter presents the conclusions of the research and proposes some future research directions.

\subsection{Conclusions}

Bioethanol is becoming increasingly attractive for transportation purposes as it is renewable and sustainable source of energy. In order to promote excessive use of bioethanol, it is extremely important to design a bioethanol that is both sustainable and robust. This research focuses on designing bioethanol supply chain that is both sustainable and robust. The research is conducted in three steps.

Firstly, a bioenergy based industrial symbiosis (BBIS) system is designed to improve the profit of the biorefinery plant. A decision framework combining linear programming (LP) models and large scale mixed integer linear programming model is proposed to determine: 1) the type of plants that should in included in BBIS, and 2) the optimal multiproduct symbiotic links (SLs) between the selected plants in the BBIS. A comprehensive case study is developed and the important managerial insights are:

- BBIS outperforms standalone in improving the profit of the bioethanol plant and other plants.

- As the number of plants and SLs increases, the profit of the BBIS increases.

- Combined heat and power (CHP) plant significantly improves the profit of biorefinery plant. The primary reason for improving profit of bioethanol by CHP plant is process steam. 
- The profit of CHP plant is significantly improved by Anaerobic Digestion (AD) plant. Therefore, in order for biorefinery plant to form stable BBIS with CHP plant, AD plant should be included in the BBIS.

- CHP plant acts as a focal plant for all the plants as it provides necessary inputs for all the plants.

Sensitivity analysis conducted on the BBIS indicates that:

- The biorefinery plant's maximum production volume decreases if the CHP plant's capacity is lower than the threshold required by the biorefinery plant. In such cases, contingency plans should be developed to meet the required production of the biorefinery plant.

- The biorefinery plant's profit is highly sensitive to the process steam price. If the process steam price is above some threshold limit in BBIS, then the SL of process steam between the CHP plant and the biorefinery plant will not be beneficial. Therefore, process steam price should be controlled below the threshold in BBIS.

- The biorefinery plant's profit is insensitive to the livestock size of the AD plant.

- BBIS configurations remain the same when input biomass types for the biorefinery plant change. However, the 2nd generation biomass improves the profit of biorefinery plant and CHP plant more compared to other biomass types. Hence, 2nd generation biomass should be used for bioethanol production if applicable.

Secondly, a hybrid generation bioethanol supply chain (HGBSC) that accounts for economic, environmental and social aspects of sustainability is designed. A stochastic model is proposed to determine the optimal HGBSC to determine: 1) whether the existing $1^{\text {st }}$ generation bioethanol plant should operate with same capacity, expand its capacity and close, 2) optimal locations of new $2^{\text {nd }}$ generation bioethanol plants, 3) optimal collection center locations, 4) optimal 
cultivation sites for biomass and 5) optimal transportation modes. A case study of North Dakota (ND) is used an application of the proposed model. Some of the important insights are:

- Economic benefits of HGBSC reduces as strict environmental and social restrictions are enforced. The profit of HGBSC reduces when GHG emissions is reduced. In addition, the profit reduces when the amount of irrigation land used is used.

- $\quad 1^{\text {st }}$ generation based bioethanol supply chain performs best in improving economic aspect. However, it does not help to improve environmental and social aspects.

- $\quad 2^{\text {nd }}$ generation based bioethanol supply chain outperforms $1^{\text {st }}$ generation in improving environmental and social aspects. However, the profit is significantly reduced. Switchgrass is preferred compared to corn stover for $2^{\text {nd }}$ generation bioethanol production because of very low yield rates of corn stover.

- $\quad 2^{\text {nd }}$ generation bioethanol production should produce high value co-products in order to compete with $1^{\text {st }}$ generation in terms of economic performance.

- The capital cost and the bioethanol production cost contributed significantly to increase the $2^{\text {nd }}$ generation bioethanol supply chain. Therefore, it is essential to find mature technologies that would significantly reduce these costs in order for the $2^{\text {nd }}$ generation to compete with the $1^{\text {st }}$ generation.

- Pipeline is not preferred because transportation cost and GHG emissions are insignificant in HGBSC. The transportation cost and GHG emissions are less in HGBSC because the geographical area considered is small.

- Bioethanol production and biomass production played major role in increasing GHG emissions. $2^{\text {nd }}$ generation outperformed $1^{\text {st }}$ generation in reducing GHG emissions 
because low GHG is emitted while producing $2^{\text {nd }}$ generation biomass compared to $1^{\text {st }}$ generation biomass.

- Tax credits decisions can be made by the policy makers to shift from lower state to higher state of sustainability through the proposed model. In addition, the proposed model provides optimal decisions to the investors to shift from lower state to higher state of sustainability.

Finally, industrial symbiosis based hybrid generation bioethanol supply chain (ISHGBSC) which is an integration of IS configurations and HGBSC is designed. A stochastic model is developed to design ISHGBSC that maximizes economic, environment, social and energy efficiency aspects under uncertainties. A case study of ND is used as an application of the proposed stochastic model and Sampling Average Approximation (SAA) is used as a solution technology. Some of the important insights are:

- The design of ISHGBSC changes significantly when different standards are applied.

- 2G-SA is always dominated by 2 G-CBIS and 2G-NBBIS and hence cannot be considered in sustainable design,

- 1G-CBIS is more sustainable in improving economic, environmental, and energy intensity aspects compared to 1G-SA. However, there is no difference in social aspect.

- 2G-NBBIS is sustainable in improving economic, environmental and social aspects. However, fails to regulate to energy intensity aspects.

- Whenever 2G-NBBIS has to be implemented, it should operate with high capacities to gain economies of scale.

- CBIS cannot generate economic benefits due to low value co-products and higher logistic costs 
- IS provides sustainability flexibility in reducing GHG emissions and social aspects.

Sensitivity analyses conducted on the model suggests that:

- 2G-CBIS can generate social issues at higher prices as it cannot compete with existing $1^{\text {st }}$ generation bioethanol production economically.

- 2G-NBBIS can be economically beneficial if the CHP unit capacity is above threshold.

\subsection{Future works}

This section discusses the future directions. The future work includes but are not limited to:

- Designing bioethanol based Industrial Symbiosis (BBIS) system that incorporates environmental, social and energy intensity aspects of sustainability. In addition, uncertainties should be incorporated while designing the BBIS.

- $\quad$ Identify more cross-sectored candidate plants, to form a more diversified BBIS.

- Identify new markets for by-products of the biorefinery plant, especially the $2^{\text {nd }}$ generation biorefinery plant, in order to transform the current lower value outputs of the biorefinery plant to high value inputs of other plants.

- Designing sustainability related policies based on environment, social and resource utilization aspects to attract candidates to form BBIS.

- Incorporation of various technologies such as biochemical and thermochemical into ISHGBSC.

- Study of markets to incorporate IS that can make 2G-CBIS economically competitive

- $\quad$ Designing ISHGBSC that will consider more diversified $2^{\text {nd }}$ generation biomass.

- Designing ISHSBSC where time based closing decisions about the existing $1^{\text {st }}$ generation plants can be made. This might require application of Markov decision Processes (MDP). In addition, it would need the use of solution technologies such as 
bender decomposition and Lagrange relaxation to solve the problem and reduce the computational time.

- A bioethanol supply chain will be designed where the technologies at each bioethanol plant will be a combination of sugar/starch and cellulosic platform. 


\section{REFERENCES}

Abbott, C. (2010, March 25). House bill extends U.S. ethanol tax breaks to 2016. Retrieved February 4, 2013, from Reuters: http://www.reuters.com/article/2010/03/25/ethanol-usaidUSN2525658920100325

Abdallah, T., Diabat, A., \& Simchi-Levi, D. (2012). Sustainable supply chain design: a closedloop formulation and sensitivity analysis. Production Planning \& Control, 23(2/3), 120-133. Doi:10.1080/09537287.2011.591622.

Ahring BK, Angelidaki I. 1997. Monitoring and controlling the biogas process. Proceeding at the $8^{\text {th }}$ international Conference on Anaerobic Digestion, 25-29 May 1997, Sendai, Japan, 1: 4050.

Akgul, O., Shah, N., \& Papageorgiou, L. G. (2012). An optimisation framework for a hybrid first/second generation bioethanol supply chain. Computers \& Chemical Engineering, 42, 101114.

Alex Marvin, W., Schmidt, L. D., Benjaafar, S., Tiffany, D. G., \& Daoutidis, P. (2012).

Economic optimization of a lignocellulosic biomass-to-ethanol supply chain. Chemical Engineering Science, 67(1), 68-79.

An, H., Wilhelm, W. E., \& Searcy, S. W. (2011). A mathematical model to design a lignocellulosic biofuel supply chain system with a case study based on a region in Central Texas. Bioresource technology, 102(17), 7860-7870.

Anderson, C. (2013, January 07). Dtn The progressive farmer. Retrieved March 31, 2013, from DDG Price Average Drops \$3 Per Ton From Pre-Holiday Levels:

http://www.dtnprogressivefarmer.com/dtnag/view/ag/printablePage.do?ID=BLOG_PRINTA 
BLE_PAGE\&bypassCache $=$ true $\&$ pageLayout $=\mathrm{v} 4 \&$ blogHandle $=$ ethanol $\&$ blogEntryId $=8 \mathrm{a} 82$ c0bc3aca540d013c1648dfc80d1 f\&articleTitle=DDG+Price+Average+Drops+\%243+Per+To $\mathrm{n}+$ From + Pre-Holiday + Lev

Appels, L., Lauwers, J., Degrève, J., Helsen, L., Lievens, B., Willems, K., et al., 2011. Anaerobic digestion in global bio-energy production: Potential. Renewable and Sustainable Energy Reviews 15, 4295-4301.

Awudu, I., \& Zhang, J. (2012 $)$. Uncertainties and sustainability concepts in biofuel supply chain management: A review. Renewable and Sustainable Energy Reviews, 16(2), 1359-1368.

Awudu, I., \& Zhang, J. (2012 $)$. Stochastic production planning for a biofuel supply chain under demand and price uncertainties. Applied Energy.

Beers, D. v., Corder, G., Bossilkov, A., Berkel, R. v., 2007. Industrial symbiosis in the Australian mineral industry: The cases of kwinana and Gladstone. Journal of Industrial Ecology 11(1), 5572.

Bernardi, A., Giarola, S., \& Bezzo, F. (2013). Spatially Explicit Multiobjective Optimization for the Strategic Design of First and Second Generation Biorefineries Including Carbon and Water Footprints. Industrial \& Engineering Chemistry Research, 52(22), 7170-7180.

Blake, M. L., \& Catlett, L. (1984). Cross Hedging Hay Using Corn Futures: An Empirical Test. Western Journal of Agricultural Economics, 127-134.

Bevill, K., 2011, March 31. ND cellulosic project revamps following feedstock study. Retrieved on 03/30/2012, from Ethanol producer magazine: http://ethanolproducer.com/articles/7633/ndcellulosic-project-revamps-following-feedstock-study. 
Boons, F., Spekkink, W., Mouzakitis, Y., 2011. The dynamics of industrialsymbiosis: a proposal for a conceptual framework based upon a comprehensive literature review. Journal of cleaner production 19 (9-10), 905-911.

Chae, S. H., Kim, S. H., Yoon, S. -G., Park, S., 2010.Optimization of a waste heat utilization network in an eco-industrial park. Applied Energy 87, 1978-1988.

Charles, M. B., Ryan, R., Ryan, N., \& Oloruntoba, R. (2007). Public policy and biofuels: The way forward?. Energy Policy, 35(11), 5737-5746.

Chen, C. W., \& Fan, Y. (2012). Bioethanol supply chain system planning under supply and demand uncertainties. Transportation Research Part E: Logistics and Transportation Review, $48(1), 150-164$.

Cheung, W. H., Choy, K. K. H., Hui, D. C. W., Porter, J. F. and Mckay, G, 2006. Use of Municipal Solid Waste for Integrated Cement Production. Dev. Chem. Eng. Mineral Process., 14: 193202. Doi: $10.1002 /$ apj.5500140117.

Chew, I. M., Tan, R. R., Foo, D. C., Chui, A. S., 2009. Game theory approach to the analysis of inter-plant water integration in an eco-industrial park. Journal of cleaner production 17, 16111619.

Combined Heat and Power Partnership. 2012, March 15. Retrieved March 28, 2012, from U.S. Environmental protection agency: http://www.epa.gov/chp/markets/wastewater.html.

Corsona, G., Vecchietti, A. R., Montagna, J. M., 2011. Optimal design for sustainable bioethanol supply chain considering detailed plant performance model. Computer and Chemical Engineering 35, 1384-1398.

Credit Suisse Report, (2012). Retrieved October 3, 2013, from:

http://www.thefinancialist.com/wp-content/uploads/2012/10/Ethanol-1-copy.pdf 
Dakota spirit agenergy. (2013). Retrieved March 31, 2013, from

http://www.growingjamestown.com/data/upfiles/Dakota\%20Spirit\%20AgEnergy\%20Update .pdf

Dal-Mas, M., Giarola, S., Zamboni, A., \& Bezzo, F. (2011). Strategic design and investment capacity planning of the ethanol supply chain under price uncertainty. Biomass and Bioenergy, 35(5), 2059-2071.

Demirbas, A. (2007). Progress and recent trends in biofuels. Progress in energy and combustion science, 33(1), 1-18.

Detailed treatment process, 2012. Retrieved 06/06/2012, from City of Fargo: http://www.cityoffargo.com/CityInfo/Departments/Wastewater/TreatmentProcess/Treatmentp rocessindetail/.

Easwaran, G., Üster, H., 2010. A closed-loop supply chain network design problem with integrated forward and reverse channel decisions, IIE Transactions, 42:11,779-792.

Eisenthal, J. (2013). The Value of Distillers Grain: One-Third of the Ethanol Story. Retrieved March 31, 2013, from ethanoltoday.com:

http://www.ethanoltoday.com/index.php?option=com_content\&task=view\&id=5\&fid=47\&It emid $=6$

Ekşioğlu, S. D., Acharya, A., Leightley, L. E., \& Arora, S. (2009). Analyzing the design and management of biomass-to-biorefinery supply chain. Computers \& Industrial Engineering, 57(4), 1342-1352.

Ethanol co-products. Retrieved 03/28/2012, from ethanol.org: http://www.ethanol.org/index.php?id=38\&parentid=8. 
Ethanol Facilities capacity by state and plant. (2012, October 17). Retrieved January 27, 2013, from Official Nebraska government website: http://www.neo.ne.gov/statshtml/122.htm.

Farm economic facts and opinions. (2001). University of illinois at Urbana-Champaign: Farm business management. http://farmdoc.illinois.edu/manage/newsletters/pdf/050201.pdf

Franceschin, G., Zamboni, A., Bezzo, F., \& Bertucco, A. (2008). Ethanol from corn: a technical and economical assessment based on different scenarios. Chemical engineering research and design, 86(5), 488-498.

Gebreslassie, B. H., Yao, Y., \& You, F. (2012). Design under uncertainty of hydrocarbon biorefinery supply chains: Multiobjective stochastic programming models, decomposition algorithm, and a comparison between CVaR and downside risk. AIChE Journal, 58(7), 21552179.

Giarola, S., Shah, N., \& Bezzo, F. (2012). A comprehensive approach to the design of ethanol supply chains including carbon trading effects. Bioresource Technology, 107, 175-185.

Gonela, V., \& Zhang, J. (2013). Design of the optimal industrial symbiosis system to improve bioethanol production. Journal of Cleaner Production.

Hardy, C., Graedel, T.E., 2002. Industrial ecosystems as food webs. Journal of industrial ecology 6(1), 29-38.

Hespell, R. B., O’Bryan, P. J., Moniruzzaman, M., \& Bothast, R. J. (1997). Hydrolysis by commercial enzyme mixtures of AFEX-treated corn fiber and isolated xylans. Applied biochemistry and biotechnology, 62(1), 87-97.

Huang, Y., Chen, C.W., Fan, Y., 2010. Multistage optimization of the supply chains of biofuels. Transportation Research Part E 46, 820-830. 
Humbird, D., Davis, R., Tao, L., Kinchin, C., Hsu, D., Aden, A., et al. (2011). Process Design and Economics for Biochemical Conversion of Lignocellulosic Biomass to Ethanol. NREL Technical Report.

Jacob, N. B., 2006. Industrial symbiosis in Kalunborg, Denmark: A quantitaive assessment of economic and environmental aspects. Journal of Industrial ecology 10 (1-2), 239-255.

Ji, G. (2009). Ecological supply chains performance evaluation and disruption risk management strategies. Human and Ecological Risk Assessment, 15(2), 351-370.

Kaylen, M., Van Dyne, D. L., Choi, Y.-S., \& Blase, M., 2000. Economic feasibility of producing ethanol from lignocellulosic feedstocks. Bioresource Technology 72, 19-32.

Kenné, J., Dejax, P., \& Gharbi, A. (2012). Production planning of a hybrid manufacturingremanufacturing system under uncertainty within a closed-loop supply chain. International Journal of Production Economics, 135(1), 81-93. Doi:10.1016/j.ijpe.2010.10.026.

Kleywegt, A. J., Shapiro, A., \& Homem-de-Mello, T. (2002). The sample average approximation method for stochastic discrete optimization. SIAM Journal on Optimization, 12(2), 479-502.

Kocoloski, M., Michael Griffin, W., \& Scott Matthews, H. (2011). Impacts of facility size and location decisions on ethanol production cost. Energy Policy, 39(1), 47-56.

Lambert, D. K., Middleton, J., 2010. Logistical design of a regional herbaceous crop residue-based ethanol production complex. Biomass and Bioenergy, 91-100.

Leao, R. R., Hamcher, S., Oliveira, f., 2011. Optimization of biodiesel supply chains based on small farmers: A case study in Brazil. Bioresource Technology 102, 8958-8963.

Limbachiya, M., Meddah, M. S., Ouchagour, Y., 2012. Use of recycled concrete aggregate in flyash concrete. Construction and Building Materials 27, 439-449. 
Lovelady, E. M., El-halwagi, M. M., 2009. Design and Integration of eco-Industrial parks for managing water resources. Environmental progress and sustainable Energy 28 (2), 265-272.

Lowe, E. A. (1997). Creating by-product resource exchanges: strategies for eco-industrial parks. Journal of Cleaner Production, 5(1), 57-65.

Mark, D. R., T. C. Schroeder, and R. Jones, 2000. Identifying economic risk in cattle feeding. J. Agribus. 18:331-344.

Martin, M., Eklund, M. , 2011. Improving the environmental performance of biofuels with industrial symbiosis. Biomass and Bioenergy 35, 1747-1755.

Marvin, A. W., Schmidt, L. D., Benjaafar, S., Tiffany, D. G., \& Daoutidis, P. (2012). Economic optimization of a lignocellulosic biomass-to-ethanol supply chain. Chemical Engineering Science, 67(1), 68-79.

Maung, T. A., \& Gustafson, C. R. (2011). The Viability of Harvesting Corn Cobs and Stover for Biofuel Production in North Dakota. Pittsburgh: Agricultural \& Applied Economics Association's 2011 AAEA \& NAREA Joint Annual Meeting.

Mele, F. D., Kostin, A. M., Guillén-Gosálbez, G., \& Jiménez, L. (2011). Multiobjective model for more sustainable fuel supply chains. A case study of the sugar cane industry in Argentina. Industrial \& Engineering Chemistry Research, 50(9), 4939-4958.

Morey, R., Douglas G., T., Hatfield, D, 2005. Biomass for Electricity and Process Heat at Ethanol Plants. ASAE Paper No. 056131, Tampa.

NASS-USDA. (2012). North Dakota 2012 County Rents \& Values. USDA. http://www.nass.usda.gov/Statistics_by_State/North_Dakota/Publications/Land_Values_and _Farm_Numbers/pub/crents12.pdf 
North Dakota 100K coal map. (n.d.). Retrieved January 27, 2013, from North Dakota geological survey: https://www.dmr.nd.gov/ndgs/Coalmaps/BLUE.COAL.asp.

Park, H.-S., Rene, E. R., Choi, S.-m., Chiu, A. S., 2008. Strategies for sustainable development of industrial park in Ulsan South Korea - From spontaneous evolution to systematic expansion of industrial symbiosis. Journal of environmental management 87, 1-13.

Peter, L., Maggie, M. ,2009. The pathway to a low carbon sustainable economy. Retrieved December 4, 2011, from http://www.nisp.org.uk/Publications/Pathway.pdf.

Quariguasi Frota Neto, J., Walther, G., Bloemhof, J., Van Nunen, J.A.E.E., Spengler, T., 2010. From closed-loop to supply chains: the WEEE case. International Journal of Production Research, 44:15, 4463-4481.

Rime, T., Lardy, G., Maddock-Carlin, K., Odde, K., Eide, W., 2006. Survey of cattle backgrounding and finishing feedlots in North Dakota. Retrieved 04/24/2012, from http://www.ag.ndsu.edu/archive/carringt/livestock/Beef\%20Report\%2006/Survey\%20of\%20 Cattle\%20Backgrounding.pdf.

Romm, Joseph (2009) The United States Needs a Tougher Greenhouse Gas Emissions Reduction Target for 2020. Center for American Progress (January 13). http://www.americanprogress.org/issues/2009/01/romm_emissions.html

Schnepf, R. (2011). Renewable Fuel Standard (RFS): Overview and Issues. DIANE Publishing. Searcy, E., Flynn, P., Ghafoori, E., \& Kumar, A. (2007). The relative cost of biomass energy transport. Applied Biochemistry and Biotechnology, 137(1), 639-652.

Shapouri, H., and Gallagher, P. (2005). USDA’s 2002 Ethanol Cost-of- Product Survey: Agricultural Economic Report Number 841. US Department of Agriculture, Washington, DC. 
Sög üt, Z., Oktay, Z., Karakoç, H., 2010. Mathematical modeling of heat recovery from a rotary kiln. Applied Thermal Engineering 30, 817-825.

Sokhansanj, S., Mani, S., Turhollow, A., Kumar, A., Bransby, D., Lynd, L., \& Laser, M. (2009). Large-scale production, harvest and logistics of switchgrass (Panicum virgatum L.)-current technology and envisioning a mature technology. Biofuels, Bioproducts and Biorefining, 3(2), $124-141$.

Summary Presentation on Ethanol benefits (SPEB)., 2011. Retrieved 03/28/2012, from National Corn Growers Association: http://www.ncga.com/presentations/.

Taskhiri, M. S., Tan, R. R., Chui, A. S. , 2011. MILP model for emergy optimization in EIP water networks. Clean techn Environ Policy 13, 703-712.

Thompson, W., Meyer, S., \& Westhoff, P. (2009). How does petroleum price and corn yield volatility affect ethanol markets with and without an ethanol use mandate?. Energy Policy, 37(2), 745-749.

Tudor, T., Adam, E., \& Bates, M. (2007). Drivers and limitations for the successful development and functioning of EIPs (eco-industrial parks): A literature review. Ecological Economics, 61(2), 199-207.

Unit Juggler. (2013, Octorber 23). Retrieved from http://www.unitjuggler.com/convert-energyfrom-kWh-to-MMBtu.html

USDA report. $\left(2012^{\mathrm{a}}\right)$. Corn Area Planted and Harvested, Yield, and Production - North Dakota by County: 2011. Fargo: USDA.

USDA Reportb. (2012b). Grain Transportation Report. Grain Transportation Report. http://www.ams.usda.gov/AMSv1.0/getfile?dDocName=STELPRDC5100454 
U.S. Environmental protection agency., (n.d.). Retrieved 03/07/, 2012, from combined heat and power partnership: http://www.epa.gov/chp/project-development/index.html.

U.S. Greenhouse Gas Inventory Report. (2013, February 5). Retrieved february 5, 2013, from EPA: http://www.epa.gov/climatechange/ghgemissions/usinventoryreport.html powerplantjobs.com. (n.d.). Retrieved January 27, 2013, from ND Power plants: http://www.powerplantjobs.com/ppj.nsf/powerplants1?openform\&cat=nd\&Count=500

Veiga, L. B., Magrini., 2009. Eco-industrial park development in Rio de janeiro, Brazil: A tool for sustainable development. Journal of cleaner production 17, 653-661.

Wang, M., Han, J., Dunn, J. B., Cai, H., and Elgowainy, A. (2012). Well-to-wheels energy use and greenhouse gas emissions of ethanol from corn, sugarcane and cellulosic biomass for US use. Environ. Res. Lett. 7045905 doi:10.1088/1748-9326/7/4/045905

Water movement in corn production. (2013, October 23). Retrieved from http://www.ncga.com/upload/files/documents/pdf/water_movement_in_corn_production.pdf

WBCSD report ${ }^{\mathrm{a}}$, Towards a sustainable cement industry, 2002. Retrieved 06/05/2012 from http://www.wbcsd.org/web/publications/batelle-full.pdf.

WBCSD report ${ }^{\mathrm{b}}$, Industrial ecology in the cement industry, 2002. Retrieved 06/05/2012 from http://www.wbcsdcement.org/pdf/battelle/final_report9.pdf.

Wheals, A. E., Basso, L. C., Alves, D. M., \& Amorim, H. V. (1999). Fuel ethanol after 25 years. Trends in biotechnology, 17(12), 482-487.

Wu, M., Wu, Y., \& Wang, M. (2006). Energy and emission benefits of alternative transportation liquid fuels derived from switchgrass: a fuel life cycle assessment. Biotechnology Progress, 22(4), 1012-1024. 
You, F., Tao, L., Graziano, D. J., \& Snyder, S. W. (2012). Optimal design of sustainable cellulosic biofuel supply chains: Multiobjective optimization coupled with life cycle assessment and input-output analysis. AIChE Journal, 58(4), 1157-1180.

Zamboni, A., Shah, N., \& Bezzo, F. (2009a). Spatially explicit static model for the strategic design of future bioethanol production systems. 1. Cost Minimization. Energy \& Fuels, 23(10), 5121-5133.

Zamboni, A., Bezzo, F., \& Shah, N. (2009b). Spatially explicit static model for the strategic design of future bioethanol production systems. 2. Multi-objective environmental optimization. Energy \& Fuels, 23(10), 5134-5143.

Zhang, J., Osmani, A., Awudu, I., \& Gonela, V. (2012). An integrated optimization model for switchgrass-based bioethanol supply chain. Applied Energy. 


\section{APPENDIX}

Table A. 1. Contribution of SRs in improving the CHP plant's profit in 5-BBIS

\begin{tabular}{|c|c|c|c|c|}
\hline Product Type & $\begin{array}{l}\text { Product sold } \\
\text { to }\end{array}$ & $\begin{array}{l}\text { Product sold } \\
\text { by }\end{array}$ & $\begin{array}{l}\text { Contribution to } \\
\text { increase in profit } \\
\text { (In Million \$) }\end{array}$ & $\begin{array}{l}\text { Percentage } \\
\text { contribution to } \\
\text { increase in profit }\end{array}$ \\
\hline Electricity & Biorefinery & $\mathrm{CHP}$ & $\$ 0.3381$ & $0.46 \%$ \\
\hline Electricity & $\mathrm{AD}$ & CHP & $\$ 0.16$ & $0.21 \%$ \\
\hline Electricity & Malt & CHP & $\$ 0.243$ & $0.33 \%$ \\
\hline Electricity & Cement & CHP & $\$ 0.0415$ & $0.05 \%$ \\
\hline Process steam & Biorefinery & $\mathrm{CHP}$ & $\$ 3.642$ & $4.94 \%$ \\
\hline Process steam & $\mathrm{AD}$ & $\mathrm{CHP}$ & $\$ 0.325$ & $0.44 \%$ \\
\hline Process steam & Malt & $\mathrm{CHP}$ & $\$ 2.25$ & $3.05 \%$ \\
\hline $\begin{array}{l}\text { Food and } \\
\text { Bio-solid } \\
\text { wastes }\end{array}$ & $\mathrm{AD}$ & $\mathrm{CHP}$ & $\$ 60.80$ & $83.57 \%$ \\
\hline Recycled water & Cement & $\mathrm{CHP}$ & $\$ 0.002$ & $0.002 \%$ \\
\hline Solid wastes & Cement & $\mathrm{CHP}$ & $\$ 2.092$ & $2.84 \%$ \\
\hline $\begin{array}{l}\text { Desulphurized } \\
\text { Gypsum }\end{array}$ & Cement & $\mathrm{CHP}$ & $\$ 0.0128$ & $0.017 \%$ \\
\hline Ashes & Cement & $\mathrm{CHP}$ & $\$ 0.0017$ & $0.002 \%$ \\
\hline Lignin pallets & $\mathrm{CHP}$ & Biorefinery & $\$ 1.184$ & $1.608 \%$ \\
\hline Wastewater & CHP & Biorefinery & $\$ 0.846$ & $1.14 \%$ \\
\hline Wastewater & CHP & $\mathrm{AD}$ & $\$ 0.0646$ & $0.087 \%$ \\
\hline Wastewater & $\mathrm{CHP}$ & Malt & $\$ 0.695$ & $0.943 \%$ \\
\hline
\end{tabular}

Table A. 2. Contribution of SRs in improving AD plant's profit in 5-BBIS

\begin{tabular}{|c|c|c|c|c|}
\hline Product Type & $\begin{array}{l}\text { Product } \\
\text { sold to }\end{array}$ & Product sold by & $\begin{array}{l}\text { Contribution } \\
\text { to increase in } \\
\text { profit } \\
\text { (In Million } \\
\text { \$) }\end{array}$ & $\begin{array}{l}\text { Percentage } \\
\text { contribution } \\
\text { to increase in } \\
\text { profit }\end{array}$ \\
\hline Electricity & $\mathrm{AD}$ & CHP & $\$ 0.16$ & $7.30 \%$ \\
\hline $\begin{array}{l}\text { Process } \\
\text { steam }\end{array}$ & $\mathrm{AD}$ & CHP & $\$ 0.325$ & $14.84 \%$ \\
\hline $\begin{array}{l}\text { Food and } \\
\text { Bio-solid } \\
\text { wastes }\end{array}$ & $\mathrm{AD}$ & CHP & $\$ 1.42$ & $64.85 \%$ \\
\hline DDG & $\mathrm{AD}$ & Biorefinery & $\$ 0.22$ & $10.04 \%$ \\
\hline Wastewater & CHP & $\mathrm{AD}$ & $\$ 0.0646$ & $2.95 \%$ \\
\hline
\end{tabular}


Table A. 3. Contribution of SRs in improving the malt plant's profit in 5-BBIS

*Indicates outside BBIS partnerships or combined contracts.

\begin{tabular}{lllll}
\hline $\begin{array}{l}\text { Product } \\
\text { Type }\end{array}$ & $\begin{array}{l}\text { Product } \\
\text { sold to }\end{array}$ & Product sold by & $\begin{array}{l}\text { Contribution to } \\
\text { increase in profit } \\
\text { (In Million \$) }\end{array}$ & $\begin{array}{l}\text { Percentage } \\
\text { contribution to } \\
\text { increase in profit }\end{array}$ \\
\hline $\begin{array}{l}\text { Electricity } \\
\text { Process } \\
\text { steam }\end{array}$ & $\begin{array}{l}\text { Malt } \\
\begin{array}{l}\text { Process } \\
\text { steam }\end{array}\end{array}$ & $\begin{array}{l}\text { CHP } \\
\text { Cement }\end{array}$ & CHP & $\begin{array}{l}\$ 0.243 \\
\$ 2.23\end{array}$ \\
$\begin{array}{l}\text { Wastewater } \\
\text { Barley }\end{array}$ & Malt & CHP & $\$ 0.1$ & $52.86 \%$ \\
\hline
\end{tabular}

Table A. 4. Contribution of SRs in improving the cement plant's profit in 5-BBIS

\begin{tabular}{|c|c|c|c|c|}
\hline Product Type & $\begin{array}{l}\text { Product } \\
\text { sold to }\end{array}$ & Product sold by & $\begin{array}{l}\text { Contribution to } \\
\text { increase in profit } \\
\text { (In Million \$) }\end{array}$ & $\begin{array}{l}\text { Percentage } \\
\text { contribution to } \\
\text { increase in profit }\end{array}$ \\
\hline Electricity & Cement & CHP & $\$ 0.243$ & $5.78 \%$ \\
\hline Process steam & Malt & Cement & $\$ 0.21$ & $5 \%$ \\
\hline Recycled water & Cement & CHP & $\$ 0.002$ & $0.04 \%$ \\
\hline Solid wastes & Cement & $\mathrm{CHP}$ & $\$ 3.73$ & $88.82 \%$ \\
\hline $\begin{array}{l}\text { Desulphurized } \\
\text { Gypsum }\end{array}$ & Cement & $\mathrm{CHP}$ & $\$ 0.0128$ & $0.3 \%$ \\
\hline Ashes & Cement & $\mathrm{CHP}$ & $\$ 0.0017$ & $0.04 \%$ \\
\hline
\end{tabular}

Table A. 5. Average values for uncertain parameters

\begin{tabular}{|c|c|c|c|c|c|}
\hline$i, j$ & $\begin{array}{l}d_{g \in e \cup e n t \xi}^{j} \\
\text { (gallons) } \\
(A L) \text { [Zhang et } \\
\text { al., 2012] }\end{array}$ & $\begin{array}{l}\beta_{g \in b n t \xi}^{i} \\
\text { (tonnes/ha) } \\
\text { (Switch grass ) } \\
\text { [Zhang et al., } \\
\text { 2012] }\end{array}$ & $\begin{array}{l}\beta_{g \in b n t \xi}^{i} \\
\text { (tonnes/acre) } \\
\text { (corn stover) } \\
\text { (Maung and } \\
\text { Gustafson, } \\
2011 \text { ) }\end{array}$ & $\begin{array}{l}\beta_{g \in b t \xi}^{i} \\
\text { (Bushels/acre) } \\
\text { (Corn ) } \\
\text { [USDA } \\
\text { report., 2012] }\end{array}$ & $\begin{array}{l}p_{g \in e \cup n t}^{j} \\
\text { (\$/gallon) } \\
\text { (Humbird, } \\
\text { et al., } \\
2011 \text { ) }\end{array}$ \\
\hline NW & 82347332 & 15.65 & 0.44 & 61.9 & 2.75 \\
\hline $\mathrm{NC}$ & 30823573 & 16.34 & 0.61 & 98.4 & 2.75 \\
\hline $\mathrm{NE}$ & 89013565 & 16.87 & 0.75 & 99.3 & 2.75 \\
\hline $\mathrm{WC}$ & 24412123 & 15.14 & 0.61 & 103.6 & 2.75 \\
\hline $\mathrm{C}$ & 29158272 & 16.73 & 0.79 & 111.8 & 2.75 \\
\hline $\mathrm{EC}$ & 145292693 & 18.5 & 0.99 & 106.3 & 2.75 \\
\hline SW & 29635150 & 14.21 & 0.33 & 79 & 2.75 \\
\hline $\mathrm{SC}$ & 99629754 & 14.98 & 0.57 & 99.4 & 2.75 \\
\hline $\mathrm{SE}$ & 33384801 & 18.45 & 1.03 & 107.5 & 2.75 \\
\hline
\end{tabular}


Table A. 6. Maximum allowable land for each of the biomass considered

\begin{tabular}{|c|c|c|c|}
\hline$i$ & $\begin{array}{l}B_{g \in b}^{i} \text { (ha) } \\
\text { (Switch grass) } \\
\text { [Zhang et al., } \\
\text { 2012] }\end{array}$ & $\begin{array}{l}B_{g \in b n}^{i} \text { (acres) } \\
(\text { corn stover }) \\
(\text { Corn }) \text { [USDA } \\
\left.\text { report }^{\mathrm{a}} ., 2012\right]\end{array}$ & $\begin{array}{l}B_{g \in b n}^{i} \text { (acres) } \\
(\text { Corn }) \\
\text { [USDA } \\
\left.\operatorname{report}^{\mathrm{a}} ., 2012\right]\end{array}$ \\
\hline NW & 85794 & 9300 & 9300 \\
\hline $\mathrm{NC}$ & 106286 & 80400 & 80400 \\
\hline $\mathrm{NE}$ & 172783 & 168000 & 168000 \\
\hline WC & 66757 & 47300 & 47300 \\
\hline $\mathrm{C}$ & 97012 & 237000 & 237000 \\
\hline $\mathrm{EC}$ & 69099 & 488000 & 488000 \\
\hline SW & 51136 & 45000 & 45000 \\
\hline $\mathrm{SC}$ & 64288 & 192000 & 192000 \\
\hline $\mathrm{SE}$ & 95435 & 793000 & 793000 \\
\hline
\end{tabular}

Table A. 7. Land rental cost

\begin{tabular}{llll}
\hline$i$ & $\begin{array}{l}\text { Corn } r c_{g \in b}^{i}(\$ / \text { acre }) \\
\text { [NASS-USDA., }\end{array}$ & $\begin{array}{l}\text { Corn stover } r c_{g \in b n}^{i} \\
\text { (\$/acre) }\end{array}$ & $\begin{array}{l}\text { Switchgrass } \\
\text { (\$/ha) }\end{array}$ \\
& 2012 ] & [NSS-USDA., & [Zhang et al., 2012] \\
& & 2012, Assumption] & \\
\hline NW & 36.66 & 0 & 19.8 \\
NC & 43 & 0 & 29.62 \\
NE & 53.33 & 0 & 28.55 \\
WC & 35 & 0 & 27.48 \\
C & 48.33 & 0 & 29.4 \\
EC & 40 & 0 & 35.32 \\
SW & 36.42 & 0 & 29.6 \\
SC & 36 & 0 & 35.56 \\
SE & 82.85 & 0 & 56.95 \\
\hline
\end{tabular}

Table A. 8. Transportation costs

\begin{tabular}{|c|c|c|c|}
\hline $\begin{array}{l}\text { Transportation } \\
\text { mode } m\end{array}$ & Fixed cost $\bar{c}_{g}^{r^{\prime} j m}$ & Variable cost $c_{g t}^{r^{\prime} j m}$ & Source \\
\hline \multicolumn{4}{|c|}{$g \in e \cup e n($ Bioethanol) } \\
\hline Truck & $\begin{array}{l}0.01159 \\
\text { \$/gallon }\end{array}$ & 0.00024 \$/gallon-mile & Searcy et al., 2007 \\
\hline Train & $\begin{array}{l}0.06183 \\
\text { \$/gallon }\end{array}$ & 6.9E-05 \$/gallon-mile & Kocoloski et al., 2011 \\
\hline Pipeline & $0.03 \$$ /gallon & $0.00025 \$ /$ gallon-mile & Searcy et al., 2007 \\
\hline
\end{tabular}

Continued 
Table A. 8. Transportation costs (Continued)

\begin{tabular}{|c|c|c|c|}
\hline $\begin{array}{l}\text { Transportation } \\
\text { mode } m\end{array}$ & Fixed cost $\bar{c}_{g}^{r^{\prime} j m}$ & Variable cost $c_{g t}^{r^{\prime} j m}$ & Source \\
\hline \multicolumn{4}{|l|}{$g \in b \quad($ Corn $)$} \\
\hline Truck & $\begin{array}{l}0.000857 \\
\$ / \text { bushel }\end{array}$ & $0.00146 \$$ /bushel-mile & USDA report $^{\mathrm{b}} ., 2012$ \\
\hline Train & $\begin{array}{l}0.000125 \\
\$ / \text { bushel }\end{array}$ & $0.000575 \$$ /bushel-mile & USDA report ${ }^{\mathrm{b}} ., 2012$ \\
\hline \multicolumn{4}{|c|}{$g \in b n$ (Corn stover/Switchgrass) } \\
\hline Truck & $6 \$ /$ tonne & 0.08 \$/tonne-mile & Sokhansanj et al., 2007 \\
\hline Train & 23 \$/tonne & 0.017 \$/tonne-mile & Sokhansanj et al., 2007 \\
\hline Pipeline & 9 \$/tonne & 0.08 4/tonne-mile & Sokhansanj et al., 2007 \\
\hline
\end{tabular}

Table A. 9. Capacity, cost, yield, and GHG emission parameters

\begin{tabular}{|c|c|c|}
\hline Source & Input parameter & Value \\
\hline \multicolumn{3}{|l|}{ Capacities } \\
\hline Assumption & $\begin{array}{l}\text { Maximum production capacity of new } 2 \mathrm{nd} \\
\text { generation bioethanol plant } \varphi n_{g}^{r^{\prime}}\end{array}$ & $150 \mathrm{MMGY}$ \\
\hline Assumption & $\begin{array}{l}\text { Maximum allowable capacity of new } 2^{\text {nd }} \\
\text { generation collection center } \bar{\varphi}_{g}^{c^{\prime} \in c n}\end{array}$ & $\begin{array}{l}1.5 \text { Million } \\
\text { Tons }\end{array}$ \\
\hline \multicolumn{3}{|l|}{ Cost } \\
\hline Assumption & $\begin{array}{l}\text { The cost of operating } 1^{\text {st }} \text { generation bioethanol } \\
\text { plant (Fixed + variable) }{ }^{c^{\prime} \in r} o_{g \in e}\end{array}$ & 0.21 \$/gallon \\
\hline $\begin{array}{l}\text { Shapouri and } \\
\text { Gallagher., (2005) }\end{array}$ & $\begin{array}{l}\text { The cost of expanding } 1^{\text {st }} \text { generation bioethanol } \\
\text { plant } c e_{g}^{r^{\prime}}\end{array}$ & $0.50 \$$ /gallon \\
\hline Assumption & $\begin{array}{l}\text { The cost of closing } 1^{\text {st }} \text { generation bioethanol } \\
\text { plant } c c_{g}^{r^{\prime}}\end{array}$ & 0.15 \$/gallon \\
\hline Assumption & $\begin{array}{l}\text { The cost of producing } 1^{\text {st }} \text { generation bioethanol } \\
p c_{g \in e t}^{r^{\prime} \in r}\end{array}$ & $0.23 \$ /$ gallon \\
\hline Assumption & $\begin{array}{l}\text { The cost of storing corn at the existing } 1^{\text {st }} \\
\text { generation collection centers and at the } \\
\text { bioethanol plants }\end{array}$ & 0.131 \$/gallon \\
\hline $\begin{array}{l}\text { Farm economic facts } \\
\text { and opinions, } 2001\end{array}$ & The cost of cultivating corn $c v t_{g \in b}^{i}$ & 357 \$/acre \\
\hline
\end{tabular}

Continued 
Table A.9. Capacity, cost, yield, and GHG emission parameters (Continued)

\begin{tabular}{|c|c|c|}
\hline Source & Input parameter & Value \\
\hline $\begin{array}{l}\text { Farm economic } \\
\text { facts and opinions, } \\
2001\end{array}$ & The cost of harvesting corn at corn fields $c_{g \in b t}^{i c^{\prime}}$ & $\begin{array}{l}28.71 \quad \text { \$acre }+ \\
\text { transportation cost } \\
\text { from } i \text { to } C\end{array}$ \\
\hline Zhang et al., 2012 & $\begin{array}{l}\text { Fixed cost of new } 2^{\text {nd }} \text { generation bioethanol plant } \\
c n^{r^{\prime} \in r n}\end{array}$ & 72 Million \$ \\
\hline $\begin{array}{l}\text { Kocoloski et al., } \\
2011\end{array}$ & $\begin{array}{l}\text { Variable facility cost of bioethanol plant based on } \\
\text { size } c \delta_{g \in e n}^{r^{\prime} \in r}\end{array}$ & 0.37 \$/gallon \\
\hline Zhang et al., 2012 & The cost of producing $2^{\text {nd }}$ generation bioethanol & $\begin{array}{l}0.9-0.56 \text { (subsidy } \\
\text { compared to corn ) } \\
=0.33 \$ / \text { gallon }\end{array}$ \\
\hline Zhang et al., 2012 & $\begin{array}{l}\text { The cost of opening new } 2^{\text {nd }} \text { generation collection } \\
\text { center } c n^{c^{\prime} \in c n}\end{array}$ & $100000 \$$ \\
\hline Zhang et al., 2012 & $\begin{array}{l}\text { The cost of storing } 2^{\text {nd }} \text { generation biomass at the } \\
\text { collection center and the bioethanol plants }\end{array}$ & $21.7 \$ /$ tonne \\
\hline Assumption & The cost of cultivating corn stover $c v t_{g \in b n}^{i}$ & $0 \$ /$ tonne \\
\hline Zhang et al., 2012 & The cost of cultivating switchgrass $c v t_{g \in b n}^{i}$ & $395 \$ /$ ha \\
\hline Interview & The cost of harvesting cornstover $c_{g \in b n t}^{i c^{\prime}}$ & $\begin{array}{l}59.4 \quad \$ / \text { acre } \\
\text { transportation cost } \\
\text { from } i \text { to } c n\end{array}$ \\
\hline Zhang et al., 2012 & The cost of harvesting switchgrass $c_{g \in b n t}^{i c^{\prime}}$ & $\begin{array}{l}49.6 \quad \$ / \text { ha } \\
\text { transportation cost } \\
\text { from } i \text { to } c n\end{array}$ \\
\hline Anderson, 2013 & DDG Selling price & 255 \$/Ton \\
\hline Assumption & Lignin pallet & $25 \$ /$ Ton \\
\hline Assumption & Shortage cost $S C_{g t}^{j}$ & $6 \$ /$ gallon \\
\hline \multicolumn{3}{|l|}{ Yield } \\
\hline $\begin{array}{l}\text { Hespell et al., } \\
1997\end{array}$ & Ethanol yield from corn & 2.85 gallons/bushel \\
\hline $\begin{array}{l}\text { Humbird et al., } \\
2011\end{array}$ & Ethanol yield rate from corn stover & 79 gallons/ton \\
\hline Zhang et al., 2012 & Ethanol yield from switchgrass & 82.63 gallons/ton \\
\hline Eisenthal, J., 2013 & Distillers Dried Grains (DDG) & $\begin{array}{l}6 \text { pounds/ gallon of } \\
\text { corn based ethanol }\end{array}$ \\
\hline $\begin{array}{l}\text { Dakota spirit } \\
\text { agenergy., (2013) }\end{array}$ & Linin pallets & $\begin{array}{l}0.0085 \text { ton/gallon } \\
\text { of } 2^{\text {nd }} \text { generation } \\
\text { bioethanol }\end{array}$ \\
\hline \multicolumn{3}{|l|}{ GHG emissions } \\
\hline $\begin{array}{l}\text { Wang et al., } 2012 \\
\text { Assumption }\end{array}$ & $\begin{array}{l}\text { GHG emissions for all the data } \\
\text { GHG }\end{array}$ & $20 \$ /$ Ton \\
\hline
\end{tabular}


Table A. 10. Average values for uncertain parameters

\begin{tabular}{lllll}
\hline$i, j$ & $\begin{array}{l}d_{g \in e \cup e n t \xi}^{j} \text { (gallons) } \\
(A L) \text { [Zhang et al., }\end{array}$ & $\begin{array}{l}\beta_{g \in b n t \xi}^{i} \\
\text { (tonnes/ha) } \\
\text { (Switch grass) } \\
\text { [Zhang et al., }\end{array}$ & $\begin{array}{l}\beta_{g \in b t \xi}^{i} \\
\text { (Bushels/acre) } \\
\text { (Corn) [USDA } \\
\text { report., 2012] }\end{array}$ & $\begin{array}{l}p_{g \in e v e n t}^{j} \\
\text { (\$/gallon) } \\
\text { (Humbird, et } \\
\text { al., 2011) }\end{array}$ \\
& 2012 ] & 15.65 & 61.9 & 2.75 \\
\hline NW & 82347332 & 16.34 & 98.4 & 2.75 \\
NC & 30823573 & 16.87 & 99.3 & 2.75 \\
NE & 89013565 & 15.14 & 103.6 & 2.75 \\
WC & 24412123 & 16.73 & 111.8 & 2.75 \\
C & 29158272 & 18.5 & 106.3 & 2.75 \\
EC & 145292693 & 14.21 & 79 & 2.75 \\
SW & 29635150 & 14.98 & 99.4 & 2.75 \\
SC & 99629754 & 18.45 & 107.5 & 2.75 \\
SE & 33384801 & & & \\
\hline
\end{tabular}

Table A. 11. Maximum allowable land for each of the biomass considered

\begin{tabular}{lll}
\hline$i$ & $\begin{array}{l}B_{g \in b}^{i}(\text { ha }) \\
\text { (Switch grass ) } \\
\text { [Zhang et al., 2012] }\end{array}$ & $\begin{array}{l}B_{g \in b n}^{i} \text { (acres) } \\
(\text { Corn }) \text { [USDA report., 2012 }{ }^{\text {a }} \text { ] }\end{array}$ \\
\hline NW & 85794 & 9300 \\
NC & 106286 & 80400 \\
NE & 172783 & 168000 \\
WC & 66757 & 47300 \\
C & 97012 & 237000 \\
EC & 69099 & 488000 \\
SW & 51136 & 45000 \\
SC & 64288 & 192000 \\
SE & 95435 & 793000 \\
\hline
\end{tabular}

Table A. 12. Rental cost for land

\begin{tabular}{lll}
\hline$i$ & $\begin{array}{l}\text { Corn } r c_{g \phi}^{i}(\$ / \text { acre }) \\
\text { [NASS-USDA., 2012] }\end{array}$ & $\begin{array}{l}\text { Switchgrass } r c_{g \in b n}^{i}(\$ / \mathrm{ha}) \\
{[\text { Zhang et al., 2012] }}\end{array}$ \\
\hline NW & 36.66 & 19.8 \\
NC & 43 & 29.62 \\
NE & 53.33 & 28.55 \\
WC & 35 & 27.48 \\
C & 48.33 & 29.4 \\
EC & 40 & 35.32 \\
SW & 36.42 & 29.6 \\
SC & 36 & 35.56 \\
SE & 82.85 & 56.95 \\
\hline
\end{tabular}


Table A. 13. Transportation costs

\begin{tabular}{|c|c|c|c|}
\hline $\begin{array}{l}\text { Transportation mode } \\
m\end{array}$ & Fixed cost $\bar{c}_{g}^{r^{\prime \prime j m}}$ & Variable cost $c_{g t}^{r^{\prime} j m}$ & Source \\
\hline \multicolumn{4}{|l|}{$g \in e \cup e n($ Bioethanol) } \\
\hline Truck & $\begin{array}{l}0.01159 \\
\text { \$/gallon }\end{array}$ & 0.00024 \$/gallon-mile & Searcy et al., 2007 \\
\hline Train & $\begin{array}{l}0.06183 \\
\text { \$/gallon }\end{array}$ & 6.9E-05 \$/gallon-mile & Kocoloski et al., 2011 \\
\hline $\begin{array}{l}\text { Pipeline } \\
g \in b \text { (Corn) }\end{array}$ & $0.03 \$ /$ gallon & $0.00025 \$ /$ gallon-mile & Searcy et al., 2007 \\
\hline Truck & $\begin{array}{l}0.000857 \\
\$ / \text { bushel }\end{array}$ & $0.00146 \$$ /bushel-mile & USDA report $^{\mathrm{b}} ., 2012$ \\
\hline Train & $\begin{array}{l}0.000125 \\
\$ / \text { bushel }\end{array}$ & 0.000575 \$/bushel-mile & USDA report ${ }^{\mathrm{b}} ., 2012$ \\
\hline \multicolumn{4}{|l|}{$g \in b n$ (Switchgrass) } \\
\hline $\begin{array}{l}\text { Truck } \\
\text { Train } \\
\text { Pipeline }\end{array}$ & $\begin{array}{l}6 \$ / \text { tonne } \\
23 \$ / \text { tonne } \\
9 \$ / \text { tonne }\end{array}$ & $\begin{array}{l}0.08 \text { \$/tonne-mile } \\
0.017 \$ / \text { tonne-mile } \\
0.08 \text { 4/tonne-mile }\end{array}$ & $\begin{array}{l}\text { Sokhansanj et al., } 2007 \\
\text { Sokhansanj et al., } 2007 \\
\text { Sokhansanj et al., } 2007\end{array}$ \\
\hline
\end{tabular}

Table A. 14. Capacity, cost, yield, GHG emissions, water and energy efficiency parameters

\begin{tabular}{|c|c|c|}
\hline Source & Input parameter & Value \\
\hline \multicolumn{3}{|l|}{ Capacities } \\
\hline Assumption & $\begin{array}{l}\text { Maximum production capacity of new } 2^{\text {nd }} \\
\text { generation bioethanol plant } \varphi n_{g}^{r^{\prime}}\end{array}$ & $150 \mathrm{MMGY}$ \\
\hline Assumption & $\begin{array}{l}\text { Maximum allowable capacity of new } 2^{\text {nd }} \\
\text { generation collection center } \bar{\varphi}_{g}^{c^{\prime} \in c n}\end{array}$ & 1.5 Million Tons \\
\hline $\begin{array}{l}\text { Assumption } \\
\text { Cost }\end{array}$ & 2G-NBBIS/CHP unit capacity & $35 \mathrm{MW}$ \\
\hline Assumption & $\begin{array}{l}\text { The cost of operating } 1^{\text {st }} \text { generation bioethanol } \\
\text { plant (Fixed + variable) }{ }^{r_{g \in e}^{\prime} \in r}\end{array}$ & $0.21 \$ /$ gallon \\
\hline $\begin{array}{l}\text { Shapouri and } \\
\text { Gallagher., (2005) }\end{array}$ & $\begin{array}{l}\text { The cost of expanding } 1^{\text {st }} \text { generation bioethanol } \\
\text { plant } c e_{g}^{r^{\prime}}\end{array}$ & $0.50 \$ /$ gallon \\
\hline Assumption & $\begin{array}{l}\text { The cost of closing } 1^{\text {st }} \text { generation bioethanol plant } \\
C c_{g}^{r^{\prime}}\end{array}$ & $0.15 \$ /$ gallon \\
\hline
\end{tabular}

Continued 
Table A.14. Capacity, cost, yield, GHG emissions, water and energy efficiency parameters (Continued)

\begin{tabular}{|c|c|c|}
\hline Source & Input parameter & Value \\
\hline Assumption & $\begin{array}{l}\text { The cost of producing } 1^{\text {st }} \text { generation bioethanol } \\
p c_{g \in e t}^{\prime^{\prime} \in r}\end{array}$ & 0.23 \$/gallon \\
\hline Assumption & $\begin{array}{l}\text { The cost of storing corn at the existing } 1^{\text {st }} \\
\text { generation collection centers and at the } \\
\text { bioethanol plants }\end{array}$ & 0.131 \$/gallon \\
\hline $\begin{array}{l}\text { Farm economic } \\
\text { facts and opinions, } \\
2001\end{array}$ & The cost of cultivating corn $c v t_{g \in b}^{i}$ & 357 \$/acre \\
\hline $\begin{array}{l}\text { Farm economic } \\
\text { facts and opinions, } \\
2001\end{array}$ & The cost of harvesting corn at corn fields $c_{g \in b t}^{i c^{\prime}}$ & $\begin{array}{l}28.71 \text { \$/acre }+ \\
\text { transportation } \\
\text { cost from } i \text { to } C\end{array}$ \\
\hline Zhang et al., 2012 & $\begin{array}{l}\text { Fixed cost of 2G-SA } \mathrm{cn}^{r^{\prime} \in r n} \\
\text { Fixed cost of } 2 \mathrm{G}-\mathrm{CBIS} \\
\text { Fixed cost of } 2 \mathrm{G}-\mathrm{NBBIS}\end{array}$ & $\begin{array}{l}72 \text { Million \$ } \\
\text { 43.2 Million \$ } \\
\text { 103.2 Million \$ }\end{array}$ \\
\hline $\begin{array}{l}\text { Kocoloski et al., } \\
2011\end{array}$ & $\begin{array}{l}\text { Variable facility cost of bioethanol plant based } \\
\text { on size } c \delta_{g \in e n}^{r^{\prime} \in n}\end{array}$ & 0.37 \$ gallon \\
\hline Zhang et al., 2012 & The cost of producing $2^{\text {nd }}$ generation bioethanol & $\begin{array}{l}0.9-0.56 \\
\text { (subsidy } \\
\text { compared to corn } \\
\text { ) }=0.33 \$ \text { /gallon }\end{array}$ \\
\hline Zhang et al., 2012 & $\begin{array}{l}\text { The cost of opening new } 2^{\text {nd }} \text { generation } \\
\text { collection center } c n^{c^{\prime} \in c n}\end{array}$ & $100000 \$$ \\
\hline Zhang et al., 2012 & $\begin{array}{l}\text { The cost of storing } 2^{\text {nd }} \text { generation biomass at } \\
\text { the collection center and the bioethanol plants }\end{array}$ & $21.7 \$ /$ tonne \\
\hline Zhang et al., 2012 & The cost of cultivating switchgrass $c v t_{g \in b n}^{i}$ & $395 \$ /$ ha \\
\hline Zhang et al., 2012 & The cost of harvesting switchgrass $c_{g \in b n t}^{i c^{\prime}}$ & $\begin{array}{l}49.6 \quad \$ / h a+ \\
\text { transportation } \\
\text { cost from } i \text { to } c n \\
255 \$ / \text { Ton }\end{array}$ \\
\hline $\begin{array}{l}\text { Assumption } \\
\text { Assumption }\end{array}$ & $\begin{array}{l}\text { Lignin pallet } \\
\text { Shortage cost } S C_{g t}^{j}\end{array}$ & $\begin{array}{l}25 \$ / \text { Ton } \\
6 \$ / \text { gallon }\end{array}$ \\
\hline \multicolumn{3}{|l|}{ Yield } \\
\hline Hespell et al., 1997 & Ethanol yield from corn & $\begin{array}{l}2.85 \\
\text { gallons/bushel } \\
82.63 \text { gallons/ton }\end{array}$ \\
\hline
\end{tabular}


Table A.14. Capacity, cost, yield, GHG emissions, water and energy efficiency parameters (Continued)

\begin{tabular}{|c|c|c|}
\hline Source & Input parameter & Value \\
\hline Eisenthal, J., 2013 & Distillers Dried Grains (DDG) & $\begin{array}{l}6 \text { pounds/ gallon of } \\
\text { corn based ethanol }\end{array}$ \\
\hline $\begin{array}{l}\text { Dakota spirit } \\
\text { agenergy., (2013) }\end{array}$ & Linin pallets & $\begin{array}{l}0.0085 \text { ton/gallon of } \\
2^{\text {nd }} \text { generation } \\
\text { bioethanol }\end{array}$ \\
\hline $\begin{array}{l}\text { Gonela and Zhang } \\
\text { (2013) }\end{array}$ & Process steam cost & $0.01 \$ /$ pound \\
\hline $\begin{array}{l}\text { Gonela and Zhang } \\
\text { (2013) }\end{array}$ & Process steam used & $\begin{array}{l}22 \text { pounds/Gallon of } \\
\text { bioethanol }\end{array}$ \\
\hline \multicolumn{3}{|l|}{ GHG emissions } \\
\hline Wang et al. (2012) & iissions for all the data & \\
\hline \multicolumn{3}{|l|}{ Energy estimates } \\
\hline Shapouri et al (2002) & $\begin{array}{l}\text { Energy content in } 1^{\text {st }} \text { generation } \\
\text { bioethanol }\end{array}$ & $\begin{array}{l}0.0748 \\
\text { MMBTU/Gallon }\end{array}$ \\
\hline Schmer et al (2008) & $\begin{array}{l}\text { Energy content in } 2^{\text {nd }} \text { generation } \\
\text { bioethanol }\end{array}$ & $\begin{array}{l}0.0660 \\
\text { MMBTU/Gallon }\end{array}$ \\
\hline Shapouri et al (2002) & Energy content in DDG & $\begin{array}{l}0.0026 \\
\text { MMBTU/Pound }\end{array}$ \\
\hline Wu et al (2006) & Energy content in Lignin pallets & 0.0014 MMBTU/Ton \\
\hline Unit Juggler (2013) & Energy content in electricity & $0.004 \mathrm{MMBTU} / \mathrm{Kwh}$ \\
\hline Assumtion & Energy content in process steam & $\begin{array}{l}\text { 5.95E-5 } \\
\text { MMBTU/Pound }\end{array}$ \\
\hline Shapouri et al (2002) & Energy consumed in corn production & $\begin{array}{l}0.0225 \\
\text { MMBTU/Bushel }\end{array}$ \\
\hline Wu et al (2006) & $\begin{array}{l}\text { Energy consumed in switchgrass } \\
\text { production }\end{array}$ & 0.217 MMBTU/Ton \\
\hline Shapouri et al (2002) & Energy consumed at $1 \mathrm{G}-\mathrm{SA}$ & $\begin{array}{l}0.0123 \\
\text { MMBTU/Gallon }\end{array}$ \\
\hline Assumption & Energy consumed at $1 \mathrm{G}-\mathrm{CBIS}$ & $\begin{array}{l}0.0008 \\
\text { MMBTU/Gallon }\end{array}$ \\
\hline Wu et al (2006) & Energy consumed at $2 \mathrm{G}-\mathrm{SA}$ & $\begin{array}{l}0.0131 \\
\text { MMBTU/Gallon }\end{array}$ \\
\hline Assumption & Energy consumed at $1 \mathrm{G}-\mathrm{CBIS}$ & $\begin{array}{l}0.001 \\
\text { MMBTU/Gallon }\end{array}$ \\
\hline $\begin{array}{l}\text { Wu et al (2006) and } \\
\text { assumption }\end{array}$ & Energy consumed at 2G-NBBIS & $\begin{array}{l}0.0101 \\
\text { MMBTU/Kwh }\end{array}$ \\
\hline Wu et al (2006) & $\begin{array}{l}\text { Energy consumed in transporting } \\
\text { bioethanol }\end{array}$ & $\begin{array}{l}0.0015 \\
\text { MMBTU/gallon/mile }\end{array}$ \\
\hline Shapouri et al (2002) & Energy consumed in transporting corn & $\begin{array}{l}0.004 \\
\text { MMBTU/Bushel }\end{array}$ \\
\hline
\end{tabular}


Table A.14. Capacity, cost, yield, GHG emissions, water and energy efficiency parameters (Continued)

\begin{tabular}{|c|c|c|}
\hline Source & Input parameter & Value \\
\hline Wu et al (2006) & $\begin{array}{l}\text { Energy consumed in transporting } \\
\text { switchgrass }\end{array}$ & 0.163 MMBTU/Ton \\
\hline Shapouri et al (2002) & $\begin{array}{l}\text { Energy consumed in transporting } \\
\text { DDG }\end{array}$ & $\begin{array}{l}0.0006 \\
\text { MMBTU/Pound }\end{array}$ \\
\hline Wu et al (2006) & $\begin{array}{l}\text { Energy consumed in transporting } \\
\text { lignin pallets }\end{array}$ & $0.003 \mathrm{MMBTU} / \mathrm{Ton}$ \\
\hline \multicolumn{3}{|l|}{ Water used } \\
\hline Wu et & Wate & $\begin{array}{l}2.64 \text { Gallons/Gallon } \\
\text { of bioethanol }\end{array}$ \\
\hline Assumption & Water consumed at $1 \mathrm{G}-\mathrm{CBIS}$ & $\begin{array}{l}0.5 \text { Gallon/gallon of } \\
\text { bioethanol }\end{array}$ \\
\hline Assumption & Water consumed at $2 \mathrm{G}-\mathrm{SA}$ & $\begin{array}{l}3 \text { Gallons/Gallon of } \\
\text { bioethanol }\end{array}$ \\
\hline Assumption & Water consumed at 2G-CBIS & $\begin{array}{l}0.6 \text { Gallon/gallon of } \\
\text { bioethanol }\end{array}$ \\
\hline $\mathrm{Wu}$ & & 2 Gallo \\
\hline $\begin{array}{l}\text { Water movement in } \\
\text { corn production (2013) }\end{array}$ & led in produci & 4000 Gallons/Bushel \\
\hline Biello 2013 & $\begin{array}{l}\text { Water consumed in producing } \\
\text { switchgrass }\end{array}$ & 38794 Gallons/Ton \\
\hline
\end{tabular}

